Prepared for the U.S. Nuclear Regulatory Commission under U.S. Department of Energy

Contract DE-AC05-76RL01830

\title{
Proactive Management of Materials Degradation - A Review of Principles and Programs
}

\section{LJ Bond SR Doctor \\ TT Taylor}

August 2008

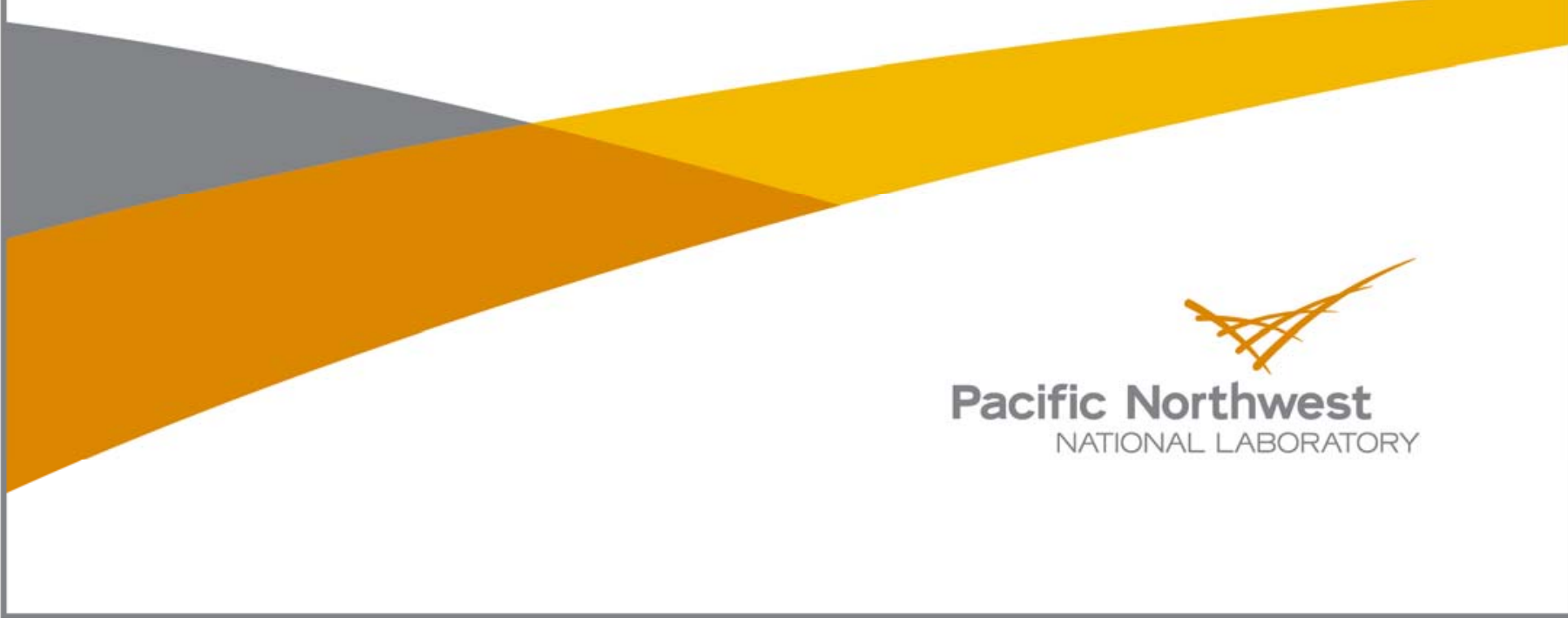




\title{
DISCLAIMER
}

This report was prepared as an account of work sponsored by an agency of the United States Government. Neither the United States Government nor any agency thereof, nor Battelle Memorial Institute, nor any of their employees, makes any warranty, express or implied, or assumes any legal liability or responsibility for the accuracy, completeness, or usefulness of any information, apparatus, product, or process disclosed, or represents that its use would not infringe privately owned rights. Reference herein to any specific commercial product, process, or service by trade name, trademark, manufacturer, or otherwise does not necessarily constitute or imply its endorsement, recommendation, or favoring by the United States Government or any agency thereof, or Battelle Memorial Institute. The views and opinions of authors expressed herein do not necessarily state or reflect those of the United States Government or any agency thereof.

\author{
PACIFIC NORTHWEST NATIONAL LABORATORY \\ operated by \\ BATTELLE \\ for the \\ UNITED STATES DEPARTMENT OF ENERGY \\ under Contract DE-AC05-76RL01830 \\ Printed in the United States of America \\ Available to DOE and DOE contractors from the \\ Office of Scientific and Technical Information, \\ P.O. Box 62, Oak Ridge, TN 37831-0062; \\ ph: (865) 576-8401 \\ fax: (865) 576-5728 \\ email: reports@adonis.osti.gov

\footnotetext{
Available to the public from the National Technical Information Service, U.S. Department of Commerce, 5285 Port Royal Rd., Springfield, VA 22161 ph: (800) 553-6847 fax: (703) 605-6900

email: orders@ntis.fedworld.gov

online ordering: http://www.ntis.gov/ordering.htm
}

This document was printed on recycled paper. 


\title{
Proactive Management of Materials Degradation - A Review of Principles and Programs
}

\author{
L. J. Bond \\ S. R. Doctor \\ T. T. Taylor
}

August 2008

Prepared for

the U.S. Nuclear Regulatory Commission

under U.S. Department of Energy

Contract DE-AC05-76RL01830

Pacific Northwest National Laboratory

Richland, Washington 99352 



\begin{abstract}
The U.S. Nuclear Regulatory Commission (NRC) has undertaken a program to lay the technical foundation for defining proactive actions so that future degradation of materials in light water reactors (LWRs) is limited and, thereby, does not diminish either the integrity of important LWR components or the safety of operating plants. This technical letter report was prepared by staff at Pacific Northwest National Laboratory in support of the NRC Proactive Management of Materials Degradation (PMMD) program and relies heavily on work that was completed by Dr. Joseph Muscara and documented in NUREG/CR-6923. This report concisely explains the basic principles of PMMD and its relationship to prognostics, provides a review of programs related to PMMD being conducted worldwide, and provides an assessment of the technical gaps in PMMD and prognostics that need to be addressed. This technical letter report is timely because the majority of the U.S. reactor fleet is applying for license renewal, and many plants are also applying for increases in power rating. Both of these changes could increase the likelihood of materials degradation and underline, therefore, the interest in proactive management in the future.
\end{abstract}





\section{Executive Summary}

The response of the nuclear industry and regulators to issues of materials degradation in the past generally has been to develop and approve mitigation actions after the degradation has occurred. These mitigation actions have involved increases and improvements in in-service inspection, changes in designs, materials, and operating conditions, and replacement of degraded components. This reactive approach has maintained the safety of operating reactors but has proved to be an inefficient and expensive way of managing materials degradation issues for the industry.

To address the issue of "reactive management of materials degradation", the NRC has initiated a program to assess the potential to identify early the components that are potentially susceptible to future degradation, so that mitigation and/or monitoring and repair actions can be proactively developed, assessed, and implemented before the degradation process could adversely impact structural integrity or safety. Two processes can be envisioned for the Proactive Management of Materials Degradation (PMMD) programs. The processes are (a) implementation of actions to mitigate or eliminate the susceptibility to materials degradation, and (b) implementation of effective inspection, monitoring, and timely repair of degradation. This study concentrated on an identification of components susceptible to future degradation and an assessment of the existing knowledge level for potential development of mitigation actions, that is, process (a) only. The Pacific Northwest National Laboratory conducted the research to find and develop the PMMD information contained in this technical letter report. This technical letter report concisely explains the basic principles of PMMD and its relationship to prognostics, provides a review of programs related to PMMD being conducted worldwide, and provides an assessment of the technical gaps in PMMD and prognostics that need to be addressed.

Degradation and aging are terms used to describe both the deterioration and aging of components, but it is useful to distinguish between them. Degradation is immediate or gradual deterioration of characteristics of systems, structures, and components (SSCs) that could impair their ability to function within acceptance criteria. Aging is a general process in which characteristics of an SSC gradually change with time or use. When aging processes are known, they can be monitored through an appropriate aging management program and plant life management (PLiM) program and potentially mitigated.

Aging degradation mechanisms are usually classified into two main categories, which are those that (1) affect the internal microstructure or chemical composition of the material and thereby change its intrinsic properties (thermal aging, creep, irradiation damage, etc.), and (2) impose physical damage on the component either by metal loss (corrosion, wear) or by cracking or deformation (stress-corrosion, deformation, cracking). As can be seen above, the phenomenon of aging degradation in nuclear power plants (NPPs) is complex and thus requires sophisticated, state of science and technology procedures to effectively manage it and ensure safe, reliable operation. It will be observed that not only technology is involved, but also an effective management system is needed in order to correctly implement mitigation or monitoring actions.

In order to meet the objective of a proactive material degradation assessment and management program, it is necessary to understand stressors and assess various damage and damage accumulation rate/severity relationships for existing and potential degradation modes, materials, environments, and operating states for the different LWR components. This assessment may be based on formulations for 
the various stressor and damage-time relationships or more generally on the basis of operating and laboratory experience and engineering judgment.

The past decade has seen major activities developing within both the nuclear and wider engineering communities to move from the use of periodic nondestructive testing to condition-based monitoring (CBM) and advanced life management with what has been called by various names, including structural health monitoring, material damage prognostics, and PMMD. Where these approaches have been applied, they have been implemented with on-line methods developed for advanced monitoring and diagnostics. As the economic value of CBM and other advanced monitoring approaches is being demonstrated, there is increasing interest in on-line monitoring and looking towards adopting prognostics, the prediction of the remaining safe or service life for both active components, such as pumps, as well as with its application to passive components, the basic structural materials.

The economics of NPP life extension has been seen to change in recent years. As a result there have been developing national and international activities to address PLiM for long-term operation (LTO), which may include plant modifications for power uprating. The primary drivers have been the changes in the economic/business climate, as well as a need to provide energy to support sustainable development and, in many countries, provide carbon-free electric generation. Various groups have been working to identify and address key issues in three broad areas:

- technology

- regulation

- business.

The pattern of activities that are developing to meet the needs of life extension for the global NPP fleet is complex, and in many cases there are many interconnections and overlapping relationships. There are various international and multi-national activities which overlay national activities. This report provides a review of the international and multi-national activities being conducted. For the purposes of this technical letter report, the 2000 NEA report formed the starting point for the review that was performed.

This report clearly illustrates that the implementation of PMMD programs will require significant basic and applied research. To date, discussion has divided the identified technical gaps into categories: the technical gaps that need to be addressed by basic science, those technical gaps in engineering, and those that need to be addressed from a regulatory/codes and standards point of view. The full scope of these needs is still being defined. This report provides some examples of the technical gaps that need to be addressed. 


\section{Acknowledgments}

This work has evolved from the efforts reported in NUREG/CR-6923 titled Expert Panel Report on Proactive Materials Degradation Assessment. The authors would like to acknowledge the pioneering efforts of Dr. Joseph Muscara who led the following panel of experts in developing NUREG/CR-6923.

\section{Panel Members:}

Peter L. Andresen, General Electric Global Research Center

F. Peter Ford, General Electric Global Research Center (Retired)

Karen Gott, Swedish Nuclear Power Inspectorate, Sweden

Robin L. Jones, Electric Power Research Institute

Peter M. Scott, AREVA Framatome ANP, France

Tetsuo Shoji, Tohoku University, Japan

Roger W. Staehle, Consultant

Robert L. Tapping, Atomic Energy Canada Ltd., Canada

The information collected and reported for various programs in the PMMD area is based on that given in cited references, discussions with numerous individuals at conferences and meetings, and information available on the Internet. Information was collected from a diverse range of Internet sites, including those for the IAEA, OECD/NEA, and numerous sites that report specific national programs. The contributions of numerous colleagues who provided information in discussions, particularly attendees at the Second International Symposium on Plant Life Management (Shanghai, China) October 2007, are gratefully acknowledged. 



\section{Acronyms and Abbreviations}

\begin{tabular}{|c|c|}
\hline AMP & Aging Management Program \\
\hline ASME & American Society for Mechanical Engineers \\
\hline ASN & Nuclear Safety Authority \\
\hline $\mathrm{B} \& \mathrm{~W}$ & Babcock \& Wilcox \\
\hline $\mathrm{BE}$ & British Energy \\
\hline BNFL & British Nuclear Fuels Ltd \\
\hline BNG & British Nuclear Group \\
\hline BWR & boiling water reactor \\
\hline CAEA & China Atomic Energy Authority \\
\hline $\mathrm{CBM}$ & condition-based monitoring \\
\hline $\mathrm{CCW}$ & component cooling water \\
\hline $\mathrm{CE}$ & Combustion Engineering \\
\hline CGI & Chockie Group International \\
\hline CNNC & China National Nuclear Corporation \\
\hline Code & Boiler and Pressure Vessel Code \\
\hline CRP & coordinated research projects \\
\hline CSNI & Committee on the Safety of Nuclear Instillations \\
\hline CSSCs & critical systems, structures, and components \\
\hline CVCS & chemical and volume control \\
\hline Dpa & displacement per atom \\
\hline EAC & environmentally assisted cracking \\
\hline ECCS & Emergency Core Cooling System \\
\hline EPRI & Electric Power Research Institute \\
\hline EU & European Union \\
\hline Gen IV & Generation IV \\
\hline HWC & hydrogen water chemistry \\
\hline IAEA & International Atomic Energy Agency \\
\hline IAGE & Integrity of Components and Structures \\
\hline INIS & International Nuclear Information System \\
\hline ISI & inservice inspection \\
\hline JAPEIC & Japan Power Engineering and Inspection Corporation \\
\hline JRC & Joint Research Center (European Commission) \\
\hline LTO & long-term operation \\
\hline LWR & light-water reactor \\
\hline MITI, presently METI & Ministry of International Trade and Industry \\
\hline NDE & nondestructive examination \\
\hline
\end{tabular}


NDT/I

NEA

NEI

NPAR

NPP

NRC

NWC

O\&M

OECD/NEA

PLEC

PLEX

PLiM

PMDA

PMMD

POD

PSA

PWR

$\mathrm{R} \& \mathrm{D}$

RCS

RHR

RI-ISI

RPV

RSMC

SALTO

SCC

SSCs

TC

WWER nondestructive testing or inspection

Nuclear Energy Agency

Nuclear Energy Institute

Nuclear Plant Aging Research

nuclear power plant

U.S. Nuclear Regulatory Commission

normal water chemistry

operation and maintenance

Organisation for Economic Co-operation and Development-Nuclear Energy Agency

Plant Life Engineering Center

plant life extension

Plant Life Management

Proactive Materials Degradation Assessment

proactive management of materials degradation

probability of detection

Petroleum Safety Authority

pressurized water reactor

research and development

reactor coolant system

residual heat removal

risk-informed, inservice inspection

reactor pressure vessel

Reactor Sites Management Company

Safety Aspects of Long Term Operation of Water Moderated Reactors

stress corrosion cracking

structures, systems, and components

technical cooperation

water cooled, water-moderated energy reactor (Soviet Union designed light water reactor that has some similar features as a U.S. design pressurized light water reactor) 


\section{Contents}

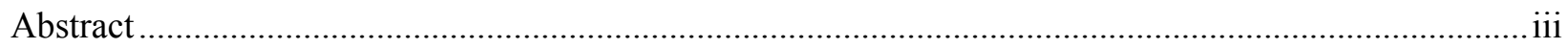

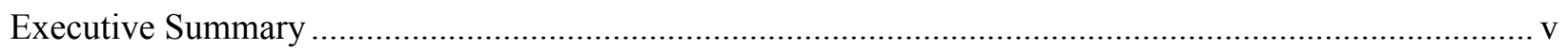

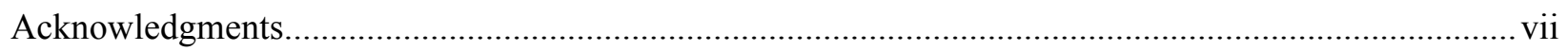

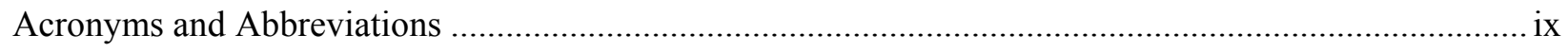

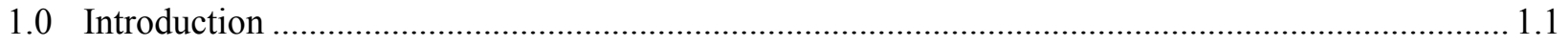

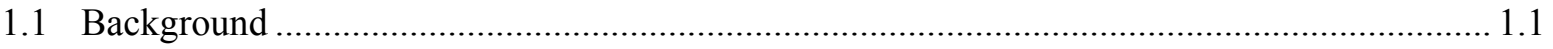

1.2 Nuclear Power Plant Life Management …..................................................................... 1.2

1.3 Objective of Proactive Materials Degradation Assessment ................................................. 1.6

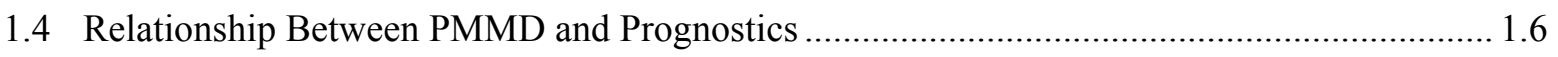

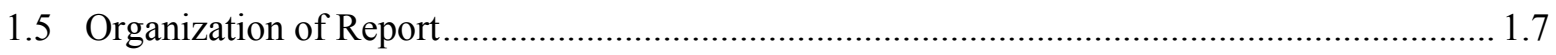

2.0 Basic Principles of PMMD: Including Conclusions from NUREG/CR-6923 ............................... 2.1

2.1 Basic Principles of Proactive Management of Materials Degradation.................................... 2.1

2.2 Major Conclusions from NUREG/CR-6923 ….............................................................. 2.3

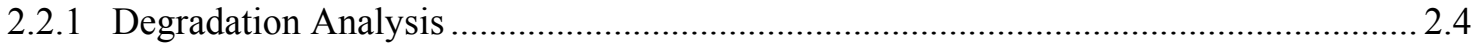

2.2.2 Pressurized Water Reactor Coolant System under Full Power Operating

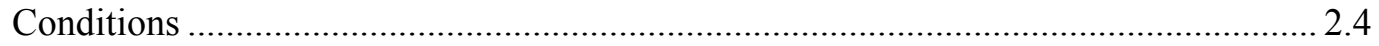

2.2.3 Boiling Water Reactor Coolant System under Full Power Operating Conditions ......... 2.6

2.2.4 PWR Systems Other than the RCS under Full Power Operating Conditions ................ 2.7

2.2.5 BWR Systems other than the RCS under Full Power Operating Conditions ................. 2.9

2.3 Generic Degradation Issues Addressed by the Database in NURG/CR-6923 ...................... 2.10

2.3.1 Identify Reactor Components that could Experience Future Degradation................... 2.11

2.3.2 Assess Effectiveness of Inservice Inspection Programs for Degradation-

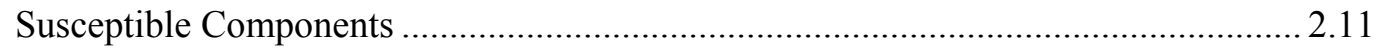

2.3.3 Assess Risk Significance Associated with the Failure of Susceptible

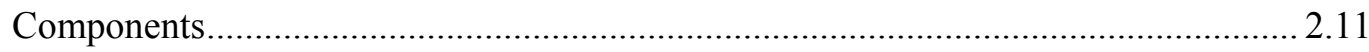

3.0 Summary of PMMD and Prognostic Programs Currently Being Conducted ................................. 3.1

3.1 Diagnostics and Prognostics: State of the Art and Potential .................................................. 3.2

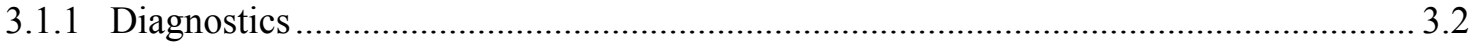

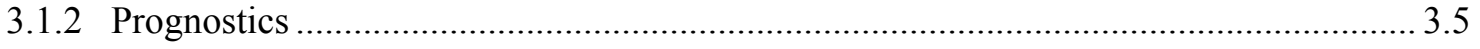

3.1.3 Lessons from U.S. License Extension Activities …..................................................... 3.7

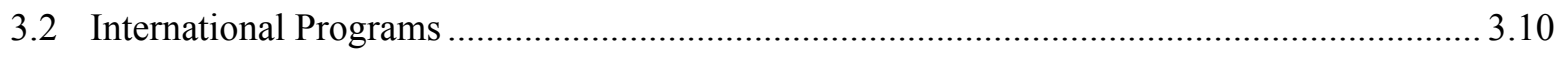

3.2.1 Organisation for Economic Co-operation and Development-Nuclear Energy

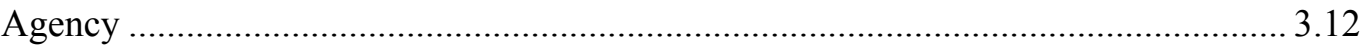

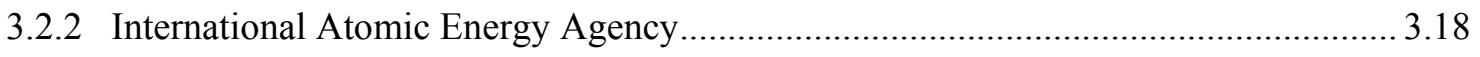

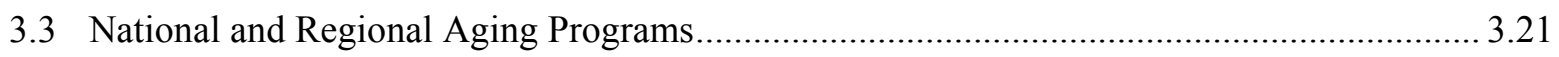




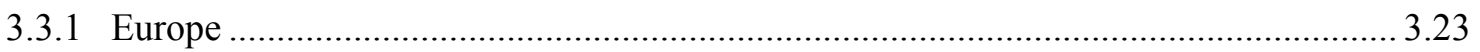

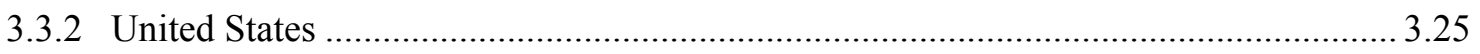

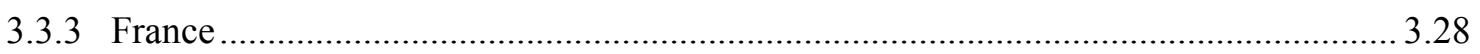

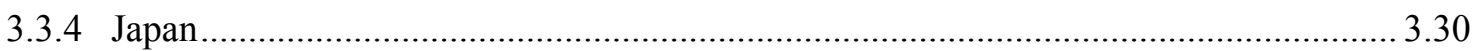

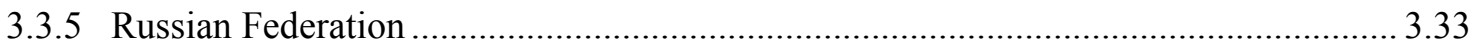

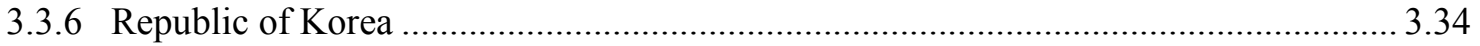

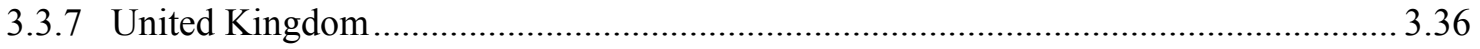

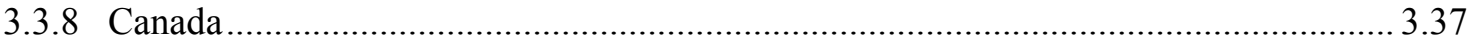

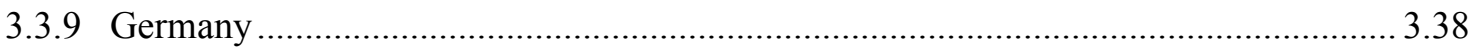

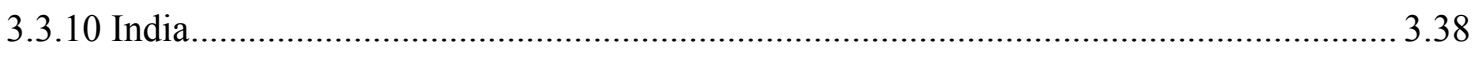

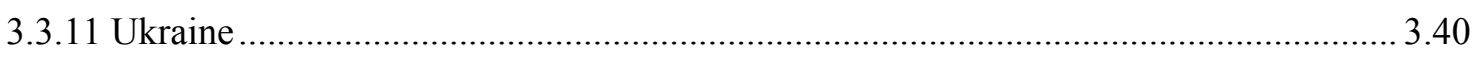

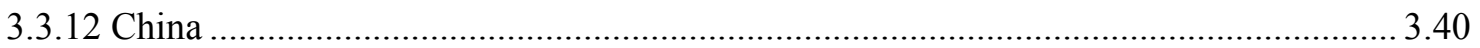

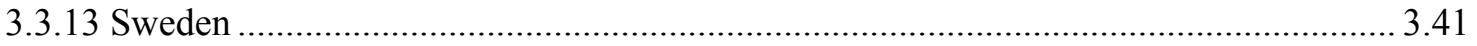

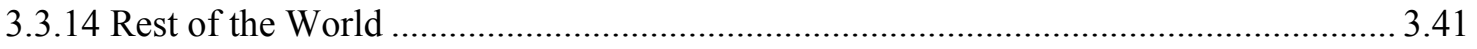

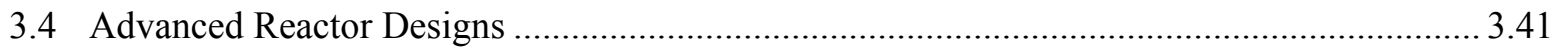

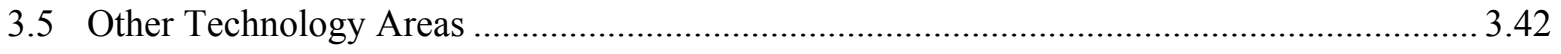

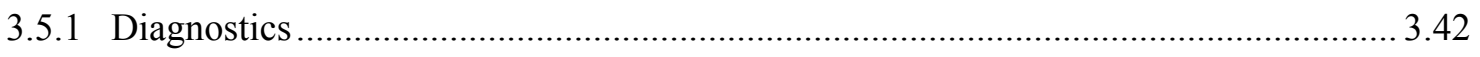

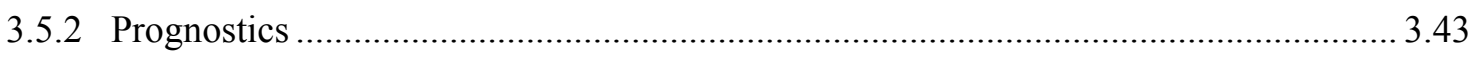

4.0 Technical GAPS that Need to be Addressed for PMMD .......................................................... 4.1

4.1 Summary of Technical Gaps from the EPRI PMMD Program ............................................. 4.1

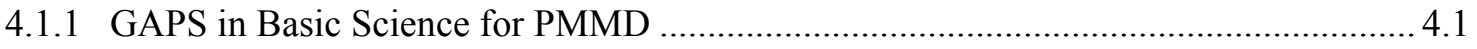

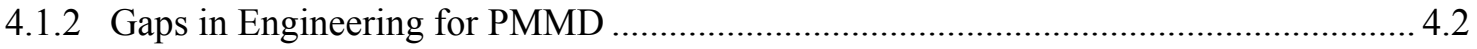

4.2 Summary of Technical Gaps from the NRC-Sponsored Reports............................................ 4.2

4.2.1 GAPS in Basic Science for PMMD ........................................................................... 4.3

4.2.2 Gaps in Engineering for PMMD ........................................................................ 4.3

4.3 Technical Gaps that Need to be Addressed within the Framework of Codes and

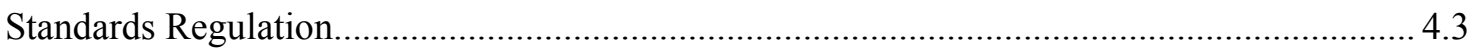

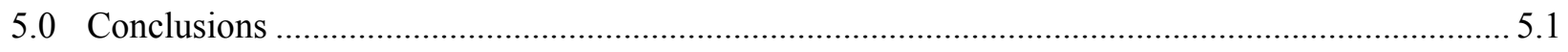

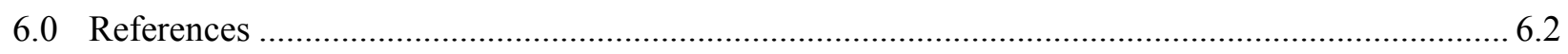

Appendix A Information on the Population of Nuclear Power Plants World-wide................................. A.1

Appendix B Draft Overview Program Plan for Cooperation on Proactive Materials Degradation Management (PMDM) Research ....................................................................................... 1 


\section{Figures}

2.1 Schematic Diagram Illustrating Degradation, or Damage, Development with Time, and the Differentiation between Reactive and Proactive Actions ............................................................ 2.2

3.1 Convergence and Relationship between NDE and Materials Science........................................... 3.5

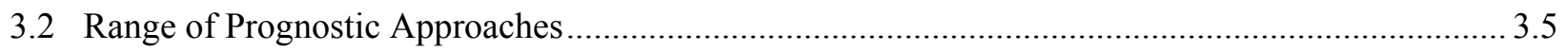

3.3 Stressor Measurement Giving Time for Intervention Prior to Failure ............................................... 3.7

3.4 Relationship of Maintenance and License Renewal Rules ....................................................... 3.10

3.5 Schematic Showing Organizational Structure of the Committee on the Safety of Nuclear

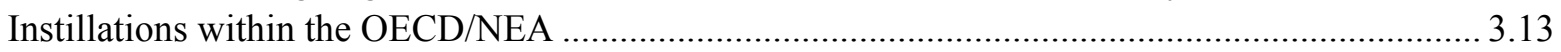

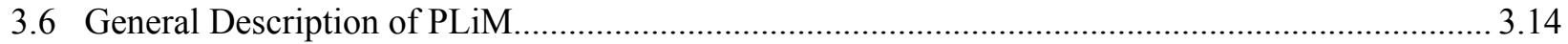

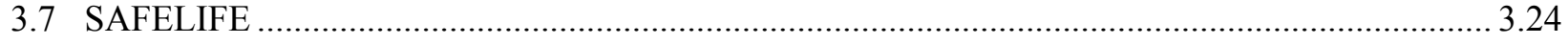

3.8 Planned Organization and Evolution of the EU NULIFE Program 2006-2011 ........................... 3.25

3.9 Example of Part of the Materials Degradation Matrix Developed by EPRI................................. 3.28

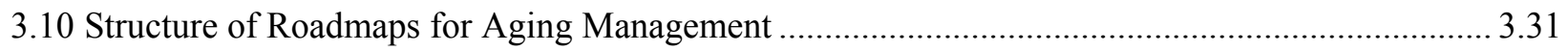

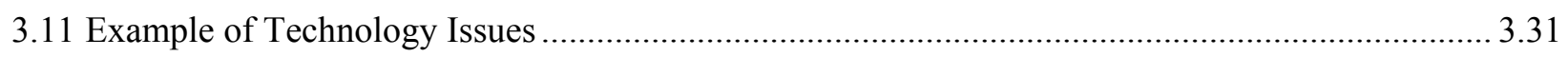

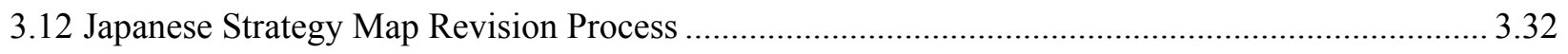

3.13 Roles in Japanese Aging Management Program............................................................................... 3.32

3.14 Schematic Showing PliM Process for Korean Kori Unit 1 ...................................................... 3.35

\section{Tables}

3.1 Estimated Variations in Flaw Detection Limits by Type of Inspection......................................... 3.3

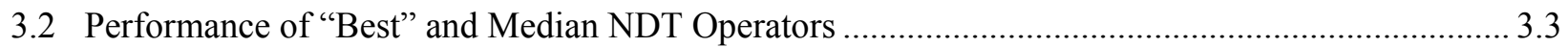

3.3 Assessment of State of Maturity for Diagnostic and Prognostic Technologies ............................... 3.6

3.4 Number of Reactors and Percent Electricity Generated for Countries with more

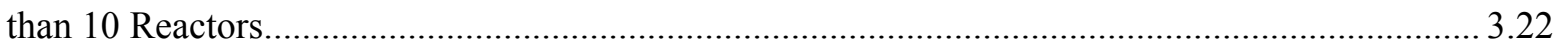

3.5 Selected Nuclear Power Plants and Generating Capacity in Greater Europe ................................ 3.23 



\subsection{Introduction}

\subsection{Background}

There are approximately 440 operating nuclear power reactors in the current global fleet. These are located in 30 countries and fall into six basic design types. The two most common design types are pressurized water reactors (PWR) and boiling water reactors (BWR), which account for 265 and 94 of the operating reactors respectively. All of the 104 commercial nuclear power reactors operating in the United States are either of the PWR or BWR design types. The details of the locations of these reactors, their types, and power generating capacity are given in Appendix A. The average age for this fleet of reactors is more than 20 years, and the initial licensing terms were typically 30 or 40 years. The existing NPPs are now considered to be too valuable to scrap at the end of their initial licensing term. The cost of building replacement generating capacity, and at the same time providing new plants that meet the growth in demand for electricity, would test the available technical, regulatory, and economic infrastructures. It is therefore important to see where technology can help to better manage existing power plants, enable license extension for the existing fleet, and contribute to both new advanced light-water reactors (LWRs) and other advanced new designs with initial licensing term of 60 years, all within the limits set by performance of materials and operational requirements.

In a number of countries, there are programs that are designed to enable operating license extension beyond 30 years, and in other countries, licensing is being extended from 40 to 60 years. The United States has already established a process for plant assessment and license extension from 40 to 60 years, and it is expected that more than 90 percent of current plants will seek a license extension. Some consideration is now being given to determine if it is feasible to extend operating lives further with "licensing beyond 60," extending operation to 80 years and potentially longer. Such activities require a new knowledgeable and streamlined regulatory framework to be established. In addition, the new technical challenges need to be identified, and technologies and operational practices developed, tested, and deployed to detect, characterize, monitor, and manage materials degradation.

All parts of an NPP are subject to the continuous time-dependent degradation of materials due to normal service conditions, which include normal operation and transient conditions; postulated accident and post-accident conditions are excluded. These time-dependent degradation phenomena need to be considered for all parts of an NPP. Such a plant is comprised of a number of broad classes of elements: concrete structures (e.g., containment), structural materials (e.g., pressure vessel and major piping), reactor internals (e.g., core internal framework, control rods and the fuel), machinery (e.g., pumps, and valves), and instrumentation and controls (including wiring, sensors and actuators, communication systems, and the control room). These elements can be considered in various categories and are commonly divided into active and passive components. The active components are those that exhibit motion under activation or motion as part of operation and include pumps, valves and rotating machinery. The passive components are those that are elements in the structure or part of the system that does not involve motion as part of its function, and examples include the concrete containment and support structures and many primary circuit elements, including the pressure vessel, the reactor vessel core internals, and the steam generator. 
The time-dependent degradation of materials in a NPP causes active and passive systems to lose, partially or totally, their design function. If not managed, degradation is a problem for active components, for which the probability of malfunction increases with time, and for passive components, because their safety margin, in terms of material properties, can potentially be reduced.

In ensuring fitness for service and appropriate safety margins, plant elements were designed to have a design life and initial quality and compliance that were assured through acceptance testing and then periodic inspections to ensure that a unit can be expected to remain in a safe operating condition until the next scheduled inspection. Managing time-dependent degradation, particularly when life extension is considered, requires adopting practices that can detect and assess the effects of aging. There are basically three methods used to assess the effects of degradation:

- analysis of operating experience

- expert opinion

- probabilistic techniques for predicting, prioritizing, and determining the risk significance of degradation.

The methods are complementary, and for the best assessment of degradation, they should all be combined. The assessments need to include a review of original design basis concerning materials, stressors, environment, and operating conditions. In addition, many operating U.S. NPPs have applied for and received approval for an uprate to operate at higher power levels, and the effect of such changes needs to be included in aging assessment. Assessment of degradation problems should determine the components, systems, and structures susceptible to degradation whose failures could have a significant adverse effect on plant safety.

In order to ensure safe long-term operation of NPPs, it is increasingly necessary to adopt new approaches and modify current operation and maintenance practices. At the heart of the new approaches is proactive material degradation assessment (PMDA). This moves degradation assessment and then its management from being reactive to being proactive - through understanding, monitoring, and managing materials degradation/aging processes and plant operational parameters to optimize life-cycle economics and still maintaining the highest levels of safety.

The past decade has seen major activities developing within both the nuclear and wider engineering communities to move from the use of periodic nondestructive testing (NDT) to condition-based maintenance (CBM) and now advanced life management with what has been called by various names including "Structural Health Monitoring" and "Material Damage Prognostics." These approaches have seen the need for new operation and maintenance practices and the implementation of new forms of advanced monitoring and diagnostics, and there is increasing interest in the application of prognostics, the prediction of the remaining safe life or service life, for both active components, such as pumps, and passive components, the basic structural materials.

\subsection{Nuclear Power Plant Life Management}

The scope of global activities in this area has been reviewed in several places by both the International Atomic Energy Agency (IAEA) and Organisation for Economic Co-operation and Development-Nuclear Energy Agency (OECD/NEA). Recent benchmarks are provided with the 
proceedings of the IAEA's Nuclear Power Plant License Management Symposium, held in Budapest, Hungary, in 2002 (IAEA 2002b), and most recently in the papers presented at the IAEA's $2^{\text {nd }}$

International Symposium on Nuclear Power Plant Life Management in 2007 (Bond et al. 2008). Related IAEA programs and activities include the Extra-budgetary Programmme on Safety Aspects of Long Term Operation of Water Moderated Reactors (SALTO). This activity started in 2003 to assist Member States considering long-term operation of water-moderated reactors to reconcile related processes and practices, to establish a general long-term operation framework, and to provide a forum for exchange of related information (IAEA 2007a). There are also a series of earlier IAEA TecDocs (IAEA 1992a) and IAEAsupported regional and national technical cooperation programs (IAEA 2004a).

There has also been a growing recognition that NPP condition assessment based on NDT at the time of fabrication, followed by intense inspections during outages, requires the adoption of conservative assumptions with regard to addressing detected indications and intervention. With aging plants there is the risk of "surprises" at refueling outages, which can cause extended down time. A recent study has concluded that current inspection intervals are too long and do not match rates of degradation growth, which adds support to the conclusion that PMMD (proactive management of materials degradation), including on-line monitoring, is needed for both current and new reactors (Anderson et al. 2008). To address these issues, many countries have research programs to develop the basis for deploying on-line monitoring and condition-based maintenance that has the potential to increase operator situational awareness, enhance safety, and provide significant cost savings.

There are significant opportunities to deploy new technologies when upgrades, including modernization of instrumentation and control systems, are implemented at existing NPP facilities. The economic benefit from a predictive maintenance program can be demonstrated from a cost/benefit analysis. An example is the program for the Palo Verde Nuclear Generating Station (Johnson and Maxwell 2002a, 2002b). An analysis of the 104 U.S. legacy systems has indicated that the deployment of on-line monitoring and diagnostics has the potential for saving more than $\$ 1 \mathrm{~B}$ per year when applied to all key active equipment (Bond et al. 2003; Bond et al. 2008). On-line monitoring is now being deployed as part of new LWR plants, for example, by AREVA in the new reactor at Olkiluoto in Finland (AREVA 2007). New designs for advanced NPPs, such as those within the Generation (Gen) IV program, are considering materials to give an initial licensing life of 60 years; they will require longer intervals between refueling and scheduled outages (potentially four years) and also shorter outages. Achieving the required performance for Gen IV reactors will require enhanced maintenance approaches, particularly for materials management involving PMMD, including the use of on-line monitoring and diagnostics, which become essential.

To move to PMMD approaches requires transition from periodic inspection to on-line monitoring for condition-based maintenance, advanced diagnostics for passive structures, and eventually prognostics that will require advances in sensors; better understanding of what and how to measure within the plant; enhanced data interrogation, communication and integration; new predictive models for damage/aging evolution; system integration for real-world deployments; quantification of uncertainties in what are inherently ill-posed problems; and integration of enhanced condition-based maintenance/prognostics philosophies into life management for both legacy and new plant designs and operation and maintenance (O\&M) approaches (Bond and Doctor 2007). A recently published report presents a methodology that incorporates predictive models and damage assessment into improvements in the ASME Code Section XI (Gosselin et al. 2007). This material is expected to be included in the next revision of the code to be published in the 2008 Addenda. 
Material studies to support new reactor designs have the potential to provide insights that can assist in better understanding of previously used materials and in developing PMMD/life-extension for legacy systems. For new designs, materials are being required to meet more demanding initial design requirements. New advanced gas reactors and Gen IV NPPs are expected to have longer initial design lives (60 years), operate with a high capacity factor $(90 \%+)$ for longer fueling cycles (4-6 years), and have necessary inspections and maintenance performed on-line or during shorter outages. One challenge is limited knowledge of material performance under the conditions expected in next-generation designs, including balance-of-plant and secondary units for process heat or hydrogen production. Gen IV NPPs will operate at higher temperatures (potentially $510^{\circ} \mathrm{C}$ to $1000^{\circ} \mathrm{C}$ ). Operation in this temperature range brings to the forefront the potential for many new degradation processes that have not been experienced to date in current reactors and thus are not well understood or accounted for in the designs. In the current LWR fleet, new degradation processes have appeared on average at a rate of one new degradation process every seven years (Wilkowski et al. 2002).

Operators need information to better manage power-plant life holistically, adjusting operating conditions to reduce the impact of stressors. Because periodic inspections, which typically occur during refueling outages, cannot be assumed to be adequate to help ensure fitness for service for critical safety systems and components or help ensure optimal plant life management for license extension with the current fleet and for new plants, developing the fundamental knowledge to support PMMD, new methodology for life management, and designing systems for on-line continuous monitoring becomes critical. On-line monitoring and diagnostics is needed to provide operators with better plant situational awareness and reliable predictions of remaining service life of critical systems and components (Bond and Doctor 2007).

In the United States there has been a long history of activities that addressed the issues of aging in the current fleet of NPPs. Many of the earlier insights gained have been summarized in a 1992 report (Blahnik et al. 1992b). There are also on-going activities and meetings that address water reactor safety/aging issues (NRC 1998a).

The American Society for Mechanical Engineers (ASME) Boiler and Pressure Vessel Code (Code) was developed for LWRs, and addresses fatigue as the dominant failure mechanism. Thus, the present Code may not be adequate to support "licensing beyond 60" for current plants, and it is not adequate as written for Gen IV NPPs. However, there are ASME code committees that are developing new requirements to include other degradation processes and Gen IV reactor designs. The new materials, new degradation mechanisms, and the new operating environments and longer service life mean that flaw acceptance standards are unknown at this time, both for fabrication flaws and for service-induced flaws. Clearly, the ASME Code needs to be evolved to support further license extension and to lead Gen IV design, construction, and operation.

Periodic inservice inspections may simply be inadequate to manage degradation because of this long service life, long intervals between refueling, and the correspondingly long intervals between inspections. One alternative would be to develop fully automated robotic nondestructive examination (NDE) and/or on-line monitoring inspection tools that could be deployed during operation so that inspections could be conducted based on degradation initiation times, degradation growth rates, and the effectiveness of the NDE being deployed. Advanced nondestructive measurements might be developed to provide a means to monitor material properties so that as these changes occur during operation they could be detected, quantified, and trended. Sensors could potentially be deployed at all key locations to monitor for the 
initiation and growth of degradation as well as for the key stressors/operational parameters that could be the precursors to degradation (Bond and Doctor 2007).

For the current fleet of operating LWRs, the majority of component failures are the failure of active components that are not operating correctly when called upon to perform a given function, such as a valve not opening or closing on demand. The failure of passive components is dominated by failures associated with service degradation. The active components are managed with a maintenance program that is based on experience and not based on the known condition of the component and its need for preventive maintenance. For the passive components, their degradation is managed through periodic inspections as dictated by the Federal Code of Regulations and the ASME Code. Over the past few years, these inservice inspection programs have changed dramatically, using risk-based management. Although there is management of risk from a safety standpoint, there are open issues that remain. These include the potential risk of having surprise failures. These surprises are related to the occurrence of new degradation mechanisms, including degradation mechanisms that are accelerated by stressor enhancement due to altered conditions or newly introduced acceleration mechanisms (e.g., corrosion due to accidental chloride introduction). These may have a long initiation time, and the fact that only the risk-important components are being periodically inspected means that fewer components are being inspected, because most of the NPP risk is associated with a small percentage of plant components. Another factor is the movement away from the original strategy of defense-in-depth where inservice inspection was to be used to detect the unexpected that had not been accounted for in design, selection of materials, fabrication processes employed, or the operating conditions (Bond et al. 2008). These lessons need to be at the heart of PMMD that is needed for "licensing beyond 60."

Opportunities exist within the nuclear power community to take advantage of the activities and technologies that have emerged in other application areas, such as the aerospace community. There has been a relatively long history of activities applied to jet engines and this expanded into wider investigations of issues that surround aging aircraft. ${ }^{\text {(a) }} \mathrm{A}$ brief history of the role and future challenges of NDE in civil aviation, which also looked towards future challenges, was provided by Weber (Weber 1995). This community is currently moving from diagnostics and early applications of prognostics to integrated schemes for vehicle health monitoring and a vision of structural health management (Chang 2003a). Similar technology evolutions are in progress in many high-technology/high-risk fields, including defense and aero-space.

For current-generation NPP aging and a move to PMMD, there needs to be consideration of the effects of aging on a diverse range of system elements:

- Reactor internals

- Structural materials

- Machinery (pumps, valves, etc.)

- Concrete structures

(a) A 1997 National Research Council report recommended that the Air Force adopt a three-pronged plan of action: (1) near-term action (3 to 5 years) to improve the maintenance and management of aging aircraft; (2) near-term R\&D to support the near-term actions; and (3) long-term R\&D. The highest-priority research issues were technologies that would lead to reduced maintenance costs, improved force readiness (by prevention and/or control of corrosion) and NDE/NDI methods to detect stress corrosion cracking. 
- Instrumentation \& Controls (wiring, sensors, etc.)

To maximize PMMD, there are needs to understand fundamental materials degradation phenomena and stressor interactions as well as a need for new on-line monitoring that can potentially support both advanced diagnostics and prognostic methodologies to support remaining life management.

In the evolution from traditional NDT/NDE to advanced inservice inspection (ISI) and conditionbased maintenance to on-line monitoring and prognostics, new fundamental science can be expected to be needed. Conventional NDT/NDE may not be sensitive to new forms of degradation, particularly to phenomena that relate to property change prior to formation of a "defect" such as a crack or other traditionally identified defect. With the evolution of measurement science including the effects of improved inspection sensitivity, detection of benign "features" or indications is being found to occur, such as those indications due to inherent anomalies in materials (e.g., region of larger-than-average grain size). PMMD, to be effective, needs to be advancing both the fundamental materials degradation science and the needed measurement sciences, both in the laboratory and for field deployment.

\subsection{Objective of Proactive Materials Degradation Assessment}

PMMD has the objective to identify materials and components where degradation may occur, both now and in the future. In some cases, the degradation may involve phenomena not yet experienced in the operating fleet but where there is laboratory data and/or a mechanistic understanding that indicates that they may be pertinent to future reactor operations.

PMMD is the methodology and actions needed to actively manage the NPP systems throughout the life cycle to minimize the impact of degradation, maintain safety, and potentially enable extensions to system operating life.

\subsection{Relationship Between PMMD and Prognostics}

PMMD is the emerging technical and methodological basis needed to support enhanced system management throughout its life, including life-extension for legacy NPPs. These approaches involve "sensing" material property changes and parameter trends that are precursors to traditionally monitored degradation mechanisms and phenomena (e.g., crack growth) that are detected by conventional NDT technologies such as eddy current or ultrasound. To be effective, PMMD needs to understand the phenomena of stressor-material interactions and sense early pre-cursor material property changes. An example of the degradation phenomena could be radiation-induced void swelling. PMMD also includes the impact of material degradation on the system or unit life-cycle.

Prognostics can be defined as being a "forecast of future performance and/or condition." Prognostics (for active and passive components) is the prediction of a remaining safe or service life, based on an analysis of the system or materials condition, stressors, degradation phenomena, and operating conditions.

In the context of materials degradation assessment, prognostics is the science enabling technology and methodologies needed to predict the remaining safe (service or licensable) life for a system or subsystem. Prognostic methodologies can be implemented in several ways, but in all cases, they seek to detect degradation phenomena by monitoring the driving stressors and using in most cases models to 
predict the degradation rate and hence extrapolate to give a prediction for the remaining life (or time at which intervention is required).

Such methods therefore can form a key element within a PMMD program by adding a "predictive" element to the proactive activities through the understanding and quantification of the rate of material degradation and resultant impact on system safety/life. Prognostic methods also have the ability to have a positive impact on Probabilistic Risk Assessment (PRA), through the ability it gives to manage and schedule outages and maintenance activities (Bond et al. 2008).

In understanding the relationship between PMMD and prognostics, it is helpful to understand some definitions within the prognostics lexicon:

- Prognostics - The ability to reliably predict the remaining useful life of mechanical components, within an actionable time period, with acceptable confidence limits (NDIA 2006).

- Prognostic Accuracy or Confidence Level - The accuracy in terms of difference between the future forecast of performance or condition and the actual future value achieved expressed as \pm an amount or as a percentage of the forecast. It may also be applied to the accuracy of the predicted time to failure, time to a given performance degradation point or percentage, or the remaining useful life.

- Prognostic Horizon - The maximum time or related parameter (such as number of cycles, etc.) for which a given Prognostic Technique will achieve a set accuracy or confidence level. For example, technique "A" may achieve a 90\% prognostic accuracy with a horizon of 200 operating hours, or Prognostic Technique "B" may achieve a $75 \%$ prognostic accuracy with a prognostic horizon of three cycles/missions.

- Prognostic Metrics - Those measures of performance of a prognostic technique or system that characterize the performance and predictive reliability of that technique or system for a specific application. These metrics may include:

- Demonstrated versus design prognostic accuracy/confidence level.

- Demonstrated versus design prognostic horizon.

- Demonstrated reliability of the prognostic system versus the system it monitors.

- Applicability or robustness of the prognostic technique or system - how many other applications can the technique be applied to with commensurate accuracy, reliability, and horizon attributes.

The quantification of the uncertainty within prognostic capabilities is central to the implementation of PMMD methodologies, particularly with regard to its integration with and impact on PRA.

\subsection{Organization of Report}

Section 1 - Provides background information that is necessary to understand the rationale for Proactive Materials Degradation

Section 2 - Introduces the basic principles of PMMD and presents major conclusion from NUREG/CR6329 that are based upon the principles of PMMD 
Section 3 - Provides a discussion of PMMD and prognostic programs currently being conducted nationally and internationally

Section 4 - Provides a discussion of the technical gaps from the view point of basic science, engineering and regulatory needs

Appendix A - Provides a list of nuclear power reactors in 2006-07 and uranium requirements from the U.S. and around the world

Appendix B - Provides a copy of a draft report titled "Overview Program Plan for Cooperation on Proactive Materials Degradation Management (PMDM) Research.” 


\subsection{Basic Principles of PMMD: Including Conclusions from NUREG/CR-6923}

Several unexpected materials degradation incidents have occurred in the recent past, such as Oconee vessel head penetration cracking, V.C. Summer hot leg cracking and Davis-Besse vessel head degradation. In part as a result of the incidents, regulators and industry concluded that a proactive approach to materials degradation assessment and management was desirable. The objective of the proactive approach included the following key elements:

- Develop a foundation for appropriate actions to keep materials degradation from adversely impacting component integrity and safety and avoid safety significant surprises

- Develop a path to PMMD following on from the extensive work on proactive materials degradation assessment (PMDA)

- Integrate regulatory and industry approaches for the effective management of materials degradation.

In developing the technical foundation and path for a proactive approach to materials degradation, the Nuclear Regulatory Commission Office of Nuclear Regulatory Research (RES) developed NUREG/CR6923. This document used expert elicitation to identify components susceptible to future degradation.

This section of the report describes the basic principles of NUREG/CR-6923, the important conclusions from that report, and the scenarios that the data in NUREG/CR-6923 can provide valuable insights.

\subsection{Basic Principles of Proactive Management of Materials Degradation}

The difference between reactive and proactive approaches to the management of materials degradation is illustrated in Figure 2.1 (the figure is taken from NUREG/CR-6923). In the reactive management scenario, there is limited time following the damage observation during which mitigation

actions can be developed before an unacceptable degree of damage occurs. This constraint may lead to the deployment of incomplete mitigation strategies. The time constraint is considerably reduced in the proactive management scenario, with the increase in available time for mitigation development being a function of the incubation time before damage starts and the subsequent kinetics of damage accumulation.

In order to meet the objective of a proactive material degradation assessment and management program, it is necessary to understand stressors and assess various damage and damage accumulation rate/severity relationships for existing and potential degradation modes, materials, environments, and operating states for the different LWR components. This assessment may be based on formulations for the various stressor and damage-time relationships or more generally on the basis of operating and laboratory experience and engineering judgment. 


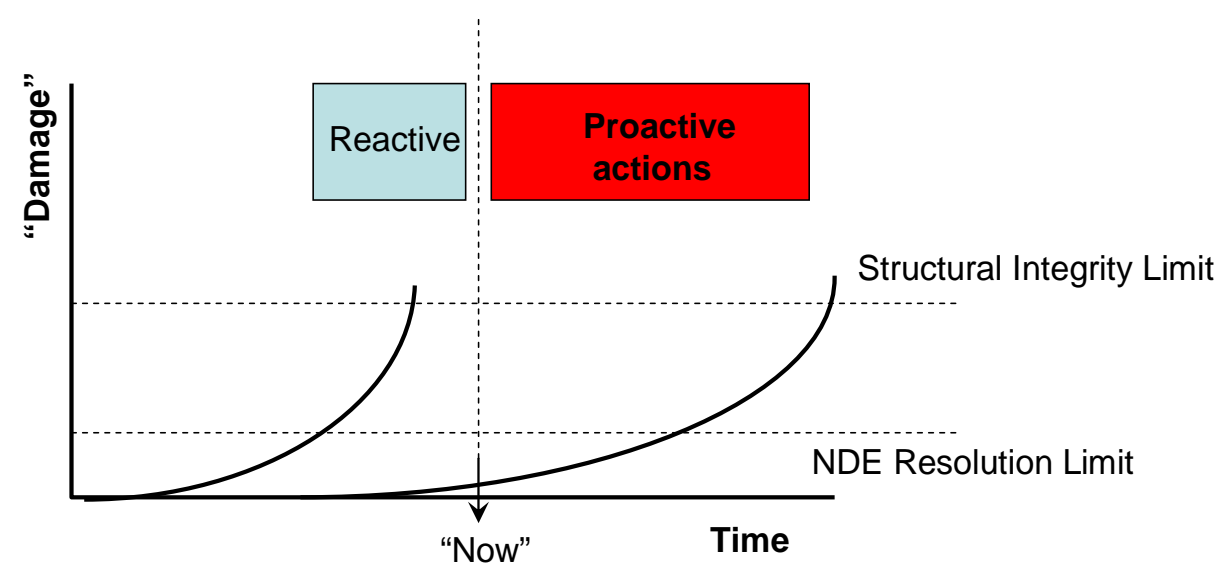

Figure 2.1. Schematic Diagram Illustrating Degradation, or Damage, Development with Time, and the Differentiation between Reactive and Proactive Actions. Note that the degradation process vs. time is rarely linear, as is often assumed

The six principles of proactive management of materials degradation were deduced from Andresen et al. (2007) and are highlighted to emphasize their importance.

Princple 1: Materials degradation has occurred in LWRs and will continue as long as LWRs are in operation. The trend within the nuclear power industry is to operate plants for longer periods of time and at increased power levels. The numbers of NPPs requesting power uprates ${ }^{(a)}$ and successfully applying for license renewal are examples of the trend. Material degradation (especially potential new modes of degradation) will likely increase as NPPs are operated for longer periods of time and at increased power levels. The use of alternate materials or modified operating conditions may potentially counteract these factors but in general are not fully qualified and can address only a fraction of the degradation modes. The technical reasons for these statements are outlined in detail in NUREG/CR 6923 (Andresen et al. 2007).

Principle 2: The proactive management of materials degradation increases the available time for mitigation, which is defined as a function of the incubation time before significant damage starts and the subsequent kinetics of accumulating damage.

Principle 3: Considering license renewal, power uprates, and the potential for "life beyond 60" years, addressing degradation in a reactive fashion has the potential to result in an unacceptable loss of safety margin. Current reactive management of materials degradation limits the time window following the damage observation during which mitigation actions can be developed before an

(a) The NRC regulates the maximum power level at which a commercial nuclear power plant may operate. With other data, this power level is used in many of the licensing analyses that demonstrate plant safety. This power level is also included in the license and technical specifications for the plant. The NRC controls any change to a license or technical specification, and the licensee may alter these documents only after NRC approves the licensee's application for change. The definition of power uprate is the process of increasing the maximum power level at which a commercial nuclear power plant may operate. 
unacceptable degree or level of damage is reached. This constraint may lead to the deployment of incomplete mitigation strategies.

Principle 4: Extended operation of a NPP requires the plant owner to address two major issues concerning degradation.

a. Developing effective aging management programs for known degradation as currently addressed in license renewal (NRC 2005a, b).

b. Developing a technically based program to understand the impact of stressors that can drive "damage" or material life utilization and then detect and mitigate both potential stressors and degradation that has not yet happened but has the potential to occur.

Principle 5: PMMD programs should include degradation mode-component combinations with applied stressors where there was a high susceptibility to degradation based in large part on multiple observations in operating plants regardless of the knowledge level concerning degradation.

Principle 6: PMMD programs should include degradation mode-component combinations where there was little or no evidence to date of degradation in the plants but where there was sufficient evidence from laboratory investigations to indicate that degradation in the plants might be expected in the future. Andresen et al. (2007) identified specific degradation mode-component combinations where the knowledge level of the system interdependencies is low and additional proactive actions (such as research) may be warranted if PMMD by mitigation is desired.

The overall approach to developing a proactive management program for materials degradation involves two steps. The first is to identify the components of interest that might undergo future degradation as compiled in Andresen et al. (2007) (also sometimes referred to as proactive materials degradation assessment, PMDA). The second step is to identify the technical gaps in NPP programs that detect, characterize, and monitor stressors resulting in degradation in all LWR components susceptible to future degradation. The technical gaps may require dedicated research projects to address the identified technical deficiency (e.g., develop effective mitigation strategies, inservice inspection and on-line monitoring techniques, and repair procedures).

\subsection{Major Conclusions from NUREG/CR-6923}

The NRC undertook a program to lay the technical foundation for defining proactive actions so that future degradation of materials in LWRs is limited and, thereby, does not diminish either the integrity of important LWR components or the safety of operating plants.

The objective of this study was to identify early the components that are potentially susceptible to future degradation, so that mitigation and/or monitoring and repair actions can be proactively developed, assessed, and implemented before the degradation process could adversely impact structural integrity or safety. The initial study conducted under the NRC's PMMD program was a study that focused on an identification of components susceptible to future degradation and an assessment of the existing knowledge level for potential development of mitigation actions. The results of this study are provided in detail in NUREG/CR-6923. 
The major conclusions from NUREG/CR-6923 are provided below.

\subsubsection{Degradation Analysis}

With regard to the degradation analyses, the major conclusions are:

- Degradation mode-component combinations where there was a high susceptibility to degradation, based in large part on multiple observations in operating plants. It would be prudent to include these components in PMMD programs regardless of the knowledge level of degradation.

- Degradation mode-component combinations where there was little (or no) evidence to date of degradation in the plants, but where there was sufficient evidence from laboratory investigations, for instance, to indicate that degradation at these locations in the plants might be expected in the future. It would also be prudent to consider these components for inclusion in PMDM programs. In addition, cases are identified where the knowledge level of the system interdependencies is low and additional proactive actions (research) may be warranted if PMMD by mitigation is desired.

The conclusions outlined above mark a departure from the reactive mode to managing materials degradation to a proactive mode of managing materials degradation and are listed as part of the basic principles of proactive materials degradation.

\subsubsection{Pressurized Water Reactor Coolant System under Full Power Operating Conditions}

The panel of material degradation experts that developed NUREG/CR-6923 provided two sets of conclusions for pressurized water reactor (PWR) reactor coolant system (RCS) components involving full power operation and non-steady state conditions such as reactor start-up, water chemistry transients, and extended plant lay-up. The conclusions follow the conclusions listed in Section 2.2.1 of this report and the basic principles of PMMD.

The following degradation modes have been observed in operating plants, and therefore, based on Principle 5 as stated in Section 2.1, "Basic Principles of Proactive Management of Materials

Degradation," components made for these materials should be considered "high susceptibility" in terms of degradation and included in a PMMD program.

- Stress corrosion cracking of Alloy 82/182 dissimilar metal welds throughout the primary system and especially in the highest temperature components such as the pressurizer.

- Stress corrosion cracking of Alloy 600MA and 600TT steam generator tubes and Alloy 600 forged components and, especially, cold worked or mechanically strained material such as steam generator tube expansion transitions, small radius U-bends, and the high-temperature components of the pressurizer.

- Corrosion of low-alloy steel components in boric acid concentrate originating from primary water leaks, specifically in the annuli between the Alloy 600 penetrations and the low-alloy steel reactor vessel or pressurizer. 
- Irradiation-induced creep and stress corrosion cracking of austenitic stainless steels at more than 0.5 dpa, (e.g., baffle bolts and other high-strength fasteners) and swelling in internals components that reach higher temperatures and much higher radiation doses.

- Fatigue due to unanticipated vibration and thermal fluctuations, e.g., in socket welds (which occur throughout the RCS), primary circuit deadlegs, and baffle bolts after irradiation-induced relaxation of pre-stress.

The following degradation modes follow Principle 6 as stated in Section 2.1 which states:

Degradation mode-component combinations where there was little (or no) evidence to date of degradation in the plants, but where there was sufficient evidence from laboratory investigations, for instance, to indicate that degradation in the plants might be expected in the future. It would also be prudent to consider these components for inclusion in PMMD programs.

Components made of the materials listed below and exposed to the specified conditions may be susceptible to particular degradation modes and thus should also be included in a PMMD program.

- Although Alloy 690TT has exhibited good resistance to stress corrosion cracking compared with Alloy 600 MA during more than 16 years of use in steam generator tubing, some panel members questioned its long-term resistance in other PWR primary water applications (e.g., pressure vessel penetrations). The potential for this degradation increases when considering effects of cold work and the use of the alternate welding alloys (Alloys 52 and 152), which present welding challenges associated with, for example, lack of fusion and ductility dip cracking.

- Stress corrosion cracking of severely mechanically strained stainless steels in PWR primary water, for example, weld shrinkage strains in heat-affected zones, pressurizer heater cladding, and cold-bent piping elbows.

- Cyclic thermal loading in the primary circuit hot leg caused by the difference in temperature between primary coolant streams exiting the center and periphery of low-leakage cores which, despite turbulence, can persist up to the steam generator channel head. While studies have shown that this cyclic loading does not produce significant thermal fatigue issues, the possible effect of ripple loading on other degradation mechanisms (such as stress corrosion cracking) could be a concern.

- Secondary side degradation (e.g., stress corrosion cracking) of steam generator tubes by potentially corrosive species (e.g., lead and low-valency sulfur ions) not previously appreciated to be widespread in the secondary system and which may also affect "more resistant" tubing materials such as Alloy 690.

- Potential degradation related to end of fuel cycle primary water chemistry, especially during cycle stretch-out, when the concentration of boron may be reduced below the minimum recommended value, thereby leading to possible localized corrosion due to excess $\mathrm{LiOH}$ in, for example, the boiling crevices in the pressurizer.

- Accelerated environmental effects on fatigue of austenitic stainless steels and nickel alloys at low electrochemical corrosion potentials, as demonstrated in the laboratory and therefore anticipated to apply in the field. 
- Less-than-anticipated fatigue resistance of some components due to the current uncertainty in the characterization of the cyclic loading conditions, particularly thermal loading, and the material response under those specific conditions.

- Reduced fracture resistance and increased susceptibility to stress corrosion cracking of cast stainless steels (and perhaps ferrite-containing stainless steel cladding and welds) as a result of thermal aging.

- Abusive grinding or machining during weld preparation or surface finishing and their adverse effects on stress corrosion and fatigue crack initiation.

\subsubsection{Boiling Water Reactor Coolant System under Full Power Operating Conditions}

The panel of material degradation experts that developed NUREG/CR-6923 provided two sets of conclusions for boiling water reactor (BWR) RCS components involving full-power operation and nonsteady state conditions such as reactor start-up, water chemistry transients, and extended plant lay-up. The conclusions follow the conclusions listed in Section 2.2.1 of this report and the basic principles of PMDM.

The following degradation modes have been observed in operating plants and, therefore, based upon Principle 5 from Section 2.1, components made for these materials should be considered "high susceptibility" in terms of degradation and included in a PMMD program. As in the PWR case discussed earlier, the listing given below is not in any order of priority.

- Stress corrosion cracking of Alloy 82/182 weldments used in joints between ferritic and austenitic components (e.g., thermal sleeves, attachment pads) and particularly Alloy 182 under normal water chemistry (NWC) conditions.

- Stress corrosion cracking of Type 304/316 stainless steel heat-affected zones (even under HWC conditions) at moderate fluences.

- Fatigue of Type 304/316 stainless steel in steam dryers under NWC and HWC conditions. This is probably design-specific, but as of now, is not quantified across the whole fleet.

- Stress corrosion cracking of Alloy 600 components and heat-affected zones throughout the reactor coolant system, particularly under NWC conditions.

- Stress corrosion cracking of Alloy X750 components throughout the reactor coolant system under both NWC and HWC conditions.

- Fatigue due to unanticipated vibration and thermal fluctuations in socket welds throughout the reactor coolant system.

The following degradation modes follow the Principle 6 from Section 2.1 which states:

Degradation mode-component combinations where there was little (or no) evidence to date of degradation in the plants, but where there was sufficient evidence from laboratory investigations, for instance, to indicate that degradation in the plants might be expected in the future. It would also be prudent to consider these components for inclusion in PMMD programs. 
Components made of the materials listed below and exposed to the specified conditions may be susceptible to particular degradation modes and, thus, should also be included in a PMMD program.

- Cast stainless steel components (e.g., CF8M brackets and guide rods and CF3 control rod guides) may experience a reduction in fracture resistance as a result of thermal aging. For the most part, however, the BWR RCS components operate at lower temperatures than PWR RCS components and, therefore, possible problems would be expected to become evident in PWRs earlier than in BWRs. Also, the possibility of stress corrosion cracking occurring in cast stainless steel components should not be dismissed without further investigation of the possible synergistic effect of thermal aging on the stress corrosion cracking degradation mode.

- The long-term effects of HWC on stress corrosion cracking are not yet clear and it is also not clear that the low potentials needed for mitigation are in fact achieved at all the high-susceptibility locations. The role of hydrogen in the stress corrosion cracking process of austenitic stainless steels is critical but is expected to be less than in high-strength nickel-base alloys. The effect of hydrogen on fatigue and its interaction with ripple loading and dynamic strain aging was noted as a potential contributor to degradation under HWC conditions.

- Several panel members suggested that additional fracture resistance tests are needed for all of the austenitic stainless steels and nickel-base alloys, particularly tests in environments simulating the full range of high-temperature service environments under both NWC and HWC conditions. Type 308 stainless steel weld metal is not as susceptible to thermal aging as cast austenitic stainless steel and therefore is also less susceptible to reduction of fracture resistance. There could, however, be some adverse effect of wet steam environments on fracture resistance.

- Accelerated environmental effects on fatigue of austenitic stainless steels and nickel alloys at low electrochemical corrosion potentials under HWC conditions. These effects have been demonstrated in the laboratory and therefore are anticipated to apply in the field.

- Stress corrosion cracking of severely cold-worked or mechanically strained stainless steels in BWR water; for example, weld shrinkage strains in heat affected zones, cold bent elbows.

- Abusive grinding or machining during weld preparation or surface finishing and their adverse effects on stress corrosion and fatigue crack initiation.

\subsubsection{PWR Systems Other than the RCS under Full Power Operating Conditions}

The degradation experts that developed NUREG/CR-6923 concluded that PWR systems other than the RCS indicated, in general, a lower likelihood of degradation primarily because these systems operate at a lower temperature than the RCS. However, as summarized below, the lower operating temperatures plus the existence of different degrees of water chemistry control, led to the identification of degradation modes that are favored under these different operating conditions.

The following degradation modes have been observed in operating plants and, therefore, based upon Principle 5 from Section 2.1, components made from these materials should be considered "high susceptibility" in terms of degradation and included in a PMDM program.

- Stress corrosion cracking of dissimilar metal Alloy 82/182 weldments in piping connected to the RCS cold leg of Combustion Engineering (CE) and Babcock \& Wilcox (B\&W) plants. Such components 
operate at high temperature $\left(291^{\circ} \mathrm{C}\right.$ up to $\left.345^{\circ} \mathrm{C}\left[556-653^{\circ} \mathrm{F}\right]\right)$ in primary water and are judged to have a high susceptibility to cracking. Some of the dissimilar metal weldments in this system are of Type 308/309 stainless steel and were judged to be of much lower susceptibility.

- The PWR Steam and Power Conversion Systems include the main steam, main feedwater, auxiliary feedwater, and steam generator blowdown subsystems. These subsystems are fabricated primarily with carbon and low-alloy steel components that are exposed to steam, condensate, or demineralized water. The degradation modes of high susceptibility are flow-accelerated corrosion and fatigue of low-carbon steel components, welds, and heat-affected zones.

- The PWR Support and Auxiliary Systems include the Service Water, Chemical and Volume Control (CVCS), Component Cooling Water (CCW) and Spent Fuel Pool subsystems. These subsystems are fabricated primarily with carbon steels, copper-base alloys, and stainless steels that are exposed to untreated and treated water or (for the CVCS lines) primary water, all at relatively low temperatures. The degradation modes, such as general corrosion, pitting, stress corrosion cracking, crevice corrosion, and microbiologically influenced fouling and corrosion, are recognized on the basis of extensive experience in the nuclear and other industries. However, predicting their occurrence in advance is still uncertain. Failures in these systems can have a significant impact on the functionality of RCS components. (For instance, chloride contamination of the steam generator system can occur as a result of turbine condenser leakage, etc.) The following high-susceptibility componentdegradation mode combinations (which are discussed in Section 3.2.4 of NUREG/CR-6923) have been observed in these PWR systems:

- Microbiologically influenced corrosion of carbon steels in service and raw water and on external surfaces of buried piping, which may lead to localized corrosion and penetration of safetysignificant components due to pitting, fouling, and stress corrosion cracking.

- Pitting and crevice corrosion of buried carbon steel piping and penetrations through concrete, and of $\mathrm{Cu}-\mathrm{Zn}$ brass (as opposed to $\mathrm{Cu}-\mathrm{Ni}$ alloy) heat exchanger tubing.

- Fatigue of socket welds throughout the support systems, but especially in the CVCS system due to unanticipated flow-assisted vibration.

- Stress corrosion cracking of $\mathrm{Cu}-\mathrm{Zn}$ brass heat exchanger tubing used in the service pump water discharge piping.

The following degradation modes follow the Principle 6 from Section 2.1 which states:

Degradation mode-component combinations where there was little (or no) evidence to date of degradation in the plants, but where there was sufficient evidence from laboratory investigations, for instance, to indicate that degradation in the plants might be expected in the future. It would also be prudent to consider these components for inclusion in PMMD programs.

Components made of the materials listed below and exposed to the specified conditions may be susceptible to particular degradation modes and thus should also be included in a PMMD program.

- Thermal fatigue in non-isolable deadlegs attached to the primary coolant circuit.

- Fatigue of socket welds throughout the Emergency Core Cooling System (ECCS) due to unanalyzed thermal stresses and flow-induced vibrations. 
- Stress corrosion cracking of cast stainless steel components in, for example, the residual heat removal (RHR) pump suction piping.

- Fatigue of austenitic stainless steels.

- Possible reduction in fracture resistance of the constrained region adjacent to welds in stainless steels.

- Stress corrosion of high-strength studs and bolts in the CVCS system.

\subsubsection{BWR Systems other than the RCS under Full Power Operating Conditions}

The degradation experts that developed NUREG/CR-6923 concluded that BWR systems other than the RCS indicated, in general, a lower likelihood of degradation primarily because these systems operate at a lower temperature than the RCS. The experts also simplified the analysis of BWR systems by excluding the following five systems because they were considered to be no different than the corresponding PWR systems already discussed above: containment isolation penetrations, spent fuel storage, spent fuel pool cooling and cleanup, service water, and component cooling water.

For BWR systems other than the RCS, the following degradation modes have been observed in operating plants, and therefore, based upon Principle 5 from Section 2.1, components made for these materials should be considered "high susceptibility" in terms of degradation and included in a PMMD program.

- The BWR Engineered Safety Features/Emergency Core Cooling System includes the low- and highpressure core spray lines, the condensate storage tank, and the RHR piping and subsystems. The components with a high degree of susceptibility to degradation were far fewer than in the RCS, primarily because these predominantly carbon and low-alloy steel systems operate in condensate cooling water or suppression pool water at significantly lower temperatures (below $38^{\circ} \mathrm{C}\left[100^{\circ} \mathrm{F}\right]$ ). The following component-degradation mode combinations were found to have a high or medium degree of susceptibility:

- Carbon and low-alloy steel components and welds exposed to suppression pool water are susceptible to crevice corrosion, general corrosion (medium), pitting corrosion, stress corrosion cracking (medium), and microbiologically influenced corrosion (medium).

- Depending on the degree of sensitization, Type 304/316 stainless steel weld heat-affected zones are susceptible to stress corrosion cracking in these systems where it is difficult to maintain HWC as a mitigation measure.

- If they are wetted, carbon steel-to-brass joints in the drywell are susceptible to galvanic corrosion and crevice corrosion.

- The BWR Steam and Power Conversion Systems include the main steam and feedwater lines, and the main condenser and its associated piping. The components in these subsystem components are fabricated primarily from carbon and low-alloy steel, and are exposed to steam, condensate, or demineralized water. The following component-degradation mode combinations were found to have high susceptibility:

- Low-alloy steel bolts for the T-quencher/sparger above the suppression pool are susceptible to pitting corrosion and stress corrosion cracking or hydrogen embrittlement. Such degradation has 
been observed and is exacerbated by the fact that the high-strength bolts are exposed to poorquality suppression pool water in conjunction with the use of a zinc primer coating.

- The outside surfaces of titanium condenser tubes are susceptible to droplet erosion if directly exposed to incoming wet steam. This is a design-specific problem that has been mitigated by fabricating the outrow of tubing (i.e., the row that takes the impact) from stainless steel.

- The BWR Support and Auxiliary Systems are fabricated primarily of carbon steels and stainless steels and are exposed to a variety of environments ranging from wet steam at $286^{\circ} \mathrm{C}\left(547^{\circ} \mathrm{F}\right)$ to suppression pool water at less than $38^{\circ} \mathrm{C}\left(100^{\circ} \mathrm{F}\right)$. The degradation modes, such as general corrosion, pitting, stress corrosion cracking, crevice corrosion and microbiologically influenced fouling and corrosion, are mostly understood on the basis of extensive experience in the nuclear and other industries. As with the corresponding PWR system, however, failures in these systems can impair the functionality of other important systems or components.

- Fatigue of carbon steel socket welds in $286^{\circ} \mathrm{C}\left(547^{\circ} \mathrm{F}\right)$ steam.

- Crevice corrosion of ferritic valve components exposed to oxygenated suppression pool water with poor chemistry control.

- Stress corrosion cracking adjacent to Type 304/316 stainless steel weldments in the reactor water clean up piping to pumps with water at $279^{\circ} \mathrm{C}\left(535^{\circ} \mathrm{F}\right)$ under $\mathrm{NWC}$ conditions.

The following degradation modes follow the Principle 6 from Section 2.1 which states:

Degradation mode-component combinations where there was little (or no) evidence to date of degradation in the plants, but where there was sufficient evidence from laboratory investigations, for instance, to indicate that degradation in the plants might be expected in the future. It would also be prudent to consider these components for inclusion in PMMD programs.

\subsection{Generic Degradation Issues Addressed by the Database in NURG/CR-6923}

The data in the Appendices in NUREG/CR-6923 address the specific topics that were described in the NRC Offices of Nuclear Reactor Regulation (NRR) User Need Request, "Materials Degradation,” dated January 12, 2004. This user need in essence requested the following of RES:

- Identify reactor components that could experience future degradation

- Assess effectiveness of inservice inspection programs for degradation-susceptible components

- Assess risk significance associated with the failure of susceptible components

- Estimate the probability of failure of susceptible components.

The objective of this section of this report is to describe specific questions that the data in the Appendices in NUREG/CR-6923 will be able to answer. This objective is achieved by describing a series of scenarios based upon the topics above. 


\subsubsection{Identify Reactor Components that could Experience Future Degradation}

Scenario: A degradation mechanism is found in a new unanticipated component or system

Within this scenario, NRC and industry are faced with a situation where degradation has been found in a component or system where the degradation was not anticipated to occur. An example of this scenario in recent history is the cracking that has occurred in Alloy 600 weld material PWR reactor coolant systems. When faced with such a scenario, NRC needs to quickly answer the following questions.

- Is there any database or data that indicates the degradation could have been anticipated?

- What other systems and/or components in PWRs and BWRs have similar material and environmental conditions where degradation may occur?

- What is known about the inspection reliability for this degradation mechanism for the components or systems where it has now been found?

A fully functional PMMD database would enable NRC and industry users to more easily search a technical database and provide technical references that may be used by NRC and industry in managing the degradation.

\subsubsection{Assess Effectiveness of Inservice Inspection Programs for Degradation- Susceptible Components}

Scenario: A degradation mechanism is found in a component that has received regular inservice inspection

Within this scenario, NRC and industry are faced with a situation where degradation has been found on components during an inservice inspection via visual observation even though the component was periodically examined using ultrasonic methods. An example of this scenario in recent history is the detection of boric acid deposits at V.C. Summer. When faced with such a scenario, NRC and industry need to quickly answer the following questions.

- Could such an event be anticipated? A corollary question would be - Is there any data (or expert opinion) that indicates what the effectiveness of inservice inspection for this component/degradation combination should be?

- What is the estimated probability of detection (POD) for the affected component?

\subsubsection{Assess Risk Significance Associated with the Failure of Susceptible Components}

Scenario: Same as above

Within the same scenario described above, the NRC and industry need to quickly assess the risk significance of susceptible components. 



\subsection{Summary of PMMD and Prognostic Programs Currently Being Conducted}

The past 10-15 years have seen a growing awareness within the international community of the value of legacy NPPs. Legacy plants can provide countries with much needed energy, beyond initial licensing life, and also make significant contributions to the management of greenhouse gas emissions. Long-term life plans, including power uprate, I\&C, and other key system modernization and replacements are all being included in life-cycle management as operators look to optimize the management of the life of NPPs, which are now viewed as very high-value economic assets. Within the technical community that is considering aging and degradation, as well as optimization of plant operations, there has been a convergence between the various strands that combine in integrated approaches to optimized plant life management (PLiM).

For new plants, initial licensing life now is being targeted at 60 years, and PliM has become a key part of the philosophical approach. There has also been a growing recognition that nuclear plant condition assessment based on nondestructive testing (NDT) at the time of fabrication, followed by intense inspections during outages, requires the adoption of conservative assumptions with regard to addressing detected indications and intervention. With aging plants, there is the risk of "surprises" at outages, which can cause extended down time. A recent study (Anderson et al. 2008) has concluded that current inspection frequencies do not match rates of degradation growth, which adds support to the conclusion that new approaches, including on-line monitoring, are needed for both current and new reactors. To address these issues, there is already a move to deploy on-line monitoring and conditionbased maintenance that has the potential to increase operator situational awareness, enhance safety, and provide significant cost savings.

In the PLiM arena, numerous international, regional, and national programs and activities are being reported at both workshops and major meetings (PLiM 2007; SMiRT-19 2007). The facility life management and extension activities are now seen as impacting all parts of the fuel facility and plant life cycle. For example, insights into aging mechanisms and effects are being gained from samples taken from decommissioned plants (Johnson Jr. et al. 2001). There is increasing interest in moving from inservice inspection to on-line monitoring. The use of modern computer-based instrumentation has provided enhanced functionality and given opportunities for near-real time data capture and analysis. The move to upgrade I\&C systems, moving from analog to digital systems, provides opportunities to deploy enhanced functionality. In a number of countries, the needs for revised regulatory frameworks are being considered and in some cases new approaches developed.

For NPPs, the operations and maintenance (O\&M) costs are estimated for various plants and countries at between 40 and $70 \%$ of the overall generating cost. In the United States, O\&M is at the higher end of the range ( $\sim 60-70 \%)$, and fuel costs are at about $15-30 \%$. Of the O\&M costs (in the United States), about $80 \%$ are related to the costs of labor. In both Europe and North America, the situation is complicated further by the problem of an aging workforce and a limited supply of replacements (Wogman et al. 2005). In the rapidly growing Asian economies and developing countries, there are also challenges in meeting the skilled workforce needs, particularly as new nuclear plants are built (Amin 2004; IAEA 2004b). 
An underlying theme of proactive materials degradation assessment is emerging, although it is still being called by a variety of names. It is seen to be at the heart of PliM and applies to both legacy and new LWRs. There is a trend to move from being reactive, based on assessments used for condition-based maintenance (CBM), with action taken after detection of some effect through CBM monitoring or ISI, to becoming proactive. Such a fundamental change in PLiM, including PMMD, requires identification and understanding of the effects of stressors on systems and the resulting effects, new or at least adapted material degradation models, new measurement technologies, remaining-life prediction (prognostics), with management of risk and quantification of uncertainty. All of the new approaches to PMMD and PLiM need to be considered in the context of probabilistic risk assessment, applied to the system and specifically to stressors and the resulting materials degradation. The focus of all the activities is to give enhanced situational awareness, early detection of degradation, and the necessary understanding to be able to reliably predict material behavior, to maintain both safe and economic plant operation. PMMD is therefore one of the key "planks" needed to build the conceptual framework and to convert advanced PliM, or activities which are alternately named PMDM, to practice.

\subsection{Diagnostics and Prognostics: State of the Art and Potential}

The past decade has seen major activities developing within both the nuclear and wider engineering communities to move from the use of periodic NDT to CBM and advanced life management with what has been called by various names, including structural health monitoring, material damage prognostics, and PMDA/PMMD. Where these approaches have been applied, they have been implemented with online methods developed for advanced monitoring and diagnostics. As the economic value of CBM and other advanced monitoring approaches is being demonstrated, there is increasing interest in prognostics, the prediction of the remaining safe or service life for both active components, such as pumps, and passive components, the basic structural materials.

\subsubsection{Diagnostics}

It was recognized in the mid-1970s that NDT needed to become a quantitative science-based technology. Research was initiated and, as a result, nondestructive evaluation (NDE) was developed (Thompson and Chimenti 1980-2007). Many of the measurement capabilities for NDT/NDE were identified as set by fundamental physics (Bond 1988). It was also recognized that different levels of performance can be achieved in the laboratory, on production parts, and in service. An example of these performance differences using traditional NDT technologies is shown with Table 3.1 (Bond 1988).

Recent years have seen the development of better understanding of the NDT/NDE measurement processes and quantification of performance in terms of a POD rather than a size for an ultimate detection limit. The operator or inspector is also recognized as a key element in the inspection system, and not all

operators perform to the same level. This issue is best illustrated with data from trials, such as the USAF Engine Structural Integrity Program (ENSIP) trials, where performance data are shown in Table 3.2 (Bond 1988). The top $10 \%$ of inspectors perform at exceptional levels. The median inspector does not achieve similar sensitivity. In part to address performance reliability for ISI, there has been a move to automation. The best automated systems can give repeatability, although they usually do not achieve the ultimate sensitivity/detection limits achieved by the best inspectors. 
Table 3.1. Estimated Variations in Flaw Detection Limits by Type of Inspection (in mm)

\begin{tabular}{lcccc}
\hline & \multicolumn{2}{c}{ Surface Cracks } & \multicolumn{2}{c}{ Internal Flaws } \\
\cline { 2 - 5 } NDT Technique & Processing & Fatigue & Voids & Cracks \\
\hline Test specimens, laboratory & inspection & & & \\
Visual $\dagger$ & 1.25 & 0.75 & + & + \\
Ultrasonic & 0.12 & 0.12 & 0.35 & 2.0 \\
Magnetic Particle & 0.75 & 0.75 & 7.5 & 7.5 \\
Penetrant & 0.25 & 0.5 & + & + \\
Radiography & 0.5 & 0.5 & 0.25 & 0.75 \\
Eddy Current & 0.25 & 0.25 & + & + \\
Production parts, production & inspection & & & \\
Visual & 2.5 & 6.0 & + & + \\
Ultrasonic & 3.0 & 3.0 & 5.0 & + \\
Magnetic Particle & 2.5 & 4.0 & + & + \\
Penetrant & 1.5 & 1.5 & + & + \\
Radiography & 5.0 & $*$ & 1.25 & + \\
Eddy Current & 2.5 & 5.0 & + & + \\
Cleaned structures, service inspection & & & + \\
Visual & 6.0 & 12.0 & + & + \\
Ultrasonic & 5.0 & 5.0 & 4.0 & + \\
Magnetic Particle & 6.0 & 10.0 & + & + \\
Penetrant & 1.25 & 1.25 & + & + \\
Radiography & 12.0 & $*$ & + & + \\
Eddy Current & 5.0 & 6.0 & & + \\
\hline + Not applicable & & & & + \\
$\dagger$ Use with magnifier & & & & + \\
*Not possible for tight cracks (based on 25 -mm ferritic steel, surface 63 RMS) & \\
\hline
\end{tabular}

Table 3.2. Performance of "Best" and Median NDT Operators (from ENSIP)

\begin{tabular}{lccc}
\hline & Average & Best & mm \\
\hline Magnetic Inspection POD & $60 \%-0.300$ in. crack & $65 \%-0.25$ in. & 6.35 \\
Penetrant Inspection & $90 \%-0.220$ in. crack & $90 \%-0.175$ in. & 4.45 \\
Eddy Current & $90 \%-0.090$ in. crack & $90 \%-0.030$ in. & 0.76 \\
Ultrasonic & $80 \%-0.375$ in. crack & $90 \%-0.180$ in. & 4.57 \\
\hline Average results obtained from majority of technicians. & & \\
Best results obtained from top 10\% technicians. & & \\
\hline
\end{tabular}

The advances in monitoring technologies developed in other industries can potentially benefit both legacy and new NPPs, particularly when using advanced on-line monitoring and diagnostics for condition-based maintenance and, in the future, prognostics. Digital I\&C and advanced diagnostics and prognostics are being developed in the wider high-technology industry communities and are now being considered for NPP deployment. There is a convergence between material damage prognostics (Larson 
et al. 2005); the civil engineering damage and damage evolution models under multiple stressors; the traditional "vibration" monitoring community looking toward new challenges in systems used by the defense community (Pusey et al. 2005); technology to achieve total structural health management (Chang 2003b); and the NDE community looking at aging due to thermal embrittlement, fatigue, and neutron degradation (Dobmann 2006).

There has also been development of new approaches to the management of life in mechanical systems (Roos et al. 2006) and research into characterization of materials in aging systems, particularly looking at early-degradation phenomena that occur before the "traditional" defects (such as cracks) that are detected by conventional NDT develop to detectable sizes (Crane et al. 1998). The trend of seeking to move from periodic NDE to on-line condition-based maintenance started several years ago in other industries (Bond 1999). A review of the current paradigms and practices in system health monitoring and prognostics has recently been provided by Kothamasu et al. (2006).

There remain significant measurement challenges associated with characterization of aging in irradiated reactor components (Doctor 1988; Dobmann 2006). An example of one major series of activities moving from NDE to characterization of aging and degradation is found in the work of Dobmann and colleagues. In their early papers, they reported using ultrasonic and micromagnetic techniques to measure strength and toughness and detect early damage (Dobmann et al. 1992). This evolved into work to address the demand for describing damage and service-related aging (Dobmann et al. 1997). This work further evolved into a significant European project involving round-robin sample characterization (Dobmann et al. 2001) and bringing together condition-dependent NDT and fracture mechanics (Schmitz et al. 2001). An increasingly diverse range of NDT/NDE tools is being considered in both laboratory and field studies (Crane et al. 1998; Dobmann 2006) for aging phenomena characterization, as shown with new applications of magnetic methods (Dobmann 2006). Techniques such as ultrasonic backscatter and acoustic birefringence are being investigated as possible tools for inservice monitoring. The development of concepts for advanced on-line structural health monitoring for next-generation reactor designs, such as IRIS, has been initiated (Nakagawa et al. 2006).

All U.S. pressurized water reactors that have been granted an operating license extension beyond the original 40 years. In completing the U.S. license renewal process, these plants have identified degradation processes, such as void swelling, that do not currently have approved in-service inspection technology that enables detecting, monitoring, or trending the degradation mechanism. In each case, the plant has performed an evaluation that demonstrates the degradation is not an eminent threat and has made commitments to the regulator for developing programs that will manage these degradation processes. However, the details of these programs are unknown at this time because the technology is still under development.

To address these challenges, a convergence is developing that is bringing together the capabilities in the materials science and NDE communities. This convergence is illustrated with Figure 3.1. A particular challenge is faced in taking characterization capabilities, which can be performed with tools such as an SEM or spectroscopic technique, into a service environment, particularly to achieve the sensitivity and resolution that seem to be needed. 


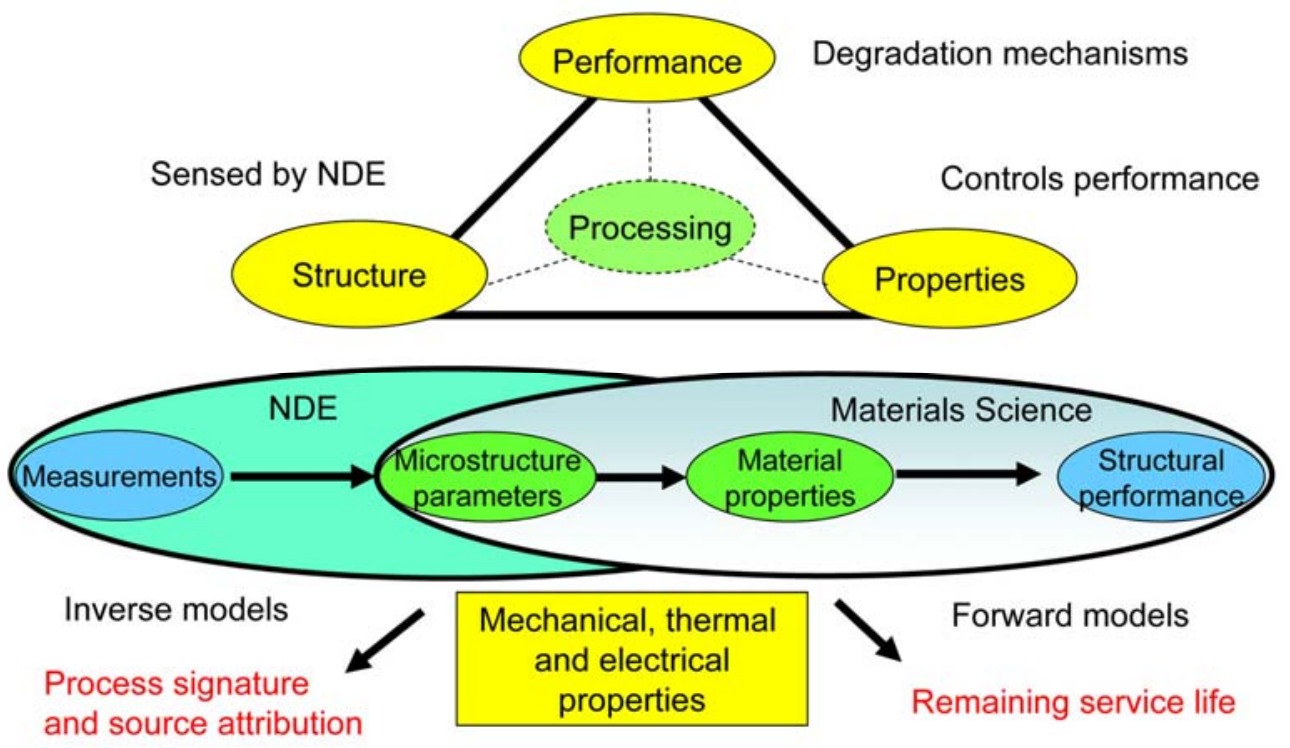

Figure 3.1. Convergence and Relationship Between NDE and Materials Science

\subsubsection{Prognostics}

Prognostics (for machinery) is the prediction of a remaining safe or service life, based on an analysis of system or material condition, stressors, and degradation phenomena. Moving from diagnostics based on observed data to prediction of life and technologies for structural health monitoring/management based on predicted behavior is requiring development of new approaches. The range of developing approaches is illustrated in schematic form in Figure 3.2. The various empirical methods for process and equipment prognostics have been reviewed by Hines (2008). An extensive review of machinery diagnostics and prognostics for condition-based maintenance is provided by Jardine et al. (2006) but does not consider nuclear power systems.

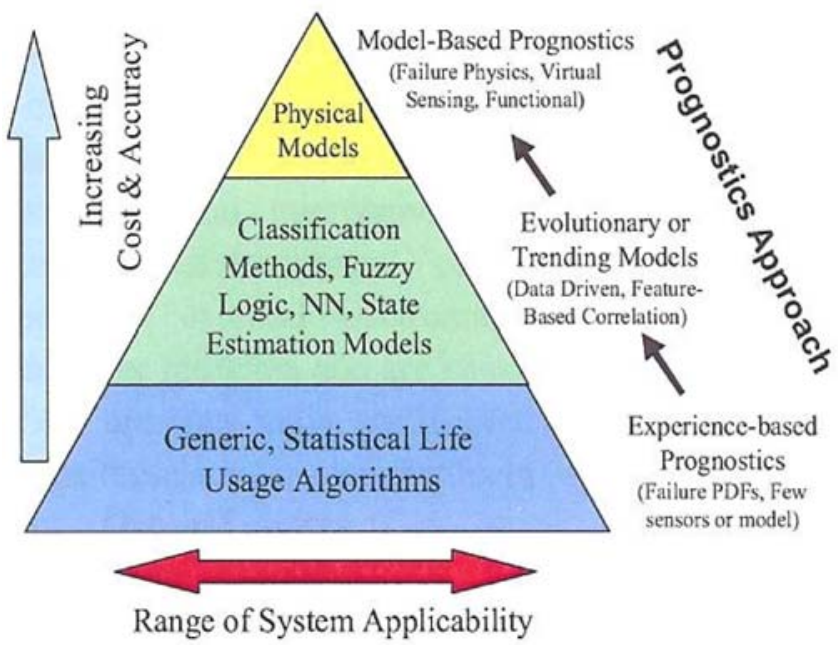

Figure 3.2. Range of Prognostic Approaches 
An assessment of the state of diagnostics and prognostics technology maturity was recently provided by Howard (2005). The current status for various system elements, including both active and passive structures, is shown in Table 3.3.

Technologies are being developed for non-nuclear applications, including instrumentation and system health monitoring for electronics, in what is being called "electronics prognostics"; for example, see Urmanov (2007). Integrated technologies also are being developed for advanced fighter aircraft and unmanned aerial vehicle system health monitoring, which include both electrical/electronic and mechanical systems. Within the field of advanced diagnostics/prognostics, systems have been deployed for individual elements, but fully integrated systems are still being developed.

Table 3.3. Assessment of State of Maturity for Diagnostic (D) and Prognostic (P) Technologies (Howard 2005)

\begin{tabular}{|c|c|c|c|c|}
\hline Diagnostic/Prognostic Technology for: & $\mathbf{A P}^{(\mathbf{a})}$ & $\mathbf{A}^{(\mathbf{b})}$ & $\mathbf{I}^{(\mathbf{c})}$ & $\mathrm{NO}^{(\mathrm{d})}$ \\
\hline Basic Machinery (motors, pumps, generators, etc.) & $\mathrm{D}$ & & $\mathrm{P}$ & \\
\hline Complex Machinery (helicopter gearboxes, etc.) & & $\mathrm{D}$ & $\mathrm{P}$ & \\
\hline Metal Structures & $\mathrm{D}$ & & $\mathrm{P}$ & \\
\hline Composite Structures & & & D\&P & \\
\hline Electronic Power Supplies (low power) & & $\mathrm{D}$ & $\mathrm{P}$ & \\
\hline Avionics and Controls Electronics & $\mathrm{D}$ & & $\mathrm{P}$ & \\
\hline Medium Power Electronics (radar, etc.) & & $\mathrm{D}$ & & $\mathrm{P}$ \\
\hline High Power Electronics (electric propulsion, etc.) & & & & $\mathrm{D} \& \mathrm{P}$ \\
\hline $\begin{array}{l}\text { (a) } \mathrm{AP}=\text { Technology currently available and prove } \\
\text { (b) } \mathrm{A}=\text { Technology currently available, but } \mathrm{V} \& \mathrm{~V} \mathrm{n} \\
\text { (c) } \mathrm{I}=\text { Technology in process, but not completely r } \\
\text { (d) NO= No significant technology development in }\end{array}$ & $\begin{array}{l}\text { ve. } \\
\text { leted. } \\
\text { V\&V. }\end{array}$ & & & \\
\hline
\end{tabular}

For the existing NPPs, particularly when life extension is being developed, there are opportunities to deploy on-line monitoring/prognostics, assuming it can be demonstrated that there is still remaining useful life in the plant. Key to developing more advanced prognostic schemes (in active systems such as pumps and valves) that give maximum warning of degradation is to focus on monitoring the stressor rather than just the subsequent effects of aging and degradation. A schematic showing system operational performance and stressor magnitude is given as Figure 3.3 (Jarrell et al. 2004; Bond et al. 2008). Researchers found (Jarrell et al. 2004; Bond et al. 2008) that monitoring of the stressor (e.g., a temperature, cavitation, vibration, or a pressure), combined with active system control parameter management across several processors, enables the use of the "warning time" ( $\Delta \mathrm{T}$ in Figure 3.3) to adjust operational parameters and limit or at least control rates of degradation for a path to failure. For this type of strategy to be successful, good physics-based models relating the stressors to the rate of aging or degradation must be developed in the prognostic scheme. 


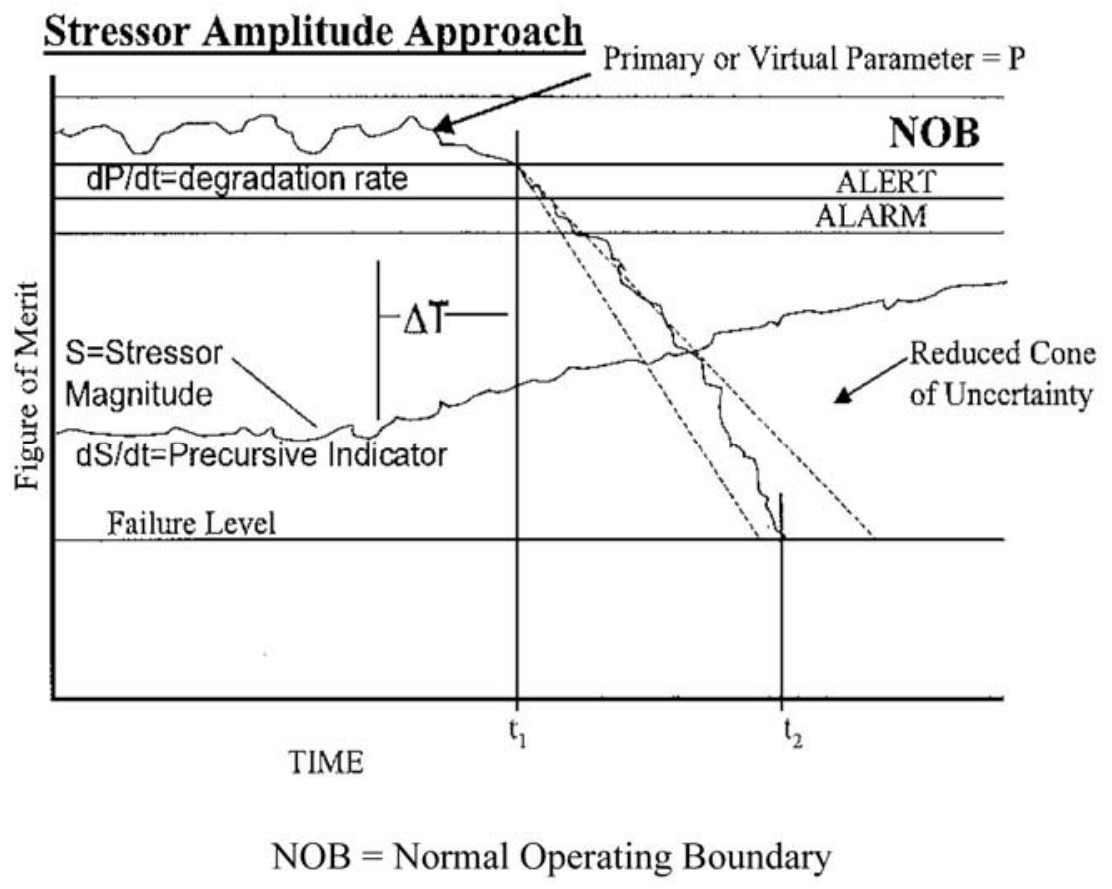

Figure 3.3. Stressor Measurement Giving Time for Intervention Prior to Failure (Jarrell et al. 2004; Bond et al. 2008)

To move from periodic inspection to on-line monitoring for condition-based maintenance and eventually prognostics will require advances in sensors; better understanding of what and how to measure within the plant; enhanced data interrogation, communication, and integration; new predictive models for damage/aging evolution; system integration for real-world deployments; quantification of uncertainties in what are inherently ill-posed problems; and integration of enhanced condition-based maintenance/ prognostics philosophies into new plant designs, operation, and operating and maintenance approaches.

\subsubsection{Lessons from U.S. License Extension Activities}

A 2006 report prepared by the Chockie Group International (CGI) (Gregor and Chockie 2006) provides an overview of U.S. aging management and life extension programs and regulations within the U.S. commercial nuclear power industry and their possible applicability to the petroleum industry in Norway. It was prepared as part of the project for the Petroleum Safety Authority (PSA) Norway, Design Life Extension Regulations (PSA Project Reference Number: NO 99B16). Associated with the 2006 report are two companion briefing reports that provide focused examinations of two important aspects of life extension requirements. These are Performance Monitoring of Systems and Active Components (CGI Report 06.21) — an examination of the Maintenance Rule requirements for effective maintenance programs - and Condition Monitoring of Passive Structures and Components (CGI Report 06.22) —a review of the License Renewal Rule requirements and process for aging management of passive and longlived structures and components. Three important principles associated with aging management are identified. These are

- maintaining the structures, systems, and components (SSCs) in "as new" condition, with no reduction in performance or safety margins 
- preventing failures of critical SSCs

- understanding and managing the age-related degradation mechanisms.

In the late 1970s, the NRC and the nuclear industry began to address the issues concerning life extension. The first initiatives were directed at determining whether or not the safe operation of the plant beyond its 40 -year licensing limit could be technically justified. That is, could the aging effects be adequately managed so the plant could be operated within the original safety margins during the period of extended operation?

To answer this question, both the NRC and the industry initiated a number of aging research programs. One of the largest aging research efforts was the Nuclear Plant Aging Research (NPAR) program. This 10-year, multi-million dollar effort was sponsored by the NRC and produced over 150 aging research reports. Other aging research programs by the industry complemented the work of the NPAR program.

Based on the results of these programs, it was concluded that many aging phenomena are readily manageable and do not pose technical issues that would preclude life extension for NPPs. As long as there are effective inspection and maintenance practices, the plant life is limited simply by the economic cost of repair or replacement of any components that do not meet specified acceptance criteria. Many of the earlier insights gained have been summarized in a 1992 report (Blahnik et al. 1992a). In addition, ongoing activities and meetings address water reactor safety/aging issues (NRC 1998b). Specific studies have considered topics such as aging of pressure sensors (Hashemian et al. 1989; Hashemian 1993) and process instrumentation (Hashemian 1995).

The NRC then moved forward with the development of license renewal requirements and published the initial License Renewal Rule in 1991. For over 15 years, the NRC and the nuclear industry have been continuously refining both the license renewal requirements and the renewal process. The resulting revised rule established a simpler, more stable, and more predictable regulatory process. The key changes that were made included

- focusing on the adverse effects of aging rather than identification of all aging mechanisms such that identification of individual aging mechanisms is not required

- simplifying the integrated plant assessment process and making it consistent with the revised focus on the detrimental effects of aging

- adding an evaluation of time-limited aging analyses

- requiring only passive, long-lived structures and components to be subject to an aging management review for license renewal, thus removing active SSCs from license renewal.

In the current light-water reactor fleet, new degradation processes have appeared on average at a rate of one every seven years (Wilkowski et al. 2002). Operators have been shown to need information to better manage power-plant life holistically, adjusting operating conditions to reduce the impact of stressors. Recently, a report (Anderson et al. 2008) has been developed that indicates that periodic inspections, which typically occur during refueling outages, may not be assumed to be adequate to help ensure fitness for service for critical safety systems and components or help ensure optimal plant life management, developing methodology and designing systems for on-line continuous monitoring becomes 
critical. It is needed to provide operators with better plant situational awareness and reliable predictions of remaining service life of critical systems and components.

For the current fleet of operating light-water reactors, the majority of component failures are the failure of active components not operating correctly when called upon to perform a given function, such as a valve not opening or closing on demand. The failure of passive components is dominated by failures associated with service degradation. The active components are managed with a maintenance program that is based on experience and not based on the known condition of the component and its need for preventive maintenance. Degradation of passive components is managed through periodic inspections as dictated by the ASME Code. Over the past few years, these inservice inspection programs have changed dramatically using risk-based management.

Although there is management of risk from a safety standpoint, open issues remain. These include the potential risk of having surprise failures. These surprises are related to the occurrence of new degradation mechanisms, including degradation mechanisms that are accelerated by stressor enhancement due to altered conditions or newly introduced acceleration mechanisms (e.g., corrosion due to accidental chloride introduction). These have a long initiation time, and the fact that only the risk-important components are being inspected periodically means that fewer components are being inspected because most of the NPP risk is associated with a small percentage of plant components. Another factor is the movement away from the original strategy of defense-in-depth where inservice inspection was to be used to detect the unexpected that had not been accounted for in design, selection of materials, fabrication processes employed, or the operating conditions. How will these lessons learned be addressed in both new-build water reactors and advanced designs under consideration for Gen IV NPPs?

An important aspect of the U.S. nuclear plant life extension requirements is the distinction between passive and active systems, structures, and components. Passive SSCs are those that do not move to function (such as structures, heat exchangers, cables, valve and pump bodies, and piping). Their agerelated degradation can be monitored and trended only by performing periodic condition assessments (such as inspections, testing, and measurements). By focusing the license renewal process on safetycritical passive and long-lived components, the process has been reduced to manageable proportionslicensees are not required to consider all SSCs to justify extended operations. A diagram of the relationship of the License Renewal and Maintenance Rules to the aging management of active and passive SSCs is shown in Figure 3.4 (Gregor and Chockie 2006).

During the renewal process, the licensee must confirm whether the original design assumptions will continue to be valid throughout the period of extended operation or whether aging effects will be adequately managed. The licensee must demonstrate that the effects of aging will be managed in such a way that the intended functions of passive or long-lived structures and components will be maintained during extended operation. 


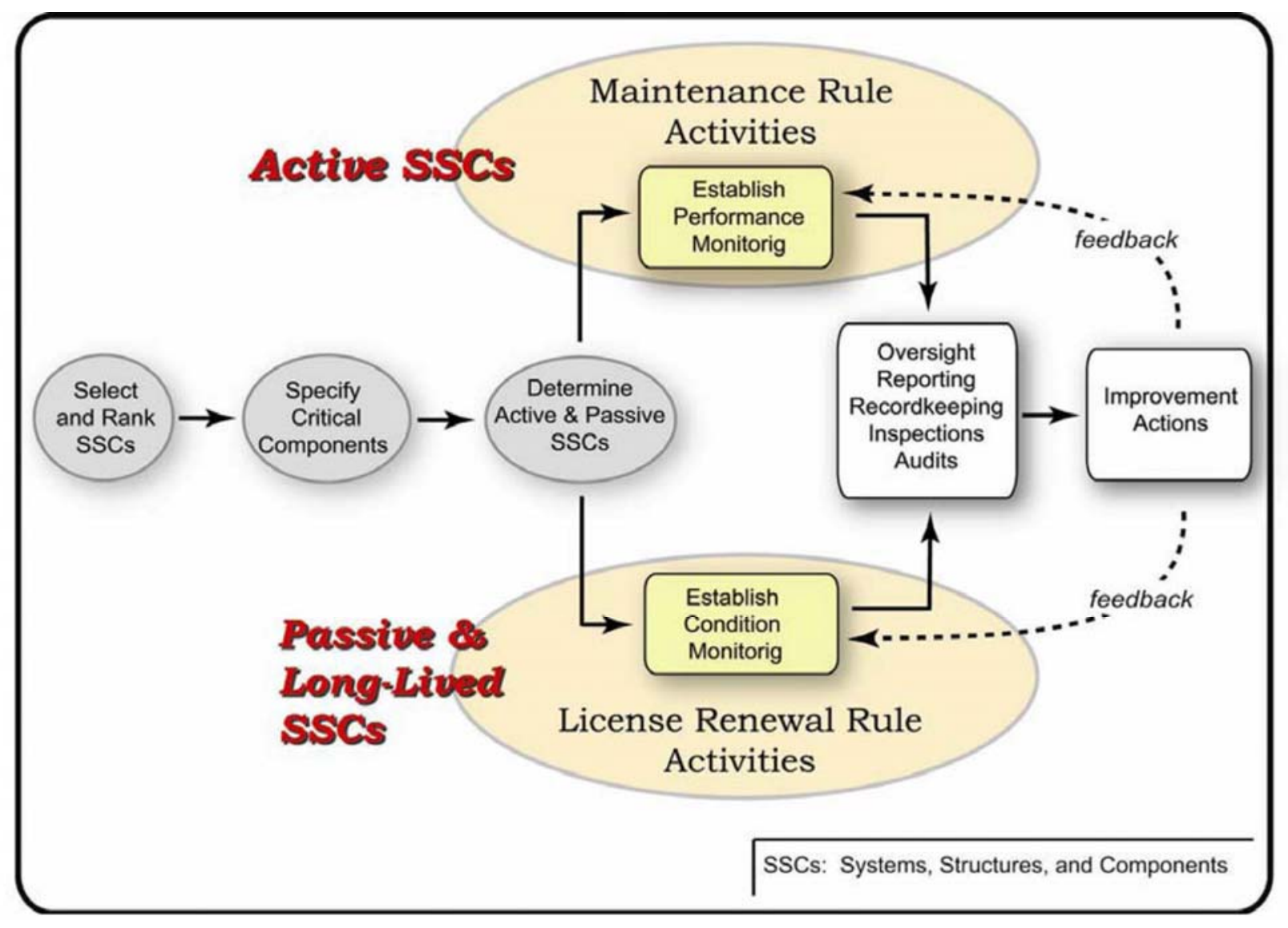

Figure 3.4. Relationship of Maintenance and License Renewal Rules (from Gregor and Chockie 2006)

New advanced gas reactors and Generation IV NPPs are expected to operate with high capacity factor $(90 \%+)$ for longer fueling cycles (4-6 years) and have necessary inspections and maintenance performed during shorter outages. One challenge is limited knowledge of material performance for next-generation designs, including balance of plant and secondary units for process heat or hydrogen production. Gen IV NPPs will operate at higher temperatures (potentially $510^{\circ} \mathrm{C}$ to $1000^{\circ} \mathrm{C}$ ). Operation in this temperature range brings to the forefront the potential for many new degradation processes that have not been experienced in current reactors and thus are not well understood or accounted for in the design.

\subsection{International Programs}

The economics of NPP life extension has changed in recent years. As a result, national and international activities have been developing to address PLiM for long-term operation (LTO), which may include plant modifications for power up-rating. The primary drivers have been the changes in the economic and business climate as well as a need to provide energy to support sustainable development and, in many countries, provide carbon-free electricity generation. Various groups have been working to identify and address key issues in three broad areas: 
- technology

- regulation

- business.

The pattern of activities that are developing to meet the needs of life extension for the global NPP fleet is complex; in many cases, there are many interconnections and overlapping relationships. Various international and multinational activities overlay national activities. Workgroups that addressed these issues met at an OECD/NEA Workshop in 2000 (NEA 2000a). At about the same time, a major NEA Expert Group provided a status report on nuclear power-plant life management in member countries (NEA 2000b). The NEA Expert Group report formed the starting point for our review of current PMMD programs documented in this section.

The OECD/NEA activities include representation in the activities of both the IAEA and the European Union (EU; in particular, Joint Research Center [JRC] Petten). In addition, two major IAEA meetings on NPP life management are associated with the IAEA PLiM programs. The first meeting was held in Budapest in 2002 and the second in Shanghai in October 2007. Bolstering the various international activities, there are now programs of some form in every country that currently operates NPPs, and plant life management and long-term operation (management of aging) are being considered as central elements in the design philosophy for new plants.

The OECD studies conclude that the principal advantages of longer-term operation are economic, in that

- Extending the life of a major generating asset avoids the need for immediate investment in new generating capacity.

- The capital costs of plant life management for LTO will be much smaller than investment in any type of replacement capacity, although there might be a need for some additional investment in plant upgrading.

- Costs per kilowatt-hour for waste management and decommissioning can be reduced.

- With nuclear fuel costs being generally lower and more stable than fossil fuel costs, LTO can be expected to provide electricity at a lower cost than any other available option, which has a clear benefit to the national economy.

It can be seen from the various programs presented in the OECD/NEA reports (NEA 2000a), and those in the wider nuclear power community, that LTO of existing NPPs beyond their original license lifetime has become an important option for countries with established nuclear programs. In most OECD countries, LTO has already been accepted as a strategic objective to ensure adequate supplies of electricity over the coming decades. LTO has significant economic advantages but can also help improve plant safety and minimize $\mathrm{CO}_{2}$ emissions. While the LTO of each plant must be considered individually in the light of its specific condition and economic circumstances, the general conclusion from studies carried out in several OECD/NEA member countries is that, for most reactor types, no significant technical challenges are known that would limit plant lifetime to less than 50 to 60 years. The remaining challenges lie, among other things, in proper planning and management, working with the existing regulatory and energy policy frameworks, obtaining public confidence, realizing the R\&D required, and 
ensuring knowledge management. International cooperation in the public and private sectors can contribute to the successful implementation of LTO.

The IAEA has implemented a number of activities addressing various economic and technical issues associated with PLiM/PLEX:

- The report, Review of Selected Cost Drivers for Decisions on Continued Operation of Older Nuclear Reactors, IAEA-TECDOC-1084, was published in 1999 (IAEA). It provides a review of published information related to three cost categories: safety upgrades necessary for continued operation of a nuclear unit, lifetime extension measures, and decommissioning. The report views the costs globally, and they are intended mainly as input for subsequent overall economic analysis.

- The activities related to the technical aspects of PLiM were implemented to facilitate the exchange of information and experience in monitoring the aging mechanisms affecting the main NPP systems and components and to provide guidance on lifetime-limiting mechanisms and the impact of mitigating measures as well as their effects on the policies and strategies of PLiM programs in Member States.

- Within the Safety Aspects of Nuclear Power Plant Aging project, a program of international cooperation for increased awareness and understanding of aging degradation processes has been established. This activity includes development of methods and guidelines to manage aging for safe and reliable operation of NPPs.

NEA is also implementing a program that is providing an opportunity for exchange of information on strategic and economic issues on PLiM/PLEX. As part of this program, the following topics are reported as being addressed:

- A glossary of aging terminology for NPP life management was published in 1999 (OECD 1999). The aim is to improve the understanding of aging phenomena, facilitating the reporting of relevant plant failure data, and promote uniform interpretations of standards and regulations that address aging. This terminology is useful in the areas of PLiM/PLEX and aging management.

- A study by an Expert Group on Refurbishment Costs of Nuclear Power Plant was completed in 1999. The report includes cost data derived from experience and from plans to implement life extension or life management programs in 10 OECD countries (Belgium, Canada, Czech Republic, Finland, France, Hungary, Mexico, the Netherlands, Spain, and the United Kingdom). However, the group decided not to publish the report and instead produced an internal document. The restriction was due to concerns expressed by participants about the confidentiality of some of the reported cost data and because the report does not include relevant data from non-participating OECD countries.

\subsubsection{Organisation for Economic Co-operation and Development-Nuclear Energy Agency}

The NEA addresses scientific, technical, and legal issues to ensure the safe, environmentally friendly, and economical use of nuclear energy for peaceful purposes, through international cooperation. The NEA has 28 of the OECD member countries participating. The inter-relationships between the various elements engaged in the OECD/NEA in the area of PliM and LTO performed under the Committee on the Safety of Nuclear Installations (CSNI) are shown in Figure 3.5 


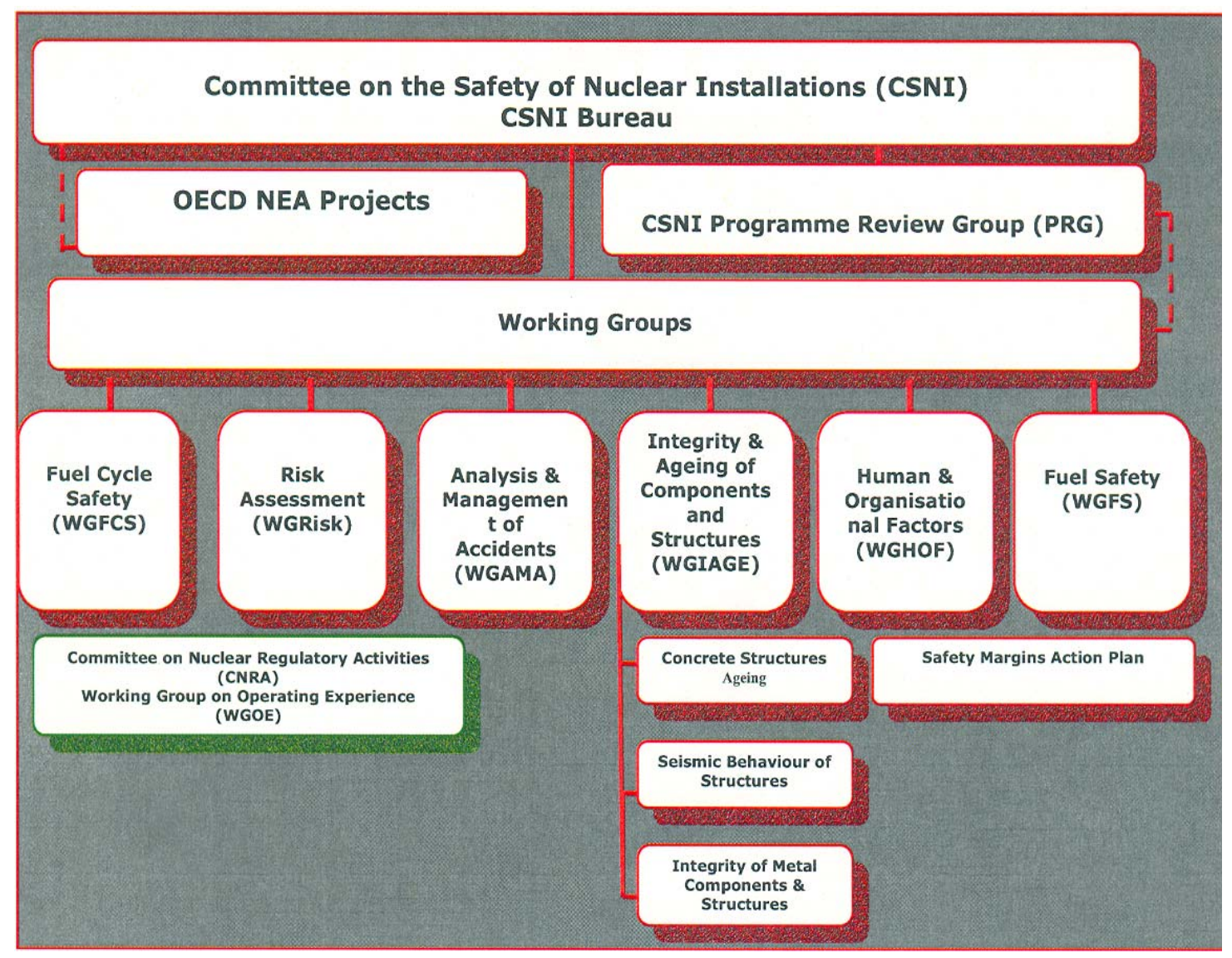

Figure 3.5. Organizational Structure of the Committee on the Safety of Nuclear Installations within the OECD/NEA

(NEA 2007). The current operating plan for 2006-2009 and the charters for the various committees are given in a recent report (NEA 2007). The status of NPP life management was extensively reviewed in a 2000 NEA report (NEA 2000b) and in the proceedings of a meeting held in the same year (NEA 2000a). A 2006 OECD report has subsequently reviewed the issues relating to the potential value, drivers, decision-making process, management issues, and international context of NPP life management and long-term operation (NEA 2006a). The elements that are considered to comprise PliM are shown in Figure 3.6. In addition, a substantial number of NEA reports review specific topical areas; see, for example, Research Efforts Related to Wire System Aging in NEA Member Countries (NEA 2004). 


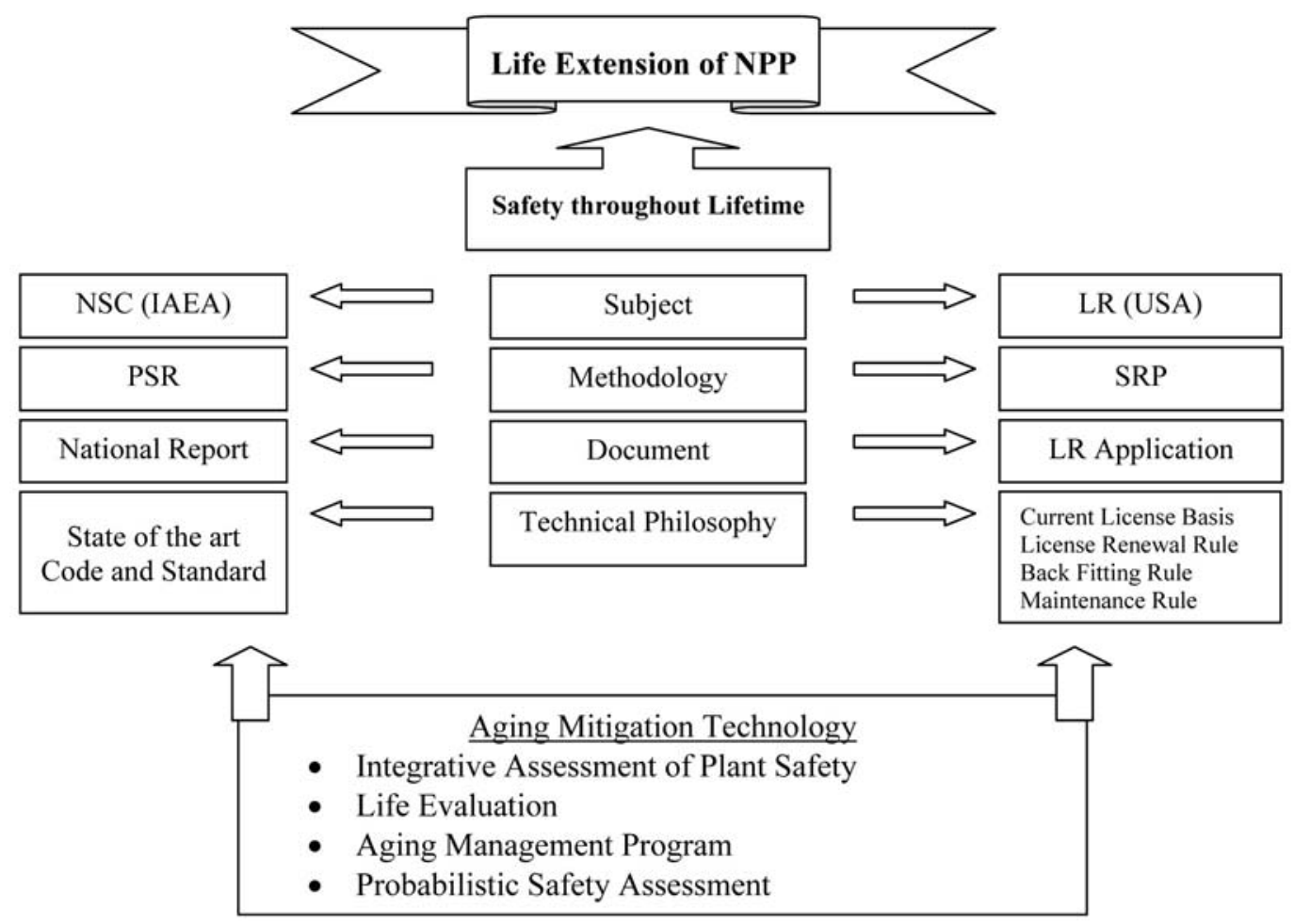

Figure 3.6. General Description of PLiM

\subsubsection{Working Group on Integrity of Components and Structures (IAGE)}

The mandate of the Working Group on Integrity of Components and Structures (IAGE) is to advise the CSNI on the topical basis for management of plant aging and to propose general principles to maintain the integrity of systems and components. The main topics investigated in this area include metal components, concrete structures, seismic behavior of structures and components, and the aging of wire systems. OECD member country representatives are joined at the group's meetings by representatives from the IAEA, the European Commission, and JRC Petten.

The main topics investigated by IAGE include the integrity of metal components, the integrity and aging of concrete structures, and the seismic behavior of structures and components. Lifetime management remains an important topic for the working group. A status report on risk-informed inservice inspection (RI-ISI) methodologies was completed in 2006 (NEA 2005b), and the group is now actively working on a benchmark study on RI-ISI methodologies. Reactor pressure vessel integrity is being addressed through a benchmark on probabilistic structural integrity methods.

An extensive report on concrete containment integrity was issued during 2006 (NEA 2005a). A workshop on corrosion and long-term performance of reinforced concrete in nuclear waste facilities was held in Cadarache, France, March 27-30, 2006 (in press), which provided insights into structural and regulatory issues. 
A workshop on seismic input motions, incorporating recent geological studies, was held in Japan November 15-17, 2005, and this meeting completed a series of workshops on seismic input motions. Methods to calculate seismic input motions for NPPs and related uncertainties continued to be explored through close cooperation with geologists and seismologists.

Integrity of metal components and structures. Recent activities of the integrity of metal components and structures sub-group include

- Developing a benchmark on the probabilistic structural integrity of a PWR reactor pressure vessel (PROSIR)

- Compiling a report that collected information on primary water stress corrosion cracking in nickelbased alloys used in the reactor vessel head penetrations and other components - in particular, Alloy 600 and its associated welds. Report on the Survey on Primary Water Stress Corrosion Cracking (PWSCC) and Nickel-based Alloy: Final Version September 2006, NEA/CSNI/R(2006)8 (Restricted), has been issued (NEA 2006b).

- Currently preparing a report examining plant aging and lifetime management.

Integrity and aging of concrete structures. The integrity and aging of concrete structures sub-group has recently been focusing on the preparation of a strategy report that identifies and ranks challenges for concrete structures for operating and new and advanced reactors.

Seismic behavior of structures and components. The seismic behavior of structures and components sub-group's recent activities include

- an ongoing activity on facilities that have experienced an earthquake, being carried out in cooperation with the IAEA

- a report on the differences in approach between nuclear and conventional seismic standards with regard to hazard definition is being developed

- a report on issues related to the definition of seismic input motions, using material from previous CSNI workshops.

\subsubsection{Ad Hoc Expert Group on the Impact of Nuclear Power Plant Life Extension}

Extending the lifetime of NPPs is becoming common practice in OECD member countries. While applying for an extended operating license, most operators are planning technical improvements, safety upgrades, and modification of fuel characteristics and performance as well as refueling patterns and lead times.

NPP lifetime extension affects operation and maintenance strategies, decommissioning schedule and strategy, radioactive waste management, and disposal requirements. It also has an impact on a country's overall nuclear energy program. When it is an alternative to ordering new nuclear units, lifetime extension raises questions in the field of education, knowledge preservation, and the maintenance of highly qualified manpower. These issues are a concern for the future of nuclear energy in some OECD member countries. 
These topics are of interest to policy makers in most OECD member countries, including those that have opted for a progressive phase-out of nuclear energy as well as those wishing to retain the option or to increase their reliance on nuclear energy. This ad hoc expert group aims to identify and analyze the technical, economic, and strategic issues raised by lifetime extension in different member country contexts.

Technical issues addressed included refurbishment requirements and timing, fuel characteristic modifications and fuel cycle delays, decommissioning, and waste disposal. The economic assessment aimed to analyze the impacts of lifetime extension versus early shutdown followed (or not) by the impact of construction of a new NPP on capital requirements, future financial liabilities, and levelized electricity generation costs.

Experts provided country statements describing the status and trends in the field of NPP life management in their respective countries. Country reports were discussed and analyzed by an ad hoc group of experts aiming at developing findings derived from various national experience and recommendations to policy makers, based on best practices. The group's study was published at the end of 2006 (NEA 2006a).

\subsubsection{OECD/NEA Stress Corrosion Cracking and Cable Ageing Project}

The Stress Corrosion Cracking and Cable Ageing Project, which is supported by 14 NEA member countries, began in 2006. According to the project web page on the Internet (http://www.nea.fr/html/jointproj/scap.html), the main objectives are stated as follows:

- to establish two complete databases with regard to major aging phenomena for stress corrosion cracking (SCC) and degradation of cable insulation, respectively, through collective efforts by $\mathrm{OECD} / \mathrm{NEA}$ member countries

- to establish a knowledge base by compiling and evaluating collected data and information systematically

- to perform an assessment of the data and identify the basis for commendable practices that would help regulators and operators to enhance aging management.

It is anticipated that the database definition and the collection of a representative amount of data for starting the assessment will take approximately two years. The assessment phase and the commendable practice report are expected to take one year each. The IAEA and the European Commission also participate as observers. Some activities in this program are funded by a voluntary contribution from Japan.

\subsubsection{The Halden Reactor Project}

The OECD Halden Reactor Project, based in Norway, is a leader in programs to develop international cooperation in an effective, results-oriented environment that addresses delivery of safe and reliable operation of NPPs. The project, which has developed over the past 50 years, is a joint undertaking of national organizations in 17 countries sponsoring a jointly financed program under the auspices of the OECD/NEA (IFA 2008). The project programs aim to generate key information for safety and licensing assessments, and the joint program is focused on three areas: 
- extended fuel utilization: basic data on how the fuel performs in commercial reactors, both at normal operation and transient conditions, with emphasis on extended fuel utilization

- degradation of core materials: knowledge of plant materials behavior under the combined deteriorating effects of water chemistry and nuclear environment

- man-machine systems: advances in computerized surveillance systems, human factors and manmachine interaction in support of upgraded control rooms.

Additional projects described on the project's Internet site: http:/www.ife.no/hrp. Discussions are reported to be under way for enlarging the member circle. Collaborations with East-European countries in support of plant safety and reliability also are being expanded.

\subsubsection{OECD/NEA-Identified Major Working Groups and Networks Acting On Aging Issues}

In addition to the OECD/NEA activities, the working groups (NEA 2006a) have identified a number of major groups and networks, with which some level of interacting is occurring. The groups identified are as follows (most of these groups have their own Internet sites where further information is given):

- AMES, Aging Materials Evaluation and Studies, is the European Network on Nuclear Component Aging Studies coordinated by JRC Petten and relies on irradiation and annealing data available by the members or to be generated. The main objectives are to provide information on neutron irradiation effects on reactor pressure vessel materials in support of designers, operators, regulators, and researchers, and to establish and execute projects in the above areas.

- ENDEF, the European Non Destructive Examination Forum, was created and launched by the Directorate General DG XVII for Energy of the European Commission to establish an industrial cooperation framework together with the Central and Eastern European countries as well as the New Independent States operating Soviet-designed reactors, considering the effectiveness and the adaptability of European NDE technology.

- ENIQ, the European Network for Inspection Qualification, issued the first edition of the European Methodology for Inspection Qualification in 1995. Qualification of inspection procedures for the well-known components of the nuclear reactor is effectively a way of harmonizing inspection requirements with the objective of being equally open to any inspection technology.

- EPERC, the European Pressure Equipment Research Council (previously know as the European Network of the Non-Nuclear Pressure Equipment Industry), connects the fields of fatigue design, high-strength steel for pressure equipment thickness reduction, harmonization of inspection programming in Europe, and flanges and gaskets.

- EPLAF, the European Plant Life Assessment Forum, was created in 1997 under the auspices of the General Directorate for Energy of the European Commission (DG XVII), to foster communication and dialogue between different European industrialists involved in Eastern Europe, Russia, and Ukraine in bilateral or multilateral projects related to the assessment of aging and remaining lifetime of Russian-designed NPP components.

- ESIS, the European Structural Integrity Society, has several technical committees dealing with issues related to structural integrity. 
- EURIS, the European Network of Risk-Informed In-Service Inspection, deals with the analysis of different approaches to the estimation of failure probabilities of components and of the failure consequences, gathering operator feedback; definition of effective ISI programs and qualification strategies are based on a risk-informed approach.

- ICG-EAC, the International Co-operative Group on Environmentally Assisted Cracking of Light Water Reactor Materials. The general objective of the ICG-EAC is to coordinate the international efforts on EAC of structural materials in LWR service environments to develop the fundamental understanding and the relevant database for disposition/design criteria for safe operation and license extension. The ICG-EAC coordinates cooperative research programs, develops recommended test procedures, advises on the interpretation of results to obtain data relevant to component design and flaw assessment, and encourages transfer of this information by organizing symposia, interacting with Code committees.

- IG-RDM, the International Group on Radiation Damage Mechanism, was established in late 1980 and is a forum of more than 100 scientists all over the world to discuss the newest results, exchange information, and initiate new projects in the field of irradiation damage mechanisms.

- IWG-LMNPP (IAEA) is the International Working Group on Life Management of Nuclear Power Plants. Its main objective is to provide information and guidance on design, materials, testing, maintenance, monitoring, and mitigation of degradation with regard to major components, with the aim of ensuring high availability and safe operation of NPPs. This activity is reporting that a first phase of an international database on NPP life management has been established, the International Nuclear Information System.

- NESC, the European Network for Evaluating Structural Components, connects the NDT/NDE methods and material aspects with the structural integrity assessment. The tasks deal with structural integrity problems like constraint, cladding, sensitivity analyses, crack arrest, residual stresses, probabilistic approach, fracture criteria consistency, transients, and large-scale projects.

- OECD NEA/CSNI IAGE Working Group is the Working Group on Integrity and Aging of Components and Structures. Its main objective is to provide information and guidance on structural integrity and aging issues, such as fracture and damage mechanics modeling, fracture toughness measurements, neutron embrittlement of reactor pressure vessel (RPV) steels, stress corrosion cracking of RPV steels and of stainless steels, fatigue of piping, NDT, NDE, residual stresses, and long-term behavior of concrete.

\subsubsection{International Atomic Energy Agency}

The IAEA has a number of activities that can be grouped into the general area of safe long-term operation for NPPs. Further details of recent activities are found on the IAEA Internet site, including meeting proceedings on materials degradation issues at NPPs (IAEA 2007c). Much of the activity in the PLiM area was reported at two NPP life management conferences (IAEA 2002c, 2007b). The IAEA has published a significant number of technical reports, guidelines, and meeting proceedings. To support and help provide access to these activities and documents, the IAEA has developed the International Nuclear Information System (INIS); a subset of the material within the database specifically addresses PLiM issues (IAEA 2008b). Recently some of these data have been made available in compact disk (CD) form and online at various meeting and workshops. The CD for the 2nd International Symposium on Nuclear 
Power Plant Life Management contains 249 bibliographic references and 136 full-text documents, including the proceedings from the 2002 Budapest PLiM Meeting.

\subsubsection{IAEA Plant Life Management}

The basic goal of the IAEA Plant Life Management (PLiM) program is to satisfy the requirements for safe and provide long-term supplies of electricity in an economically competitive way. This activity supports the basic goal of the operating company and the owners of NPPs, which is to operate as long as economically reasonable and possible from a safety point of view. PLiM is an approach and management tool for accomplishing this goal.

Within the IAEA PLiM program is a system of programs and procedures that satisfy requirements for safe operation, competitive power production, and maintaining a plant in operation for a time that is rational when considered from both technical and economic perspectives. PLiM is not a technical system but rather a philosophy that can be adopted by an operating company; the philosophy seeks to keep the plant in operation as long as possible from safety and business perspectives (IAEA 2006a).

The IAEA provides various services including plant assessments (IAEA 2008a). The common objectives for a PLiM assessment are to help and review the pre-conditions that exist before PLiM and long-term operation approaches are implemented. The PLiM philosophy and methodologies should be considered as part of normal operations and not associated just with extension of the operational lifetime of the NPP. The effectiveness of PLiM programs can be measured by three complementary forms of assessment:

1. self-assessment

2. peer review

3. comprehensive program review by the plant owner/operator.

To support such activities, the IAEA provides the assessment service for peer review of PLiM. The specific objectives of the PLiM assessment are as follows:

- to give knowledge to better understand PLiM

- to investigate and assess the Member-State approach on PLiM

- to take proper action to minimize material degradation

- to formulate guidelines for aging management of critical systems, structures, and components (SSC)

- to review detailed plants license evaluation and establishment of PLiM programs.

Recent activities by the Nuclear Power Engineering Section in PLiM have included technical support through technical cooperation projects:

- regional technical cooperation (TC) projects:

- RER/04/27: strengthening capabilities for NPP performance and service life including engineering aspects 
- RLA/4/021: Cracking and Structural Integrity of Components in Light Water Reactors

- RAS/4/028: Integrated Management Systems for Expanding Nuclear Power Program

- national TC projects:

- China: Aging Management of Critical Components

- Mexico: Life Management program for Laguna Verde NPPs

- Hungary: License Renewal of Paks Nuclear Power Plant Operation

- Ukraine: Action Plans for Nuclear Power Plant Lifetime Management

- Argentina: PLiM program for Embalse NPP

The NPES has developed and published a series of technical documents that relate to the PLiM area. Recent examples include

- PLiM Guidelines for Light Water Reactors (IAEA 2006a)

- Heavy Water Reactor PLiM Refurbishment - Processes \& Technology (IAEA 2006b)

- Reactor Irradiation Effects in RPV Steels (IAEA 2005b, 2005c)

- Reactor Pressure Vessel (RPV) Core Internals Behavior and Technology for Repair and Replacement $^{(\mathrm{a})}$

In addition, there are coordinated research projects on reactor pressure vessel integrity, with the participation of 15 member states:

- Master Curve Approach to Monitor the Fracture Toughness of RPV in Nuclear Power Plants (2005-2007) (IAEA 2005c)

- Review and Benchmark of Calculation Methods for Structural Integrity Assessment of RPVs During Pressurized Thermal Shock (2005-2008)

- Material degradation workshops on both technology and managerial topics

These activities are directed and coordinated through a Technical Working Group for NPP Life Management (TWG LM-NPP), which is composed of representatives from 25 member states. The IAEA reports that activities in the PLiM area are planned to grow. A PLiM assessment service is reported to be being developed. This activity will be initiated, however, only after it has been formally approved and funded and the technical cooperation project established. When approved, it is stated that it is expected that the scope of the review should be agreed upon between relevant organizations (e.g., utility or an industry) and the IAEA.

The 2nd International Symposium on Nuclear Power Plant Life Management was organized by the IAEA in cooperation with China Atomic Energy Authority (CAEA) and China National Nuclear Corporation (CNNC). It focused on topical issues affecting nuclear power PLiM. Thirty-five countries and five international organizations were represented at the four-day event, which also emphasized the

(a) IAEA. 2007. Proceedings of a Technical Meeting TM on Core Internals Behaviour and Technology for Repair and Replacement. CD-ROM, in preparation. 
role of PLiM programs in ensuring safe and reliable NPP operation. The meeting proceedings are currently in preparation (IAEA 2007, 2008c).

\subsubsection{International Nuclear Information System}

The International Nuclear Information System (INIS) is the world's leading information system for accessing material on the peaceful uses of nuclear science and technology. Part of the INIS addresses the needs of PLiM, LTO, and aging. It provides access to a unique collection of references, extended abstracts, and full-text documents related to NPP life management (IAEA 2008b). At the recent PLiM Symposium, a CD was provided that gave access to a subset of the INIS database materials on specific topics, including

- specific probabilistic approaches to aging management

- environmental-assisted cracking, flow-accelerated corrosion

- integrity and material degradation issues

- economics of plant life management

- regulatory issues concerned with plant life management

- issues important to the safe and reliable long-term operation of NPPs.

The INIS is based on information provided as part of the international cooperation activities of participating member states and international organizations. INIS can be accessed via the IAEA Internet site: http://www.iaea.org/inis/.

The IAEA continues to develop various programs in the life-extension technical area. One example is a new three-year program in the PLiM area, starting in 2008, which addresses advanced surveillance, diagnostics, and prognostics techniques used for health monitoring of systems, structures, and components in NPPs. This initiative builds on previous workshops and activities that have been assessing needs and developing technical documents, including in the area of on-line monitoring (IAEA 2007, 2008c). Further details are to be found on the IAEA Internet site, http://www.iaea.org/nuclearpower/IandC/.

\subsection{National and Regional Aging Programs}

Globally, there are currently approximately 440 operational NPPs (see Appendix A) located in 30 countries. Associated with every plant are some activities that relate to long-term management of operations and maintenance, in-service inspections, and increasingly to more advanced condition-based maintenance. In some countries, the activities are linked with the various international coordinated activities discussed in Section 3.2. In other cases, activities are focused more locally, addressing the specific needs of one or a small number of facilities. There also are activities within the various owners and design-based groupings that cross international boundaries and provide a second set of relationships. The owners' group activities are not explicitly discussed in this document.

The proceedings for the recent IAEA PLiM meeting (IAEA 2008e) provide an overview of the majority of the current and emerging national programs. The status for activities in $14 \mathrm{OECD} / \mathrm{NEA}$ 
member countries was extensively reviewed in a 2000 report (NEA 2000b). In addition to the international activities, an increasing number of both national meetings and workshops address technical topics. Technical papers on aspects of aging and plant life extension also are now being included in special sessions in more general nuclear and energy conferences.

Some general issues of the cost drivers for the assessment of NPP life extension have been discussed in a number of reports, both internationally (IAEA 2002a) and nationally. This section discusses European activities and then the national activities for each of the 13 countries with 10 or more NPPs. A final section briefly addresses those plants and activities for NPPs in the rest of the world.

The number of reactors and percentage electricity generated for countries with more than 10 reactors are shown as Table 3.4. The data for Greater Europe are given in Table 3.5. These countries encompass almost $50 \%$ of the global reactor fleet and include a number of design families, including those that were developed in the former Soviet Union.

Table 3.4. Number of Reactors and Percentage Electricity Generated for Countries with More Than 10 Reactors

\begin{tabular}{lcc}
\hline \multicolumn{1}{c}{ Country } & Number of Reactors & Electricity, \% \\
\hline United States & 104 & 19 \\
France & 59 & 78 \\
Japan & 55 & 30 \\
Russian Federation & 31 & 16 \\
Korea (South) & 20 & 39 \\
United Kingdom & 19 & 18 \\
Canada & 18 & 16 \\
Germany & 17 & 32 \\
India & 17 & 2.6 \\
Ukraine & 15 & 48 \\
China & 11 & 1.9 \\
Sweden & 10 & 48 \\
\hline
\end{tabular}


Table 3.5. Selected Nuclear Power Plants and Generating Capacity in Greater Europe (EU and non-member European states) [from European Nuclear Society (ENS 2008)]

\begin{tabular}{lrccc}
\hline & \multicolumn{2}{c}{ In Operation } & \multicolumn{2}{c}{ Under Construction } \\
\cline { 2 - 5 } \multicolumn{1}{c}{ Country } & Number & $\begin{array}{c}\text { Net Capacity, } \\
\text { MWe }\end{array}$ & Number & $\begin{array}{c}\text { Net Capacity, } \\
\text { MWe }\end{array}$ \\
\hline Belgium & 7 & 5,824 & - & - \\
Bulgaria & 2 & 1,906 & 2 & 1,906 \\
Czech Republic & 6 & 3,523 & - & - \\
Finland & 4 & 2,696 & 1 & 1,600 \\
France & 59 & 63,290 & - & - \\
Germany & 17 & 20,425 & - & - \\
Hungary & 4 & 1,755 & - & - \\
Lithuania & 1 & 1,185 & - & - \\
Netherlands & 1 & 482 & - & - \\
Romania & 2 & 1,310 & - & - \\
Russian Federation & 31 & 21,743 & 5 & 4,585 \\
Slovakian Republic & 5 & 2,034 & - & - \\
Slovenia & 1 & 666 & - & - \\
Spain & 8 & 7,450 & - & - \\
Sweden & 10 & 9,034 & - & - \\
Switzerland & 5 & 3,220 & - & - \\
Ukraine & 15 & 13,107 & 2 & 1,900 \\
United Kingdom & 19 & 10,222 & - & - \\
Total & $\mathbf{1 9 7}$ & $\mathbf{1 6 9 , 8 4 2}$ & $\mathbf{1 2}$ & $\mathbf{9 , 9 9 1}$ \\
\hline
\end{tabular}

\subsubsection{Europe}

The European Union now comprises 27 countries, of which 14 have NPPs. About 33\% of EU electricity is generated by nuclear plants. There are also a significant number of NPPs in adjacent nonEU countries. Widely ranging activities are developing in Europe, including countries that were formerly part of the Soviet Union and have Soviet-designed legacy NPPs.

The first Joint Research Center networks on structural integrity of critical components for nuclear installations were set up in 1992. They now include six programs:

- Assessment of Nuclear Power Plant Core Internals (AMALIA)

- Aging Material European Strategy or Ageing Materials Evaluation and Studies (AMES)

- European Network for Inspection and Qualification (ENIQ)

- Network for Evaluating Structural Components (NESC)

- Network on Neutron Techniques Standardization for Structural Integrity (NET)

- Safety of Eastern European Type Nuclear Facilities (SENUF). 
The activities within the EU have focused on understanding phenomena that could affect nuclear safety, and results from projects have been reported in numerous papers (Contri and Vaisnys 2007). For instance, the in-service inspection qualification methodology developed by ENIQ is now a reference point both in Europe and internationally for qualification of the inspection techniques used to check for the presence of defects or cracks. The network organized a series of practical trials leading to the publication of eight recommended practices demonstrating the application of the qualification methodology. Some elements of these programs did include participation from outside the EU.

The programs performed in the EU in the 1990s have subsequently evolved into an integrated EU program, SAFELIFE, and further details are on the program Internet site (http://SAFELITE.JRC.EC.EUROPA.UE/). The SAFELIFE activities, which form an integrated approach to NPP life management, are shown in Figure 3.7.

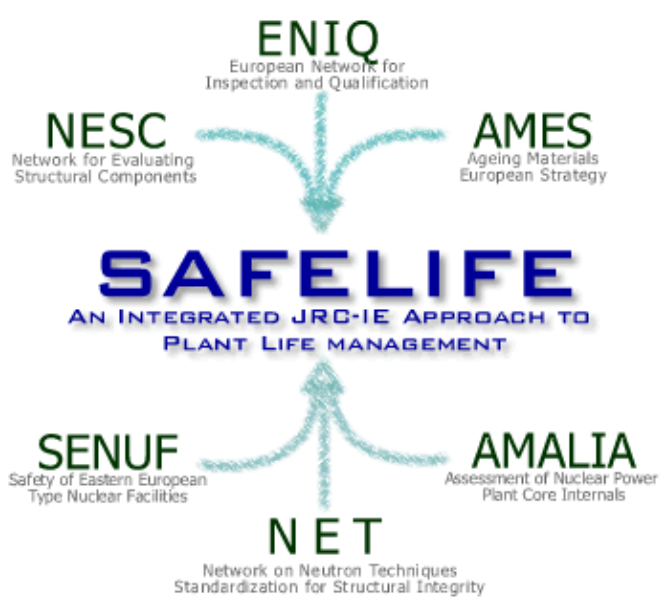

Figure 3.7. SAFELIFE (EU Program) (http://SAFELITE.JRC.EC.EUROPA.UE/)

SAFELIFE is described as providing an integrated approach to research and development (R\&D) activities on critical issues for plant life management of aging nuclear power installations. The focus is on establishing European best practices for deterministic and risk-informed structural integrity assessment of key components, covering the main R\&D disciplines involved and considering all NPP designs, both western and Russian-type. The principal objectives and overall work planning are set out in the detailed work scopes (http://projects-2008.jrc.ec.europa.eu/ [search under SAFELIFE]). The activities are reported as started in 2003 in collaboration with all major international organizations (e.g., IAEA) and consisted of experimental studies on thermal and irradiation effects on critical safety components (e.g., RPV, internals, piping), including characterization of mechanical properties, fracture properties and residual stresses, qualification and validation of inspection, and surveillance practices. The activities formed a contribution to development of European guidelines for lifetime assessment of NPP components and development of key facilities to support European Network activities and training, together with contribution to and operation of nuclear safety-related European Networks and integrated projects and development and promotion of a related Network of Excellence within the framework of the European Research Area. 
The activities in the EU have continued to develop. The most recent program is NULIFE and is led by the VTT Research Centre in Finland (Rintamaa et al. 2007). This activity is focused on nuclear plant life prediction. It is a five-year program launched in October 2006. The expected evolution for NULIFE between 2006 and 2011 is shown in Figure 3.8. It is seeking to provide methods and tools to assess service life of NPP materials and structures as well as to underpin upgrades and refurbishment (Rintamaa et al. 2007).

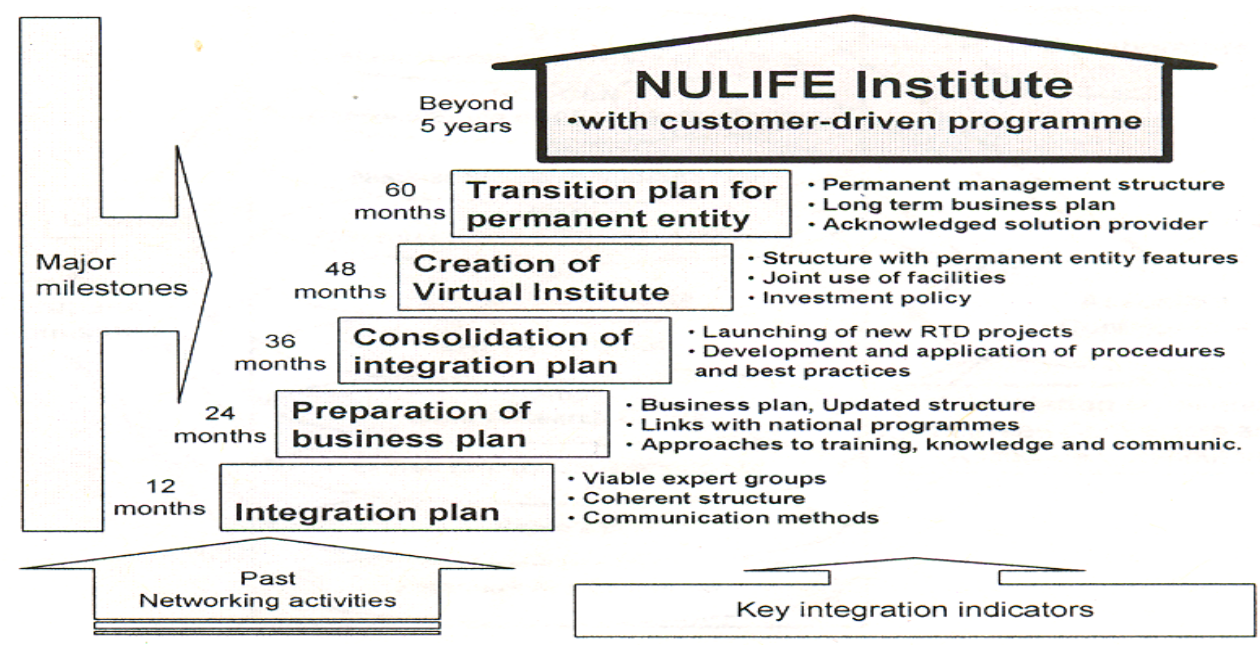

Figure 3.8. Planned Organization and Evolution of the EU NULIFE Program 2006-2011 ${ }^{\text {(a) }}$

\subsubsection{United States}

The United States currently has 104 nuclear power reactors that provide about $19 \%$ of the total electricity production. About 25 new reactors currently are being proposed. A status report for U.S. nuclear power plant life management is provided as a country report in a 2000 OECD/NEA report (NEA 2000b). A more extensive look at aging management and life extension in the U.S. nuclear power industry is provided in a report by Gregor and Chockie (2006). This report was intended to provide an overview that could be used to assess potential lessons that could transfer to the petroleum industry, but it is also a valuable resource for those addressing U.S. NPP needs.

The 2000 OECD/NEA report stated "At present there is no fully integrated and mutually agreed upon national strategy, plan, or organization responsible for plant life management" (NEA 2000b). There are, however, significant activities in progress within the United States. The NRC has developed a regulatory process that is being used to review applications for life extensions from 40 to 60 years for the current fleet. The Nuclear Energy Institute (NEI) and Electric Power Research Institute (EPRI) are coordinating collaborative research, including in the area of plant life management, and owners' groups are engaged in performing generic evaluations that can be shared by several operators. A more coordinated approach to identifying, and potentially addressing research needs for "life/licensing beyond 60," is developing (NRC/DOE Workshop on U.S. Nuclear Power Plant Life Extension Research and Development Life

(a) From NULIFE contract description at http://vtt.fi/project/nulife/nulife project_21122006.pdf 
Beyond 60, held February 19-21, 2008) (Energetics Inc. 2008). The U.S. Department of Energy also is promoting plant life management, although in recent years funded research in this area has been modest.

The operators of U.S. NPPs are looking at opportunities to deploy more cost-effective operation and maintenance practices, as well as opportunities provided through adoption of new plant life management philosophies and technologies. As part of the 40- to 60-year license renewal activity, plants are providing commitments to aging management plans, although in some cases there remain open technical issues. The activities of plant operators have been pragmatic and focused on meeting regulator requirements needed to reach a 60 -year operating life. With consideration now being given to longer-term operation (60-80 years, and potentially beyond), aging issues are receiving new attention.

The research programs that have been addressing aging have been performed by several organizations, including work in the university community. Aspects of the various U.S. activities have been reported at various conferences and in journal papers.

\subsubsection{U.S. Department of Energy}

A brief summary of U.S. activities and the DOE role was provided by Marcus in 2000 (Marcus 2002), and this report was prepared in the same time-frame as the OECD/NEA United States Country Report (NEA 2000b). At that time, DOE was supporting six programs, which included technical topics potentially related to long-term operation. The specific DOE Office of Nuclear Energy programs are NEPO, NERI, University Programs, ATW, I-NERI and GEN IV. In each area, the research funds are at a modest level. These have also included work supported by DOE Office of Science, Basic Energy Sciences (BES), which has addressed basic materials issues. BES held a workshop on Basic Research Needs for Advanced Nuclear Energy Systems (BES-DOE 2006). There are also U.S. government initiatives (Advanced Energy Initiative and the American Competitive Initiative) that include aspects of the science and technology needed to provide electricity nuclear energy. In connection with GEN IV and NGNP/GNEP (advanced reactors) activities, there have been significant studies that have sought to gather materials information (Corwin 2007). In all of the advanced reactor work, materials issues are central: activities in programs such as GEN IV that consider materials have potential to be leveraged in looking at PMMD for legacy nuclear systems, as life beyond 60 is considered.

The DOE also was central to providing much of the technical capability needed for previous aging investigations relating to legacy light water reactors, particular with regard to the 40- to 60-year life extensions for U.S. legacy plants. Several of the DOE national laboratories are continuing in investigating aspects of long-term operation, PMMD, and advanced technologies (Jarrell et al. 2004). A recent NRC/DOE Workshop on U.S. Nuclear Power Plant Life Extension Research and Development Life Beyond 60 (held February 19-21, 2008) provided a forum for discussions on operating NPPs for 60 years, and a central theme in the discussions was management of materials degradation (Energetics Inc. 2008). The DOE Office of Nuclear Energy is again seeking to promote activities in plant life management and a new program in LWR sustainability is being proposed to be started in fiscal year 2009.

\subsubsection{U.S. Nuclear Regulatory Commission}

In 2006, the NRC completed an Expert Panel report on proactive materials degradation assessment (Andresen et al. 2007). The data in the report, NUREG/CR-6923, has now been placed into an 
information tool that can be accessed on the Internet (http://pmmd.pnl.gov). The NRC also has sponsored three meetings in 2005-2006 that gathered information regarding research needs that could potentially help to define needs for a cooperative program in PMMD (Andresen et al. 2007); the findings from the workshops are given as Appendix B of this report. Further NRC activities in the PMMD, which leverage ongoing projects, are being developed in areas that include materials degradation, NDE and in-service inspection, probabilistic risk assessment (PRA), and related activities for advanced reactors, and NRC is establishing cooperation and connections with the DOE Office of Nuclear Energy LWR Sustainability Program.

\subsubsection{Nuclear Energy Institute}

The U.S. nuclear plant operators, through the NEI materials technology advisory group, have been working to identify and address common materials issues. A summary of the management of materials issue from the NEI-industry perspective was provided to the NRC Commissioners in a 2004 presentation (Crane 2004). Related activities are being performed also through EPRI.

\subsubsection{Electric Power Research Institute}

A focus for much of the EPRI activity is to provide utilities with the science and technology needed to ensure the safe and reliable operation of the U.S. legacy NPPs. Aging and degradation of both active and passive components are potential threats to the long-term economic viability of the existing fleet of LWRs. When addressing the needs to ensure long term operation of major structural components, there is need for concerted action in the areas of corrosion research, water chemistry, and plant operation and management. To address this need, EPRI has identified the research activities included in the Materials Degradation/Aging Action Plan (EPRI 2004). The plan, together with extensive detailed technical reports, helps nuclear plant owners and operators maximize useful plant life; employ cost-based and riskfocused decision-making processes; develop technologies to address materials degradation and aging; anticipate and avoid safety events; and improve plant capacity, reliability, and availability. Activities within the EPRI Action Plans are closely linked with related activities at the Nuclear Energy Institute and the Institute of Nuclear Power Operation (INPO). An example of a material degradation matrix developed by EPRI is shown in Figure 3.9 (Crane 2004).

In recent years, there has been increasing globalization and teaming among entities with common interests in life-cycle management. One such program has been an EPRI/EDF collaboration (EPRI 2003). A major development in aging research activities and coordination, announced by EPRI in the technical press in February 2008, was teaming with EDF and Tokyo Electric Power Company (TEPCO) to create the international Materials Aging Institute, a collaborative research facility located in France. The Material Ageing Institute will examine the critical link between materials science and power plant component performance and degradation. It was reported that the Institute will have an initial budget of $\$ 13.1$ million, and that research will consider equipment corrosion, component and material degradation due to irradiation, non-metallic material performance (e.g., polymers), and concrete aging.

\subsubsection{Plant Operators and Owners Groups}

The Institute of Nuclear Power Operation (INPO) activities are closely linked with those within the EPRI Action Plans (EPRI 2004) and are also closely linked with related activities at the Nuclear Energy 
Institute. Some activities also are performed within the owners' groups for plants provided by specific suppliers (e.g., Westinghouse Owners' Group) that support life-cycle management and license renewal (Meyer and Giddens 1994).

\section{|Materials Degradation Matrix}

Level 1

\begin{tabular}{|c|c|c|c|c|c|c|c|c|}
\hline \multicolumn{3}{|c|}{ PWR } & \multicolumn{3}{c|}{ BWR } \\
\hline $\begin{array}{c}\text { PWR Reactor } \\
\begin{array}{c}\text { Pressure } \\
\text { Vessel }\end{array}\end{array}$ & $\begin{array}{c}\text { PWR } \\
\text { Pressurizer }\end{array}$ & $\begin{array}{c}\text { PWR } \\
\text { SG } \\
\text { Shell }\end{array}$ & $\begin{array}{c}\text { PWR } \\
\text { Reactor } \\
\text { Internals }\end{array}$ & $\begin{array}{c}\text { PWR } \\
\text { Piping }\end{array}$ & $\begin{array}{c}\text { PWR SG } \\
\text { Tubes \& } \\
\text { Internals }\end{array}$ & $\begin{array}{c}\text { BWR } \\
\text { Pressure } \\
\text { Vessel }\end{array}$ & $\begin{array}{c}\text { BWR } \\
\text { Reactor } \\
\text { Internals }\end{array}$ & $\begin{array}{c}\text { BWR } \\
\text { Piping }\end{array}$ \\
\hline
\end{tabular}

Level 2

\begin{tabular}{|c|c|c|c|c|c|c|c|c|c|c|c|c|c|c|c|c|c|c|c|}
\hline \multirow{3}{*}{$\begin{array}{c}\text { PWR } \\
\text { Component }\end{array}$} & \multirow{3}{*}{$\begin{array}{c}\text { Material } \\
\text { Subdivision } \rightarrow\end{array}$} & \multirow{2}{*}{\multicolumn{5}{|c|}{$\begin{array}{l}\text { SCC } \\
\underline{\text { SCC }} \\
\end{array}$}} & \multirow{2}{*}{\multicolumn{4}{|c|}{$\begin{array}{c}\text { Corrosion/Wear } \\
\underline{C \& W}\end{array}$}} & \multirow{2}{*}{\multicolumn{3}{|c|}{$\begin{array}{c}\text { Fatigue } \\
\text { Fat. }\end{array}$}} & \multicolumn{6}{|c|}{$\begin{array}{c}\text { Reduction in Toughness } \\
\text { RiT }\end{array}$} \\
\hline & & & & & & & & & & & & & & \multirow{2}{*}{$\begin{array}{c}\text { Aging } \\
\text { Th }\end{array}$} & \multicolumn{5}{|c|}{ Irradiation } \\
\hline & & IG & IA & TG & LTCP & PW & Wstg & Pit & Wear & FAC & $\mathrm{HC}$ & LC/Th & Env & & Emb & VS & SR & $\mathbf{T h}_{\mathrm{n}}$ & Fl \\
\hline \multirow{3}{*}{$\begin{array}{l}\text { PWR } \\
\text { Pressurizer }\end{array}$} & C\&LAS & $\begin{array}{c}? \\
\mathrm{e} 002\end{array}$ & $\mathrm{~N}$ & $\begin{array}{c}? \\
e 002\end{array}$ & $\mathrm{~N}$ & $\begin{array}{c}? \\
\mathrm{e} 003\end{array}$ & $\begin{array}{c}\mathrm{Y} \\
\mathrm{e} 004\end{array}$ & $\mathrm{~N}$ & $\mathrm{~N}$ & $\begin{array}{c}Y \\
\mathrm{e} 005\end{array}$ & $\mathrm{~N}$ & $\begin{array}{c}\mathrm{Y} \\
\mathrm{e} 006\end{array}$ & $\begin{array}{c}\mathrm{Y} \\
\mathrm{e} 007\end{array}$ & $\begin{array}{c}\mathrm{Y} \\
\mathrm{e} 008\end{array}$ & $\mathrm{~N} / \mathrm{A}$ & $\mathrm{N} / \mathrm{A}$ & N/A & $\mathrm{N} / \mathrm{A}$ & $\mathrm{N} / \mathrm{A}$ \\
\hline & $\frac{\text { C\&LAS }}{\text { Welds }}$ & $\stackrel{?}{\mathrm{e} 002}$ & $\mathrm{~N}$ & $\stackrel{?}{e 002}$ & $\mathrm{~N}$ & $\stackrel{?}{\mathrm{e} 003}$ & $\begin{array}{c}\mathrm{Y} \\
\mathrm{e} 004 \\
\end{array}$ & $\mathrm{~N}$ & $\mathrm{~N}$ & $\begin{array}{c}\mathrm{Y} \\
\mathrm{e} 005 \\
\end{array}$ & $\mathrm{~N}$ & $\begin{array}{c}\mathrm{Y} \\
\mathrm{e} 006 \\
\end{array}$ & $\begin{array}{r}\mathrm{Y} \\
\mathrm{e} 007 \\
\end{array}$ & $\begin{array}{r}\mathrm{Y} \\
\mathrm{e} 008 \\
\end{array}$ & $\mathrm{~N} / \mathrm{A}$ & N/A & $\mathrm{N} / \mathrm{A}$ & $\mathrm{N} / \mathrm{A}$ & $\mathrm{N} / \mathrm{A}$ \\
\hline & $\frac{\text { Wrought }}{\text { SS }}$ & $\begin{array}{c}? \\
\mathrm{e} 012 \\
\end{array}$ & $\mathrm{~N}$ & $\begin{array}{c}? \\
\mathrm{e} 012 \\
\end{array}$ & $\stackrel{?}{e 013}$ & $\begin{array}{c}? \\
\mathrm{e} 012 \\
\end{array}$ & $\mathrm{~N}$ & $\mathrm{~N}$ & $\mathrm{~N}$ & $\mathrm{~N}$ & $\mathrm{~N}$ & $\begin{array}{c}\mathrm{Y} \\
\mathrm{e} 014 \\
\end{array}$ & $\begin{array}{c}\mathrm{Y} \\
\mathrm{e} 015 \\
\end{array}$ & $\mathrm{~N}$ & $\mathrm{~N} / \mathrm{A}$ & $\mathrm{N} / \mathrm{A}$ & $\mathrm{N} / \mathrm{A}$ & $\mathrm{N} / \mathrm{A}$ & $\mathrm{N} / \mathrm{A}$ \\
\hline \multirow{3}{*}{$\begin{array}{l}\text { Including } \\
\text { Shell, Surge } \\
\text { and Spray } \\
\text { Nozzles, Heater } \\
\text { Sleeves and } \\
\text { Sheaths, } \\
\text { Instrument } \\
\text { Penetrations) }\end{array}$} & $\frac{\text { SS Welds \& }}{\text { Clad }}$ & $\begin{array}{r}\mathrm{Y} \\
\mathrm{e} 016 \\
\end{array}$ & $\begin{array}{c}? \\
\mathrm{e} 017 \\
\end{array}$ & \begin{tabular}{|c|}
$\mathrm{Y}$ \\
$\mathrm{e} 018$ \\
\end{tabular} & 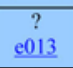 & $\begin{array}{c}? \\
\mathrm{e} 019 \\
\end{array}$ & $\mathrm{~N}$ & $\mathrm{~N}$ & $\begin{array}{c}? \\
\mathrm{e} 020 \\
\end{array}$ & $\mathrm{~N}$ & $\mathrm{~N}$ & $\stackrel{?}{\mathrm{e} 014}$ & $\begin{array}{c}\mathrm{Y} \\
\underline{\mathrm{e} 015} \\
\end{array}$ & $\begin{array}{c}\mathrm{Y} \\
\mathrm{e} 022 \\
\end{array}$ & $\mathrm{~N} / \mathrm{A}$ & $\mathrm{N} / \mathrm{A}$ & $\mathrm{N} / \mathrm{A}$ & $\mathrm{N} / \mathrm{A}$ & $\mathrm{N} / \mathrm{A}$ \\
\hline & $\frac{\text { Wrought }}{\text { Ni Allovs }}$ & $\mathrm{N}$ & $\mathrm{N}$ & $\mathrm{N}$ & $\stackrel{?}{\mathrm{e} 023}$ & $\begin{aligned} Y \\
\mathrm{e} 023 \\
\end{aligned}$ & $\mathrm{~N}$ & $\mathrm{~N}$ & $\mathrm{~N}$ & $\mathrm{~N}$ & $\begin{aligned} \mathrm{Y} \\
\mathrm{e} 014 \\
\end{aligned}$ & $\begin{array}{c}\mathrm{Y} \\
\mathrm{e} 014 \\
\end{array}$ & $\begin{aligned} \mathrm{Y} \\
\mathrm{e} 015 \\
\end{aligned}$ & $\mathrm{~N}$ & $\mathrm{~N} / \mathrm{A}$ & $\mathrm{N} / \mathrm{A}$ & $\mathrm{N} / \mathrm{A}$ & $\mathrm{N} / \mathrm{A}$ & $\mathrm{N} / \mathrm{A}$ \\
\hline & $\frac{\frac{\text { Ni-base }}{\text { Welds \& }}}{\text { Clad }}$ & $\mathrm{N}$ & $\begin{array}{c}? \\
\text { e024 } \\
\end{array}$ & $\mathrm{N}$ & $\begin{array}{c}\mathrm{Y} \\
\mathrm{e} 023 \\
\end{array}$ & $\begin{array}{c}\mathrm{Y} \\
\mathrm{e} 025 \\
\end{array}$ & $\mathrm{~N}$ & $\mathrm{~N}$ & $\mathrm{~N}$ & $\mathrm{~N}$ & $\mathrm{~N}$ & $\begin{array}{c}\mathrm{Y} \\
\mathrm{e} 014 \\
\end{array}$ & $\begin{array}{c}\mathrm{Y} \\
\mathrm{e} 015 \\
\end{array}$ & $\mathrm{~N}$ & $\mathrm{~N} / \mathrm{A}$ & $\mathrm{N} / \mathrm{A}$ & $\mathrm{N} / \mathrm{A}$ & $\mathrm{N} / \mathrm{A}$ & $\mathrm{N} / \mathrm{A}$ \\
\hline
\end{tabular}

\section{Level 3}

e030 Corrosion-assisted fatigue is a known phenomenon on secondary side (e.g., in the vicinity of girth welds in steam generator shells and in the region of feedwater nozzles) and is not like environmental fatigue described in other areas of this DM. Environmental fatigue research relevant to this specific phenomenon is not ongoing within MRP Fatigue ITG, and is a potential gap.

$1 \quad$ Copyright $\odot 2004$ Electric Power Research Institute, Inc. All rights reserved.

EF㠯।

Figure 3.9. Example of Part of the Materials Degradation Matrix Developed by EPRI (Crane 2004)

\subsubsection{France}

France currently operates 59 reactors that generate $78 \%$ of the country's electricity. An overview of French NPP life management, in the form of a country report, is provided in a 2000 OECD/NEA report (NEA 2000b). The French "plant life program," which provides a systematic study of life management, was established in 1985 by Electricite de France (EdF) to coordinate all issues relating to aging and lifetime management. EdF reports periodically on the activities to the French safety authorities. An overview of the EdF approaches to plant life management was provided recently by Hedin (2007).

The nuclear electricity generating system in France comprises 58 PWRs, all managed by a single operator, EdF. The EDF system is unique in that it uses standardization of the designs, which gives a large number of technically similar reactors. These features have justified the adoption of a generic 
approach to aging management. Also France does not issue its NPPs a license for operation for a specified period of time. The original license for a plant gives an operating life of 40 years. The French safety authorities are then required to give an authorization to restart each unit after an outage (fuel reloading) at the end of each cycle (which is typically between 12 and 16 months) (IAEA 2002a). In 2002, French nuclear safety authorities approved a further decade of operation for the EdF 900-MW-class PWRs. This action marked the end of a systematic safety review and upgrade process that had taken more than a decade. A process is established in which a new safety review cycle will be initiated for the plants before the 30-year outage.

Activities are reported as having been initiated to consider opportunities for longer-term operation. The standardization in French NPP designs has advantages for the owners but also creates a need to anticipate any risk of the occurrence of generic defects. This primarily concerns the problem of aging for both the primary system and for the civil engineering side. Preparation for the 900-MW third 10-yearly outage is under way, but current activities still are assuming life is limited to 40 years. Tests and checks conducted during the 10-year outages are being used as an opportunity for owners and authorities to gain a clear picture of the current level of safety of the installations. This proactive approach is ongoing and will lead to back-fitting work, for which the completion dates must be both justified in terms of safety and realistic in terms of implementation. The operator aims to improve safety through periodic safety reviews that compare the reactors with the most recent standards develop probabilistic safety studies, within the framework of a realistic approach to risk reduction. At the same time, EdF is talking about the possibility of extending the life of some power plants beyond that.

In support of plant life extension, the various French research and nuclear organizations are strongly engaged in activities at EdF laboratories, with the EU, and with EPRI nuclear safety programs. There are also significant projects looking at renewal scenarios that interface with Generation III and Generation IV reactors being on line by about 2020 and 2035, respectively.

In February 2008, EdF and EPRI announced in the a press release to the technical press and in announcements posted on their Internet sites, that they have teamed with Tokyo Electric Power Company (TEPCO) to create the international Materials Aging Institute, a collaborative research facility that will examine the critical link between materials science and power plant component performance and degradation. The Institute will be based at EDF's facilities in Les Renardières, France. EDF is investing $\$ 22.3$ million to erect a new building to house the institute and is purchasing modern laboratory equipment, including three electron microscopes and powerful numerical simulation tools. The institute initially will be staffed by members of EDF, EPRI, TEPCO, utility organizations, national laboratories and universities. To address global concerns regarding the medium- to long-term availability of a capable workforce for the electric power industry, the institute will include a formal training program for young engineers.

In recent years, the French regulatory organizations have undergone changes. Until 2002, the French regulator was the Direction de la Surete des Installations Nucleaires (DSIN). In February 2002, there was the formation of the Directorate General for Nuclear Safety and Radiation Protection, which, with the support of the Divisions for Nuclear Safety and Radiation Protection within the regional directorates for research, industry, and the environment, constitute the new Nuclear Safety Authority (ASN) in charge of Nuclear Safety and Radiation Protection. At the same time, the former technical support organizations of the regulatory authorities, both IPSN (nuclear safety) and OPRI (radiation protection), were merged into the Technical Support Organization (TSO) responsible for technical assessment and research, the Institute 
for Radiation Protection and Nuclear Safety (IRSN). Based upon the organizational changes, research issues that deal with PMMD would now be addressed to IRSN.

\subsubsection{Japan}

Japan currently operates 55 nuclear reactors, and these generate about $30 \%$ of the country's electricity. An overview of Japanese NPP life management is provided in a 2000 OECD/NEA report (NEA 2000b) in the form of a country report. The initial program has been reported in several papers (Maeda and Tajima 2004). An updated overview was provided at the recent IAEA PLiM meeting in Shanghai in October 2007 (IAEA 2007b) and at program meetings held in Japan in 2007 and 2008 [e.g., Nei (2007)and Sekimura (2007)].

In Japan, the regulatory authority is the Ministry of International Trade and Industries (MITI). The operational license for an NPP is granted for an indefinite period. There is reported to be no specific regulatory process in place for plant life extension. A periodic inspection system is defined, and an NPP is shut down yearly to undergo annual inspections before approval is given to operate for another year. MITI endorses the safety of a plant as long as it meets the safety standards at the time. Nuclear power plants can continue to operate as long as the operator can prove annually that the plant can operate safely for one more year. In addition, periodic safety reviews are conducted at each plant at approximately 10 -year intervals.

Activities that support development of the science and technology needed for long-term operation of NPPs in Japan have been developing for more than a decade. In 1996, MITI launched a program to provide a conceptual framework by which the integrity of aging NPPs is examined and addressed. Pilot projects were developed for three plants that have been in operation since 1970/1971 (Mihama 1, Tsuruga 1, and Fukushima Daiichi-1). This program assumes that the plants ultimately will operate for 60 years (IAEA 2002a).

To perform research activities that address NPP aging, the Plant Life Engineering Center (PLEC) was established by the Japan Power Engineering and Inspection Corporation (JAPEIC) in April 2000. The PLEC is sponsored by Ministry of International Trade and Industry (MITI, presently METI), and activities have included performing a needs survey that has resulted in a roadmap for aging phenomena. The data have been summarized in table form (Research Maps) that categorizes them under

- "inspection and monitoring,"

- "evaluation method for aging," and

- "preventive maintenances and refurbishment."

The PLEC program has been described and results reported at various meetings, including the Nuclear Safety Research Forum, held in Tokyo in March 2007. Presentations from that meeting are posted on the meeting Internet site (http://www.nsc.go.jp/forum/2007/). The resulting research themes have been reviewed, and they are further categorized as either medium- or long-term research issues. The review process has now provided prioritized research themes, and new research themes are proposed by various organizations and considered for funding by METI every year. Examples of various roadmaps and their relationships are shown in schematic form in Figure 3.10; an example of technology issues is shown in Figure 3.11 (Sekimura 2007). 
A review of activities indicates that the Japanese program is well structured and processes are in place for continuous revision of the strategy maps (Figure 3.12).

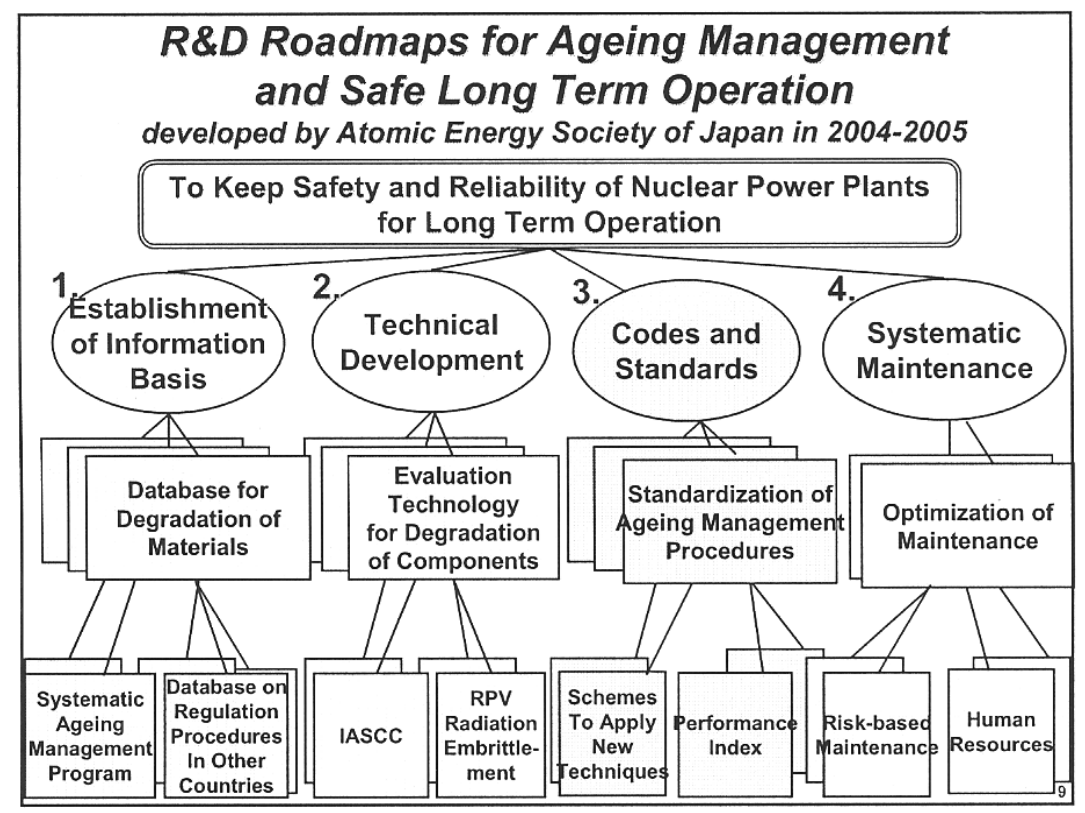

Figure 3.10. Structure of Roadmaps for Aging Management (Sekimura 2007)

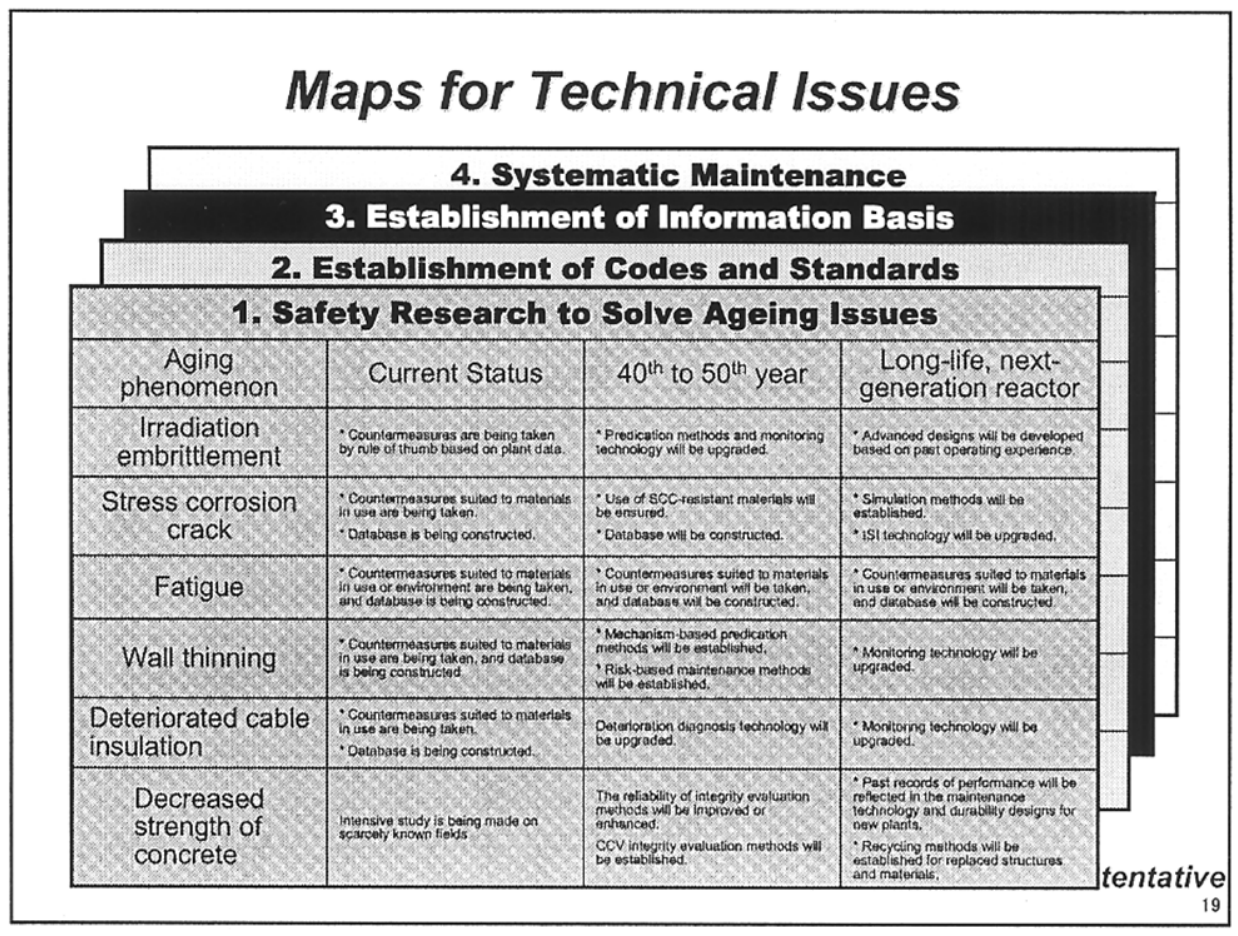

Figure 3.11. Example of Technology Issues (Sekimura 2007) 


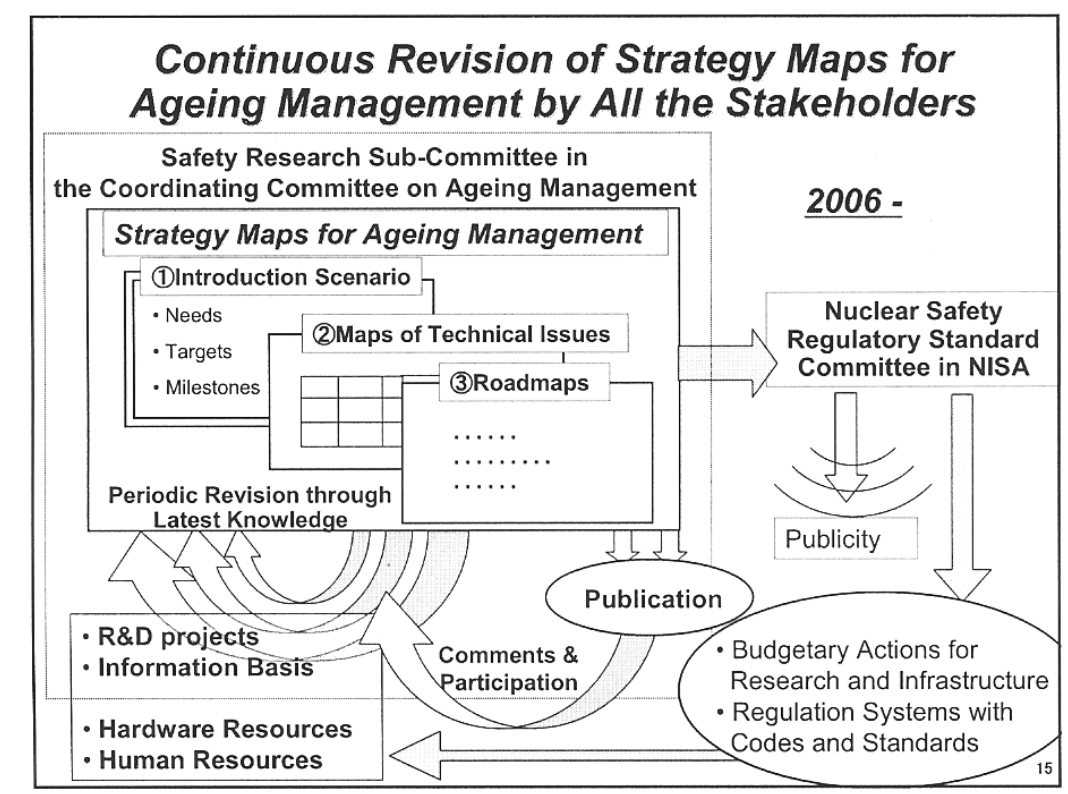

Figure 3.12. Japanese Strategy Map Revision Process (Sekimura 2007)

These Japanese activities bring together government, academia, and industry (Figure 3.13). Opportunities for international partnerships are reportedly also being sought (IAEA 2007b). The activities are being developed through four regional consortia, and progress is reported at the annual Symposium on the Ageing Management and Maintenance of Nuclear Power Plants. There is also Japanese participation on the EdF and EPRI team with Tokyo Electric Power Company (TEPCO) to create the international Materials Aging Institute (discussed in Section 3.3.3).

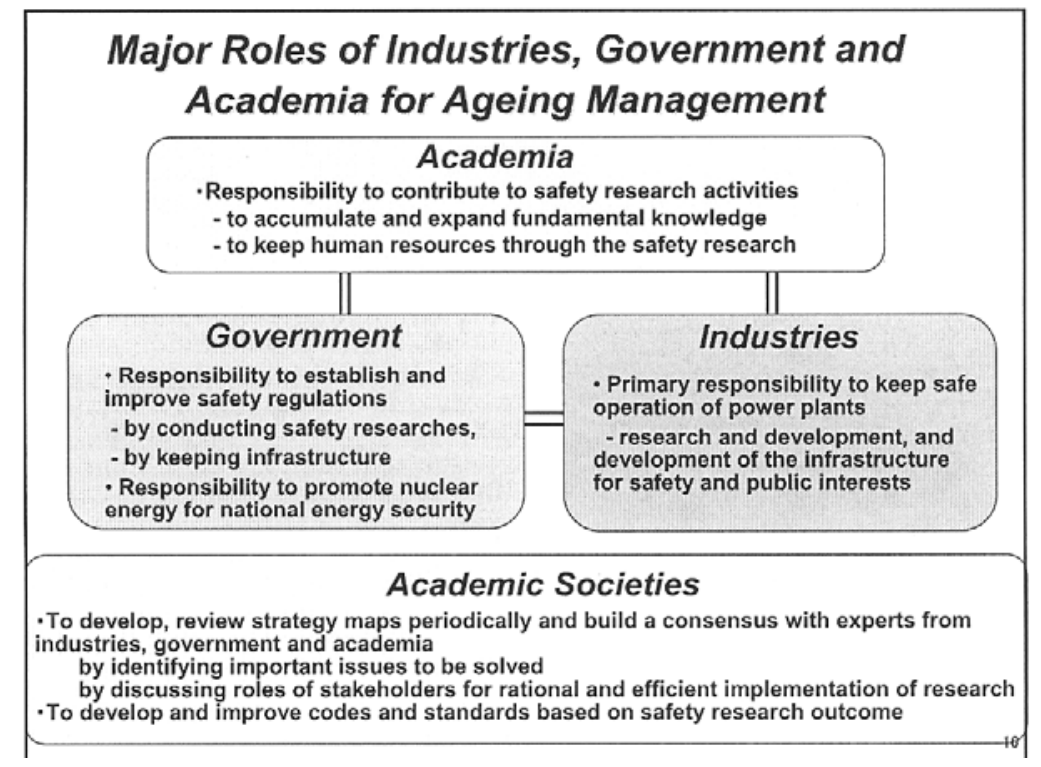

Figure 3.13. Roles in Japanese Ageing Management Program (Sekimura 2007) 


\subsubsection{Russian Federation}

The Russian Federation currently operates 31 nuclear reactors with a total capacity of 22.2 gigawatts (GWt) that generate about 16\% of the country's electricity. Russia has decided to extend the operation of NPPs that pass their original design life. A review of life extension of Russian NPP's was provided at the 2002 PLiM meeting (IAEA 2002c); and aspects of the program were discussed further at the 2007 PLiM meeting (Bakirov et al. 2007b). There are also a number of papers in the wider technical literature, which include a recent discussion of the safety philosophy for RBMK-1000 plants (Burlakov et al. 2007).

Russia is actively implementing a program to extend the life of its nuclear power reactors to enable them to operate beyond their initial 30-year design life. Russia is seeking to extend the service life of its first-generation EGP-6, VVER-440, and RBMK-1000 types of reactors by up to 15 years and plans to move to a $15+30$ (where 15 is the extended life span in years and 30 years is the initial design life). Burlakov et al. (2007) reported that by the end of 2005, life extension work was completed at seven firstgeneration NPP reactors. In the same period, Burlakov (2007) also reports that Russia is preparing for life extension for another eight NPP reactors whose planned service life runs out after 2008 (up to 2013).

The program has assumed that the original design life estimate of 30 years was conservative, that significant upgrades performed during the original designed life have been performed, and that these support life extension. There is also reported to be a good financial justification for life extension, given that life-extension costs are significantly less than those for constructing new reactors.

\subsubsection{Extending the Reactors' Engineered Life Spans}

A number of major research centers are engaged in life extension research in Russia. They are also interacting with the IAEA and participating in IAEA PLiM projects and meetings. In supporting these activities, it is recognized that human resource issues, similar to those being faced in other countries, are developing. A significant number of experts are expected to retire. Issues have been identified regarding knowledge transfer in the technical area of reactor pressure vessel (RPV) embrittlement, in particular with regard to in-depth knowledge of materials behavior and related neutron embrittlement issues. In addition, for the Russian-designed RPVs, a significant fragmentation of the knowledge took place with the dissolution of the Soviet Union and the disruption of technical support activities that occurred, given that various WWERs now are located in several countries outside Russia, particularly in Hungary, Slovakia, Czech Republic, Bulgaria, and Ukraine.

The IAEA and EU have been engaged in supporting life extension activities for NPPs in the Russian Federation, and those reactors that were formerly in the Soviet Union. Russia's Central Research Institute of Structural Materials is organizing a major meeting to be held in October 2008 (http://www.crismprometey.ru/Conferences/Nuclear2008), and the program shows representation from a number of centers and institutes.

\subsubsection{Institute for Nuclear Power Plant Research (INPPR)}

The INPPR (VNIIAES) has a long history of research into a diverse range of NPP issues, including plant life extension. The institute's activities are at the heart of the Russian PLiM program. The methodology for managing the service life of NPPs, including developing the technical justification that supports 10- to 15-year life extensions for Russian reactors, are reported by Bakirov et al. (2007a). This 
paper also includes a discussion of mechanisms degradation and NDT that needs to be employed to support these reactor designs.

\subsubsection{Center of Material Science and Lifetime Management (CMSLM)}

The CMSLM (Moscow) has a 20-year history of working on NDT and property measurements, including projects in the area of aging and life extension. This center is reported to be active at all Russian NPPs as well as in Ukraine, Czech Republic, and Bulgaria.

\subsubsection{Republic of Korea}

The Republic of Korea currently has 20 operational reactors that generate about $39 \%$ of the country's electricity. An overview of the Korean NPP life management program, in the form of a country report, is provided in a 2000 OECD/NEA document (NEA 2000b). The overview was updated in an IAEA report (IAEA 2006b). The regulatory strategy for operational safety and aging management is described in a 2003 paper (Kim et al. 2003). More recently, papers were presented at the second PLiM meeting in Shanghai (IAEA 2008d).

Plant life extension is seen as a major activity needed to support the current fleet of NPPs in Korea. The Korea Electric Power Research Institute (KEPRI) developed a comprehensive PLiM project for a CANDU plant (Wolsong Unit 1) working in cooperation with Korea Hydro and Nuclear Power (KHNP) (Song et al. 2006). The project was conducted to understand the aging status of major components at the plant and to develop methods and technology needed to address areas for action so as to enable continued operation beyond its original license life. The study investigated the continued operation and reviewed aspects of technology, economics, and regulatory environments. Detailed life evaluation and development of aging management programs for continued operation are ongoing. The general approach of aging assessment in Korea includes screening of critical structures and components and leveraging of experience for aging assessments of, for example, fuel channels, which are the most critical component in CANDU plants.

Korea also is addressing life extension for PWRs (Kim et al. 2006). Kori-1, South Korea's first nuclear power reactor, was provided on a turnkey basis. It began commercial operations in 1978. It is a two-loop, Westinghouse pressurized light water reactor; its sister plant is the Kewaunee NPP in Wisconsin, United States. Kori-1 was constructed under the first phase of South Korea's nuclear power program in which foreign firms were contracted to design and build the reactors with Korean firms playing only a minimal role. The primary goal of this first phase of NPP development was for South Korean industries to gain the knowledge and expertise needed to manufacture the equipment and components for NPPs. During this period, foreign capital was the primary source of financing NPP construction, as South Korea required potential contractors to provide financing sources with their bids. In 1995, a project to replace aging components was launched that included the replacement of two steam generators and plant auxiliary systems. Kori-1 was originally planned to be decommissioned in 2008 when its license expires, but in 2003, KHNP began negotiating for a 10-year extension. In addition, nine other NPPs have been operating for more than 10 years in Korea.

As the number of aging plants increases, public concern over the safety of existing operating NPPs also has increased (Kim et al. 2006). Comprehensive and systematic safety assessments, in addition to 
existing safety reviews, are proposed as an effective way to verify that operating NPPs maintain high levels of safety. To ensure safe operation, the Ministry of Science and Technology (MOST), Korea's nuclear regulatory body, recently established an institutional process through revision of the Atomic Energy Act to introduce the periodic safety review (PSR). The PSR considers, among other factors, improvements in safety standards and practices, the cumulative effects of plant aging, operating experience, and the evolution of science and technology. In particular, the assessment and management of plant aging is one of the major areas. It includes identification of SSCs for aging management, assessment of aging effects, and implementation of aging management programs. In addition, the PSR results could be one of the procedural requirements employed to approve life extension or renewal of an operating license of an NPP. The current regulatory requirements for operational safety and aging management, technical requirements for aging assessment and management, regulatory strategy, objectives, and approach of the PSR process recently established in Korea have been reported in recent papers (Kim et al. 2003).

The Korean organizations are strongly engaged in international activities and have developed their own program to address what is seen as a critical national need. NPP aging-related research supported by MOST is being performed at several universities.

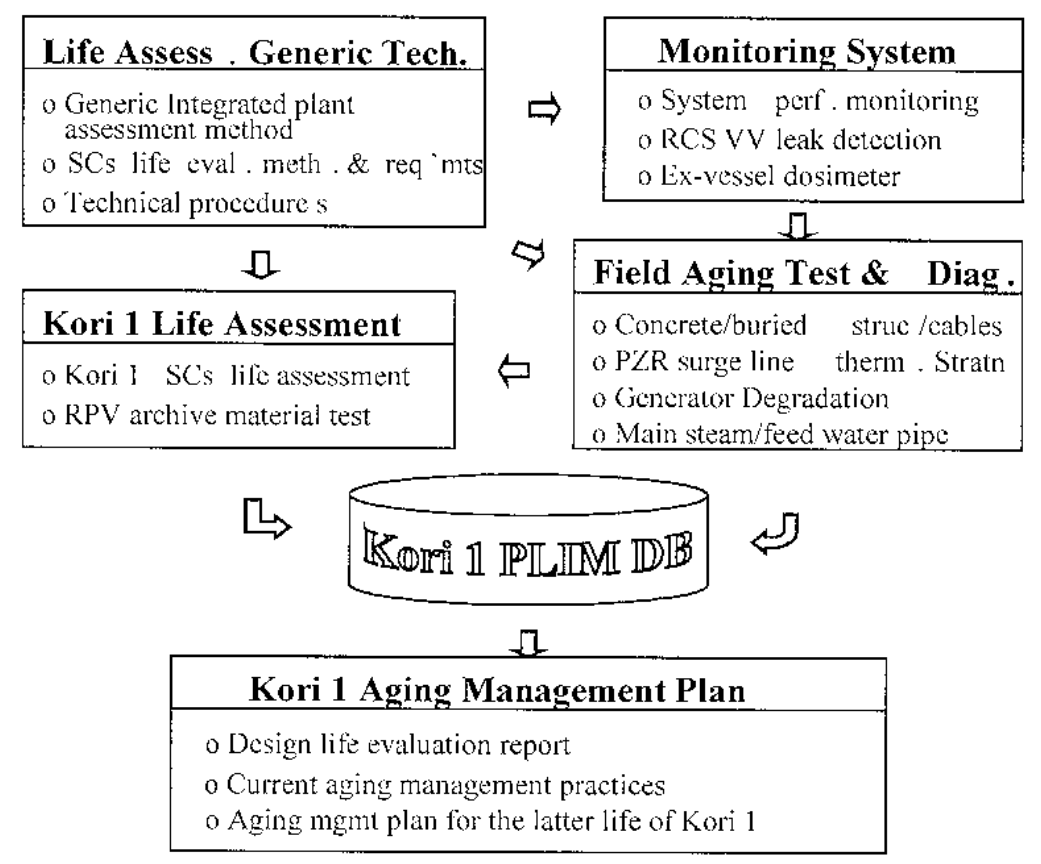

Figure 3.14. Schematic Showing PliM Process for Korean Kori Unit 1 (Kim et al. 1999)

According to Kim et al. (1999), the Korean government policy is to continue to have nuclear power as a major contributor to electricity production. Kim also reports that theMinistry of Science and Technology is planning to develop the South Korean nuclear industry into one of the top five in the world, with about $60 \%$ of electricity coming from nuclear by 2035 . Another eight reactors are expected to come into operation by 2017 ; four will be the larger APR-1400s. 


\subsubsection{United Kingdom}

The United Kingdom currently operates 19 nuclear power reactors that generate about $18 \%$ of the country's electricity. In addition, about $3 \%$ of UK electricity demand is met by imports of nucleargenerated power from France, so overall nuclear-generated electricity totals about $22 \%$ of UK consumption. An overview of the UK's NPP life management program, in the form of a country report, is provided in a $2000 \mathrm{OECD} / \mathrm{NEA}$ report (NEA 2000b). The UK has a mix of reactor types in its national fleet and is currently working to develop a new national energy policy, which is expected to include a nuclear component. One major driver for the renewed interest in nuclear power is the need to replace generating capacity because all but one of the current 19 reactors will be retired by 2023. In 1978, the decision was made to build an initial PWR (at Sizewell). This large Westinghouse unit started up in 1995 and was intended to be the first of four. It is typical of much of the world capacity but newer and more complex than most PWRs. If new-build activities are initiated, new-generation plants could be expected to be on line about 2017. The UK also is working to re-establish nuclear infrastructure that would be needed to support construction of new reactors.

Ageing is seen as an important problem for the UK's nuclear power generating capacity (IAEA 2002). In 2006, the Nuclear Installations Inspectorate gave formal consent to decommission Sizewell-A and Dungeness A power stations, both 40 years old; both were closed at the end of 2006 . They will be defueled by 2009, and site decommissioning is scheduled for 2110-2011, although decommissioning may begin sooner. The remaining two Magnox power stations - the only ones with pre-stressed concrete pressure vessels (rather than steel) - are due to close in 2008 and 2010. In 2006, British Energy (BE) closed four AGRs because of boiler degradation in the non-nuclear part of the plants. It was reported that the intent was to restart the units after a few months, but approval was not given until May 2007. All four plants will operate at about $60 \%$ capacity, but BE states that it intends to increase this to $70 \%$. A December 2007 decision was expected regarding a 5-year life extension for the units to 2016, which involved a commitment to spend $£ 90$ million ( $\sim \mathrm{US} \$ 180 \mathrm{M})$, beyond a current $£ 150$ million ( US\$300M) upgrade program, to achieve. According to British Energy, a further life extension will be considered in 2013 and is likely to occur if electricity prices stay high. Life extensions for other AGR plants will be considered at least 3 years before the scheduled closure of each unit. ${ }^{\text {(a) }}$

However, part of the long-term problem in UK is that costs for decommissioning gas-cooled reactors are much higher per unit of capacity than for light water reactors - at least five times that for Magnox. This is due to the large volume of material and the need to dispose of a lot of graphite moderator. Decommissioning waste volumes per unit capacity for Magnox are ten times those for western light water reactors. The Nuclear Generation Decommissioning Fund was set up to ensure a secure source of funds for eventual decommissioning of NPPs operated by BE. British Energy was the only contributor to the fund, to which final payment will be made in 2035 or whenever Sizewell B is closed down.

British Energy was hit in January 2008 by recent closures at its Hartlepool and Heysham 1 sites. The two have the capacity to supply power to about 1.5 million homes. The costs associated with the problems are expected to run nearly US\$74 million, and the company has already spent more than US\$44 million to buy out disrupted contracts. The company manages eight nuclear power stations built since 1965 but has recently begun struggling with cracks in boilers and other aging issues.

(a) See www.british-energy.com/ for various fact sheets and press releases. 
The United Kingdom supports the IAEA PLiM activities and is engaged with the various European Networks, AMES, NSEC and ENIQ and PWR aging consortium activities. Efforts are in progress to reestablish research capabilities though several university consortia, including two that are based at the Dalton Nuclear Institute (University of Manchester) and Imperial College (University of London). Imperial College is leading an effort known as KNOO (Keep the Nuclear Option Open) and is looking to leverage and re-establish efforts that involved the University of Oxford and former UKAEA (Harwell) staff. Activities are in process also to convert the Sellafield site into a UK national nuclear laboratory.

\subsubsection{Canada}

Canada's 18 operational nuclear power reactors produce $16 \%$ of the country's electricity. These reactors are part of a global fleet of 44 CANDU reactors. Many CANDU reactors are nearing the end of their initial licensing life, and life extension is being considered. An overview of Canadian power plant life management, in the form of a country report, is provided in a 2000 OECD/NEA report (NEA 2000b) and in a second document (IAEA 2006b). An overview of the Canadian regulatory approach to ensuring effective aging management programs for CANDU NPPs was reported at SMiRT in 2007 (Blahoianu et al. 2007). Papers presented at that meeting also reported on aging studies relating to concrete and other parts of plant structure. Other research papers presented at the IAEA PLiM meetings in 2002 and 2007 also provide information on the Canadian approach.

The CANDU reactor design is significantly different from both the PWRs and BWRs that account for most of the plants in the global NPP fleet. The design differences and technical issues associated with the CANDU reactor design have led to the development of a somewhat separate technical community that holds meetings, many organized through the Canadian Nuclear Society and AECL. These organizations address specific CANDU issues (CNS 1980-2007).

Over the past 10 to 15 years, all of the Canadian CANDU owner/operators and Atomic Energy Canada Limited (AECL) have been involved in PLiM programs and activities. The PLiM programs have used various terminologies (such as Life Cycle Management and Integrated Age Management), and there have been some variations in detailed activities that respond to various ageing issues and utility practices. The activities have been focused primarily on ensuring that CANDU plants will operate successfully and reliably throughout their license life, thus preserving the option to extend plant life license. Comprehensive CANDU PLiM programs have been developed from the operational knowledge gained from the Pickering A and Bruce A stations, and from the four original CANDU 6 plants. The CANDU PLiM programs are based also on relevant information from the CANDU industry research and development programs and from other national and international sources. Processes to systematically identify and evaluate the critical systems, structures, and components (CSSCs) in Canadian HWRs have been developed and implemented.

The CANDU owners' group includes operating units in a range of countries outside North America. AECL is working with national authorities to develop and deploy PLiM for the global CANDU fleet. An example of activities includes those associated with the Wolsong 1 CANDU 6 nuclear reactor in South Korea.

In developing PLiM for CANDU reactors AECL adopted the IAEA's Periodic Safety Review (PSR) process (IAEA 2003), and IAEA requirements for research reactors (IAEA 2005a) as the basis for the PSR Gap Analysis employed. AECL is reported as implementing a "living" Aging Management 
Program. This is a formal and structured program, which seeks to provide assurance that the facility systems, structures, and components function as designed to provide safe and reliable operation of the plant.

Regulatory guidance for life extension of NPPs was issued as a draft for public comment in May 2006 and subsequently issued as formal guidance in 2008 (CNSC 2008). Canada is participating in international activities through the IAEA and the OECD/NEA (Blahoianu et al. 2007). It is also providing technical leadership with the CANDU owners' group and is participating in EPRI and INPO programs. AECL supports a modest research program, mostly directed toward meeting the technical needs of CANDU reactors.

\subsubsection{Germany}

Germany currently operates 17 nuclear reactors for electricity generation, and these reactors provide about $32 \%$ of the country's electricity. An overview of the German NPP life management activities, in the form of a country report, is provided in a 2000 OECD/NEA report (NEA 2000b). There is a complex political situation in Germany in that there had been an expectation that nuclear power would be phased out. In looking at the need to meet the country's energy needs, that decision is being revisited. At present, there is no special organization in German to look at the issues of NPP aging and plant life management. A diverse range of government, industry, and research organizations are engaged in the area.

Germany is strongly engaged in EU activities, particularly in AMES and the SAFELIFE programs discussed in Section 0.

\subsubsection{Fraunhofer Institutes (IZFP)}

Much of the technical expertise in this area of NPP aging is found in the Fraunhofer-institutes. NDT and materials characterization activities have been developed at IZFP (Saarbruechen). Both institutes have excellent Internet sites, and the details of their programs may be found at http://www.fraunhofer.de/EN/institutes/index.jsp for the Fraunhofer Institute and http://www.izfpd.fraunhofer.de/english/ for IZFP.

\subsubsection{India}

India currently operates 17 NPPs that generate about $2.6 \%$ of the country's electricity. The current nuclear power capacity of $2720 \mathrm{MWe}$ and India is planning an aggressive increase to up to 9335 MWe by March 2012 and reach 20,000 MWe by the year 2020 (Puttaswamy 2002). The safety record of nuclear power in India has been very good over the past several decades, and India has achieved a high overall annual average plant capacity load factor of $85 \%$.

India appears to be developing activities to support plant life management for its NPPs. Papers presented have reported in-service inspection as a key contributor to monitoring and health assessment for critical plant components (Ramu et al. 2006; Shah 2006). 
India has a diverse range of reactor types. Plant life management for the pressurized heavy water reactors (PHWRs) in India is reported to generally follow the practices identical to CANDU reactors. Nuclear Power Corporation of India Ltd (NPCIL) reports that it conducts PLiM activities at its plants in accordance with requirements specified in NPCIL HQI-7005 and Atomic Energy Regulatory Board safety guide SG-O-14. These guidelines cover requirements based on both national and international experience, including guidance provided by various IAEA reports (IAEA 1990, 1992b, 1998, 2000).

The Indian nuclear regulatory body, the Atomic Energy Regulatory Board (AERB), initially grants authorization for operation for a specified period that may range from five to nine years and then extend this period based on an assessment of plant safety. For extended operation, a comprehensive safety review of the plant is required, which considers the cumulative effects of plant ageing and irradiation damage, results of in-service inspection, system modifications, operational feedback, and status of safety systems. The AERB safety guide on Renewal of Authorization for Operation of Nuclear Power Plants SG-O-12 covers the requirements (Koley et al. 2006). The process used for safety review and license renewal is carried out several times during the operating life of an NPP. This comprehensive safety review is defined as the periodic safety review (PSR) in the Indian literature.

The available information on PLiM and activities is limited. There are a small number of papers in the technical literature, and the Indian nuclear community is holding regional/national meetings on aging topics. India is reported to have allowed a delegation from the World Association of Nuclear Operators to visit one power plant recently, but findings remain confidential. The November 15, 1999 issue of Business Week Online reported that India is also grappling with whether it should continue to operate two 30-year-old American-built reactors near Bombay. The NPCIL has extended the lifetime of the aging General Electric plants, and some refurbishment activity is in progress.

The importance and growing interest in PLiM within the technical community in India is known and recognized. A workshop reportedly is being planned to cover "Nuclear Power Plant Life Management: Emphasis on Interdisciplinary Science and Technology," October 20-23, 2008, at the Indira Gandhi Centre for Atomic Research, Kalpakkam, India. The workshop will cover a wide range of technical topics, including

- an overview of ageing management, in-service inspection, risk analysis, life prediction, refurbishment and life extension

- life extension of PHWR, BWR, PWR and sodium-cooled FBRs

- international scenario and practice on life management of NPPs

- classification of components for ageing management

- ageing management of metallic materials, long term properties, damage mechanism, fracture mechanics, mitigation strategies, new materials, materials modeling

- ageing management of non-metallic structures and components including concrete

- ageing management of cables and instrumentation

- issues related to safety upgradation and redundancy

- regulatory guidelines and licensing renewal procedures

- waste storage and disposal during extended periods of plant life 
- economics of nuclear plant life management

- public acceptance

- international cooperation in research and development programs

A range of international experts is being invited to participate in this event.

\subsubsection{Ukraine}

Ukraine has 15 nuclear power reactors that provide $48 \%$ of the country's electricity. Several plant life extension activities are in progress. The core of the NPP lifetime management activities is an "Action Plans for Nuclear Power Plant Lifetime Management," which is being developed as an IAEA technical cooperation program (see the IAEA Internet site for SKALTO Program descriptions and documents, http://www-ns.iaea.org/tech-areas/engineering-safety/skalto/pubs-ageing.htm). This activity was initiated in 2003 to create a strategy and action plan for lifetime management for all NPPs in Ukraine. The institutes involved are the Ministry of Fuel and Energy of Ukraine, State Nuclear Regulatory Committee of Ukraine, and the Ministry of Fuel and Energy of Ukraine; Department of Technical Norms.

Ukraine also has strong links to technical activities being performed in Russia and technical interactions with the EU and a number of IAEA activities. In addition, for the Russian-designed RPVs, a significant fragmentation of the knowledge took place when the USSR dissolved, limiting the ongoing interactions with operators of the various WWERs in Hungary, Slovakia, Czech Republic, and Bulgaria.

\subsubsection{China}

China currently operates 11 nuclear power reactors that generate $1.9 \%$ of the country's electricity. Nuclear power plant operation started in China in 1991 when Quinshan-I, a 300-MWe PWR, went on line. Since then, the nuclear industry has been growing. Nuclear power development has been in progress for more than 30 years in China but has never been incorporated into the national electric power plan. Instead, power projects were arranged and constructed individually. In 2003, for the first time, China initiated plans for major nuclear power developments as a key component within the state electric power plan. China is also seeking to include PLiM as a key enabling philosophy for its nuclear power program. The prospects for PLiM in China were discussed by Zheng and Dou at the 2007 PLiM meeting in Shanghai (IAEA 2008d).

The Chinese national activities in nuclear power are requiring design requirements that consider and even facilitate PLiM as NPP programs develop (Mingguan and Yikang 2008). China has established a Technical Cooperation program with the IAEA to address aging management of critical components. Through this program, China is adopting the IAEA approaches to PLiM.

The initial goal for PLiM in China is to address the needs of the Qinshan NPP (Qinshan-I), China's first nuclear plant, and seek to double its operational life through a cutting-edge PLiM program. The expectation is that with effective plant life management methods, Qinshan-I will probably be able to continue to operate for another 20-40 years after its initial 30-year design life. The Shanghai Nuclear Engineering Research and Design Institute (SNERDI) and the Research Institute of Nuclear Power Operation of Wuhan in Central China are providing PliM technical support for Qinshan-I (Mingguan and Yikang 2008). 


\subsubsection{Sweden}

Sweden currently operates 10 nuclear power reactors that generate approximately $48 \%$ of the country's electricity. The Swedish NPP life management activities are overviewed in the form of a country report in a 2000 OECD/NEA report (NEA 2000b). An update on ageing management in Sweden was provided at the IAEA 2nd PLiM meeting in Shanghai in 2007 (Gott 2008).

In 1980 a referendum in Sweden canvassed three options for phasing out nuclear power but none for continuing it. In 1997, the energy policy changed to retain most of the country's nuclear plants, but earlier decisions had resulted in premature closure of one 2-unit plant.

On July 1, 2008, the Swedish government merged the Swedish Radiation Protection Institute (SSI, founded 1965) and the Reactor Safety Inspectorate (SKI, 1974) into a single agency, the Swedish Radiation Safety Authority (SSM). Sweden believes the merger will provide a step toward more effective cooperation between two organizations, many of whose duties have overlapped. Nuclear safety has topped the agenda of both, but whereas SKI has been more strictly focused on the engineering aspects of nuclear technology, SSI's responsibilities have included public health and environmental protection implications as well.

Swedish Government-funded R\&D totaled SKR 10.5 million in 2007, focused on reactor safety as well as ensuring that Sweden maintains competence in the nuclear industry. A ban on nuclear research was removed in 2006. The country is increasingly participating in several IAEA and OECD/NEA activities [e.g., a cable aging and stress corrosion cracking activity with the NEA (Yamamoto et al. 2007)].

\subsubsection{Rest of the World}

There are approximately 100 reactors in countries that are not included in either Europe or the specific countries discussed above. In almost all cases, plant life management and plant life extension activities either are in place or are being developed. Many of these countries reported aspects of their programs at the IAEA 2007 PLiM meeting (IAEA 2008d).

In many cases, there are links into the plant life management activities within the OECD/NEA, IAEA or through user groups or supplier networks. For example, there are 44 CANDU reactors in the global fleet; only 18 of these plants in Canada. In many cases, the regulatory guidance, codes, and standards of the supplier nation are employed in combination with varying degrees of locally developed regulators' guidance, codes, standards, and local technical and research activities.

\subsection{Advanced Reactor Designs}

New LWRs as well as GEN III and Gen IV fission and fusion reactor designs are causing an increased emphasis on material topics. Many new reactors are being proposed with 60 -year initial design lives. For Generation IV reactors these are expected to have more demanding operating conditions, and the GEN IV program has resulted in the collecting and review of much materials data. 


\subsection{Other Technology Areas}

The past decade has seen significant development within both the nuclear and wider engineering communities from the use of periodic NDT to condition-based maintenance and advanced life management. These activities have been called by various names, including structural health monitoring, material damage prognostics, and PMMD. Where these approaches have been applied, they have been implemented with on-line methods developed for advanced monitoring and diagnostics. As the economic value of CBM and other advanced monitoring approaches is demonstrated, there is increasing interest in prognostics, the prediction of the remaining safe or service life for both active components such as pumps as well as passive components that do not need any external input to operate (such as basic structural materials).

\subsubsection{Diagnostics}

It was recognized in the mid-1970s that NDT needed to become a quantitative, science-based technology. A series of excellent technical research is documented in the books Review in Progress in Quantitative Nondestructive Evaluation (Thompson and Chimenti 1980-2007). Many of the measurement capabilities for nondestructive testing and evaluation (NDT/NDE) were identified as set by fundamental physics (Bond 1988). It was also recognized that there are different levels of performance that can be achieved in the laboratory, on production parts, and in-service.

Recent years have seen development of better understanding of the NDT/NDE measurement processes and quantification of performance in terms of a probability of detection (POD) rather than a size for an ultimate detection limit. The operator or inspector is also recognized as a key element in the inspection system, and not all operators perform to the same level. The top $10 \%$ of inspectors have been found to perform at exceptional levels (Bond 1999). The median inspector does not achieve similar sensitivity. In part to address performance reliability for ISI, there has been a move to automation. The best automated system can give repeatability, although it usually does not reach the ultimate sensitivity/detection limits achieved by the best inspectors.

Advances in monitoring technologies from other industries can potentially benefit both legacy and new NPPs, particularly when using advanced on-line monitoring and diagnostics for condition-based maintenance and, in the future, prognostics. Digital instrumentation/controls and advanced diagnostics/prognostics are being developed in high-technology industry communities and are now being considered for NPP deployment. There is a convergence between materials damage prognostics (Larson et al. 2005); the civil engineering damage and damage evolution models under multiple stressors; the traditional "vibration" monitoring community looking towards new challenges in systems used by the defense community (Pusey et al. 2005); technology to achieve total structural health management (Chang 2003b); and the NDE community looking at aging due to thermal embrittlement, fatigue, and neutron degradation (Dobmann 2006).

There have also been new approaches to the management of life in mechanical systems (Roos et al. 2006) and research into characterization of materials in aging systems, particularly early-degradation phenomena that occur before the "traditional" defects (such as cracks) detected by conventional NDT develop into detectable sizes (Crane et al. 1998). The trend of seeking to move from periodic NDE to online condition-based maintenance started several years ago in other industries (Bond 1999). A review of 
the current paradigms and practices in system health monitoring and prognostics has recently been provided (Kothamasu et al. 2006).

There remain significant measurement challenges associated with characterization of aging in irradiated reactor components (Doctor 1988; Dobmann 2006). An example of one major series of activities moving from NDE to characterization of aging and degradation is found in the work of Dobmann and colleagues. In early papers, they reported using ultrasonic and micromagnetic techniques to measure strength and toughness and detecting early damage (Dobmann et al. 1992). This evolved into work that addresses the demand for describing damage and service-related aging (Dobmann et al. 1997), which evolved into a significant European project involving round-robin sample characterization (Dobmann et al. 2001) and bringing together condition-dependent NDT and fracture mechanics (Schmitz et al. 2001). An increasingly diverse range of NDT/NDE tools are being considered in both laboratory and field studies (Crane et al. 1998; Dobmann 2006) for aging phenomena characterization, as shown with new applications of magnetic methods (Dobmann 2006). Techniques such as ultrasonic backscatter and acoustic birefringence are being investigated as possible tools for in-service monitoring. The development of concepts for advanced on-line structural health monitoring for next-generation reactor designs such as International Reactor Innovative \& Secure (IRIS) has been initiated (Nakagawa et al. 2006).

As this article is being written, 42 U.S. operating commercial NPPs have completed the license extension process (see the NRC Internet site http://www.nrc.gov/reactors/operating/licensing/renewal/ applications.html for detailed information on the license extension process in the United States). Every plant granted license extension has committed to developing the tools to manage degradation processes such as void swelling where no accepted or reliable detection or measurement technology presently exists. Therefore, the working details of these degradation management programs have yet to be defined, and the regulator has to review or accept these future programs.

To address these challenges, a convergence is developing that is bringing together capabilities in the materials science and NDE communities.

\subsubsection{Prognostics}

Prognostics (for machinery) is the prediction of a remaining safe or service life based on an analysis of system or material condition, stressors, and degradation phenomena. Based on observed data and predicted behavior, moving from diagnostics to prediction of life and technologies for structural health monitoring/management requires development of new approaches. The range of developing approaches is illustrated in schematic form in Figure 3.3. The various empirical methods for process and equipment prognostics have been reviewed by Hines et al. (2008). An extensive review of machinery diagnostics and prognostics for condition-based maintenance is provided by Jardine et al. (2006) but again, it does not consider nuclear power systems.

An assessment of the state of diagnostics and prognostics technology maturity was recently provided (Howard 2005). The current status for various system elements, including both active and passive structures, is shown in Table 3.3.

Technologies are being developed for non-nuclear applications (including instrumentation and system health monitoring for electronics) in what is being called "electronics prognostics" (Urmanov 2007). For 
example, there are integrated technologies being developed for advanced fighter aircraft and unmanned aerial vehicle system health monitoring, which include both electrical/electronic and mechanical systems. Within advanced diagnostics/prognostics, systems have been deployed for individual elements, but fully integrated systems are still being developed.

For the existing NPPs, particularly when life extension is being developed, there are opportunities to deploy on-line monitoring/prognostics, assuming it can be demonstrated that there is still remaining useful life in the plant. Key to developing advanced prognostic schemes (in active systems such as pumps and valves) that give maximum warning of degradation focuses on monitoring the stressor rather than solely the subsequent effects of aging and degradation. A schematic showing system operational performance and stressor magnitude is shown in Figure 3.3. The monitoring of the stressor (e.g., a temperature, cavitation, vibration, or a pressure) combined with active system control parameter management across several processors enables use of the "warning time" ( $\Delta \mathrm{T}$ in Figure 3.3) to adjust operational parameters and limit or at least control rates of degradation for a path to failure. In order for this type of strategy to be successful, physics-based models relating the stressors to the rate of aging or degradation must be developed in the prognostic scheme.

To move from periodic inspection to on-line monitoring for condition-based maintenance (and eventually prognostics) will require advances in sensors; better understanding of what and how to measure within the plant; enhanced data interrogation, communication, and integration; new predictive models for damage/aging evolution; system integration for real-world deployments; quantification of uncertainties in what are inherently ill-posed problems; and integration of enhanced, condition-based maintenance/prognostics philosophies into new plant designs, operation, and operating and maintenance approaches. 


\subsection{Technical Gaps That Need To Be Addressed for PMMD}

Clearly, implementation of PMMD programs will require significant investments in basic and applied research to achieve the needed advances required to enable effective PMMD programs. Appendix B of this report contains a draft of a report titled - "Overview Program Plan for Cooperation on Proactive Materials Degradation Management (PMDM) Research" that was compiled and edited by Roger Staehle and Joe Muscara. The report presents a summary of a number of research plans that experts who attended two workshops felt needed to be conducted to develop the technical basis for effective PMMD programs. The report also identifies potential international cooperative research that could lead to the implementation of effective PMMD programs.

This section of the report provides examples of the technical gaps contained in Appendix B and divides the gaps into categories: the technical gaps that need to be addressed by basic science, those technical gaps in engineering, and those that need to be addressed from a regulatory/codes and standards point of view. The full scope of these needs is still being defined.

\subsection{Summary of Technical Gaps from the EPRI PMMD Program}

\subsubsection{Gaps in Basic Science for PMMD}

In order to move from a reactive mode to a proactive mode when dealing with degradation, there are fundamental materials science gaps that need to be addressed. EPRI has developed a detailed description of several gaps that require basic science to develop reasonable solutions.

- Limited mechanistic understanding of environmentally assisted cracking of reactor coolant system components in light water reactors: Material degradation problems due to environmentally assisted cracking have cost the U.S. nuclear industry at least $\$ 10$ billion in the last 30 years because of forced and extended outages, increased inspection requirements, component repairs and replacements, and increased scrutiny by the regulator. A better mechanistic understanding of crack initiation and early crack propagation processes that cause stress corrosion cracking and irradiation-assisted stress corrosion cracking is required to develop reliable predictive models and cost-effective mitigation technologies. The EPRI Primary System Corrosion Research Program has the lead for overcoming this barrier.

- Incomplete understanding of the effects of some LWR water-chemistry variables: Detailed understanding of water chemistry variables is essential in the design and implementation of chemistry programs that limit operational and maintenance impacts. Improved understanding would enable plant owners and operators to define optimized chemistry programs on a plant-specific basis to reduce corrosion damage, minimize the release of corrosion products into coolant systems, and mitigate the impact of chemistry-related problems on plant safety, operation, and profitability. The EPRI Water Chemistry Control Program has the lead for overcoming this barrier. 


\subsubsection{Gaps in Engineering for PMMD}

In order to move from a reactive mode to a proactive mode when dealing with degradation, there are gaps in engineering that need to be addressed and require the basic science that supports the engineering solution. EPRI has developed a description of several gaps that require engineering to develop reasonable solutions.

- Lack of an integrated, proactive approach for managing degradation of reactor coolant system components in pressurized water reactors, including the steam generator: The lack of a comprehensive and integrated approach for addressing materials degradation issues in PWR reactor coolant systems can result in ineffective diagnosis and maintenance of nuclear equipment and components. Refined approaches are needed to provide the technical bases for resolving four pressing issues: cracking of nickel-alloy components and welds in primary piping and penetrations; reactor vessel internals cracking; reactor pressure vessel integrity; and piping fatigue damage. The Materials Reliability Program has the lead for overcoming this barrier.

- Lack of an integrated, proactive approach for managing degradation of reactor coolant system components in boiling water reactors: The lack of a comprehensive and integrated approach for addressing materials degradation issues in BWR reactor coolant systems can result in ineffective diagnosis and maintenance of nuclear equipment and components. Refined approaches are needed to develop strategies and technology that enable plant operators to inspect, assess, mitigate, and repair stress corrosion cracking in core shrouds, other major reactor vessel internals components, and primary pressure-boundary piping. The EPRI Boiling Water Reactor Vessel and Internals Program has the lead for overcoming this barrier.

\subsection{Summary of Technical Gaps from the NRC-Sponsored Reports}

Two NRC-sponsored reports provide valuable thoughts from international experts on research that is needed to develop Proactive Management of Materials Degradation (PMMD) programs. NUREG/CR6329 titled Expert Panel Report on Proactive Materials Degradation Assessment contains significant information on degradation mechanisms and an assessment of our knowledge of the degradation mechanism. This document provides an excellent starting point for prioritizing the research needs for basic material science. Appendix B of this PNNL technical letter report contains a draft report that provides an overview of a research program plan, including descriptions of work plans (WPs) aimed at developing knowledge and technology that would allow for the development and implementation of PMMD programs for light water reactors (LWRs). The research program plans presented in the Appendix B draft report is based upon the information that was presented at the following workshops.

- Snowbird Resort, Salt Lake city, Utah, USA, August 16 and 19, 2005

- Japan Nuclear Energy Safety Organization, Tokyo, November 9-11, 2005

- Mills House Hotel, Charleston, South Carolina, USA, May 11-13, 2006

The research described below is a brief summary of the more essential research presented in the NRC-sponsored reports. 


\subsubsection{GAPS in Basic Science for PMMD}

- Limited understanding of basic material science behavior associated with degradation mechanisms: NUREG/CR-6329 titled Expert Panel Report on Proactive Materials Degradation Assessment contains significant information on degradation mechanisms and an assessment of our knowledge of the degradation mechanism. This document provides an excellent starting point for prioritizing the research needs for basic material science. The draft report included as Appendix B to the PNNL technical letter report contains 46 detailed scopes of research for assessing degradation of materials.

\subsubsection{Gaps in Engineering for PMMD}

- Continuous monitoring for detecting LWR materials degradation: There are significant limitations to the required NDE that is performed on a periodic basis as part of the inservice inspection (ISI) program. Improvements can be made to ISI programs to overcome some of the limitations through improvements in how frequently inspections are performed (reduction from a 10 year interval to every refueling outage), the effectiveness of the NDE method (employing SAFT or phased arrays versus conventional amplitude based UT), etc. Other limitations are not solvable with simplistic improvements in the ISI program. For example, there are a number of locations where access to the areas requiring inspection are limited because the surface of the component is in an as welded condition or surface geometries (tapers) limit inspection. This demonstrates a need to develop and demonstrate continuous on-line methods to monitor all forms of LWR materials degradation as it initiates and grows.

- Detection and characterization of material degradation precursors: NDE is used to identify defects (cracks, fabrication flaws, wall thinning) that have already developed and may challenge component integrity. The capability to detect and characterize the precursors to degradation initiation enables proactive materials degradation management by mitigation as well as by timely repair or replacement. The precursor stage of degradation may exhibit physical characteristics substantially different than the macro-defect that ultimately manifests. The ability to predict degradation by detecting and characterizing precursor state(s) may require an inspection capability that is:

- evolutionary (i.e., higher spatial resolution ultrasound)

- revolutionary (i.e., entirely new application of physics/engineering to this NDE problem)

The technical issues for development of new NDE approaches to precursor detection and characterization range from advanced engineering concepts to more fundamental understanding of how physical states and material features (or properties) are exhibited and hence, measurable.

\subsection{Technical Gaps That Need To Be Addressed within the Framework of Codes and Standards Regulation}

Currently, Section XI of the ASME Boiler and Pressure Vessel Code only specifies criteria for periodic inspections that must be conducted for active and passive components. There is no specific guidance or criteria for PMMD programs. 



\subsection{Conclusions}

The move from periodic inspections to condition-based maintenance and now consideration of prognostics has the potential to significantly impact the operation of legacy NPPs. It has been demonstrated that the application of stressor-based prognostics to active LWR components (e.g., pumps, valves, motors, etc.) has the potential greatly improve performance reliability of power plants, maintain and monitor safety and to reduce operations and maintenance costs significantly. The proactive management of materials degradation program being investigated by the NRC extends consideration to include major passive systems (e.g. piping and pressure vessels). It builds on advanced diagnostic and prognostic methods developed in the wider engineering community and addresses key needs as the nuclear power community looks at extended operation, which in the United States is licensing beyond 60 years. To achieve the goals of extended operation, various forms of on-line monitoring and predictive remaining-life methodologies will need to be developed, demonstrated and deployed.

Based upon the clear need to continue to operate nuclear reactors in the U.S. for extended periods of time, the knowledge that new degradation mechanisms have the potential to challenge the safety design safety margins of reactors and the advances in diagnostics and prognostics, the information in this report provides the basis for the following conclusions.

1. The NRC will need to develop tools that enable NRC staff to evaluate the impact of degradation more quickly and effectively.

2. Addressing the technical gaps needed to develop effective PMMD programs will require substantially more resources than are available to the NRC. Therefore, the NRC will need to develop a major program that prioritizes NRC regulatory needs, leads the appropriate research efforts based upon priorities and participates in national and international research to supplement NRC resources.

3. Actively participate in the development of the national codes and standards that will support effective PMMD programs.

The conclusions described above will help address the following needs.

- There is a need to establish the science base necessary to develop effective PMMD programs. This science base needs to address the following topics.

- The material science that underpins NPP component aging and degradation

- Understand stressor impacts

- The need for new and improved on-line monitoring that will enable early detection and characterization of degradation.

- Ensures the development of the technical basis for regulatory and standards framework that requires effective PMMD programs

There is a need for NRC to more fully engage both national and international efforts relevant to PMMD. 


\subsection{References}

Amin FM. 2004. "Passing the tourch: the Asian network for education in nuclear technology." IAEA Bulletin 46(1):15-17.

Anderson MT, SR Doctor, DS Kupperman and J Muscara. 2008. Assessment of Current Inservice Inspection and Leak Monitoring Practices for Detecting Materials Degradation in Light Water Reactors. U.S. Nuclear Regulatory Commission, Washington, DC.

Andresen PL, FP Ford, K Gott, RL Jones, PM Scott, T Shoji, RW Staehle and RL Tapping. 2007. Expert Panel Report on Proactive Materials Degradation Assessment. NUREG/CR-6923, BNL-NUREG77111-2006. U.S. Nuclear Regulatory Commission, Washington, DC.

AREVA. 2007. OneproD MVX and MVP On-Line Systems. Product Literature. AREVA, Oilkiluoto 3, Finland.

Bakirov MB, OG Kamyshnikov and VV Potapov. 2007a. "Managing the Service Life of HeatExchanging and Mechanical Equipment and Pipelines Operating at Russian Nuclear Power Stations." Therm Eng 54(2):87-93.

Bakirov MB, VV Potapov, A Kan, A Dementev, V Levchuc, E Bakhus, S Chubarov, V Ilyn, E Mamaeva and A Mazepa. 2007b. "The Experience of Service Life Prolongation of NPP Units of the First Generation." In Second International Symposium on Nuclear Power Plant Life Management, Book of Extended Synopses, p. 40. October 15-18, 2007, Shanghai, China. International Atomic Energy Agency, Vienna, Austria.

BES-DOE. 2006. Basic Research Needs for Advanced Nuclear Energy Systems, Report of the Basic Energy Sciences Workshop on Basic Research Needs for Advanced Nuclear Energy Systems, July 31August 3, 2006. Office of Basic Energy Sciences, U.S. Department of Energy, Washington, DC.

Blahnik DE, DA Casada, JL Edson, DL Fineman, WE Gunther, HD Haynes, KR Hoopingarner, MJ Jacobus, DB Jarrell, RC Kryter, HL Magelby, GA Murphy and MM Subudhi. 1992a. Insights gained from aging research. NUREG/CR-5643, BNL-NUREG-52323. U.S. Nuclear Regulatory Commission, Washington, DC.

Blahnik DE, DA Casada, JL Edson, DL Fineman, WE Gunther, HD Haynes, KR Hoopingarner, MJ Jacobus, DB Jarrell, RC Kryter, HL Magelby, GA Murphy and MM Subudhi. 1992b. Insights gained from aging research. NUREG/CR-5643, BNL-NUREG-52323. Nuclear Regulatory Commission, Washington, D.C.

Blahoianu A, T Viglasky, CD Moses and K Kirkhope. 2007. "Canadian Regulatory Approach to Ensuring the Implementation of Effective Ageing Management Programs for Nuclear Power Plants." Transactions, SMiRT 19. August 12-17, 2007. Toronto.

Bond LJ. 1988. "Review of existing NDT technologies and their capabilities." In Proc. of AGARD/SMP Review of Damage Tolerance for Engine Structures; 1. Non-Destructive Evaluation, p. 16. May 1-6, Luxembourg. AGARD.

Bond LJ. 1999. "Predictive Engineering for Aging Infrastructure." In Nondestructive Evaluation of Utilities and Pipelines III, Proceedings of SPIE, 3588, pp. 2-13.Newport Beach, CA. ed: WG Reuter. 
Bond LJ and SR Doctor. 2007. "From NDE to Prognostics: A Revolution in Asset Management for Generation IV Nuclear Power Plants." Transactions, SMiRT 19. August 13-18, 2007. Toronto, Canada. International Association for Structural Mechanics in Reactor Technology.

Bond LJ, SR Doctor, DB Jarrell and JWD Bond. 2008. "Improved economics of nuclear plant life management." Second International Symposium on Nuclear Power Plant Life Management. October 1518, 2007. Shanghai, China. International Atomic Energy Agency, Vienna, Austria. IAEA Paper IAEACN-155-008KS (in press).

Bond LJ, DB Jarrell, TM Koehler, RJ Meader, DR Sisk, DD Hatley, KS Watkins, J Chai and K Kim. 2003. NERI Final Project Report: On-line intelligent self-diagnostic monitoring for next generation nuclear plants. PNNL-14304. Pacific Northwest National Laboratory, Richland, Washington.

Burlakov EV, BA Gabaraev, YM Nikitin, AA Petrov, AA Potapov and NM Sorokin. 2007. "Safety Philosophy of the Operating RBMK-1000 Plants." Transactions, SMiRT 19. August 12-17, 2007. Toronto.

Chang F-K. 2003a. "Structural Health Monitoring." In Proc. 4th Int. Workshop on Structural Health Monitoring,Stanford University. DEStech Pubs., Lancaster, Pennsylvania.

Chang F-Ke. 2003b. "Structural Health Monitoring." In Proc. 4th Int. Workshop on structural Health Monitoring, September 15-17, 2003, Stanford University. DEStech Pubs., Lancaster, PA.

CNS. 1980-2007. "Proceedings Canadian Nuclear Society Conferences." In Annual CNS Conferences. Canadian Nuclear Society. http://www.cns-snc.ca/home_eng.html.

CNSC. 2008. Regulatory Document, RD-360, Life Extension of Nuclear Power Plants. Canadian Nuclear Safety Commission, Ottawa, Ontario, Canada.

Contri P and P Vaisnys. 2007. "Optimal integration of Maintenance Programs with other safety related programs in a Plant Life Management framework." Transactions, SMiRT 19. August 12-17, 2007. Toronto.

Corwin WR. 2007. Next Generation Nuclear Plant Phenomena Identification and Ranking Tables (PIRTs), Vol. 4: High-Temperature Materials PIRTs. NUREG/CR-6944, Vol. 4; ORNL/TM-2007/147, Vol. 4. U.S. Nuclear Regulatory Commission, Washington, DC.

Crane C. 2004. Management of Materials Issues. Available at http://www.nrc.gov/reading-rm/doccollections/commission/slides/2004/20041108/nei_files/frame.html.

Crane RL, JD Achenbach, SP Shar, TE Matikas, PT Khuri-Yakub and RS Gilmore, Eds. 1998. Nondestructive characterization of materials in aging systems, Proceedings of Materials Research Society Symposium. Materials Research Society, Boston, MA.

Dobmann G. 2006. "NDE for material characterization of aging due to thermal embrittlement, fatigue and neutron degradation." Int. J. Mater. Prod. Tech. 26:122-139.

Dobmann G, L Debarberis and J-F Coste. 2001. "Aging material evaluation and studies by nondestructive techniques (AMES-NDT) - a European network project." Nucl. Eng. Des. 206:363-374. 
Dobmann G, M Kroning, W Theiner, W Herbert and U Fiedler. 1992. "Nondestructive characterization of materials (ultrasonic and micromagnetic techniques) for strength and toughness prediction and the detection of early creep damage." Nucl. Eng. Des. 157:137-158.

Dobmann G, N Mayendorf and E Schneider. 1997. "Nondestructive characterization of materials: a growing demand for describing damage and service-life-relevant aging processes in plant components." Nucl. Eng. Des. 171:95-112.

Doctor SR. 1988. "Measurement challenges associated with irradiated reactor components." In Nondestructive characterization of materials in aging systems, Materials Research Soc. Symposium Proc, 503, pp. 163-168.Boston, MA. eds: RL Crane, JD Achenbach, SP Shar, TE Matikas, PT Khuri-Yakub and RS Gilmore. Materials Research Society.

Energetics Inc. 2008. Life Beyond 60 Workshop Summary Report, NRC/DOE Workshop, U.S. Nuclear Power Plant Life Extension Research and Development, February 19-21, 2008, Bethesda, Maryland. Energectics, Incorporated, Columbia, Maryland.

ENS. 2008. Nuclear power plants, world-wide. European Nuclear Society. Brussels, Belgium. Accessed May 28, 2008 at http://www.euronuclear.org/info/npp-ww.htm.

EPRI. 2003. 2003 EDF/EPRI Collaboration on Life Cycle Management and Nuclear Asset Management, Proceedings 2003. Report No. 1008947. Electric Power Research Institute, Palo Alto, California.

EPRI. 2004. An EPRI Nuclear Power Action Plan, Materials Degradation and Aging. Electric Power Research Institute, Palo Alto, California.

Gosselin SR, FA Simonen, PG Heasler and SR Doctor. 2007. Fatigue crack flaw tolerance in nuclear power plant piping. A basis for improvements to ASME Code Section XI Appendix L. NUREG/CR-6934, PNNL-16192. Nuclear Regulatory Commission, Washington, D.C.

Gott K. 2008. "Ageing Managment in Sweden " In Second International Symposium on Nuclear Power Plant Life Management, October 15-18, 2007, Shanghai, China. International Atomic Energy Agency. Paper No. IAEA-CN-155-079. (In Press).

Gregor F and A Chockie. 2006. Aging Management and Life Extension in the US Nuclear Power Industry. CGI Report 06:03. Chockie Group International, Inc., Seattle, Washington.

Hashemian HM. 1993. Long Term Performance and Aging Characteristics of Nuclear Plant Pressure Transmitters. NUREG/CR-5851. U.S. Nuclear Regulatory Commission, Washington, DC.

Hashemian HM. 1995. On-Line Testing of Calibration of Process Instrumentation Channels in Nuclear Power Plants. NUREG/CR-6343. U.S. Nuclear Regulatory Commission, Washington, DC.

Hashemian HM, KM Petersen, RE Fain and JJ Gingrich. 1989. Effect of aging on response time of nuclear plant pressure sensors. NUREG/CR-5383. U.S. Nuclear Regulatory Commission, Washington, DC.

Hedin F. 2007. "Approaches to plant life management in France." IAEA 2nd International Symposium on Nuclear Power Plant Life Management. October 15-18, 2007. Shanghai, China. 
Hines JW, J Garvey, J Preston and A Usynin. 2008. "Empirical Methods for Process and Equipment Diagnostics, Tutorial Notes." IEEE Reliability and Maintability Symposium (RAMS-08). January 23-26, 2008. Las Vegas, Nevada.

Howard P. 2005. "Prognostic Technology - new challenges." In Proc. 59th MFPT Soc, pp. 38.Virginia Beach, Virginia. Soc. Machinery Failure Prevention Technology.

IAEA. 1990. Safety Aspects of Nuclear Power Plant Ageing. IAEA-TECDOC-540. International Atomic Energy Agency, Vienna, Austria.

IAEA. 1992a. Methodology for Ageing Management of Nuclear Power Plant Component Important to Safety. Technical Reports Series No. 338. International Atomic Energy Agency, Vienna.

IAEA. 1992b. Methodology for the Management of Ageing of Nuclear Power Plant Components Important to Safety. Technical Reports Series No. 338. International Atomic Energy Agency, Vienna, Austria.

IAEA. 1998. Assessment and Management of Ageing of Major Nuclear Power Plant Components Important to Safety: CANDU Pressure Tubes. IAEA-TECDOC-1037. International Atomic Energy Agency, Vienna, Austria.

IAEA. 1999. Review of Selected Cost Drivers for Decisions on Continued Operation of Older Nuclear Reactors. IAEA-TECDOC-1084. International Atomic Energy Agency, Vienna, Austria.

IAEA. 2000. Assessment and Management of Ageing of Major Nuclear Power Plant Components Important to Safety: In-containment Instrumentation and Control Cables. Volume I. IAEA-TECDOC1188. International Atomic Energy Agency, Vienna, Austria.

IAEA. 2002. Cost drivers for the assessment of nuclear power plant life extension. IAEA-TECDOC1309. International Atomic Energy Agency, Vienna, Austria.

IAEA. 2002a. Cost drivers for the assessment of nuclear power plant life extension. IAEA-TECDOC1309. International Atomic Energy Agency, Vienna, Austria.

IAEA. 2002b. Proceedings, Symposium Nuclear Power Plant Life Management. Conference \& Symposium Paper 21/P. International Atomic Energy Agency, Vienna, Austria.

IAEA. 2002c. International Symposium on Nuclear Power Life Management. Budapest, Hungary.

IAEA. 2003. Periodic Safety Review of Nuclear Power Plants, Safety Guide. IAEA Safety Standards Series No. NS-G-2.10. International Atomic Energy Agency, Vienna, Austria.

IAEA. 2004a. Note by the Secretariat, Providing for the Application of the Agency's Safety Standards: Activities during 2003, A Report supporting the Nuclear Safety Review for the Year 2003. IAEA 2004/Note 8. International Atomic Energy Agency, Vienna.

IAEA. 2004b. The nuclear power industries aging workforce: transfer of knowledge to the next generation. IAEA-TECDOC-1399. International Atomic Energy Agency, Vienna, Austria.

IAEA. 2005a. Safety of Research Reactors, Safety Requirements. IAEA Safety Standards Series No. NS-R-4. International Atomic Energy Agency, Vienna, Austria. 
IAEA. 2005b. Application of surveillance programme results to reactor pressure vessel integrity assessment - Results of a coordinated research project 2000-2004. IAEA-TECDOC-1435. International Atomic Energy Agency, Vienna, Austria.

IAEA. 2005c. Guidelines for Application of the Master Curve Approach to Reactor Pressure Vessel Integrity in Nuclear Power Plants Technical Reports Series No. 429. International Atomic Energy Agency, Vienna, Austria.

IAEA. 2006a. Plant Life Management for Long Term Operation of Light Water Reactors, Principles and Guidelines. Technical Reports Series No. 448. International Atomic Energy Agency, Vienna, Austria.

IAEA. 2006b. Nuclear power plant life management processes: Guidelines and practices for heavy water reactors. IAEA-TECDOC-1503. International Atomic Energy Agency, Vienna, Austria.

IAEA. 2007. On-line Monitoring for Improving Performance of Nuclear Power Plants, Part 1: Instrument Channel Monitoring. IAEA-NE-D-NP-T-1. International Atomic Energy Agency.

IAEA. 2007a. Final Report of the Programme on Safety Aspects of Long Term Operation of Water Moderated Reactors. Recommendations on the scope and content of programms for safe long term operation. IARA, IAEA-EBP-SALTO. International Atomic Energy Agency, Vienna, Austria.

IAEA. 2007b. 2nd International PLiM Symposium 2007. Shanghai, China.

IAEA. 2007c. Technical proceedings on Material Degradation and Related Managerial Issues at Nuclear Power Plants. International Atomic Energy Agency. Vienna, Austria. Accessed May 28, 2008 at http://www.iaea.org/OurWork/ST/NE/NENP/NPES/Activity/lcm recent.html\#A106.

IAEA. 2008a. Fact Sheet on Plant Life Management for Safe Long Term Operation of Nuclear Power Plants. International Atomic Energy Agency. Vienna, Austria. Accessed August 19, 2008 at http://www.iaea.org/OurWork/ST/NE/Downloads/NETCFactSheets/ne tc fs 02.pdf.

IAEA. 2008b. International Nuclear Information System (INIS) and Nuclear Knowledge Management Section. International Atomic Energy Agency. Vienna, Austria. Accessed May 28, 2008 at http://www.iaea.org/inisnkm/ (last updated May 19, 2008).

IAEA. 2008c. On-line Monitoring for Improving Performance of Nuclear Power Plants, Part 2: Process and Component Condition Monitoring and Diagnostics. IAEA-NE-D-NP-T-3. International Atomic Energy Agency.

IAEA. 2008d. Proceedings of 2nd International Symposium on Nuclear Plant Life Management. International Atomic Energy Agency, Vienna, Shanghai, China. October 15-18, 2007.

IAEA. 2008e. Proceedings of Second International Symposium on Nuclear Power Plant Life Management. International Atomic Energy Agency, Vienna, Austria, Shanghai, China. In press.

IFA. 2008. 50 Years of Safety-related Research: The Halden Project 1958-2008. Institute for Energy Technology, Tistedalsgata, Halden, Norway.

Jardine AKS, D Lin and D Banjevic. 2006. "A review on machinery diagnostic and prognostics implementing condition based maintenance." Mech. Syst. Signal Process. 20:1483-1510. 
Jarrell DB, DR Sisk and LJ Bond. 2004. "Prognostics and conditioned-based maintenance: a new approach to precursive metrics." Nucl. Tech. 145:275-286.

Johnson B and H Maxwell. 2002a. "Predictive maintenance - the effect on a company's bottom line, Part 1 - The Global View." In Proc. 56th MFPT Soc, pp. 453-468.Virginia Beach, Virginia. Society Machinery Failure Prevention Technology.

Johnson B and H Maxwell. 2002b. "Predictive maintenance - the effect on a company's bottom line, Part 2 - Calculating the avoided cost." In Proc. 56th MFPT Soc, pp. 469-482.Virginia Beach, Virginia. Society Machinery Failure Prevention Technology.

Johnson Jr. AB, SK Sundaram and FA Garner. 2001. Program Plan for Acquiring and Examining Naturally Aged Materials and Components for Nuclear Reactors. PNNL-13930. Pacific Northwest National Laboratory, Richland, Washington.

Kim HJ, HK Kim and TE Jin. 2003. "Regulatory Strategy for Operational Safety and Aging Management of NPPs in Korea." Transactions of the 17th International Conference on Structural Mechanics in Reactor Technology (SMiRT 17). August 17-22, 2003. Prague, Czech Republic.

Kim T-h, P-s Kim and Y-s Yu. 2006. "Current Status of Continued Operation for Kori Unit 1 Beyond Design Life." In 2006 International Congress on Advances in Nuclear Power Plants - ICAPP'06, pp. 979-987. June 4-8, 2006, Reno, Nevada. American Nuclear Society, La Grange Park, Illinois.

Koley J, S Harikumar, SAH Ashraf, SK Chande and SK Sharma. 2006. "Regulatory practices for nuclear power plants in India." Nucl. Eng. Des. 236(7-8):894-913. Available at http://www.sciencedirect.com/science/article/B6V4D-4JJGCBX2/2/a6ab9bb64514770f269ffc36b62f9f33.

Kothamasu R, SH Huang and WH VerDuin. 2006. "System health monitoring and prognostics - a review of current paradigms and practices." Int. J. Adv. Manuf. Tech. 28:1012-1024.

Larson JM, L Christodoulou, JR Calcaterra, ML Dent, MM Derriso, WJ Hardman, J Wayne Jones and SM Rusa, Eds. 2005. Materials Damage Prognosis - Proceedings of a Symposium of the Materials Science and Technology 2004 Conference. Proceedings of Symposium, Materials Science \& Technology. TMS Publication, New Orleans, Louisiana.

Maeda N and K Tajima. 2004. "Research Activities for Nuclear Power Plant Promoted by PLEC, JPAEIC, Japan." JSME International Journal Series B 47(2):358-362.

Marcus GH. 2002. "Welcome Address." Nuclear Power Plant Life Management in a Changing Business World, Workshop Proceedings, 26-27 June 2000. June 26-27, 2000. Washington, DC. Prepared by the Expert Group on Nuclear Power Plant Life Management, Nuclear Energy Agency, Committee for Technical and Economic Studies on Nuclear Energy Development and Fuel Cycle, OECD Publishing, Paris, France. pp. 45-48.

Meyer CE and JM Giddens, Jr. 1994. "Westinghouse owners group life cycle management / license renewal program." IEEE Nuclear Science Symposium \& Medical Imaging Conference. October 30November 6, 1993. San Francisco, California. IEEE, Piscataway, New Jersey. pp. 1044-1047. 
Mingguan Z and D Yikang. 2008. "Prospects of PLiM in China." 2nd International Symposium on Nuclear Plant Life Management. October 15-18, 2007. Shanghai, China. International Atomic Energy Agency, Vienna. Paper \#IAEA-CN-155-003KS.

Nakagawa N, F Inanc, A Frishman, RB Thompson, WR Junker, FH Ruddy, AR Dulloo, JM Beatty and NG Arlia. 2006. "On-line NDE and structural health monitoring for advanced reactors." In Advanced nondestructive evaluation I, Parts 1 and 2, Proceedings Key Engineering Materials, pp. 321-323 and 234-239.

NDIA. 2006. "Final Report of the Systems Engineering Division, Integrated Diagnostics Committee." E-Prog II Electronic Prognostics Workshop. January 24-25, 2006. Miami, Florida. National Defense Industries Association.

NEA. 2000a. Nuclear Power Plant Life Management in a Changing Business World, Workshop Proceedings. June 26-27, 2000, Washington, DC. Nuclear Energy Agency, Organisation for Economic Co-operation and Development, Paris, France.

NEA. 2000b. Status Report on nuclear power plant life management. NEA/SEN/NDC(2000)6. Prepared by the Expert Group on Nuclear Power Plant Life Management, Nuclear Energy Agency, Committee for Technical and Economic Studies on Nuclear Energy Development and Fuel Cycle, OECD Publishing, Paris, France.

NEA. 2004. Research Efforts Related to Wire System Aging in NEA Member Countries. NEA/CSNI/R(2004)12. Nuclear Energy Agency, Committee on the Safety of Nuclear Installations, OECD Publishing, Paris, France.

NEA. 2005a. International Standard Problem 48, Analysis of 1:4-Scale Prestressed Concrete Containment Vessel Model Under Severe Accident Conditions. NEA/CSNI/R(2005)7. Nuclear Energy Agency, Committee on the Safety of Nuclear Installations, Lyon, France. April 6-7, 2005.

NEA. 2005b. Status Report on Developments and Co-operation on Risk-Informed In-Service-Inspection (RI-ISI) and Non-destructive Testing (NDT) Qualification in OECD/NEA Member Countries. NEA/CSNI/R(2005)9. Nuclear Energy Agency, Paris, France.

NEA. 2006a. Nuclear Power Plant Life Management and Longer-term Operation. NEA No. 6105. Nuclear Energy Agency, OECD Publishing, Paris, France.

NEA. 2006b. Report on the Survey on Primary Water Stress Corrosion Cracking (PWSCC) and Nickelbased Alloy: Final Version September 2006. NEA/CSNI/R(2006)8. Nuclear Energy Agency, Committee on the Safety of Nuclear Installations. Restricted.

NEA. 2007. Operating Plan (2006-2009). NEA/CSNI/R(2007)7. Nuclear Energy Agency, Committee on the Safety of Nuclear Installations, OECD Publishing, Paris, France.

Nei H. 2007. "Securing of Ageing Nuclear Power Plants Stability - Improvement of Inspection System and Promotion of Safety Research." Nuclear Safety Research Forum 2007. March 9, 2007. The Inoue Enryo Hall, Toyo University, Tokyo, Japan.

NRC. 1998a. Proc. of the 25th Water Reactor Safety Information Meeting. NUREG/CP-0162, Vol. 1-3. U.S. Nuclear Regulatory Commission, Washington, DC. 
NRC. 1998b. Proceedings of the 25th Water Reactor Safety Information Meeting. NUREG/CP-0162. U.S. Nuclear Regulatory Commission, Washington, DC.

NRC. 2005a. Generic Aging Lessons Learned (GALL) Report - Summary. NUREG-1801, Vol. 1, Rev. 1. Office of Nuclear Reactor Regulations, U.S. Nuclear Regulatory Commission, Washington, DC.

NRC. 2005b. Generic Aging Lessons Learned (GALL) Report - Tabulation of Results. NUREG-1801, Vol. 2, Rev. 1. Office of Nuclear Reactor Regulations, U.S. Nuclear Regulatory Commission, Washington, DC.

OECD. 1999. Glossary of Nuclear Power Plant Ageing. OECD Nuclear Energy Agency; Organisation for Economic Co-operation and Development, Issy-les-Moulineaux, France. ISBN 9789264058422.

PLiM. 2007. International PLiM Symposium 2007. International Atomic Energy Agency. Vienna, Austria. Accessed May 28, 2008 at http://www.iaea.org/OurWork/ST/NE/NENP/NPES/Activity/lcm_plim 2007.html.

Pusey HC, SC Pusey and WR Hobbs. 2005. "Essential Technologies for Successful Prognostics." In Proc. 59th MFPT Soc., April 18-21, 2005, Virginia Beach, Virginia. MFPT Publication.

Puttaswamy AL. 2002. "A Seminar on Indian Nuclear Power Programme." An International Journal of Nuclear Power 16(1-2):63-64.

Ramu A, MD Mangsulikar, M Bandyopadhyay, M Mohan Babu, KR Anilkumar, BL Sharma, S Bhattacharjee and U Ramamurty. 2006. "In-Service Inspection - A Vital Role in Monitoring \& Health Assessment of Nuclear Pressure Vessels, Piping \& Components at Tarapur Atomic Power Station- 1\&2, NPCIL." In Proceedings National Seminar on Non-Destructive Evaluation (NDE 2006), pp. 171-181. December 7-9, 2006, Hyderabad, India. Indian Society for Non-Destructive Testing, Hyderabad Chapter.

Rintamaa R, I Aho-Mantila and N Taylor. 2007. "New European initiative - NULIFE network for plant life management." Transactions, SMiRT 19. August 12-17, 2007. Toronto.

Roos E, K-H Herter and X Schuler. 2006. "Lifetime management of mechanical systems, structures and components in nuclear power plants." Int. J. Pres. Ves. Pip. 83:756-766.

Schmitz V, M Kroning, E Roos, D Blind and U Eisele. 2001. "Planning and use of condition-dependent NDT for the interaction between fracture mechanics and quantitative NDT." Nucl. Eng. Des. 206:291309.

Sekimura N. 2007. "Ageing Management for Safe Long Term Operation of Japanese Nuclear Power Plants - Strategy Maps for Safety Research Basis." Nuclear Safety Research Forum 2007. March 9, 2007. The Inoue Enryo Hall, Toyo University, Tokyo, Japan.

Shah BK. 2006. "In-service Inspection of Nuclear Power Plant Components." In Proceedings National Seminar on Non-Destructive Evaluation, December 7-9, 2006, Hyderabad, India. Indian Society for Non-Destructive Testing.

SMiRT-19. 2007. 19th International Conference on Structural Mechanics in Reactor Technology. Accessed May 28, 2008 at http://www.engr.ncsu.edu/smirt-19/. 
Song T-H, I-S Jeong, S-Y Hong and S-D Lee. 2006. "The Status of Plant Life Assessment Program of Wolsong Unit 1." In 2006 International Congress on Advances in Nuclear Power Plants - ICAPP'06, pp. 964-968. June 4-8, 2006, Reno, Nevada. American Nuclear Society, La Grange Park, Illinois.

Thompson DO and DE Chimenti, Eds. 1980-2007. Review of Progress in Quantitative Nondestructive Evaluation. AIP Conference Proceedings Series. Plenum.

Urmanov A. 2007. "Electronic prognostics for computer servers." 2007 53rd Annual Reliability and Maintainability Sympsoium, RAMS. January 22-25, 2006. Orlando, FL. DOI

10.1109/RAMS.2007.328047. Institute of Electrical and Electronics Engineers Inc., Piscataway, NJ. pp. $65-70$.

Weber HJ. 1995. "Role of nondestructive evaluation in civil aviation: historical development, current status, future developments." In SPIE Conference Proceedings, Vol. 2455, pp. 45-53. June 6-8, 1995, Oakland, California.

Wilkowski G, R Tregoning, P Scott and D Rudland. 2002. "Status of Efforts to Evaluate LOCA Frequency Estimates Using Combined PRA and PFM Approaches." 28th MPA-Seminar. October 2002. Universitaet Stuttgart, Germany. Materials Testing Institute.

Wogman NA, LJ Bond, AE Waltar and RE Leber. 2005. "The nuclear education and staffing challenge: Rebuilding critical skills in nuclear science and technology." J. Radioanal. Nucl. Chem. 263(1):137-143.

Yamamoto A, A Huerta, K Gott and T Koshy. 2007. "SCAP: the Nea project on stress corrosion cracking and cable ageing." NEA News 2007 25(1):18-21. 


\section{Appendix A}

\section{Information on the Population of Nuclear Power Plants World-wide}





\section{Appendix A}

\section{Information on the Population of Nuclear Power Plants World-wide}

\section{A.1 World Nuclear Power Reactors 2006-07 and Uranium Requirements}

\begin{tabular}{|c|c|c|c|c|c|c|c|c|c|c|c|}
\hline \multicolumn{12}{|c|}{17 October 2007} \\
\hline & \multicolumn{2}{|c|}{$\begin{array}{c}\text { Nuclear } \\
\text { Electricity } \\
\text { Generation } 2006\end{array}$} & \multicolumn{2}{|c|}{$\begin{array}{c}\text { Reactors } \\
\text { Operable } \\
\text { October } 2007 \\
\end{array}$} & \multicolumn{2}{|c|}{$\begin{array}{c}\text { Reactors Under } \\
\text { Construction } \\
\text { October } 2007\end{array}$} & \multicolumn{2}{|c|}{$\begin{array}{c}\text { Reactors } \\
\text { Planned } \\
\text { October } 2007\end{array}$} & \multicolumn{2}{|c|}{$\begin{array}{c}\text { Reactors } \\
\text { Proposed } \\
\text { October } 2007 \\
\end{array}$} & \multirow{2}{*}{$\begin{array}{c}\text { Uranium } \\
\text { Required } \\
2007 \\
\text { Tonnes } \\
\text { U }\end{array}$} \\
\hline & kWh & $\% \mathbf{e}$ & No. & MWe & No. & MWe & No. & MWe & No. & MWe & \\
\hline Argentina & 7.2 & 6.9 & 2 & 935 & 1 & 692 & 1 & 740 & 1 & 740 & 135 \\
\hline Armenia & 2.4 & 42 & 1 & 376 & 0 & 0 & 0 & 0 & 1 & 1000 & 51 \\
\hline Bangladesh & 0 & 0 & 0 & 0 & 0 & 0 & 0 & 0 & 2 & 2000 & 0 \\
\hline Belarus & 0 & 0 & 0 & 0 & 0 & 0 & 2 & 2000 & 0 & 0 & 0 \\
\hline Belgium & 44.3 & 54 & 7 & 5728 & 0 & 0 & 0 & 0 & 0 & 0 & 1079 \\
\hline Brazil & 13.0 & 3.3 & 2 & 1901 & 0 & 0 & 1 & 1245 & 4 & 4000 & 338 \\
\hline Bulgaria & 18.1 & 44 & 2 & 1906 & 0 & 0 & 2 & 1900 & 0 & 0 & 255 \\
\hline Canada* & 92.4 & 16 & 18 & 12595 & 2 & 1540 & 4 & 4000 & 2 & 2200 & 1836 \\
\hline China & 51.8 & 1.9 & 11 & 8587 & 5 & 4540 & 30 & 32000 & 86 & 68000 & 1454 \\
\hline $\begin{array}{l}\text { Czech } \\
\text { Republic }\end{array}$ & 24.5 & 31 & 6 & 3472 & 0 & 0 & 0 & 0 & 2 & 1900 & 550 \\
\hline Egypt & 0 & 0 & 0 & 0 & 0 & 0 & 0 & 0 & 1 & 1000 & 0 \\
\hline Finland & 22.0 & 28 & 4 & 2696 & 1 & 1600 & 0 & 0 & 1 & 1000 & 472 \\
\hline France & 428.7 & 78 & 59 & 63473 & 1 & 1630 & 0 & 0 & 1 & 1600 & 10368 \\
\hline Germany & 158.7 & 32 & 17 & 20339 & 0 & 0 & 0 & 0 & 0 & 0 & 3486 \\
\hline Hungary & 12.5 & 38 & 4 & 1826 & 0 & 0 & 0 & 0 & 2 & 2000 & 254 \\
\hline India & 15.6 & 2.6 & 17 & 3779 & 6 & 2976 & 10 & 8560 & 9 & 4800 & 491 \\
\hline Indonesia & 0 & 0 & 0 & 0 & 0 & 0 & 2 & 2000 & 0 & 0 & 0 \\
\hline Iran & 0 & 0 & 0 & 0 & 1 & 915 & 2 & 1900 & 1 & 300 & 143 \\
\hline Israel & 0 & 0 & 0 & 0 & 0 & 0 & 0 & 0 & 1 & 1200 & 0 \\
\hline Japan & 291.5 & 30 & 55 & 47577 & 2 & 2285 & 11 & 14945 & 1 & 1100 & 8872 \\
\hline Kazakhstan & 0 & 0 & 0 & 0 & 0 & 0 & 0 & 0 & 1 & 300 & 0 \\
\hline $\begin{array}{l}\text { Korea DPR } \\
\text { (North) }\end{array}$ & 0 & 0 & 0 & 0 & 0 & 0 & 1 & 950 & 0 & 0 & 0 \\
\hline $\begin{array}{l}\text { Korea RO } \\
\text { (South) }\end{array}$ & 141.2 & 39 & 20 & 17533 & 2 & 2000 & 6 & 7600 & 0 & 0 & 3037 \\
\hline Lithuania & 8.0 & 69 & 1 & 1185 & 0 & 0 & 0 & 0 & 2 & 3200 & 134 \\
\hline Mexico & 10.4 & 4.9 & 2 & 1310 & 0 & 0 & 0 & 0 & 2 & 2000 & 257 \\
\hline Netherlands & 3.3 & 3.5 & 1 & 485 & 0 & 0 & 0 & 0 & 0 & 0 & 112 \\
\hline Pakistan & 2.6 & 2.7 & 2 & 400 & 1 & 300 & 2 & 600 & 2 & 2000 & 64 \\
\hline Romania & 5.2 & 9.0 & 2 & 1310 & 0 & 0 & 2 & 1310 & 1 & 655 & 92 \\
\hline Russia & 144.3 & 16 & 31 & 21743 & 7 & 4920 & 8 & 9600 & 20 & 18200 & 3777 \\
\hline Slovakia & 16.6 & 57 & 5 & 2064 & 2 & 840 & 0 & 0 & 0 & 0 & 299 \\
\hline Slovenia & 5.3 & 40 & 1 & 696 & 0 & 0 & 0 & 0 & 1 & 1000 & 145 \\
\hline
\end{tabular}




\begin{tabular}{|c|c|c|c|c|c|c|c|c|c|c|c|}
\hline \multicolumn{12}{|c|}{17 October 2007} \\
\hline & \multicolumn{2}{|c|}{$\begin{array}{c}\text { Nuclear } \\
\text { Electricity } \\
\text { Generation } 2006\end{array}$} & \multicolumn{2}{|c|}{$\begin{array}{c}\text { Reactors } \\
\text { Operable } \\
\text { October } 2007\end{array}$} & \multicolumn{2}{|c|}{$\begin{array}{c}\text { Reactors Under } \\
\text { Construction } \\
\text { October } 2007\end{array}$} & \multicolumn{2}{|c|}{$\begin{array}{c}\text { Reactors } \\
\text { Planned } \\
\text { October } 2007\end{array}$} & \multicolumn{2}{|c|}{$\begin{array}{c}\text { Reactors } \\
\text { Proposed } \\
\text { October } 2007\end{array}$} & \multirow{2}{*}{$\begin{array}{c}\text { Uranium } \\
\text { Required } \\
2007 \\
\text { Tonnes } \\
\text { U }\end{array}$} \\
\hline & $\begin{array}{c}\text { Billion } \\
\text { kWh }\end{array}$ & $\%$ e & No. & MWe & No. & MWe & No. & MWe & No. & MWe & \\
\hline $\begin{array}{l}\text { South } \\
\text { Africa }\end{array}$ & 10.1 & 4.4 & 2 & 1842 & 0 & 0 & 1 & 165 & 24 & 4000 & 332 \\
\hline Spain & 57.4 & 20 & 8 & 7442 & 0 & 0 & 0 & 0 & 0 & 0 & 1473 \\
\hline Sweden & 65.1 & 48 & 10 & 9086 & 0 & 0 & 0 & 0 & 0 & 0 & 1468 \\
\hline Switzerland & 26.4 & 37 & 5 & 3220 & 0 & 0 & 0 & 0 & 1 & 1000 & 575 \\
\hline Thailand & 0 & 0 & 0 & 0 & 0 & 0 & 0 & 0 & 4 & 4000 & 0 \\
\hline Turkey & 0 & 0 & 0 & 0 & 0 & 0 & 0 & 0 & 3 & 4500 & 0 \\
\hline Ukraine & 84.8 & 48 & 15 & 13168 & 0 & 0 & 2 & 1900 & 20 & 27000 & 2003 \\
\hline $\begin{array}{l}\text { United } \\
\text { Kingdom }\end{array}$ & 69.2 & 18 & 19 & 11035 & 0 & 0 & 0 & 0 & 0 & 0 & 2021 \\
\hline USA & 787.2 & 19 & 104 & 99049 & 0 & 0 & 7 & 10180 & 25 & 32000 & 20050 \\
\hline Vietnam & 0 & 0 & 0 & 0 & 0 & 0 & 0 & 0 & 2 & 2000 & 0 \\
\hline WORLD** & 2658 & 16 & 439 & 372,002 & 33 & 26,838 & 94 & 101,595 & 222 & 193,095 & 66,529 \\
\hline
\end{tabular}

\section{Sources:}

Reactor data: WNA to $17 / 10 / 07$.

IAEA- for nuclear electricity production \& percentage of electricity (\% e) 5/07.

WNA: Global Nuclear Fuel Market (reference scenario) - for U. Includes first cores for new reactors.

- Operating $=$ Connected to the grid

- Building/Construction = first concrete for reactor poured, or major refurbishment under way

- Planned = Approvals, funding or major commitment in place, mostly expected in operation within 8 years, or construction well advanced but suspended indefinitely

- Proposed = clear intention or proposal but still without firm commitment. Planned and Proposed are generally gross MWe

- $\mathrm{TWh}=$ Terawatt-hours (billion kilowatt-hours), $\mathrm{MWe}=$ Megawatt net (electrical as distinct from thermal), $\mathrm{kWh}=$ kilowatt-hour.

NB: $66,529 \mathrm{tU}=78,458 \mathrm{t} \mathrm{U} 3 \mathrm{O} 8$

* In Canada, ‘construction' figure is 2 laid-up Bruce A reactors.

** The world total includes 6 reactors operating on Taiwan with a combined capacity of $4884 \mathrm{MWe}$, which generated a total of 38.3 billion $\mathrm{kWh}$ in 2006 (accounting for $20 \%$ of Taiwan's total electricity generation). Taiwan has two reactors under construction with a combined capacity of $2600 \mathrm{MWe}$.

\section{A.2 Nuclear Power Plants, World-Wide, Reactor Types}

Mainly pressurized water reactors (PWR) are used in the nuclear power plants world-wide $-61 \%$ according to the number, $65 \%$ according to the output - followed by boiling water reactors (BWR) $-23 \%$ according to the number, $23 \%$ according to the output. 


\section{A.3 Nuclear Power Plants, World-Wide, Reactor Types, 30 September 2007}

\begin{tabular}{lcc}
\hline & \multicolumn{2}{c}{ Operational } \\
\cline { 2 - 3 } \multicolumn{1}{c}{ Reactor Type } & Number & Electr. Net Output MW \\
\hline PWR & 265 & 243,218 \\
BWR & 94 & 85,044 \\
CANDU/D 2 O-PWR & 44 & 22,367 \\
GGR/AGR & 18 & 9,034 \\
RBMK & 16 & 11,404 \\
FBR & 2 & 690 \\
Total & $\mathbf{4 3 9}$ & $\mathbf{3 7 1 , 7 5 7}$ \\
\hline
\end{tabular}

From European Nuclear Soc Web site http://www.euronuclear.org/info/encylopedia/n/npp-reactortypes.htm

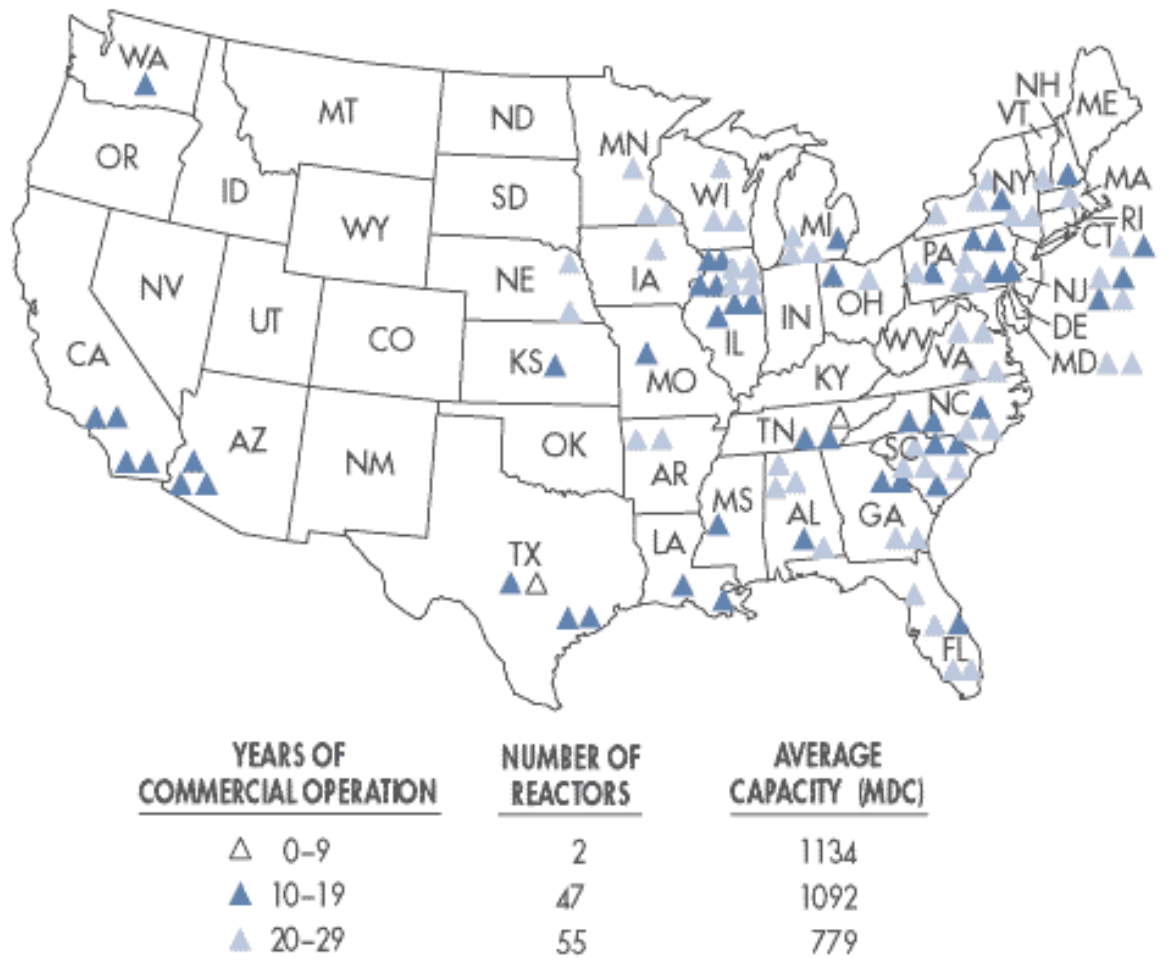

Note: There are no commercial reactors in Alaska or Hawaii. Calculated data as of 12/00.

(NRC site)

$\underline{\text { Home }}>\underline{\text { Nuclear Reactors }}>$ Operating Reactors $>$ List of Power Reactor Units List of Power Reactor Units

For more information, see Map of Power Reactor Sites and our annually published Information Digest, Appendix A. 


\begin{tabular}{|c|c|c|c|c|}
\hline $\begin{array}{c}\text { Plant Name } \\
\text { Docket Number }\end{array}$ & $\begin{array}{c}\text { Reactor } \\
\text { Type }\end{array}$ & Location & Owner/Operator & $\begin{array}{c}\text { NRC } \\
\text { Region }\end{array}$ \\
\hline$\frac{\text { Arkansas Nuclear } 1}{05000313}$ & PWR & $6 \mathrm{MI}$ WNW of Russellville, AR & $\begin{array}{l}\text { Entergy Nuclear } \\
\text { Operations, Inc. }\end{array}$ & 4 \\
\hline$\frac{\text { Arkansas Nuclear } 2}{05000368}$ & PWR & 6 MI WNW of Russellville, AR & $\begin{array}{l}\text { Entergy Nuclear } \\
\text { Operations, Inc. }\end{array}$ & 4 \\
\hline $\begin{array}{l}\text { Beaver Valley } 1 \\
05000334\end{array}$ & PWR & 17 MI W of McCandless, PA & $\begin{array}{l}\text { FirstEnergy Nuclear } \\
\text { Operating Co. }\end{array}$ & 1 \\
\hline$\frac{\text { Beaver Valley } 2}{05000412}$ & PWR & $17 \mathrm{MI}$ W of McCandless, PA & $\begin{array}{l}\text { FirstEnergy Nuclear } \\
\text { Operating Co. }\end{array}$ & 1 \\
\hline $\begin{array}{l}\text { Braidwood 1 } \\
05000456\end{array}$ & PWR & 24 MI SSW of Joilet, IL & $\begin{array}{l}\text { Exelon Generation Co., } \\
\text { LLC }\end{array}$ & 3 \\
\hline $\begin{array}{l}\text { Braidwood } 2 \\
05000457\end{array}$ & PWR & 24 MI SSW of Joilet, IL & $\begin{array}{l}\text { Exelon Generation Co., } \\
\text { LLC }\end{array}$ & 3 \\
\hline $\begin{array}{l}\text { Browns Ferry } 1 \\
05000259\end{array}$ & BWR & 10 MI NW of Decatur, AL & $\begin{array}{l}\text { Tennessee Valley } \\
\text { Authority }\end{array}$ & 2 \\
\hline$\frac{\text { Browns Ferry } 2}{05000260}$ & BWR & 10 MI NW of Decatur, AL & $\begin{array}{l}\text { Tennessee Valley } \\
\text { Authority }\end{array}$ & 2 \\
\hline$\frac{\text { Browns Ferry } 3}{05000296}$ & BWR & 10 MI NW of Decatur, AL & $\begin{array}{l}\text { Tennessee Valley } \\
\text { Authority }\end{array}$ & 2 \\
\hline$\frac{\text { Brunswick 1 }}{05000325}$ & BWR & 2 MI N of Southport, NC & Progress Energy & 2 \\
\hline$\frac{\text { Brunswick 2 }}{05000324}$ & BWR & 2 MI N of Southport, NC & Progress Energy & 2 \\
\hline$\frac{\text { Byron 1 }}{05000454}$ & PWR & 17 MI SW of Rockford, IL & $\begin{array}{l}\text { Exelon Generation Co., } \\
\text { LLC }\end{array}$ & 3 \\
\hline$\frac{\text { Byron 2 }}{05000455}$ & PWR & 17 MI SW of Rockford, IL & $\begin{array}{l}\text { Exelon Generation Co., } \\
\text { LLC }\end{array}$ & 3 \\
\hline $\begin{array}{l}\text { Callaway } \\
05000483 \\
\end{array}$ & PWR & $10 \mathrm{MI}$ SE of Fulton, MO & Ameren UE & 4 \\
\hline $\begin{array}{l}\text { Calvert Cliffs 1 } \\
05000317\end{array}$ & PWR & 40 MI S of Annapolis, MD & Constellation Energy & 1 \\
\hline$\frac{\text { Calvert Cliffs 2 }}{05000318}$ & PWR & 40 MI S of Annapolis, MD & Constellation Energy & 1 \\
\hline$\frac{\text { Catawba } 1}{05000413}$ & PWR & 6 MI NW of Rock Hill, SC & $\begin{array}{l}\text { Duke Energy Power } \\
\text { Company, LLC }\end{array}$ & 2 \\
\hline$\frac{\text { Catawba } 2}{05000414}$ & PWR & $6 \mathrm{MI}$ NW of Rock Hill, SC & $\begin{array}{l}\text { Duke Energy Power } \\
\text { Company, LLC }\end{array}$ & 2 \\
\hline $\begin{array}{l}\text { Clinton } \\
05000461\end{array}$ & BWR & $6 \mathrm{MI} \mathrm{E}$ of Clinton, IL & $\begin{array}{l}\text { Exelon Generation Co., } \\
\text { LLC }\end{array}$ & 3 \\
\hline $\begin{array}{l}\frac{\text { Columbia }}{\text { Generating Station }} \\
05000397\end{array}$ & BWR & 12 MI NW of Richland, WA & Energy Northwest & 4 \\
\hline$\frac{\text { Comanche Peak } 1}{05000445}$ & PWR & 4 MI N of Glen Rose, TX & $\begin{array}{l}\text { TXU Generating } \\
\text { Company LP }\end{array}$ & 4 \\
\hline $\begin{array}{l}\text { Comanche Peak } 2 \\
05000446\end{array}$ & PWR & 4 MI N of Glen Rose, TX & $\begin{array}{l}\text { TXU Generating } \\
\text { Company LP }\end{array}$ & 4 \\
\hline$\frac{\text { Cooper }}{05000298}$ & BWR & 23 MI S of Nebraska City, NE & $\begin{array}{l}\text { Nebraska Public Power } \\
\text { District }\end{array}$ & 4 \\
\hline
\end{tabular}




\begin{tabular}{|c|c|c|c|c|}
\hline $\begin{array}{c}\text { Plant Name } \\
\text { Docket Number }\end{array}$ & $\begin{array}{c}\text { Reactor } \\
\text { Type }\end{array}$ & Location & Owner/Operator & $\begin{array}{c}\text { NRC } \\
\text { Region }\end{array}$ \\
\hline$\frac{\text { Crystal River 3 }}{05000302}$ & PWR & 7 MI NW of Crystal River, FL & Progress Energy & 2 \\
\hline$\frac{\text { D.C. Cook } 1}{05000315}$ & PWR & 11 MI S of Benton Harbor, MI & $\begin{array}{l}\text { Indiana/Michigan Power } \\
\text { Co. }\end{array}$ & 3 \\
\hline$\frac{\text { D.C. Cook } 2}{05000316}$ & PWR & 11 MI S of Benton Harbor, MI & $\begin{array}{l}\text { IndianaMichigan Power } \\
\text { Co. }\end{array}$ & 3 \\
\hline$\frac{\text { Davis-Besse }}{05000346}$ & PWR & $21 \mathrm{MI}$ ESE of Toledo, $\mathrm{OH}$ & $\begin{array}{l}\text { FirstEnergy Nuclear } \\
\text { Operating Co. }\end{array}$ & 3 \\
\hline $\begin{array}{l}\text { Diablo Canyon 1 } \\
05000275\end{array}$ & PWR & $\begin{array}{l}12 \text { MI WSW of San Luis Obispo, } \\
\text { CA }\end{array}$ & $\begin{array}{l}\text { Pacific Gas \& Electric } \\
\text { Co. }\end{array}$ & 4 \\
\hline $\begin{array}{l}\text { Diablo Canyon 2 } \\
05000323\end{array}$ & PWR & $\begin{array}{l}12 \text { MI WSW of San Luis Obispo, } \\
\text { CA }\end{array}$ & $\begin{array}{l}\text { Pacific Gas \& Electric } \\
\text { Co. }\end{array}$ & 4 \\
\hline$\frac{\text { Dresden } 2}{05000237}$ & BWR & 9 MI E of Morris, IL & $\begin{array}{l}\text { Exelon Generation Co., } \\
\text { LLC }\end{array}$ & 3 \\
\hline$\frac{\text { Dresden } 3}{05000249}$ & BWR & 9 MI E of Morris, IL & $\begin{array}{l}\text { Exelon Generation Co., } \\
\text { LLC }\end{array}$ & 3 \\
\hline$\frac{\text { Duane Arnold }}{05000331}$ & BWR & 8 MI NW of Cedar Rapids, IA & $\begin{array}{l}\text { Florida Power \& Light } \\
\text { Co. }\end{array}$ & 3 \\
\hline$\frac{\text { Farley } 1}{05000348}$ & PWR & $18 \mathrm{MI}$ SE of Dothan, AL & $\begin{array}{l}\text { Southern Nuclear } \\
\text { Operating Co. }\end{array}$ & 2 \\
\hline$\frac{\text { Farley } 2}{05000364}$ & PWR & 18 MI SE of Dothan, AL & $\begin{array}{l}\text { Southern Nuclear } \\
\text { Operating Co. }\end{array}$ & 2 \\
\hline$\frac{\text { Fermi } 2}{05000341}$ & BWR & 25 MI NE of Toledo, $\mathrm{OH}$ & Detroit Edison Co. & 3 \\
\hline FitzPatrick & BWR & 8 MI NE of Oswego, NY & $\begin{array}{l}\text { Entergy Nuclear } \\
\text { Operations, Inc. }\end{array}$ & 1 \\
\hline $\begin{array}{l}\text { Fort Calhoun } \\
05000285\end{array}$ & PWR & 19 MI N of Omaha, NE & $\begin{array}{l}\text { Omaha Public Power } \\
\text { District }\end{array}$ & 4 \\
\hline $\begin{array}{l}\text { Ginna } \\
05000244\end{array}$ & PWR & 20 MI NE of Rochester, NY & Constellation Energy & 1 \\
\hline$\frac{\text { Grand Gulf } 1}{05000416}$ & BWR & 25 MI S of Vicksburg, MS & $\begin{array}{l}\text { Entergy Nuclear } \\
\text { Operations, Inc. }\end{array}$ & 4 \\
\hline $\begin{array}{l}\text { Hatch 1 } \\
05000321\end{array}$ & BWR & 11 MI N of Baxley, GA & $\begin{array}{l}\text { Southern Nuclear } \\
\text { Operating Co., Inc. }\end{array}$ & 2 \\
\hline$\frac{\text { Hatch } 2}{05000366}$ & BWR & 11 MI N of Baxley, GA & $\begin{array}{l}\text { Southern Nuclear } \\
\text { Operating Co., Inc. }\end{array}$ & 2 \\
\hline $\begin{array}{l}\text { Hope Creek 1 } \\
05000354\end{array}$ & BWR & 18 MI SE of Wilmington, DE & PSE\&G Nuclear & 1 \\
\hline$\frac{\text { Indian Point } 2}{05000247}$ & PWR & 24 MI N of New York City, NY & $\begin{array}{l}\text { Entergy Nuclear } \\
\text { Operations, Inc. }\end{array}$ & 1 \\
\hline$\frac{\text { Indian Point } 3}{05000286}$ & PWR & 24 MI N of New York City, NY & $\begin{array}{l}\text { Entergy Nuclear } \\
\text { Operations, Inc. }\end{array}$ & 1 \\
\hline$\frac{\text { Kewaunee }}{05000305}$ & PWR & 27 MI E of Green Bay, WI & Dominion Generation & 3 \\
\hline$\frac{\text { La Salle } 1}{05000373}$ & BWR & 11 MI SE of Ottawa, IL & $\begin{array}{l}\text { Exelon Generation Co., } \\
\text { LLC }\end{array}$ & 3 \\
\hline$\frac{\text { La Salle } 2}{05000374}$ & BWR & $11 \mathrm{MI}$ SE of Ottawa, IL & $\begin{array}{l}\text { Exelon Generation Co., } \\
\text { LLC }\end{array}$ & 3 \\
\hline
\end{tabular}




\begin{tabular}{|c|c|c|c|c|}
\hline $\begin{array}{c}\text { Plant Name } \\
\text { Docket Number }\end{array}$ & $\begin{array}{c}\text { Reactor } \\
\text { Type }\end{array}$ & Location & Owner/Operator & $\begin{array}{c}\text { NRC } \\
\text { Region }\end{array}$ \\
\hline$\frac{\text { Limerick } 1}{05000352}$ & BWR & 21 MI NW of Philadelphia, PA & $\begin{array}{l}\text { Exelon Generation Co., } \\
\text { LLC }\end{array}$ & 1 \\
\hline$\frac{\text { Limerick } 2}{05000353}$ & BWR & 21 MI NW of Philadelphia, PA & $\begin{array}{l}\text { Exelon Generation Co., } \\
\text { LLC }\end{array}$ & 1 \\
\hline$\frac{\text { McGuire } 1}{05000369}$ & PWR & $17 \mathrm{MI} N$ of Charlotte, $\mathrm{NC}$ & $\begin{array}{l}\text { Duke Energy Power } \\
\text { Company, LLC }\end{array}$ & 2 \\
\hline$\frac{\text { McGuire 2 }}{05000370}$ & PWR & 17 MI N of Charlotte, NC & $\begin{array}{l}\text { Duke Energy Power } \\
\text { Company, LLC }\end{array}$ & 2 \\
\hline$\frac{\text { Millstone 2 }}{05000336}$ & PWR & $\begin{array}{l}\text { 3.2 MI WSW of New London, } \\
\text { CT }\end{array}$ & Dominion Generation & 1 \\
\hline$\frac{\text { Millstone } 3}{05000423}$ & PWR & $\begin{array}{l}\text { 3.2 MI WSW of New London, } \\
\text { CT }\end{array}$ & Dominion Generation & 1 \\
\hline$\frac{\text { Monticello }}{05000263}$ & BWR & 30 MI NW of Minneapolis, MN & $\begin{array}{l}\text { Nuclear Management } \\
\text { Co. }\end{array}$ & 3 \\
\hline $\begin{array}{l}\text { Nine Mile Point } 1 \\
05000220\end{array}$ & BWR & $6 \mathrm{MI}$ NE of Oswego, NY & Constellation Energy & 1 \\
\hline$\frac{\text { Nine Mile Point } 2}{05000410}$ & BWR & $6 \mathrm{MI}$ NE of Oswego, NY & Constellation Energy & 1 \\
\hline$\frac{\text { North Anna 1 }}{05000338}$ & PWR & 40 MI NW of Richmond, VA & Dominion Generation & 2 \\
\hline$\frac{\text { North Anna 2 }}{05000339}$ & PWR & 40 MI NW of Richmond, VA & Dominion Generation & 2 \\
\hline$\frac{\text { Oconee } 1}{05000269}$ & PWR & 30 MI W of Greenville, SC & $\begin{array}{l}\text { Duke Energy Power } \\
\text { Company, LLC }\end{array}$ & 2 \\
\hline$\frac{\text { Oconee } 2}{05000270}$ & PWR & $30 \mathrm{MI}$ W of Greenville, SC & $\begin{array}{l}\text { Duke Energy Power } \\
\text { Company, LLC }\end{array}$ & 2 \\
\hline $\begin{array}{l}\text { Oconee } 3 \\
05000287\end{array}$ & PWR & $30 \mathrm{MI}$ W of Greenville, SC & $\begin{array}{l}\text { Duke Energy Power } \\
\text { Company, LLC }\end{array}$ & 2 \\
\hline$\frac{\text { Oyster Creek }}{05000219}$ & BWR & 9 MI S of Toms River, NJ & $\begin{array}{l}\text { Exelon Generation Co., } \\
\text { LLC }\end{array}$ & 1 \\
\hline$\underline{\text { Palisades }}$ & PWR & 5 MI S of South Haven, MI & $\begin{array}{l}\text { Entergy Nuclear } \\
\text { Operations, Inc. }\end{array}$ & 3 \\
\hline $\begin{array}{l}\text { Palo Verde } 1 \\
05000528\end{array}$ & PWR & 36 MI W of Phoenix, AZ & $\begin{array}{l}\text { Arizona Public Service } \\
\text { Co. }\end{array}$ & 4 \\
\hline$\frac{\text { Palo Verde } 2}{05000529}$ & PWR & $36 \mathrm{MI} \mathrm{W}$ of Phoenix, AZ & $\begin{array}{l}\text { Arizona Public Service } \\
\text { Co. }\end{array}$ & 4 \\
\hline $\begin{array}{l}\text { Palo Verde } 3 \\
05000530\end{array}$ & PWR & $36 \mathrm{MI}$ W of Phoenix, AZ & $\begin{array}{l}\text { Arizona Public Service } \\
\text { Co. }\end{array}$ & 4 \\
\hline $\begin{array}{l}\text { Peach Bottom 2 } \\
05000277\end{array}$ & BWR & 17.9 MI S of Lancaster, PA & $\begin{array}{l}\text { Exelon Generation Co., } \\
\text { LLC }\end{array}$ & 1 \\
\hline$\frac{\text { Peach Bottom } 3}{05000278}$ & BWR & 17.9 MI S of Lancaster, PA & $\begin{array}{l}\text { Exelon Generation Co., } \\
\text { LLC }\end{array}$ & 1 \\
\hline$\frac{\text { Perry } 1}{05000440}$ & BWR & $7 \mathrm{MI}$ NE of Painesville, $\mathrm{OH}$ & $\begin{array}{l}\text { FirstEnergy Nuclear } \\
\text { Operating Co. }\end{array}$ & 3 \\
\hline$\frac{\text { Pilgrim 1 }}{05000293}$ & BWR & 4 MI SE of Plymouth, MA & $\begin{array}{l}\text { Entergy Nuclear } \\
\text { Operations, Inc. }\end{array}$ & 1 \\
\hline$\frac{\text { Point Beach 1 }}{05000266}$ & PWR & 13 MI NNW of Manitowoc, WI & $\begin{array}{l}\text { FPL Energy Point } \\
\text { Beach, LLC }\end{array}$ & 3 \\
\hline
\end{tabular}




\begin{tabular}{|c|c|c|c|c|}
\hline $\begin{array}{c}\text { Plant Name } \\
\text { Docket Number }\end{array}$ & $\begin{array}{c}\text { Reactor } \\
\text { Type }\end{array}$ & Location & Owner/Operator & $\begin{array}{c}\text { NRC } \\
\text { Region }\end{array}$ \\
\hline$\frac{\text { Point Beach 2 }}{05000301}$ & PWR & 13 MI NNW of Manitowoc, WI & $\begin{array}{l}\text { FPL Energy Point } \\
\text { Beach, LLC }\end{array}$ & 3 \\
\hline$\frac{\text { Prairie Island } 1}{05000282}$ & PWR & 28 MI SE of Minneapolis, MN & $\begin{array}{l}\text { Nuclear Management } \\
\text { Co. }\end{array}$ & 3 \\
\hline$\frac{\text { Prairie Island } 2}{05000306}$ & PWR & 28 MI SE of Minneapolis, MN & $\begin{array}{l}\text { Nuclear Management } \\
\text { Co. }\end{array}$ & 3 \\
\hline$\frac{\text { Quad Cities 1 }}{05000254}$ & BWR & 20 MI NE of Moline, IL & $\begin{array}{l}\text { Exelon Generation Co., } \\
\text { LLC }\end{array}$ & 3 \\
\hline $\begin{array}{l}\text { Quad Cities 2 } \\
05000265\end{array}$ & BWR & 20 MI NE of Moline, IL & $\begin{array}{l}\text { Exelon Generation Co., } \\
\text { LLC }\end{array}$ & 3 \\
\hline $\begin{array}{l}\text { River Bend } 1 \\
05000458\end{array}$ & BWR & 24 MI NNW of Baton Rouge, LA & $\begin{array}{l}\text { Entergy Nuclear } \\
\text { Operations, Inc. }\end{array}$ & 4 \\
\hline$\frac{\text { Robinson 2 }}{05000261}$ & PWR & $26 \mathrm{MI}$ from Florence, $\mathrm{SC}$ & Progress Energy & 2 \\
\hline $\begin{array}{l}\text { Saint Lucie 1 } \\
05000335\end{array}$ & PWR & 12 MI SE of Ft. Pierce, FL & $\begin{array}{l}\text { Florida Power \& Light } \\
\text { Co. }\end{array}$ & 2 \\
\hline$\frac{\text { Saint Lucie } 2}{05000389}$ & PWR & 12 MI SE of Ft. Pierce, FL & $\begin{array}{l}\text { Florida Power \& Light } \\
\text { Co. }\end{array}$ & 2 \\
\hline$\frac{\text { Salem 1 }}{05000272}$ & PWR & 18 MI S of Wilmington, DE & PSE\&G Nuclear & 1 \\
\hline$\frac{\text { Salem 2 }}{05000311}$ & PWR & 18 MI S of Wilmington, DE & PSE\&G Nuclear & 1 \\
\hline $\begin{array}{l}\text { San Onofre } 2 \\
05000361\end{array}$ & PWR & 4 MI SE of San Clemente, CA & $\begin{array}{l}\text { Southern California } \\
\text { Edison Co. }\end{array}$ & 4 \\
\hline $\begin{array}{l}\text { San Onofre } 3 \\
05000362\end{array}$ & PWR & 4 MI SE of San Clemente, CA & $\begin{array}{l}\text { Southern California } \\
\text { Edison Co. }\end{array}$ & 4 \\
\hline$\frac{\text { Seabrook } 1}{05000443}$ & PWR & 13 MI S of Portsmouth, NH & $\begin{array}{l}\text { Florida Power \& Light } \\
\text { Co. }\end{array}$ & 1 \\
\hline$\frac{\text { Sequoyah } 1}{05000327}$ & PWR & 9.5 MI NE of Chattanooga, TN & $\begin{array}{l}\text { Tennessee Valley } \\
\text { Authority }\end{array}$ & 2 \\
\hline$\frac{\text { Sequoyah } 2}{05000328}$ & PWR & 9.5 MI NE of Chattanooga, TN & $\begin{array}{l}\text { Tennessee Valley } \\
\text { Authority }\end{array}$ & 2 \\
\hline $\begin{array}{l}\text { Shearon Harris 1 } \\
05000400\end{array}$ & PWR & 20 MI SW of Raleigh, NC & Progress Energy & 2 \\
\hline$\frac{\text { South Texas 1 }}{05000498}$ & PWR & 12 MI SSW of Bay City, TX & $\begin{array}{l}\text { STP Nuclear Operating } \\
\text { Co. }\end{array}$ & 4 \\
\hline $\begin{array}{l}\text { South Texas 2 } \\
05000499\end{array}$ & PWR & 12 MI SSW of Bay City, TX & $\begin{array}{l}\text { STP Nuclear Operating } \\
\text { Co. }\end{array}$ & 4 \\
\hline$\frac{\text { Summer }}{05000395}$ & PWR & 26 MI NW of Columbia, SC & $\begin{array}{l}\text { South Carolina Electric } \\
\& \text { Gas Co. }\end{array}$ & 2 \\
\hline$\frac{\text { Surry } 1}{05000280}$ & PWR & 17 MI NW of Newport News, VA & Dominion Generation & 2 \\
\hline $\begin{array}{l}\text { Surry } 2 \\
05000281\end{array}$ & PWR & 17 MI NW of Newport News, VA & Dominion Generation & 2 \\
\hline $\begin{array}{l}\text { Susquehanna 1 } \\
05000387\end{array}$ & BWR & 7 MI NE of Berwick, PA & PPL Susquehanna, LLC & 1 \\
\hline $\begin{array}{l}\text { Susquehanna 2 } \\
05000388\end{array}$ & BWR & 7 MI NE of Berwick, PA & PPL Susquehanna, LLC & 1 \\
\hline
\end{tabular}




\begin{tabular}{|c|c|c|c|c|}
\hline $\begin{array}{c}\text { Plant Name } \\
\text { Docket Number }\end{array}$ & $\begin{array}{c}\text { Reactor } \\
\text { Type }\end{array}$ & Location & Owner/Operator & $\begin{array}{c}\text { NRC } \\
\text { Region }\end{array}$ \\
\hline $\begin{array}{l}\text { Three Mile Island } 1 \\
05000289\end{array}$ & PWR & 10 MI SE of Harrisburg, PA & $\begin{array}{l}\text { Exelon Generation Co., } \\
\text { LLC }\end{array}$ & 1 \\
\hline$\frac{\text { Turkey Point } 3}{05000250}$ & PWR & 25 MI S of Miami, FL & $\begin{array}{l}\text { Florida Power \& Light } \\
\text { Co. }\end{array}$ & 2 \\
\hline $\begin{array}{l}\text { Turkey Point } 4 \\
05000251\end{array}$ & PWR & 25 MI S of Miami, FL & $\begin{array}{l}\text { Florida Power \& Light } \\
\text { Co. }\end{array}$ & 2 \\
\hline $\begin{array}{l}\text { Vermont Yankee } \\
05000271\end{array}$ & BWR & 5 MI S of Brattleboro, VT & $\begin{array}{l}\text { Entergy Nuclear } \\
\text { Operations, Inc. }\end{array}$ & 1 \\
\hline$\frac{\text { Vogtle 1 }}{05000424}$ & PWR & 26 MI SE of Augusta, GA & $\begin{array}{l}\text { Southern Nuclear } \\
\text { Operating Co. }\end{array}$ & 2 \\
\hline$\frac{\text { Vogtle 2 }}{05000425}$ & PWR & $26 \mathrm{MI}$ SE of Augusta, GA & $\begin{array}{l}\text { Southern Nuclear } \\
\text { Operating Co. }\end{array}$ & 2 \\
\hline$\frac{\text { Waterford 3 }}{05000382}$ & PWR & 20 MI W of New Orleans, LA & $\begin{array}{l}\text { Entergy Nuclear } \\
\text { Operations, Inc. }\end{array}$ & 4 \\
\hline$\frac{\text { Watts Bar 1 }}{05000390}$ & PWR & 10 MI S of Spring City, TN & $\begin{array}{l}\text { Tennessee Valley } \\
\text { Authority }\end{array}$ & 2 \\
\hline$\frac{\text { Wolf Creek } 1}{05000482}$ & PWR & 3.5 MI NE of Burlington, KS & $\begin{array}{l}\text { Wolf Creek Nuclear } \\
\text { Operating Corp. }\end{array}$ & 4 \\
\hline
\end{tabular}




\section{Appendix B}

\section{Draft}

\section{Overview Program Plan for Cooperation on Proactive Materials Degradation Management (PMDM) Research}

This draft plan was Compiled and Edited by Roger Staehle and Joe Muscara. 



\section{Appendix B}

\section{Draft}

\section{Overview Program Plan for Cooperation on Proactive Materials Degradation Management (PMDM) Research}

Based on meetings and contributions by attendees at:

- Snowbird Resort, Salt Lake city, Utah, USA August 16 and 19, 2005

- Japan Nuclear Energy Safety Organization, Tokyo, November 9-11, 2005

- Charleston, South Carolina, Mills House Hotel, May 11-13, 2006

and on

Individual submittals by prospective participants 


\section{Table of Contents}

1.0 Abstract $\quad x$

2.0 Executive summary $\quad x$

3.0 Introduction $\quad x$

4.0 Principal themes and guidelines for work plans $\mathrm{x}$

4.1 Proactivity and prediction long term $\quad x$

4.2 The evolution of SCC $\quad x$

4.3 The continua and applicability $\quad \mathrm{x}$

4.4 Interactions and complexity $\quad x$

$\begin{array}{ll}\text { 4.5 Statistical framework } & \mathrm{x}\end{array}$

5.0 Understanding and quantifying degradation of materials and components $\mathrm{x}$

5.1 Components $\quad x$

5.1.1 Steam generators and their environments $\quad \mathrm{X}$

5.1.2 Piping, welds $\quad x$

5.1.3 Socket welds and weldolets $\quad \mathrm{x}$

5.2 Materials $\quad x$

5.2.1 Cast stainless steel $\quad \mathrm{x}$

5.2.2 High Strength materials, bolting $\quad \mathrm{x}$

5.2.3 Low temperature creep cracks in steel $\quad \mathrm{x}$

5.3 Phenomena $\quad x$

5.3.1 SCC Precursors $\quad x$

5.3.2 SCC Initiation $\quad x$

5.3.3 SCC Propagation $\quad x$

5.3.4 Cold work: Surface and bulk $\quad$ x

5.3.5 Compounds and kinetics at grain boundaries $\quad \mathrm{x}$

5.3.6 Irradiation effects $\quad x$

5.3.7 Flow assisted corrosion, FAC $\quad x$

5.3.8 Fracture resistance $\quad x$

6.0 Mitigation, repair and replacement $x$

7.0 Nondestructive examination techniques for inservice inspection and monitoring $\mathrm{x}$

Appendix: Attendees at PMDM planning meetings $\quad \mathrm{x}$ 


\subsection{Abstract}

This overview research plan presents a number of summary work plans (WPs) for the conduct of international cooperative research that could lead to the implementation of Proactive Materials Degradation Management (PMDM) programs. These plans are aimed at developing knowledge and technology necessary to predict and manage materials degradation that can occur in light water reactors (LWRs). These plans provide a broad framework for the specific detailed research plans to be developed by the participants for the research they will contribute to the cooperation. One of the important aims of the WPs is to include the broadest possible consideration of conditions that include the current range of LWRs. Thus, a study of electrochemical potential would include oxygenated and deoxygenated conditions. A study of alloys would include Alloy 690TT, 600TT, 800, and stainless steel. The work plans are directed mainly to modes of degradation that have already shown to be the most aggressive, mainly stress corrosion cracking. In this consideration of relatively rapid penetration, flow assisted corrosion (FAC) is also important.

The scope of this international cooperative research program encompasses research and development of technology related to a) degradation mechanisms including the identification and quantification of important parameters and dependencies that affect the degradation initiation and growth, b) mitigation techniques to ameliorate or eliminate susceptibility to degradation, c) nondestructive examination techniques and continuous monitoring for early detection of degradation and its precursors, and d) effective repair/replacement techniques. 


\subsection{Executive Summary}

This overview research program plan describes work plans (WPs) aimed at developing knowledge and technology that would allow for the development and implementation of proactive materials degradation management (PMDM) programs for light water reactors (LWRs). This PMDM could be accomplished either by the development and implementation of mitigation processes or by the reliable inspection, monitoring and timely repair of susceptible components. These WPs represent recommendations from technical leaders in the world nuclear community for specific work that should be undertaken within the International Cooperative Research Program for Proactive Materials Degradation Management program ICRP-PMDM). These recommendations have been developed from participation by these world technical leaders in three meetings and from separate written inputs provided by several of them.

The ICRP-PMDM emphasizes stress corrosion cracking (SCC) as the most likely to produce significant degradation and the majority of the WPs reflect this emphasis. This emphasis on SCC is consistent with past experience.

The current overview research plan contains 46 WPs for assessing degradation of materials, 7 for development of mitigation strategies, and 5 for nondestructive examination (NDE) technique developments. The latter two categories are presented broadly, and many more research projects can fit under these categories.

Emphasis is also placed on the WPs to address the continua of which they are a part. For example, rather than a WP emphasizing only the standard BWR RCS temperature of $288^{\circ} \mathrm{C}$, the ICRP-PMDM encourages research programs to include a broader range of temperature such as both PWR and BWR temperatures. Such an approach provides a broader understanding applicable to both designs and connects already existing data. Other such continua include $\mathrm{pH}$, electrochemical potential, chemical species, alloy composition, alloy structure, cold work, irradiation, and stress.

The ICRP-PMDM also recognizes that, while it is desirable to evaluate degradation initiation and progression over 60 years of reactor operation, no SCC phenomena known require the longer times to occur. Rather, it appears that such times will result from the necessity of conditions, which are required for SCC, to develop; such conditions are in the general province of aging that is associated with local metallurgy, surface deposits, and solid state diffusion. In the past such processes have been associated, for example, with the accumulation of deposits inside drilled hole crevices of tube supports. Until such deposits accumulated, the necessary chemicals to produce SCC could not accumulate; only then, after two preliminary steps could SCC develop. The period over which such preliminary processes develop before SCC could start is called the "precursor period" in this overview research plan.

The ICRP-PMDM also recognizes that prediction depends both on a sound starting point and a solid scientifically based avenue for projecting predictions. Thus, experiments in the ICRP-PMDM will utilize alloys such as Alloy 600MA and similar early materials for a basis; the prediction depends on the projections from this point.

A review of recommendations for research programs proposed by the international community at three coordination workshops for the ICRP-PMDM and of the additional individual inputs indicates that: 
1. There is a body of excellent science and engineering that has been recommended for work plans.

2. The organizations who have participated in recommending these plans represent major nuclear countries.

3. There are clear avenues for developing the knowledge to predict and quantify future degradation.

4. There are also sound avenues for developing mitigations for possible degradations as well as for developing advanced NDE programs.

5. There is also significant personal commitment on the part of those who have actively participated in meetings and provided input to this overview cooperative research program plan. 


\subsection{Introduction}

Reactor operating experiences indicate that a proactive approach to materials degradation management would be preferred to the reactive approaches of the past.

The NRC has been pursuing a two-step approach to facilitate implementation of proactive materials degradation management programs.

The first step was to identify materials and components that could realistically be expected to degrade in the future. This first step has been accomplished with the completion of a Phenomena Identification and Ranking Table (PIRT) study by eight international experts. Their work was published as NUREG/CR6923, "Expert Panel Report on Proactive Materials Degradation Assessment."

The second step is to assemble an international cooperative research group and program to develop the knowledge and technology to allow implementation of Proactive Materials Degradation Management (PMDM) programs.

Given that the components susceptible to future degradation have been identified in the NRC proactive materials degradation assessment study and other studies, PMDM of susceptible components could be accomplished by two approaches:

a. Take actions to either eliminate or mitigate the susceptibility of components to degradation, and/or

b. Inspect, monitor, and conduct timely repair or replacement of susceptible components.

Implementation of either approach will require certain knowledge and technology. Management of degradation using the first approach of eliminating or mitigating the susceptibility, will require knowledge of degradation mechanisms and a quantitative understanding of the important parameters and dependencies that affect the degradation mechanisms. Degradation management using the second approach of inspection, monitoring, and timely repair will require knowledge and technology such as effective inservice inspection (ISI) and continuous crack monitoring techniques in addition to crack initiation and growth rate information for implementing effective timing and frequency of inspections and timely repairs. Also effective (and-benign) welding and repair techniques and processes are needed.

This overview program plan presents preliminary work plans (WP) for different subjects that have been developed as a part of organizing the ICRP-PMDM. The WPs may be used by prospective participants in the ICRP-PMDM to develop detailed research proposals for the research that they will conduct and contribute to the cooperation. Input for these WPs has been provided by experts in the world water reactor community as individual write-ups and through group discussion and writing at three working meetings at which the ICRP-PMDM was discussed:

- Snowbird Resort, Salt Lake city, Utah, USA August 16 and 19, 2005,

- Tokyo, Offices of Japan Nuclear Energy Safety Organization, November 9-11, 2005, and

- Charleston South Carolina, Mills House Hotel, May 11-13, 2006. 
A list of attendees at these meetings is given in the Appendix.

During these three meetings the ideas of these work plans were developed in active floor discussions and breakout sessions. Some of the ideas in these work plans were also developed during deliberations for the NRC proactive materials degradation assessment study (NUREG/CR-6923) over the period 2004-2005. Many work plans were prepared by international contributors in extensive detail and submitted to Muscara (NRC) before and after the three PMDM coordination meetings. In this overview research plan, the essences of these work plans are given.

The principal objective of the WPs described in this overview research program plan is to provide a framework from which individual participants can develop detailed program plans for the research they will conduct and contribute to the cooperation. The subjects of the WPs are those that the international community believes should be incorporated in the ICRP-PMDM. Additional WPs under the broad areas addressed in this overview program plan can be suggested by prospective participants and incorporated in the plan.

Section 4.0 describes the central issues for developing an understanding of degradation as related to initiation of SCC, propagation of SCC, and aging processes. SCC is emphasized since experience and proactive materials degradation assessment studies have shown that this mode is the most likely to lead to unexpected and rapid degradation. Some other rapid processes, e.g. fast fracture and FAC are also considered.

Section 5.0 describes the specific draft WPs where analysis and experiments are proposed for developing an understanding of degradation processes and quantitative relationships of the important parameters and dependencies that affect degradation initiation and progression. This understanding and relationships will provide bases for a) proactive prediction of potential future degradation of water reactor components, $b$ ) developing mitigating actions and techniques to reduce or eliminate the susceptibility of components to the potential degradation, and c) for implementing timely inspection and replacement of components.

Section 6.0 describes specific WPs for developing mitigation and repair/replacement strategies. Section 7.0 describes specific WPs for developing nondestructive examination (NDE) techniques for ISI and monitoring. 


\subsection{Principal themes and guidelines for work plans}

The purpose of this section is to describe the expected scopes and guidelines for the WPs in Section 5 related to developing an understanding of degradation processes and to identifying and quantifying the important parameters and dependencies that affect degradation initiation and growth. Each of the work plans emphasizes a small but critical quantity of work aimed at the overall goals stated above. However, each work plan and the subsequent detailed research plans developed by individual participants should consider guidelines in this section.

\subsection{Proactivity and long term predictions}

The overall goal of the ICRP-PMDM is to allow implementation of proactive actions to effectively manage potential future degradation of materials. As such, each WP and subsequent research plans should consider:

1. Assuring that the basis for future understanding and prediction is credible and quantitative, i.e. predicting from an uncertain basis would not provide a credible prediction.

2. The avenue for developing knowledge and prediction is based on good fundamental science since predicting decades into the future needs some authoritative support because there may be no base of reactor experience on which to calibrate the predictions.

3. Using some of the past data from materials now in use, e.g. Alloy 600MA, to calibrate predictions.

4. Understanding and predicting degradation over time periods up to 60 years of reactor operation under past and future operating conditions and environments.

5. Operating conditions are expected to become more intense as operators desire more power output. This direction implies higher temperatures, higher flows, and longer cycles. Further, pressure will increase to minimize time and frequency of inspections.

\subsection{The evolution of SCC}

A major part of the research under Section 5 emphasizes quantifying SCC since, based on past experience, it is the most likely mode of degradation that leads to perforation or disabling of components.

The NRC proactive materials degradation assessment report (NUREG/CR-6923) presents detailed discussions on the evolution of SCC. Figure 1, taken from that report, describes schematically the evolution of SCC. This figure includes the following stages: 


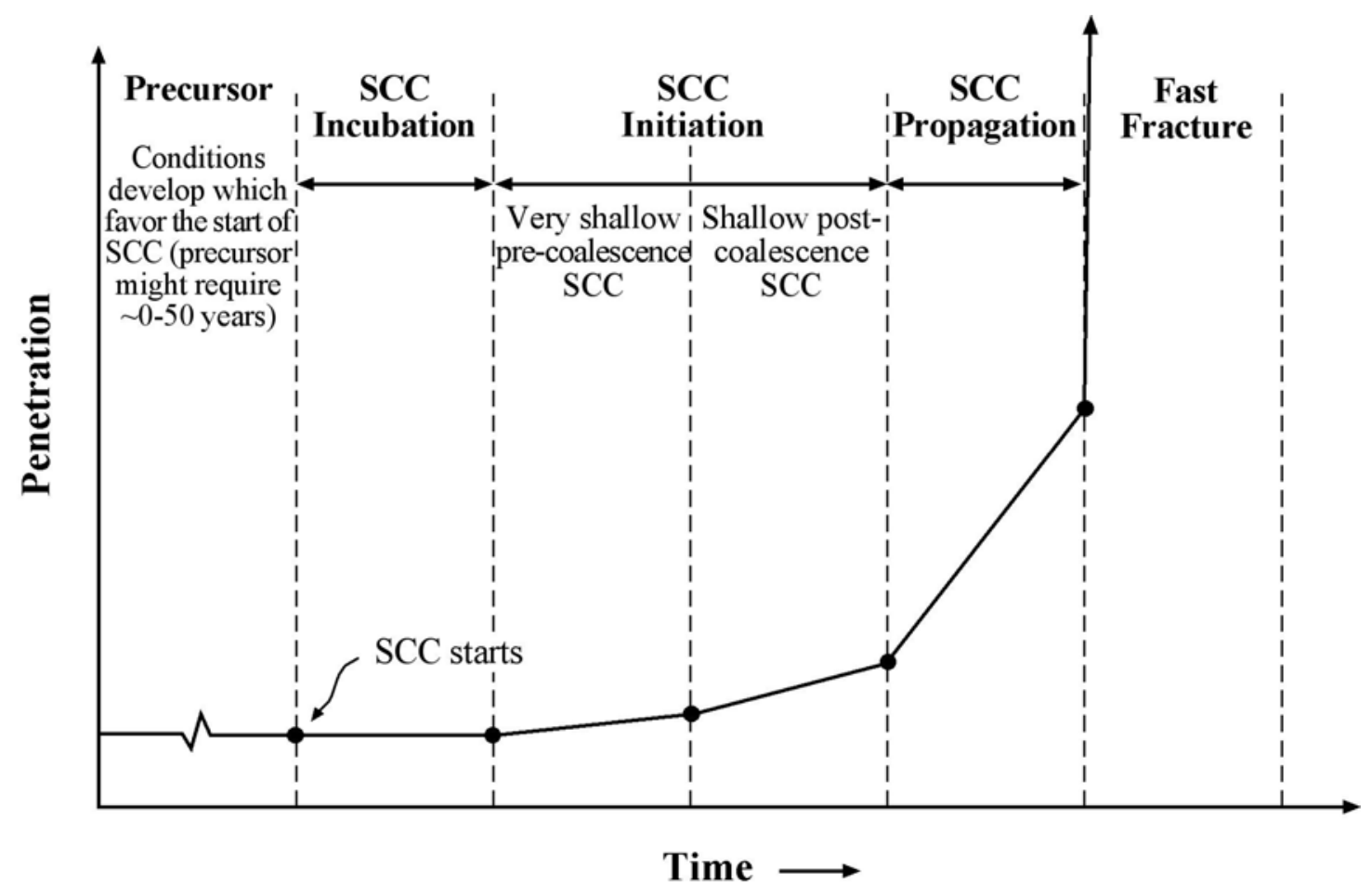

Figure 1 Schematic view of penetration vs. time for the six stages of SCC

1. Precursor: The precursor stage is the time during which conditions for the initiation of SCC develop. During this precursor period the processes that occur have nothing to do with the evolution of the SCC itself. During the precursor period, the principal processes that prepare conditions for subsequent SCC might include changing the surface chemistry in an adjacent deposit, changing the grain boundary chemistry due to thermal or irradiation processes, surface mechanical abuse, adsorbing species that favor absorption of hydrogen, or changing local stresses due to accumulation of constrained corrosion products. Precursor times vary for different degradation occurrences: No precursor as is the cases for FAC or LPSCC; relatively short precursors such in the case for most of the SCC in steam generators associated with the buildup of deposits and chemicals in superheated crevices; and long precursors such as those cases where tens of years are required before the necessary conditions are present for SCC to start.

2. Incubation: Here, the earliest processes occur that lead specifically to the beginning of SCC, but these are not readily detected. These processes may involve absorbing hydrogen, changing the properties of the passive film, diffusion of environmental species into grain boundaries, intergranular corrosion, or relative enrichment/depletion of alloy species.

3. Early initiation: These processes are those involved with the formation of very short SCC sometimes in "colonies" which are typically called "pre-coalescence SCC." Not all SCC submodes exhibit this step.

4. Later initiation: In the "later initiation" step the small SCC begin to coalesce and the local stress begins to play a specific role in continued coalescence and lengthening. Typically low rates are observed but higher than that of the small initial SCC. 
5. Propagation: In propagation, a generally single SCC develops and the velocity is typically ten times or more than that of the SCC in "later initiation" step.

6. Fast fracture: Here, the SCC is sufficiently deep that the prevailing local stresses produce fast fracture.

Some general comments on the stages of initiation and propagation:

1. The stages through "later initiation" tend to be chemically dominated and are directly related to perforation in thin sections such as SG tubes.

2. The "propagation" stage tends to be less dominated by external environments and is more dominated by general crack tip chemistry. Propagation dominated conditions tend to be more relevant to thick sections. However, initiation cannot be so readily dismissed

3. While it is usually presumed that the initiation stage is easily, although slowly overcome, this is not always true and some SCC processes, e.g. in cold worked primary piping, may be inhibited at the initiation stage.

4. The steps portrayed in Figure 1 apply to both intergranular SCC and transgranular SCC. However, in LWRs most of the SCC has been intergranular.

5. The characteristics of existing SCC indicate that it is not likely that it should require more than about 10 years for full initiation and propagation although very low crack velocities have been measured. It is more likely that long times are associated with long precursor times related to aging where thermal diffusion, accumulation of surface chemistries, change in alloy structure and similar processes that depend on long times are involved. (Ref. NUREG/CR-6923, Appendix B-15)

Research in the ICRP-PMDM program can beneficially be directed to any or a combination of the six steps in Figure 1 where more knowledge and quantification is needed for prediction or where there may be slow steps that can be exploited to prevent the overall development of SCC. The precursor step is one of the most fruitful for investigating long times before SCC reaches the fast fracture step.

\subsection{The continua and applicability}

An important aim of the ICRP-PMDM is that the research findings be broadly applicable, e.g. to various types of water reactors including PWR, BWR, CANDU, and VVVRs and where these are produced by various manufacturers and used by different utilities. This general mandate is not to suggest that each WP or participants' research plans "be all things to all people;" but rather, where possible, multiple materials or multiple environments should be considered.

The "broad applicability" mandate also produces a great benefit in that it produces connections among sets of data where the quantitative patterns can be compared, contrasted, and permit synergistically derived predictions. Such broader bases provide further credibility to analytical models. 
This "broad applicability" suggests that the WPs and research plans consider, where possible, the following continua:

1. Electrochemical potential: A specific example here is the possible connection between extensive data for the effect of potential on crack velocity obtained for BWR normal water chemistry (NWC) applications and for PWR primary water chemistry applications. By conducting experiments from either end of the potential scale typical of these reactor types but extending the experiments into the domain of electrochemical potentials of the other, both applications benefit. Such a connection also permits direct application of data to the secondary side of PWR steam generators (SGs) and to hydrogen water chemistry (HWC) for BWRs.

2. $\mathrm{pH}$ at temperature: Somewhat different $\mathrm{pHs}$ exist on the primary side of PWRs, the reactor coolant system (RCS) of BWRs, the secondary side of PWRs, ad the primary side of CANDUs. Further, pHs in crevices are generally known but are also associated with varying concentrations of more concentrated electrolytes. Since the formation of protective films depends so closely to the $\mathrm{pH}$, developing $\mathrm{pH}$ continua in the WPs would be valuable similar to such continua of potential.

3. Concentrations of species: In the bulk electrolytes the concentrations of impurity and intentionally added species are generally low according to guidelines for water chemistry. However, in superheated crevices and with deposits on surfaces, local concentrations, especially of impurity species, increase. Concentrations of impurity species inside SCC also seems to increase owing to effects of potential gradients on migration. Regardless, the continua of concentrations of species need to be considered as conditions vary among reactor applications.

4. Alloy composition: All of the LWR reactor types utilize most of their structural materials from the Fe$\mathrm{Cr}-\mathrm{Ni}$ alloy system, sometimes in similar or somewhat different heat treatments. Also, the welding alloys and cast alloys come from this system. Thus, VVVR data should be applicable to primary piping; alloy 800 data should be applicable to stainless steels and to high nickel alloys. e.g. lead studies show such connections. LPSCC is known to occur in stainless steels. While some of these connections are fragmentary, sparse data suggest either connections or legitimate boundaries.

5. Alloy structure: Elements of alloy structure that form continua include grain size, sensitization, wrought and weld structures. There are well known dependencies of SCC on grain size although some of the results from studies of SCC in LWRs exhibit opposite dependencies. Sensitization is known to inhibit some of the submodes of SCC, e.g. LPSCC; why sensitization exerts such effects is not clear but there is an important continuum of degree of sensitization. It appears that anisotropy provides another continuum associated with the SCC of alloys.

6. Cold work: Both initiation and propagation exhibit strong dependencies on cold work up to 20-30\%. Further, cold work on the surface and in the bulk are often different owing to such factors as surface abuse or machining effects. Cold work is often the difference between significant SCC and not. Increasing cold work produces SCC in Alloy 690TT exposed to pure water. Cold work arises in welding as well as in fabrication of complex geometries such as bends. Further, it appears that many of the effects of cold work are similar to effects of irradiation or higher strength achieved by heat treatments. 
7. Irradiation: Irradiation is not pertinent to all locations in the primary and secondary systems. However, it is clear that irradiation accelerates SCC, e.g., IASCC. It is also clear that there is some connection among cold work, alloy strength, and irradiation. Where applicable, this continuum of irradiation should be considered.

8. Temperature: The range of temperatures of interest to LWR performance includes 50 to $350^{\circ} \mathrm{C}$. In the full power operating range temperatures from $200-350^{\circ} \mathrm{C}$ range are relevant. In these ranges, both $1 / \mathrm{T}$ patterns apply as do bi-modal patterns of both + and - slopes on the 1/T correlations depending on the water chemistry and material. This bi-modal option means that extrapolations should be carried out with caution. Further, it means that some more robust explanations of the bimodal patterns are needed.

9. Stress: Both initiation and propagation depend strongly on stress with exponents in the range of 4 depending broadly on other factors. Further, stresses of direct application to SCC are less frequently the calculated applied stresses but more likely from residual stresses. Also, stresses seem to interact differently with initiation than propagation although the criteria for such transitions are not clear. Stresses, which are applicable to SCC propagation, often vary greatly within the component. The stress continuum is important as it includes both applied stresses and residual stresses, the latter of which is often the dominating factor of stress.

Within the domain of the stress continuum other stress-related parameters are important to understanding degradation:

\section{a. Mean stress.}

b. R ratio including what is called "ripple" stresses, which have been shown to produce important accelerative effects with small differences in magnitude in the maximum and minimum stresses.

c. Periodic loading and unloading. This may be a form of "ripple" effect but this is not clear.

d. Cyclic frequency where frequencies below $1 \mathrm{~Hz}$ seem to be more accelerative for both initiation and propagation.

e. Slow constant straining.

f. Stress intensifications for geometrical reasons.

Considering the stress continuum is complicated by the lack of certainty of residual stresses and the fact that the intensity of SCC so greatly depends on the total stress at the site of the SCC advance. It is important to establish reliable estimates of magnitudes and directions for the local sum of applied and residual stresses.

Further, regarding residual stresses, they exist at surfaces as result of surface abuse, along with local cold work; and they vary through the bulk and influence the course of propagation.

While less frequent, the contribution of corrosion products to stresses inside SCC or inside constricted crevices have been shown to be significant. Such a situation could produce the "denting" phenomenon at the tops of tubesheets even with 690TT alloy tubes. 
Finally, the continuum of stress also includes that between SCC and CF or between static loads and fully cyclic loads. From a design point of view there is no clear fundamentally based and quantitative connection between the two. Nonetheless this is an important continuum.

\subsection{Interactions and complexity}

Starting from the point of view of the desire to incorporate various continua into experimental and analytical work aimed at predicting degradation, the interaction of these continua should also be considered. Considerations of such complexity are relevant to engineering applications; however, remaining focused on the continua provides good bounding conditions.

Certain complexities should be considered in the ICRP-PMDM. Such complexities should remain with the judgment of the individual investigators and discussed in the individual research plans developed by the participants.

\subsection{Statistical framework}

In developing an understanding of degradation and predicting the times to the occurrence of future degradation, it is important to recognize that such predictions cannot be deterministic and must acknowledge the inherent statistical nature of degradation. Thus, there will always be a "first failure" from any group of components. The evolution of such degradation always continues and an increasing number of components fails. There is rarely any basis for the concept of a "bad heat." Thus, some of the PMDM research needs to address the fundamental basis for the dispersion of degradation occurrences as well as addressing the mean values. Such first failures are often unexpected. 


\subsection{Understanding and quantifying dependencies for degradation of materials and components}

The purpose of this section is to present specific topics and WPs for research on materials which are directed toward developing an understanding of degradation mechanisms and identifying and quantifying the important parameters and their dependencies as they affect degradation initiation and propagation in LWRs. Contributions for topics of interest and for the WPs were presented in various of the PMDM planning meetings in Snowbird, Tokyo, and Charleston as well as in the NRC proactive materials degradation assessment report (NUREG/CR-6923) and separate submittals to Muscara (NRC). An objective of the work plans here is to develop understanding and predict some aspect of critical degradation before it occurs over long times.

Since no LWR has performed for long times exceeding 30-40 years and since some plants are still in the range of 20-40 years, the predictions here start from the basis of present knowledge, e.g. the behavior of Alloy 600MA, and project for longer times based largely on reasonable physical principles.

Those who have recommended the topics and writeups for Sections 5, 6, and 7 are world experts (See the Appendix for participants in PMDM meetings) who are broadly experienced in nuclear power and therefore have substantial insights into the processes that should be considered for developing the necessary knowledge, predictions, and technology. The descriptions of these contributions for the WPs of this overview research program plan for international cooperation are relatively short and give the essences of the discussions and submittals by various authors.

\subsection{Components}

\subsubsection{Steam generators and their environments}

Consideration of degradation in modern steam generators (SGs) is dominated by the following:

1. Tubes are fabricated of Alloys 690TT, 800, 600TT, and stainless steels. Tubes used in horizontal steam generators are fabricated from stainless steels.

2. Tube supports are no longer drilled holes with flow holes but rather line contact supports using either broached holes or "egg crate" designs.

3. Field data and laboratory studies have shown that all of the advanced alloys used for tubing are prone to SCC in lead and lower valence sulfur species. Lead species have been shown to concentrate on surfaces and in cracks of steam generator tubes despite the low concentrations, in the range of $10 \mathrm{ppt}$, in feed water. Low valence sulfur species result from a reaction between hydrazine and sulfate, and this reaction has also been confirmed. The question is not whether such degradation occurs, but why it is not occurring more extensively.

4. The answer to why not more such SCC is occurring seems to be related to conditions that produce local insolubilities through the formation of compounds of $\mathrm{Pb}$ or $\mathrm{S}$ with other species thereby lowering the chemical activities. 
5. The joint at the tube to tubesheet intersection remains prone to denting owing to the low alloy steel used for the tubesheet and the small but significant crevice.

6. The alloys in item 1 above are generally more resistant to LPSCC than Alloy 600MA. However, laboratory testing shows that Alloy 690TT is not totally resistant to SCC especially with increasing amounts of cold work.

7. In the presence of lead, alloys with higher chromium, including Alloy 800 and Alloy 690TT exhibit a scaling reaction unlike the lower chromium alloys, such as Alloy 600MA. The importance of this scaling to crack growth and denting have yet to be established.

\subsubsection{Introduction to proposed work plans (WPs)}

Steam generators in recirculating units contend with two slightly different bulk environments on the primary and secondary side of tubes with approximately $1 \mathrm{~mm}$ wall. The primary and secondary sides differ in the following aspects, which are important to degradation:

1. The concentration of hydrogen in the bulk water on the primary side is about 2 ppm; whereas, on the secondary side is about $1 \mathrm{ppb}$. This difference accounts for about $200 \mathrm{mV}$ of electrochemical potential higher on the secondary side. This difference is quite significant from a degradation point of view.

2. The average temperature on the primary side is about $25^{\circ} \mathrm{C}$ higher than the average temperature on the secondary side. In general this difference accounts for a factor of about 20x in rates of stress corrosion cracking.

3. Hydrazine, $\mathrm{N}_{2} \mathrm{H}_{4}$, is used on the secondary side to minimize the concentration of oxygen. The hydrazine also reduces sulfate impurities to lower valences including to -2 , which is particularly aggressive both to localized corrosion and to SCC, including for Alloy 690TT.

4. Tube support and tube sheet crevices on the secondary side are locations where the local environments are superheated and lead to concentrating of impurities.

5. At the crevices at the top of the tubesheet the locally concentrated solution can corrode the low alloy tube sheet and may eventually produce denting and significant stresses in addition to those present owing to the expansion.

6. The crevices at tube supports, while now having a line contact geometry, still accumulate deposits, which will exacerbate the accumulation of aggressive chemicals, including lead and low valence sulfur. It is not clear how $\mathrm{Pb}$ and $\mathrm{S}$ accumulate in such geometries and whether local concentrations or chemical forms are adequate to produce SCC.

7. The gradual expansion at the TTS raises stresses and introduces cold work both of which accelerate SCC. 
8. Actions of the anti-vibration bars produce some wear and fretting thereby producing some penetration over time.

9. The outside surfaces of tubes are prone to being scratched with the result of local cold work, which has been shown to accelerate SCC on the free span for Alloy 600MA and is also possible to occur in Alloy 690TT.

\subsubsection{WP: Improving the boundaries on a recommended ECP/pH zone for minimizing SG tube degradation}

\section{Background}

Many of the degradation phenomena are now known to depend, among other variables, strongly on the electrochemical variables of potential and $\mathrm{pH}$. Such dependencies relate directly to the oxygen, hydrogen, hydrazine, and flow of environments. To date experimental and theoretical work has been carried out and shows that these dependences can be used to define the intensity of degradation over ranges of operation of the major SG alloys including Alloys 800, 600, 400 and 690. These maps can define optimum conditions for operation of plants.

\section{Objective of WP}

Extend work to refine patterns and boundaries for important alloys, impurities, and surface conditions such as deposits and crevices.

\section{$\underline{\text { 3. Work outline }}$}

Work will be undertaken to characterize and rationalize effects of lead, chlorides, sulfates ( +6 valence), and sulfide (-2 valence) on the patterns and rates of degradation. Analytical and experimental work will aim at increased precision of the topography of degradation.

\subsubsection{WP: Define electrochemical properties of line contact relevant to secondary side tube supports.}

\section{$\underline{1 . \text { Background }}$}

The action of impurities in the older drilled hole design involved concentration in the small space between the OD of the tube and the ID of the drilled hole. Flow was directed through flow holes. The superheat then caused boiling in this restricted geometry with the impurities remaining. The extent to which deposits form in line contact geometries of both egg crate and broached holes is not known nor has it been studied significantly with respect to accumulation of impurities. Such information is particularly important for understanding the role of lead and low valence sulfur as these impurities must first accumulate before they can exert their destructive degradation on such alloys as 800,690 , and stainless steel. 


\section{Objective of WP}

Characterize the rate of depositing oxides and other materials, such as silicates, and then characterize properties that affect accumulation of impurities.

\section{$\underline{\text { 3. Work outline }}$}

Adapt existing system for studying heated tubes in support plates to line contact geometries. Develop methods for measuring thermal, electrochemical, and local chemical properties in a dynamically flowing system. Experimental programs follow.

\subsubsection{WP: Study the key factors leading to the PbSCC initiation and propagation of SG tube Alloys under plausible secondary side SG crevice chemistry conditions.}

\section{$\underline{1 . \text { Background }}$}

The current status is that the envelope of environmental, material and mechanical conditions required for SCC, particularly in the presence of lead for the nickel base Alloys (Alloys 400, 600, 800, and 690) are still poorly defined and sometimes are controversial. This is especially true for near-neutral high-temperature $\mathrm{pH}$ conditions where most SGs operate and where non-lead secondary side SCC is suppressed. With only a few exceptions, most testing has been performed under unrealistic chemistry conditions different from the plausible SG secondary side chemistry conditions.

\section{Objective of WP}

The objective for this study is to establish a model to determine the initiation and propagation of SCC for the SG tube alloys exposed to secondary side SG crevice conditions including the presence of $\mathrm{Pb}$.

\section{$\underline{\text { 3. Work outline }}$}

Mechanistic studies are required to study the key factors leading to the passivity breakdown and the initiation of pitting/crevice corrosion/SCC under realistic SG crevice chemistry conditions. The studies will include:

a. Study the detrimental effect of $\mathrm{Pb}$ on $\mathrm{SG}$ tube degradation as functions of potential and $\mathrm{pH}$ of the solution.

b. Characterize the effect of lead and other impurities on the electronic structure and the composition of the passive films formed on SG alloys.

c. Determine the effect of stress in the migration and incorporation of lead in passive films.

d. Determine the effect of $\mathrm{Pb}$-contamination on mechanical properties of passive films.

e. Following the study on the SG tube degradation initiation, key factors leading to the propagation of pitting/crevice corrosion/SCC are to be determined. 


\subsubsection{WP: Solubility of lead compounds}

\section{$\underline{1 . \text { Background }}$}

Knowledge of the regions of thermodynamic stability and solubility for lead species are necessary to determine lead mobility. It will also provide insights into the possible mechanism of SCC.

Currently, there is a lack of high-temperature, $\mathrm{pH}$-dependent experimental solubility data of lead compounds possibly existing under secondary side SG conditions.

\section{Objective of WP}

Determine the solubility of $\mathrm{Pb}$ in various solutions and provide bases for transport models.

With solubility data, it is expected that the following will be learned:

a. which species of lead are most likely to precipitate in the steam generator and crevice environment;

b. which species of lead are most likely to cause or promote lead assisted corrosion or cracking;

c. a simple model to simulate the migration of lead species towards to the metal alloy can be developed and verified.

\section{$\underline{\text { 3. Work outline }}$}

Work should be conducted to measure the solubility of:
a. lead oxide
b. lead sulfate
c. lead chloride
d. lead carbonate
e. lead silicate
f. metallic lead
g. lead sulfate in the presence of chloride.

\subsubsection{WP: Identification of the stable phases of lead under SG conditions}

\section{$\underline{1 . \text { Background }}$}

The $\mathrm{Pb}$-containing compounds at reactor operating temperatures seem to be the bases for immobilizing $\mathrm{Pb}$ and preventing it from being active in producing PbSCC. While numerous nominally stable minerals containing $\mathrm{Pb}$ exist, it is not known whether such compounds exist and are stable at reactor operating conditions. 


\section{Objective of WP}

Determine what $\mathrm{Pb}$-containing compounds exist at reactor operating temperature and the extent of their stability as functions of potential and $\mathrm{pH}$.

\section{$\underline{\text { 3. Work outline }}$}

The thermodynamically stable lead phases under selected sets of steam generator operating conditions will be determined experimentally through autoclave tests.

\subsubsection{WP: Lead mobility}

\section{$\underline{\text { 1. Background }}$}

Lead mobility (dissolution, precipitation, and transport by diffusion, convection and advection) in the steam cycle and inside the SG is required to develop an overall model for effects of $\mathrm{Pb}$ in SGs.

\section{Objective of WP}

Provide bases for overall model of lead movement in SGs.

\section{Work outline}

In conjunction with the solubility data from the WP in Section 5.1.1.5, a model will be developed to elucidate how lead drifts towards the metal-deposit interface and induces tube degradation. It is anticipated that this will provide insights as to the water chemistries under which lead could cause SCC, and those water chemistries where PbSCC could be avoided.

Develop a practical set of equations to describe lead mobility and conduct experiments to measure the transport dependencies involving dissolution rates, precipitation, convection, and advection to validate and update the equations.

\subsubsection{WP: Sulphur chemistry under SG conditions}

\section{$\underline{\text { 1. Background }}$}

The normal concentration of high valence sulfur, e.g. sulfates, species in feedwater for SGs is in the range of $10 \mathrm{ppb}$ although sometimes transients due to the release of resin species raise this concentration.

In addition, hydrazine is intentionally added to the secondary side to minimize the concentration of oxygen and to maintain the electrochemical potential relatively low.

Owing to the thermodynamic properties of the high valence sulfur and the hydrazine, the high valence of sulfur species can be reduced to -2 or +2 valence species such as $\mathrm{HS}^{-}$or $\mathrm{H}_{2} \mathrm{~S}_{\text {and }} \mathrm{S}_{2} \mathrm{O}_{3}{ }^{2-}$ depending on the $\mathrm{pH}$. 
These low valence sulfur species have been shown to accelerate corrosion of high nickel alloys, including Alloys 600MA, 600TT, and 690TT, as well as to accelerate SCC. These low valence sulfur species should be especially aggressive to the higher strength iron base alloys used in turbines.

So far. quantitative data for the rate, conditions, and speciation of reduction of high valence species of sulfur are lacking.

\section{Objective of WP}

Develop rate theory relationships for the reduction of sulfate to lower valences.

\section{$\underline{\text { 3. Work outline }}$}

a. Develop a model SG system and conduct experiments in which the reduction of high valence sulfur species will be characterized under realistic conditions of steam generator operation.

b. Develop refined laboratory equipment and conduct experiments where the reaction rates of high valence sulfur species with hydrazine will be characterized quantitatively.

c. Develop laboratory equipment and carry out experiments where the carryover of sulfur species to turbines will be quantitatively characterized.

d. Conduct surveys of turbines in the shutdown condition for the presence and distribution of reduced sulfur species.

\subsubsection{WP: Measurement of accumulation of $\mathrm{Pb}$ and $\mathrm{S}^{\mathrm{y}-}$ in line contact crevices of steam generators}

\section{$\underline{1 . \text { Background }}$}

Modern steam generators in PWRs use line contact tube supports on the secondary side in place of the older drilled holes and associated flow holes. In the line contact crevices, secondary coolant flows through the spaces in the line contact geometries and cools the outside surfaces of tubes more directly than in the drilled hole geometries.

While it was expected that the line contact geometries would produce little accumulation of deposits on tube surfaces, in fact, the accumulation of deposits is significant; and it is likely that the superheat conditions produced by drilled holes may occur with the line contact geometries.

\section{Objective of WP}

a. Measure the rate of accumulation and properties of deposits in line contact geometries.

b. Determine the effects of subsequent chemical cleaning on these deposits.

c. Determine the properties of these crevices relative to OD surface temperatures, distribution of surface temperatures, existence of two phase regions, associated electrochemical potentials and $\mathrm{pH}$.

d. Determine the rate of accumulation of $\mathrm{Pb}$ and $\mathrm{S}^{\mathrm{y}-}$ in deposits in line contact geometries, emphasizing the hottest surfaces on the inlet side. 
e. Determine the existence and distribution of species that immobilize both $\mathrm{Pb}$ and $\mathrm{S}^{\mathrm{y}-}$ species.

f. Determine the rate of accumulation of $\mathrm{Pb}$ and $\mathrm{S}^{\mathrm{y}-}$ species as well as their speciations.

\section{$\underline{\text { 3. Work outline }}$}

a. Obtain deposits from operating SGs with line contact geometries to assess general patterns of properties of deposits and chemical species and their distributions.

b. Develop a laboratory system, where flow and heat flux of operating SGs can be modeled, and where important quantities such as distributions of local temperatures, electrochemical potential, chemical species can be measured as functions of time. Possibly two such systems should be available for long and short term experiments.

c. Using the laboratory system from item $b$. above, determine the rate of accumulation and subsequent distribution and speciation of $\mathrm{Pb}$ and $\mathrm{S}^{\mathrm{y}}$.

d. Determine effects of possibly inhibitive species that would minimize the deleterious effects of $\mathrm{Pb}$ and $\mathrm{S}^{\mathrm{y}-}$.

\subsubsection{WP: SCC and mitigation for Alloy 600TT and 690TT in Pb and $\mathrm{S}^{\mathrm{y}-}$ contaminated solutions}

\section{$\underline{1 . \text { Background }}$}

The chronology of PbSCC and $\mathrm{S}^{\mathrm{y}} \mathrm{SCC}$ has been reviewed in detail at specialists' meetings both at the $\mathrm{Pb} / \mathrm{S}$ workshop held at Argonne National Laboratory and at the Environmental Degradation meeting held in during 2005. Essentially, it appears that PbSCC could have been a contributor, if not the major contributor, to the past ODSCC of Alloy 600MA.

Further, Alloy 690TT is more prone to PbSCC than Alloy 600MA in alkaline solutions. $\mathrm{Pb}$ is readily enriched in superheated crevices starting with concentrations of $\mathrm{Pb}$ in the feedwater in the range of 10100 ppt. Pb might be further enriched by possible electrodeposition on metallic surfaces.

While there have been significant experiments on the PbSCC of high nickel alloys, in fact, there is little knowledge that provides bases for prediction.

Also, there is little basis for explaining the transitions between TGSCC and IGSCC for PbSCC.

Finally, there are no bases yet for explaining the large variability of SCC of Alloy 600MA.

In view of the potential for future degradation of Alloy 690TT and he lack of a coherent basis for PbSCC, this submode of SCC needs a quantitative foundation.

\section{Objective of WP}

a. Develop multiple facilities for conducting controlled studies of both PbSCC and $\mathrm{S}^{\mathrm{y}-\mathrm{SCC}}$ over ranges of $\mathrm{pH}$, potential, concentration, and temperature that are relevant to the secondary side. 
Owing to problems of contamination, facilities for the $\mathrm{Pb}$ and $\mathrm{S}^{\mathrm{y}-}$ need to be separate. Further, it is unlikely that such facilities can be utilized for studying other chemistries owing to contamination from the $\mathrm{Pb}$ or $\mathrm{S}^{\mathrm{y}-}$.

b. Obtain specimens from operating SGs to calibrate the magnitudes of concentrations of $\mathrm{Pb}$ and $\mathrm{S}^{\mathrm{y}-}$ as well as other species present that may contribute to immobilizing or activating the aggressiveness of the $\mathrm{Pb}$ and $\mathrm{S}^{\mathrm{y}}$.

c. Concentrate mainly on initiation of SCC since the application is thin walled SG tubing.

d. Direct some experiments to rationalizing the intergranular or transgranular morphology manly of PbSCC.

e. Develop approaches to mitigating $\mathrm{Pb}$ and $\mathrm{S}^{\mathrm{y}-}$.

\section{$\underline{\text { 3. Work outline }}$}

a. Determine the dependencies of $\mathrm{PbSCC}$ and $\mathrm{S}^{\mathrm{y}-\mathrm{SCC}}$ on $\mathrm{pH}$, potential, concentration, and temperature in ranges that are relevant to the deposits on free surfaces, TTS crevices, and line contact crevices.

b. Assess the action of possible inhibitors for PbSCC and $\mathrm{S}^{\mathrm{y}} \mathrm{SCC}$.

c. Assess the possible acceleration of $\mathrm{PbSCC}$ and $\mathrm{S}^{\mathrm{y}-} \mathrm{SCC}$ when normal impurities, e.g. Si, Al, are depleted from crevices, with respect to the possibility that such impurities are providing inhibition.

\subsubsection{WP: Scaling of Alloy 690TT in Pb-containing environments}

\section{$\underline{\text { 1. Background }}$}

In the development of the Alloy 690TT chemistry, in addition to assessing the occurrence of SCC in $\mathrm{Pb}$ solutions as a function of compositions of $\mathrm{Ni}, \mathrm{Cr}$, and $\mathrm{Fe}$, the rate of scaling was also determined as a function of the same alloy variables. While the occurrence of SCC decreased in Pb-containing solutions of otherwise pure water with increasing $\mathrm{Cr}$ and $\mathrm{Fe}$, scaling in the same solutions increased with increasing Cr but decreased with increasing Fe. Scaling on high nickel alloys has been observed on Alloy 690TT and Alloy 800 but not on Alloy 600MA in accordance with the early comprehensive studies of alloy dependencies.

The scaling process becomes important both from denting types of processes in tube supports and TTS geometries and in the acceleration of crack growth via the wedging action inside growing scales. The magnitudes of scaling for the various higher $\mathrm{Cr}$ alloys are such as to justify these concerns.

This scaling process in $\mathrm{Pb}$-contaminated solutions depends first on the accumulation of $\mathrm{Pb}$ under heat transfer deposits. If no $\mathrm{Pb}$ accumulates, then the scaling does not seem to occur.

\section{Objective of WP}

a. Determine the rate of growth and properties of scales on Alloys 690TT and 800 as a function of potential, $\mathrm{pH}$, concentration of $\mathrm{Pb}$, and temperature. 
b. Develop rate laws that permit extrapolating data to long times.

c. Determine the magnitude of forces that can be produced in tight geometries.

\section{$\underline{\text { 3. Work outline }}$}

a. Measure rates of growth of scales on Alloys 690TT and 800 compared with Alloy $600 \mathrm{MA}$ in Pbcontaminated water as a function of chemistries expected to occur in deposits in line contact TSP geometries and in TTS crevices as well as on free span surfaces such as in OTSG upper bundles. Include variables of electrochemical potential, $\mathrm{pH}$ and temperature.

b. Measure forces that can be exerted by such scales.

\subsubsection{Piping, Welds}

\subsubsection{Introduction to proposed WPs}

The reactor coolant systems in both PWR and BWR technology are fabricated from stainless steel with welds variously of like materials of stainless steels or dissimilar materials of nickel-base alloys or stainless steels having higher chromium and nickel. Few significant stress corrosion cracks have occurred in these pipes except for sensitized stainless steels used early in BWRs. However, some SCC has been associated with welds. Issues associated with welds as components are the following:

1. The welding process produces both high residual stresses and high cold work, both of which accelerate SCC.

2. Welds are often the subject of surface grinding to smooth the weld contour. Such grinding can be abusive and accelerates inititiation.

3. There is to date no good correlation between FEM and model of actual welds.

4. Welding often produces hot cracking that initiates SCC.

5. The metallurgy of welded structures is often metallurgically unstable.

6. Welds associated with Alloy 600 components in the NWC of BWRs are particularly prone to SCC.

7. Stress corrosion cracking of dissimilar metal Alloy $82 / 182$ weldments in piping connected to the RCS cold legs operate at high temperature in primary water and are highly susceptibile to SCC. Weldments of Type 308/309 stainless steel are less susceptible.

In addition to the problems with welds, the non-welded portions of pipes are prone to SCC as cold work increases. The SCC velocity is sufficient at $20 \%$ cold work, the degree of cold work of a bend that is not stress relieved, to perforate the wall of a thick primary pipe in a few years. The combination of the initiation and propagation stages are not well understood. 


\subsubsection{WP: Improved understanding of microstructural/micro-chemical evolution and hot cracking in nickel-base alloys and weld metals}

\section{$\underline{1 . \text { Background }}$}

Hot cracking occurs in welds of $182 / 82$ and $152 / 52$. This hot cracking provides sites for initiating SCC and $\mathrm{CF}$. Thus there is a need to better understand and provide mitigation for the known weld metal cracking.

\section{Objective of WP}

Determine the microstructural bases for the occurrence of hot cracking.

\section{Work outline}

Characterizations will be performed at moderate-to-high resolutions of weldments removed from LWR service, mock-ups welds and various test welds made with alloy 182/82 and alloy 152/52. Base weldment microstructural features will be documented including inclusions, precipitates, interdendritic boundaries and grain boundaries using scanning electron microscopy (SEM). Microchemical analysis will be performed using EDS and compositional mapping to document micrometer-scale segregation/precipitation in the SEM and nanometer-scale elemental distributions in the transmission electron microscope (TEM). The intent will be to greatly expand the understanding of weld metal structures in actual and simulated LWR service components with a focus on solidification segregation and second-phase precipitation particularly at interdendritic grain boundaries. The microstructural and microchemical features will be related to the susceptibility to hot cracking for both the low-Cr alloy 182/82 welds and the high-Cr, alloy 152/52 welds. The same SEM and TEM approaches will be employed to establish relationships between interdendritic segregation/precipitation and the cracking morphology at both micro-and nanometer resolutions particularly where hot cracks have propagated. Tips of advancing hot cracking will be characterized.

\subsubsection{WP: Influence of weld metal microstructure/micro-chemistry and pre-existing hot cracks on stress-corrosion cracking of nickel-base alloys}

\section{$\underline{1 . \text { Background }}$}

There are differences of opinion in the technical community between those who believe that cracking in Ni-base alloy weld metal (alloy 182 or 82) can occur solely due to SCC and others who perceive that susceptibility primarily results from pre-existing hot cracks due to poor manufacturing. Further, there are questions about the relative contributions of dendritic and grain boundary compositions as well as relative orientations.

\section{Objective of WP}

Determine the critical factors for hot cracking in initiating and propagating SCC. 


\section{$\underline{\text { 3. Work outline }}$}

a. critically assess the influence of not only pre-existing hot cracks, but solidification segregation or precipitation on SCC.

b. Conduct Gleeble experiments and document the effects of controlled heating and cooling on interfacial structure and composition to establish an improved understanding of dendritic and grain boundary compositions in weld metals.

c. Use the information from item $b$. above to systematically create realistic weld material conditions and samples for quantitative SCC tests.

d. Conduct experiments using well characterized realistic laboratory samples and mockup welds where hot cracking has occurred to determine the critical factors affecting whether initiation occurs and the velocity of SCC.

e. Finally, the influence of pre-existing hot cracks on SCC initiation and propagation will be evaluated.

\subsubsection{WP: Assessment of strain and stress states in weld metal and heat-affected-zone regions of LWR weldments}

\section{Background}

Whether and how rapidly SCC initiates and propagates in welds depends in part on the local stresses and plastic strains which are in turn affected by the initial manufacturing and fabrication conditions. It is now possible with modern systems to measure residual plastic strains and stresses in stainless steel and Nibase alloy welds. These stresses and strains are affected by initial welding and repair welding as well as the complex geometries of welds.

\section{Objective of WP}

To develop the quantitative capability to assess strains and stresses in realistic LWR weldments through an integrated experimental and modeling program.

\section{$\underline{\text { 3. Work outline }}$}

a. Conduct systematic studies using Orientational Imaging Microscopy (OIM) on various stainless alloy weldments in both the as-welded and repair-welded condition.

b. Employ finite-element modeling to investigate welding parameters that modify the stress/strain profiles throughout the weld.

c. Conduct controlled experiments to test model parameters and help validate predictions.

d. Finalize predictive capability for tailoring weld parameters to optimize material microstructure and final stress/strain condition. 


\subsubsection{WP: SCC of cold worked pipes}

\section{$\underline{1 . \text { Background }}$}

Piping used in primary system, including BWR RCS, is fabricated of stainless steel. In many instances these stainless steels need to be deformed to meet geometric requirements. Cold work in the range of $20 \%$ can be incurred. The damage of cold work is often relieved by heat treatment and sometimes not. Despite the well known proneness of these areas of cold work to SCC, they are often not inspected. Existing data show that, while experimental work indicates high crack growth rates of these cold worked materials, virtually no SCC has occurred in the field. There is no explanation for this contradiction.

\section{Objective of WP}

Develop quantitative bases for initiation and propagation of SCC in cold bent elbows. Determine effectiveness of stress relief heat treatments.

\section{$\underline{\text { 3. Work outline }}$}

Develop a quantitative description of initiation of SCC on cold worked pipe sections using both direct measurements of SCC initiation and TEM measurements of early initiation stages.

Develop a quantitative description of propagation of SCC in cold worked stainless steel components.

Develop an integrated model for the initiation and propagation of SCC in cold worked components.

\subsubsection{Socket welds and weldolets}

\subsubsection{Introduction to proposed WP}

"Socket welds" and "weldolets" constitute a particular geometry usually involving a large pipe or cross section to which a relatively small pipe is fastened by welding. These geometries often degrade by perforation due to SCC or corrosion fatigue. Owing to the high moment at the joint between large and small piping and the expected relative movement or vibration at the joint, the occurrence of perforation is not surprising. In general, it appears that the issue here is not one of why such degradations occur but the lack of a design basis for calculating stresses and their time-dependence.

\subsubsection{WP: Developing an improved design basis for perforations at the joint between large and small piping.}

\section{Background}

The fact that there are relative large numbers of perforations at joints between large and small piping does not seem to relate so much to lack of understanding of mechanisms of SCC and CF but rather to the lack of adequate bases for designing such joints. Such SCC and CF is accelerated by the ripple loading superimposed on high local mean stresses. Also, such perforations seem to be related to unanticipated flow induced vibration which is not well characterized. 


\section{Objective of WP}

Develop improved design bases for welded joints between large and small diameter piping.

\section{$\underline{\text { 3. Work outline }}$}

Collect analyses of perforations in the field, then develop a laboratory model that can be used together with a FEM analysis to develop an improved basis for design.

\subsection{Materials}

\subsubsection{Cast stainless steel}

\subsubsection{Introduction to work plan}

Cast stainless steels are widely used in applications such as housings for impellers in primary coolant pumps and for other cast components. The fracture properties of cast stainless steels have been investigated. Performance of cast stainless steels has been good without any serious degradation. However, the SCC and CF behavior, particularly in the aged condition, has not been significantly studied. The reproducibility of metallurgical properties of cast stainless steels is not well documented.

\subsubsection{WP: Aging and future degradation of cast stainless steels}

\section{$\underline{1 . \text { Background }}$}

Cast stainless steels are widely used in critical locations of important components especially in primary systems. There have not been any significant degradation of such components. This lack of significant degradation is consistent with good and reproducible fracture toughness. However, the metallurgical properties of cast stainless steels are not reproducible and the cast materials are not stable metallurgically over long times.

\section{Objective of WP}

Characterize the changes in metallurgical structure with time at temperature, especially at grain, phase, and dendrite boundaries. Assess the significance of these changes on the initiation and propagation of SCC and CFF.

\section{$\underline{\text { 3. Work outline }}$}

Using existing data and an activation energy extrapolation determine changes in local chemistries of metallurgical boundaries and phase stabilities with time to long times.

Determine the variation of metallurgical phases and boundaries among heats of cast stainless steels. 
Determine effects of changes in metallurgical structure due to aging on the SCC and CF of cast stainless steels, initially in primary water chemistry for the full range of relevant electrochemical potentials.

Determine also effects of these changes on the absorption of hydrogen.

\subsubsection{High Strength materials, bolting}

\subsubsection{Introduction to work plans}

High strength bolting is required in many applications in light water nuclear plants. Essential issues with the applications of high strength materials in bolting are:

1. Increasing strength of materials almost always increases rates of initiation and rates of propagation of SCC in all materials. These rates increase substantially as the strength of the alloy increases.

2. Irradiation exposure increases the proneness to SCC of high strength even more.

3. The actual applied load on bolts is often uncertain.

4. Residual stresses are often high as a result of fabrication procedures.

5. Bolts have built in stress intensifications owing to configuration of threads.

6. Bolts are often used where the immediately adjacent environments are sequestered such the oxidizing or reducing conditions are intensified.

7. In addition to the loss of integrity owing to the degradation of bolts, the loose pieces from the bolts can impinge on critical components.

\subsubsection{WP: Determine the rates of initiation and propagation together with statistical distributions of bolting of low alloy and high alloy steels.}

\section{$\underline{1 . \text { Background }}$}

In order to predict to behavior of high strength bolting an improved experimental method is required for measuring initiation and propagation. Such a method may involve a potential drop method now used for CT specimens. This method needs to distinguish early SCC from later propagation.

\section{Objective of WP}

Develop a useful experimental method for measuring the earliest stages of SCC where such a method can be used to assess methods for reducing the proneness of high strength bolting to SCC.

\section{Work outline}

Measure initiation and propagation of SCC in high strength bolting materials from low alloy steel and higher iron and nickel base alloys. 
Conduct these experiments in the expected engineering environments including internal and external chemistries as well as PWR and BWR (NWC, HWC).

Characterize the initiation and growth of such SCC with ATEM.

\subsubsection{WP: Determine effects of alloy structure as affected by sequences of heat treatments}

\section{$\underline{\text { 1. Background }}$}

Existing data show the resistance of high strength bolts to SCC can be increased by various heat treatments while achieving the same strength. While there is probably a limit to such improvements, they can also increase the margin for long life performance.

\section{Objective of WP}

Develop principles and procedures for heat treating high strength bolts with the aim of improving resistance to SCC.

\section{$\underline{\text { 3. Work outline }}$}

Develop foundations in physical metallurgy for heat treating high strength bolts that can achieve greater resistance to SCC.

Determine how the metallurgical structures interact with initiating and advancing SCC in relevant environments.

\subsubsection{WP: Assess the magnitudes and distributions of residual stresses in bolts using neutron and x-ray diffraction}

\section{$\underline{1 . \text { Background }}$}

Patterns of SCC in bolts suggest that residual stresses contribute substantially to the initiation and propagation of SCC. Identifying the magnitude and distribution of these stresses is the first step in assessing approaches to minimizing such residual stresses.

\section{Objective of WP}

Determine quantitatively the magnitudes and distributions of residual stresses in standard bolting used in exterior and interior applications.

\section{$\underline{\text { 3. Work outline }}$}

Choose typical bolts used in different applications including low alloy steels and highly alloyed stainless and high nickel types. Characterize the distribution of residual stresses and hardness. Correlate with metallurgical phases. 
Determine magnitudes and orientations of residual stresses using neutron diffraction and x-ray methods.

\subsubsection{WP: Environments and their effects for high strength bolts}

\section{$\underline{1 . \text { Background }}$}

The local environments, which surround bolts, especially inside the reactors are subject to different chemistries owing to the local gamma heating and lack of mixing with surrounding bulk environments. These environments need to be assessed for possibly different effects on SCC than available from bulk water chemistries.

\section{Objective of WP}

Determine in detail local environments around high strength bolts.

\section{$\underline{\text { 3. Work outline }}$}

Develop instrumentation for monitoring the local chemistry and thermal conditions adjacent to high strength bolts. Measure potential, $\mathrm{pH}$, temperature, and specific ions (specific ion electrodes). Having characterized these environments, they would be used in testing for measuring initiation and propagation of SCC.

\subsubsection{WP: Surface treatments to inhibit initiation of SCC of bolts}

\section{$\underline{1 . \text { Background }}$}

Since all SCC must start at the surface, altering the stresses, composition, and metallurgical structure at the surface provides options for minimizing SCC. The reproducibility of such treatments needs to be established.

\section{Objective of WP}

Significantly improve the resistance of bolts to SCC degradation through surface treatments.

\section{$\underline{\text { 3. Work outline }}$}

Survey methods of changing the surfaces of threads by water jet peening, laser peening, transient thermal pulses, atomic bombardment and subsequent diffusion and chemical treatments such as carburizing. Demonstrate effects of such treatments on initiation and propagation of SCC. 


\subsubsection{Low temperature creep cracks in steel}

\subsubsection{Introduction to work plans}

Cracks have been experienced in the primary heat transport system of some CANDU reactors. Metallurgical investigations discounted the role of fatigue or SCC in this cracking. The cracking occurred on the outside surfaces of SA 106B carbon steel piping which has been cold worked in the range of 20$30 \%$ and not stress relieved. This cracking occurred on several pipes after exposure on the order of 40,000 hours and in the temperature range about $310^{\circ} \mathrm{C}$. No particular outside environment was present other than reactor room air.

Similar cracking of such steels has been observed in fossil plants in the range of $360^{\circ} \mathrm{C}$. Investigations revealed a $100 \%$ intergranular fracture with little to no microstructural damage away from the crack. Laboratory investigation into these degradations led to the recognition of a new degradation mechanism, low temperature creep cracking. The temperature at which this process is active is below that previously thought to be necessary for creep process to occur at meaningful engineering rates in carbon steels. Subsequent research has established the occurrence of creep cracking in cold worked pipe material to temperatures as low as $340^{\circ} \mathrm{C}$ in carbon steel, and as low as $320^{\circ} \mathrm{C}$ in a low alloy steel heat treated to simulate a coarse grained heat affected zone.

This cracking from the outside of cold worked and non-stress relieved carbon steel suggests similar possibilities in all carbon steels, especially those that are cold worked by bending or at welds. Therefore it is important to investigate the potential for low temperature creep cracking of carbon steels under LWR conditions.

\subsubsection{WP: Investigation of metallurgical variables affecting the low temperature creep cracking susceptibility of carbon steel piping}

\section{$\underline{1 . \text { Background }}$}

The cracking described in Section 5.2.3.1 is new to the LWR industry although not so to the fossil industry. This cracking is also occurring at temperatures somewhat lower than have occurred in the fossil industry. Therefore, a database has first to be established to provide a basis for extrapolating into the future.

\section{Objective of WP}

Establish a data base. Develop a screening test for evaluating heats of steel.

\section{$\underline{\text { 3. Work outline }}$}

a. Testing should continue to the temperatures of interest to the LWR industry.

b. Material from the flank of the bends, which has only been cold worked approximately $15 \%$ should be tested. 
c. Steels from other heats should be tested that comprise a range of chemistries within the SA 106B specification. Special attention should be given to the concentrations of phosphorous and sulfur and if there is any enrichment of these species at the grain boundaries.

d. Free nitrogen is known to promote dynamic strain aging at reactor operating temperatures. Heats of high and low free nitrogen steel should be tested to evaluate their susceptibility to cracking.

\subsubsection{WP: Microscopic characterization of low temperature creep cracks}

\section{$\underline{1 . \text { Background }}$}

At temperatures less than $340^{\circ} \mathrm{C}$ no features in the micron scale are associated with the cracking which is purely intergranular and follows one well defined crack path with no branching. Transmission electron microscope work is virtually non-existent with regards to studying this mechanism.

A project of detailed SEM and TEM has been concluded studying cracks in failed ex-service piping. The results from this investigation did not reveal any new insights into the microstructural parameters associated with cracking.

\section{Objective of WP}

Determine detailed correlations of cracking with microstructural characteristics.

\section{$\underline{\text { 3. Work outline }}$}

The production of creep crack samples in the laboratory allows material for detailed microscopic examination at the optical, SEM and TEM scales. Cracks of known history in well characterized materials will be available for study. Examination of such material offers a higher probability of identifying the relevant microstructural parameters than studying degradations from the field.

\subsubsection{WP: Investigation of the role of hydrogen in enhancing low temperature creep cracking of carbon steels}

\section{$\underline{1 . \text { Background }}$}

The presence of a flux of hydrogen through the walls of carbon steel in question has been well established due to oxidation reactions, which are part of FAC. The concentration of hydrogen is below that required for hydrogen embrittlement of steel. Indeed no microstructural evidence of hydrogen damage has been observed in failed pipes. However hydrogen concentrations below those necessary for hydrogen embrittlement are known to accelerate movement of dislocatons in carbon steel.

\section{Objective of WP}

Determine whether a connection exists between the observed cracking and the flux of hydrogen from inside surfaces as produced by FAC. 


\section{$\underline{\text { 3. Work outline }}$}

Measure rates of creep cracking in the presence of an internal hydrogen flux such as might occur during FAC.

\subsection{Phenomena}

Section 5.3 deals specifically with phenomena that are central to several materials and components and addresses the scientific bases for understanding degradation and projecting into the future.

\subsubsection{SCC Precursors}

\subsubsection{Introduction}

Following the discussion associated with Figure 1, "precursors" are those processes that come before the SCC itself and provide the conditions where SCC can initiate and propagate. The main reason for identifying the concept of precursors is that usual SCC cannot be rationalized in terms of existing insights as requiring 5-10 years at the longest. Thus, developing an understanding of degradation that occurs at longer times during a 60 -year period of operation requires that other preliminary processes operate before the SCC initiates. Such processes can easily be imagined as requiring long times based on processes that require long times, e.g. for thermally activated diffusion and accumulations.

The detailed background on the concept of a precursor and sources of processes that become precursors are discussed in Appendix B-15 of the NRC proactive materials degradation assessment report (NUREG/CR-6923).

\subsubsection{WP: Long term LPSCC of Alloy 690TT}

\section{$\underline{1 . \text { Background }}$}

While Alloy 690TT has performed well both in service and in some laboratory testing, the alloy is quite prone to SCC in alkaline solutions and in Pb-containing solutions especially at mild to concentrated alkalinity. Further, Alloy 690 sustains significant SCC in mildly acidic solutions at somewhat elevated potentials in the higher part of the range expected on the secondary side of steam generators.

Studies of SCC propagation for Alloy 690TT have shown that it sustains SCC.

Further, studies of surfaces of Alloy 690TT in concentrated alkaline solutions show that chromium is preferentially depleted from the surface. Further, the transition from $\mathrm{Cr}^{+3}$ to $\mathrm{Cr}^{+6}$ exhibits a decreasing slope that is twice that of the $\mathrm{H}_{2} \mathrm{O} / \mathrm{H}_{2}$ equilibrium; this means that the potential for the $\mathrm{Cr}^{+6} / \mathrm{Cr}^{+3}$ transition is accessible to the potentials in the $\mathrm{SG}$ in the range of about $\mathrm{pH}_{\mathrm{T}} 8$.

Alloy 690TT is inherently reactive owing to the high concentration of chromium.

Finally, the observation in stainless steels that nickel is enriched at the tip of cracks in the metal ahead of the crack tip suggests that the metal ahead of crack tips for Alloy 690TT may also enrich in Ni and 
therefore become li1 Alloy 600 and therefore prone to LPSCC. The rate of growth of LPSCC then would be related to the rate of depletion of $\mathrm{Cr}$ from the material ahead of the crack.

\section{Objective of WP}

a. Determine the critical processes that affect the initiation and propagation of LPSCC for Alloy $690 \mathrm{TT}$.

b. Determine the long term dependence for the initiation and propagation of SCC in Alloy 690TT as a function of PWR and BWR environments.

\section{$\underline{\text { 3. Work outline }}$}

The first step in this study would involve the ATEM study of crack tips from Alloy 690TT that have been exposed over a range of conditions. These results would be compared with those from Alloy 600MA. Again, this work would concentrate on the material ahead of the crack tip with respect to structure and composition.

\subsubsection{WP: Surface aging and relationship with SCC crack initiation for Alloy 600 and Alloy 182 in PWR primary water environments}

\section{$\underline{\text { 1. Background }}$}

Changes in surface and near-surface metallurgy in nickel-base alloys will be assessed in both service and laboratory samples after long-term exposures (10-30 yrs) to PWR primary-water environments. The need for proactive management of crack initiation drives this research as well as the lack of knowledge of surface aging processes

\section{Objective of WP}

Characterize microstructural features affecting SCC after long times.

The goal of all characterizations is to establish environment-induced aging (changes to near surface metallurgy) and to link observations to SCC initiation and short-crack-growth processes.

\section{$\underline{\text { 3. Work outline }}$}

The focus of the examinations will be on nickel-base Alloy 600 and alloy 182 weldments. Service samples will be prepared from various PWR upper head penetrations and steam generator tubing that have been removed over the last decade. In both cases, heats/conditions have been identified as being highly susceptible or more resistant to IGSCC in PWR primary water. Laboratory test materials will be also identified to obtain specific heats/conditions highly susceptible and resistant to SCC initiation after reasonable long-term exposures (months to years). Cross-sections will be fabricated at locations near crack-initiation sites (when present) enabling surface and near surface examinations by a combination of micro-to-nanometer resolution analytical techniques including analytical electron microscopy. Microstructural and micro-chemical characteristics of the multi-layer, surface corrosion-product films, metal/oxide interface regions and the altered metal zone beneath the surface film will be systematically 
documented for each material. Particular emphasis will be placed on identifying changes that may have occurred at grain boundaries intersecting the surface.

\subsubsection{WP: Practical assessment of Pourbaix diagrams for assessing thermodynamics and kinetics of forming corrosion product films on Fe-and Ni-base alloys}

\section{$\underline{1 . \text { Background }}$}

Reliable SCC susceptibility predictions are inhibited by the lack of understanding of oxide kinetics and stability.

\section{Objective of WP}

Characterize in quantitative detail the interaction of thermodynamic boundaries and associated kinetic processes in the formation of protective films on Fe-and Ni-base alloys for application to understanding bases for SCC.

\section{Work outline}

Integrated experiments will map important regions of the high-temperature-water potential/pH diagrams for Ni- and Fe-base stainless alloys including alloy 600, alloy 690, alloy 800 and 300-series stainless steels. Contact electric resistance will be used to identify the metal to metal-oxide transition as a function of realistic changes in potential and $\mathrm{pH}$ expected at the surface and possible at crevices or crack tips. Laser Raman spectroscopy will be conducted for selected materials and conditions. Oxide structures will be identified in-situ at several potential/pH/temperature combinations and Raman measurement will be repeated after the high-temperature-water environment is removed. Final detailed characterizations will then be conducted by high-resolution analytical transmission electron microscopy (ATEM) on crosssection samples to quantitatively determine the surface film structures and compositions. The combination of all three unique techniques on the same alloys during or after exposure to critical potential/pH/temperature conditions will provide key insights into the fundamental corrosion/oxidation processes controlling performance in LWR environments.

\subsubsection{WP: Evaluating material composition and solution chemistry effects on corrosion-product film formation}

\section{$\underline{1 . \text { Background }}$}

The integrated series of experiments proposed in Section 5.3.1.4 can also be effectively used to elucidate the influence of LWR solution additions/impurities and alloy composition differences. Knowledge of these influences enables predictive mitigation of alloy cracking. Potential changes in the thermodynamics and kinetics of surface film formation should be studied isolating the influence of independent additions of $\mathrm{S}, \mathrm{Pb}$ and $\mathrm{Zn}$. 


\section{Objective of WP}

Characterize contributions of impurities in crack tip solutions arising from grain boundary species and bulk environments to the advance of SCC.

\section{$\underline{\text { 3. Work outline }}$}

A few LWR environments should be chosen to represent realistic crevice and crack-tip potential/ph conditions. Compositions of segregated grain boundaries would be chosen. This would include nonequilibrium thermal segregation in mill-annealed 316SS where grain boundary Mo concentrations can reach $\sim 10$ at $\%$ and radiation-induced segregation in SS where Ni and Si concentrations can exceed 30 at $\%$ and 15 at $\%$. Such large non-equilibrium enrichments would be produced in a bulk alloy by high-rate sputter deposition, thereby producing a bulk material with the grain boundary composition. Surface film formation can then be dynamically measured in-situ by contact electric resistance and laser Raman, then quantitatively evaluated with cross-section ATEM. These results would be compared to high resolution ATEM characterizations of crack-tip films from the work in Section 5.3.3.2.

\subsubsection{SCC Initiation}

\subsubsection{Introduction}

The role of initiation in SCC is shown schematically in Figure 1. Initiation is an important consideration in SG tubes since the thickness of the tubes is on the order of the depth over which initiation is affected by external environments. Initiation is sometimes less important for thick sections where propagation seems to consume the overall time to perforation. Initiation is greatly accelerated by surface abuse and cold work.

\subsubsection{WP: Initiation and propagation of SCC in cold worked stainless steel and Alloys 600 and 690: fundamental assessments of crack tips}

\section{Background}

Cold work accelerates both the initiation and propagation of SCC in stainless steels and high nickel alloys. Increasing cold work increases the intensity of both initiation and propagation. The observed rates of propagation in laboratory testing are sufficient to perforate thick piping in relatively short times, possibly several years. The initiation of SCC in cold worked surfaces can acquire sufficient depth to continue in less cold worked materials.

This task is aimed at understanding the processes whereby cold work affects the initiation and propagation of SCC via detailed characterizations of crack tips using analytical transmission electron microscopy (ATEM) and theoretical metallurgical and mechanics analysis of crack tips.

\section{Objective of WP}

a. Provide fundamental bases for predicting long term effects of cold work on the initiation and propagation of SCC in stainless steels and high nickel alloys of interest to LWRs. 
b. Integrate the observations of ATEM work on both material ahead of the SCC tip and at the tip of SCC with fundamental studies of theoretical mechanics and solid state processes.

\section{$\underline{\text { 3. Work outline }}$}

a. Characterize in detail the chemical composition ahead of propagating SCC with ATEM.

b. Characterize the geometry of advancing SCC during propagation and during early stages of initiation.

c. Characterize stainless steels and high nickel alloys in low potential and high potential ranges as are related to hydrogenated and non-hydrogenated environments.

d. Develop improved theoretical models for strain distributions immediately adjacent to very narrow tips of SCC.

e. Develop models for the creation of vacancies, their mobility, and the implications for diffusion of alloy species in the region of crack tips.

f. Develop models for the relaxation of strains at tips of advancing SCC.

\subsubsection{WP: Surface aging and insights into SCC crack initiation and short-crack growth for 304SS and 316SS in BWR environments}

\section{$\underline{1 . \text { Background }}$}

Similar to the study in WP Of Section 5.3.1.3 for Ni-base alloys, changes in surface and near-surface metallurgy of stainless steels will be assessed in both service and laboratory samples after long-term exposures to BWR water environments. The focus of the examinations will be on 300 -series stainless steels and may include heat-affected-zone regions. Service examples will include 304 and/or 316SS pipe samples where SCC has been promoted by surface grinding or damage. Laboratory test materials will be identified to obtain heats/conditions of highly susceptible and resistant heats to SCC initiation.

\section{Objective of WP}

Characterize in high magnification detail early stages of SCC in stainless steels initiated from surface abuse.

\section{$\underline{\text { 3. Work outline }}$}

Samples and near-surface regions that will be characterized by analytical TEM techniques will depend on the variability observed among different surface/near-surface structures, IG attack/oxidation, cracks and crack tips. Microstructures will be documented at several magnifications to illustrate corrosion-product films, sub-surface degradation and the near-surface alloy microstructure. A combination of techniques including high-resolution TEM imaging and nano-diffraction will be employed to characterize the multilayer films and altered base material that may be present near the surface. Nano-probe microchemical analysis will be performed using EDS (including compositional mapping) and possibly electron energy loss spectroscopy (EELS) techniques. 
The final step, after establishing critical aspects of long-term LWR service aging for both Ni- base and Fe-base stainless alloys, should be to conduct SCC initiation tests in the laboratory. These tests should be designed to provide quantitative evaluations of the surface and near-surface metallurgy effects on cracking. As possible, actual LWR service materials should be used after detailed characterizations described above have been completed along with well-controlled laboratory samples.

\subsubsection{SCC Propagation}

\subsubsection{Introduction}

SCC propagation differs from initiation in several important ways

1. Propagation depends less on the external environment and more on the crack tip environment.

2. Propagation depends on the continuum crack tip stress fields to a first approximation although in detail the stress fields at crack tips have not been quantified.

3. Propagation depends on some prior defect or initiation stage before it becomes a propagating SCC.

4. Whereas initiation depends on stress at the surface as applied and residual sources add, propagation must contend with the changing stresses throughout the depth.

5. While propagation is often viewed as the limiting case, i.e. "everything initiates" this is not always so and sometimes initiation is the limiting case as for cold worked stainless steel pipes in primary water.

6. A propagating SCC is subject to large changes in internal chemistry owing to effects of migration to the point of achieving saturation with the latter being the driving force for migration to the crack tip.

\subsubsection{WP: Film formation in SCC cracks and at crack tips for insights into environment-assisted crack-growth mechanisms}

\section{$\underline{\text { 1. Background }}$}

Initiation and propagation of LPSCC in high nickel alloys in primary water of PWRs seem to exhibit maxima at the $\mathrm{NiO} / \mathrm{Ni}$ equilibrium. The reason for such a correlation is unknown. The advent of applying the ATEM to the study of morphology and chemistry of crack tips has provided an avenue for detailed studies of chemical processes of advancing SCC. This WP integrates the in-situ and ex-situ surface film examinations in WPs of Sections 5.3.1.4, and 5.3.1.5 with processes that occur at the SCC crack tip during propagation.

\section{Objective of WP}

Examine the thermodynamic conditions associated with SCC. Especially consider the significance of the $\mathrm{NiO} / \mathrm{Ni}$ equilibrium as the location of most intense $\mathrm{SCC}$. 


\section{$\underline{\text { 3. Work outline }}$}

a. Stress-corrosion, crack-growth-rate (SCC-CGR) tests will be conducted on selected Ni- and Febase stainless alloys in LWR environments under well-controlled potential/ph/temperature conditions. These tests will be performed spanning the $\mathrm{Ni} / \mathrm{NiO}$ phase transition on Alloy 600 using low-high hydrogen additions to move from an electrochemical condition where $\mathrm{NiO}$ is stable to one where Ni metal is stable.

b. These specific conditions will be mapped following previous research performed at other laboratories. Samples will be removed under load and prepared for cross-section ATEM enabling quantitative characterization of crack and crack-tip corrosion films and local metallurgy changes. Fundamental alterations in the crack tips will be established by comparing each potential $/ \mathrm{pH} /$ temperature condition and linking results to the surface work from the WP of Section 5.3.1.4.

c. Oxide film differences can be documented as a function of distance from the crack tip (very short exposure time) to the crack mouth (exposure times reaching several months). The kinetics of oxidation can be studied since crack-growth rates have been accurately established helping quantify exposure time along the length of the SCC cracks.

d. Key solution chemistry conditions will be selected where significant influence on the SCC-CGR is observed, i.e., where $\mathrm{S}$ and $\mathrm{Pb}$ enhances $\mathrm{SCC}$ propagation and where $\mathrm{Zn}$ decreases growth.

e. The influence of Mo grain boundary segregation and high matrix Si concentration will be evaluated on SCC growth rates followed by detailed ATEM crack-tip characterizations.

\subsubsection{WP: Application of finite element modeling to characterizing the electrochemical conditions at crack tips.}

\section{$\underline{1 . \text { Background }}$}

Finite element methods are widely used to characterize processes occurring in complex geometries. The crack tip of an advancing SCC is one of the complex geometires.

\section{Objective of WP}

Apply FEM to characterizing propagating SCC tips.

\section{$\underline{\text { 3. Work outline }}$}

The first step is to set up equations and boundary conditions. These could be most reasonably based on work on crack tip geometries now being observed.

Once such a set of equations has been developed the results from these equations could be compared with direct observations from ATEM work. 


\subsubsection{Cold work: Surface and bulk}

\subsubsection{Introduction}

Cold work is an important, even critical, contributor to the occurrence and rate of SCC. Increasing cold work increases the intensity of initiation and propagation. Cold work changes an otherwise SCC-resistant alloy into one quite prone to SCC.

Cold work seems to play different, but significant, roles in initiation and propagation.

Important background items concerning cold work:

1. Cold work at the surface at thicknesses of tens of microns is potent for accelerating SCC. This is shown in the SCC observed in BWR shrouds. Such cold work results from surface preparation or abuse.

2. Scratches observed on the free span of Alloy 600 mill annealed steam generator tubes on the cold leg side of operating plants, nucleated hundreds of SCC events per inch of scratch. No superheat nor secondary side deposits were present. Furthermore, the cold leg side temperatures were significantly lower than the hot leg side surfaces and of the secondary side surfaces inside superheated crevices. Once the SCC was nucleated it penetrated the wall completely and substantially beyond the domain of cold work from the scratch. This pattern is much like the surface-initiated SCC from BWR shrouds.

3. Cold work from scratches also nucleated the SCC in the upper bundle of a once-through steam generator, but these were associated with the deposits of secondary impurities on the superheated surfaces. However, the SCC was focused at the scratches.

4. The preferential SCC on surfaces of control rod drive mechanisms during the 1990s seemed to be preferentially associated with machining abuse preferentially associated with specific fabricators. In some cases no SCC was observed and in other cases excessive SCC was observed.

5. Preferential SCC related to surface abuse occurred in Alloy 600 tubes used in housings for pressurizers. Depending on the machining practice, SCC occurred or it did not.

6. In the case of bulk cold work in components in contrast to that at surfaces, such cold work results from the cold bending of piping, especially where warm working or post stress relief is not utilized. Laboratory experiments as well as field data show that $90^{\circ}$ bends sustain $20-30 \%$ strain and that this strain can lead to SCC at operating temperatures as well as at temperatures in the range of $50^{\circ} \mathrm{C}$.

7. Cold work also results from welding where the weld strains produce cold work effects.

8. Cold work of components, where stress relief is not utilized, is a special concern since such components are not routinely inspected as are welds.

9. Measurements of SCC propagation in pure water shows that Alloy 690TT sustains slow but significant crack growth. 
The damaging effects of increasing cold work both in the bulk and on surfaces is widely appreciated. What is not so clear is why cold work exerts such effects or how such effects can be predicted and mitigated. There are no insights to the extent of inspections that should be applied. Further, lacking are:

1. The ranges of temperature over which cold work accelerations are important.

2. The extent of stress relief required.

3. The depth and character of surface abuse that exerts the surface effects.

4. The interaction of cold work with alloy chemistry (Alloys 600MA, 690TT, 800, stainless steels) and environmental chemistry.

5. The broader but nominally obvious connection of cold work with alloy strength and irradiation.

6. The interaction of cold work with alloy structure including grain size and second phases.

7. An explanation of why cold work so greatly accelerates SCC propagation in stainless steels in PWR primary chemistries but the initiation stage is so greatly inhibited.

8. A prediction of the cold work effects that result from progressive denting at the TTS location over time for Alloy 690TT SG tubes.

While the effects of cold work are wide spread and while there are many important situations that are not explained, mechanisms by which cold work exerts its effects are less well understand making long term predictions tenuous or absent:

1. A frequent explanation for cold work exerting acceleration of propagation is related to the capacity of the crack tip to sustain increasing hydrostatic stresses with increasing local strength due to cold work. However, such cold work also produces increased cross slip which relaxes stresses due to dislocation pile ups.

2. At the surface, an explanation for cold work is more difficult since there is no pre-existing SCC. Further, cold work favors extensive cross slip, which relaxes local stress intensifications at barriers.

3. It appears that the role of cold work may be more related to production of vacancies, which nucleate small cracks. As dislocations interact during cold work vacancies are produced as dislocations on different slip planes pass through each other.

4. The role of cold work introducing vacancies has been indicated in two laboratories where extensive diffusion has been observed in the metal ahead of crack tips. Such diffusion requires the presence of relatively high concentrations of vacancies. 


\subsubsection{WP: Behavior of grain boundaries in cold worked stainless steel exposed to PWR primary chemistries}

\section{$\underline{1 . \text { Background }}$}

Data are available to show that SCC propagates relatively rapidly in cold work stainless steel piping when exposed to PWR chemistries. However, no such degradations have been observed. This suggests that the limiting factor is initiation rather than propagation.

\section{Objective of WP}

Elucidate the mechanism by which grain boundaries facilitate both initiation and propagation of SCC in PWR primary water.

\section{$\underline{\text { 3. Work outline }}$}

Experiments to compare rates of propagation and initiation in both BWR normal water chemistry (NWC) and PWR environments.

Detailed experiments to examine grain boundary rotation as a mechanistic avenue for SCC of stainless steels.

Creep experiments at higher temperatures to provide data on rates of grain boundary rotation and morphology of resulting cracking.

\subsubsection{WP: Characterize cold worked surface layers on stainless steels and effects on the rate of initiation of SCC in BWR and PWR chemistries.}

\section{$\underline{\text { 1. Background }}$}

Failures in shrouds of 316L stainless steel associated with cold worked layer about $300 \mathrm{~m}$ deep. Significant molybdenum at grain boundaries observed.

\section{Objective of WP}

Determine why thin cold worked layer produces such extensive damage.

\section{$\underline{\text { 3. Work outline }}$}

Determine effect of extent of cold work on initiation of SCC: depth of cold work, degree of cold work.

Determine the effect of PWR and BWR chemistry on the initiation due to such cold worked layers.

Study the structure of cold work layers using ATEM before and after initiation of SCC. 


\subsubsection{Compounds and kinetics at grain boundaries}

\subsubsection{Introduction}

Most of the SCC observed in primary and secondary systems of PWR and in the BWR reactor coolant system (RCS) is intergranular. This includes SCC in high nickel and stainless steel alloys. In addition some intergranular corrosion also occurs.

Further, unlike the general effects of sensitization in producing accelerated intergranular SCC (IGSCC) in stainless steels, SCC in the high nickel alloys is generally inhibited by the presence of grain boundary carbides especially exposed to pure water.

In the pure water of BWRs (NWC) IGSCC also occurs in low carbon non-sensitized stainless steels used in major structural applications.

In addition to the interests in compounds, the possible diffusion of oxygen in grain boundaries has been the subject of speculation and needs further investigation.

Thus, the experiences of performance of Fe-Cr-Ni alloys in the pure water of PWR and BWRs are different from expectations based on other industry experiences with these alloys.

\subsubsection{WP: Metallurgical chemistries of $316 \mathrm{~L}$ commercial stainless steels involving $\mathrm{Ni}_{3} \mathrm{P}_{2}$ and CaS}

\section{$\underline{1 . \text { Background }}$}

While there has been significant interest in the formation of carbides at grain boundaries of stainless steels, there is a body of information showing that significant amounts of $\mathrm{Ni}_{3} \mathrm{P}_{2}$ and $\mathrm{CaS}$ also segregate at grain boundaries during sensitizing heat treatments.

\section{Objective of WP}

Determine the conditions that influence the segregation of $\mathrm{Ni}_{3} \mathrm{P}_{2}$ and $\mathrm{CaS}$ at grain boundaries.

Determine effects of these compounds on chemical reactivity and SCC of stainless steels.

Determine the extent to which these compounds are important to Ni-base alloys.

\section{$\underline{\text { 3. Work outline }}$}

Prepare commercial Fe- and Ni-base alloys with appropriate heat treatments.

Examine grain boundaries with ATEM and micro-EDS with special interest in $\mathrm{Ni}_{3} \mathrm{P}_{2}$ and $\mathrm{CaS}$.

Determine the chemical reactivity of the compounds by high temperature polarization. 


\subsubsection{WP: Role of carbides at grain boundaries}

\section{$\underline{1 . \text { Background }}$}

Carbides in high nickel alloys seem to be beneficial even to the point of depleting chromium. This effect is inverse to the sensitization of stainless steels where the opposite is true.

A satisfactory explanation is desired for the role of carbides in minimizing SCC at boundaries especially in pure water.

Some progress in explaining the role of carbides in the high nickel alloys comes from the idea that at least LPSCC is related to the rotation or sliding of grain boundaries, which can be expected to be inhibited by the presence of insoluble compounds at the boundaries.

\section{Objective of WP}

Determine the role of carbides in high nickel binary Fe-Ni and ternary Fe-Cr-Ni alloys.

\section{$\underline{\text { 3. Work outline }}$}

Explore the effects of carbides on grain boundary sliding or grain rotation. Use creep experiments and fiducial marking. Examine grain boundaries after experiments with ATEM and EDS.

\subsubsection{WP: Role of grain boundaries in low carbon stainless steels with no grain boundary carbides}

\section{$\underline{1 . \text { Background }}$}

Extensive SCC of Type 316L stainless steel has been experienced in the core shrouds of BWR plants operating with NWC. The cracks started in the cold worked surface layers but extended into the bulk material. Such a result is nominally contrary to the expectation of SCC only related originally to sensitized stainless steels having normal carbon concentrations.

The grain boundaries where this SCC occurs seem greatly enriched in molybdenum.

With high concentrations of molybdenum, the grain boundaries would be expected to become more reactive owing to the high solubility of molybdenum in water above $\mathrm{pH}$ of about 3 (RT).

\section{Objective of WP}

Determine the composition of grain boundaries of low carbon stainless steels with varying amounts of cold work up to $20 \%$. Include in the study Alloy 800, Alloy 600MA, Ni-20Fe, and Alloy 690TT. Give particular attention to aging effects. 


\section{Work outline}

Use existing commercial materials used in LWR applications where possible and laboratory heats where required. Prepare alloys with 0 and $20 \%$ cold work. Using activation energies for the average diffusion rates of substitutional solutes prepare alloys with aging times of 10 and 40 years. Unfortunately, these temperatures may also relax the cold work effects. Some optimum condition should be determined.

Examine grain boundaries with ATEM and EDS to measure concentrations of solutes as a function of alloy, cold work and aging times.

\subsubsection{WP: Diffusion of oxygen in grain boundaries}

\section{$\underline{\text { 1. Background }}$}

There is some evidence that oxygen diffuses along grain boundaries and produces some kind of embrittlement that may be a part of the mechanism of at least LPSCC. Such a process may also be important to other alloys in the Fe-Cr-Ni alloys.

The diffusion of oxygen in grain boundaries should be measured definitively. Further, this diffusion should be measured as a function of the oxygen activity at the surface as it is equivalent to the range of potentials that include BWR NWC and PWR primary environments.

\section{Objective of WP}

Determine the diffusivity of oxygen in significant grain boundaries of relevant alloys including the Ni-Fe binary analogous to Alloy 600MA.

Determine a mechanism by which such diffusion can embrittle grain boundaries.

\section{$\underline{\text { 3. Work outline }}$}

Develop optimum method for measuring the diffusion of oxygen in grain boundaries of the relevant $\mathrm{Fe}-$ $\mathrm{Cr}-\mathrm{Ni}$ alloys. This method should produce the same oxygen activities on the surfaces as result from the range of potentials observed in BWR NWC and PWR environments.

Measure the extent of embrittlement and determine the mechanism of embrittlement.

\subsubsection{Irradiation effects}

\subsubsection{Introduction}

Core internals in BWR and PWR applications sustain high fluxes that are now known to affect many aspects of metal properties possibly leading to premature degradation. Most important are changes in properties at surfaces where degradation initiates although the bulk properties of core internals need to sustain loading. Also, the formation of local bubbles produces non-uniform strains that degrade properties. 
Specimens with high doses and experimental equipment, e.g. ATEM, are now available that provide the capacity to develop mechanistically based predictions.

\subsubsection{2: WP: Detrimental material changes and embrittlement in highly irradiated stainless steels}

\section{$\underline{1 . \text { Background }}$}

Several evaluations have indicated that stainless-steel LWR core internals may become susceptible to intergranular embrittlement at high irradiation doses. Microstructure/property relationships at high LWR doses have not been sufficiently explored for proactive management of irradiation embrittlement. Recently, nanometer-scale cavities have been identified at grain boundaries during limited examinations on isolated samples by transmission electron microscopy (TEM) that may promote this low-toughness, intergranular fracture. More extensive research is needed on the microstructure, microchemistry, deformation and mechanical properties of highly irradiated stainless steels.

\section{Objective of WP}

Determine detailed mechanistic bases for embrittlement of core internals.

\section{Work outline}

Primary work should be centered on the dose-dependence material changes in BWR thimble tubes examining low-fluence $(<0.1 \mathrm{dpa})$, moderate-fluence (20-40 dpa) and high-fluence (60-85 dpa) locations.

Specially designed deformation tests will be conducted at $\sim 300^{\circ} \mathrm{C}$ on 3 -mm disc samples documenting localized channeling behavior and grain boundary interactions to access precursors to intergranular cracking. Attempts should also be made to obtain high-dose PWR materials, such as baffle bolts, where comparative data could be generated to the BWR thimble tube response.

Detailed microstructural and microchemical characterization will be performed including the presence of bubbles, voids, dislocation loops, cold work recovery and segregation in the matrix and at/near grain boundaries. Helium and hydrogen will be measured and related to the cavity observations. Where possible, these observations will be compared to existing tensile test data and to additional shear punch test assessing radiation hardening and ductility.

Small test materials of commercial stainless steels and of high-purity stainless steels with single-element additions have been irradiated to doses of 5, 10, 20, 45 and 65 dpa. Once again, important comparisons can elucidate the radiation-induced microstructure and microchemistry influences on mechanical behavior (deformation, strength and fracture).

High-purity alloys with and without $\mathrm{Si}$ will be evaluated in detail since strong radiation-induced segregation of this element occurs to grain boundaries and may impact the susceptibility to intergranular embrittlement. 


\title{
5.3.6.3 WP: Surface and near-surface aging in stainless steel core internals and influence on irradiation-assisted stress corrosion cracking
}

\author{
$\underline{1 . \text { Background }}$
}

SCC initiates at surfaces. Therefore detailed characterization of surfaces of reactor core internals should be specifically evaluated. Such surfaces should be specifically evaluated in order to develop models for the initiation of SCC over time of irradiation exposure.

\section{Objective of WP}

To examine changes in the near-surface that have been produced by the simultaneous irradiation and high-temperate water exposure for more than 20 years to help predict crack initiation.

\section{$\underline{\text { 3. Work outline }}$}

Surface and near-surface metallurgy changes affecting initiation and short-crack growth will be assessed in a PWR baffle bolt and BWR top guide where IASCC has been discovered during service.

Examine changes in the near-surface that have been produced by the simultaneous irradiation and hightemperate water exposure for more than 20 years. Cross-sections will be fabricated at locations near crack-initiation sites enabling surface and near surface examinations by high-resolution analytical electron microscopy. Microstructural and microchemical characteristics will be documented and related to potential radiation- and environment-induced changes impacting SCC initiation.

Microstructures will be documented at several magnifications to illustrate corrosion-product films, subsurface degradation and the near-surface alloy microstructure. A combination of techniques including high-resolution TEM imaging and nano-diffraction will be employed to characterize the multilayer films and altered base material that may be present near the surface. Nano-probe micro-chemical analysis will be performed using EDS (including compositional mapping) and possibly electron energy loss spectroscopy (EELS)

Local compositions at grain boundaries will also be established as a function of distance below the surface and boundary regions leading to intergranular attack or SCC will be evaluated if such degradation is observed. Detailed analysis of corrosion product phases in tight cracks will be performed by these various methods and the possibility of selective oxidation ahead of the crack tip will be assessed. The presence of solution impurities within existing cracks and in corrosion films will be ascertained. Composition profiles will be taken to indicate changes across films at the surface and at near-surface crack-tip regions. 


\subsubsection{WP: Isolating matrix and grain boundary deformation mechanisms on irradiation-assisted stress corrosion cracking}

\section{$\underline{1 . \text { background }}$}

Recent studies have investigated matrix channeling and grain boundary sliding in charged-particleirradiated stainless steels. Stacking fault energy has been implicated as an important parameter controlling localized deformation and potentially susceptibility to IASCC.

\section{Objective of WP}

To conduct assessments on neutron-irradiated stainless steels with direct links to SCC crack initiation.

\section{Work outline}

a. Research focuses on quantitative deformation studies on stainless steels where extensive IASCC testing has been performed.

b. Disc-bulge tests will be conducted on polished sub-size samples at different levels of plastic strain and surface slip steps quantified by a combination of SEM and atomic-force microscopy (AFM) examinations.

c. Detailed characterizations of channel intersections with grain boundaries will be conducted.

d. Boundary distributions will be established by orientational imaging microscopy (OIM) to help quantify importance of boundary interactions.

e. Direct comparisons will be made between surface slip steps and boundary interactions to previously measured IASCC response.

\subsubsection{Flow assisted corrosion}

\subsubsection{Introduction}

Flow assisted corrosion (FAC) produces rapid penetrations relative to general corrosion but at rates generally in the range of $1 / 10$ of slow SCC propagation. These comparisons vary. Numerous serious failures have resulted from FAC especially where adequate monitoring was not in place or where special flow conditions - e.g. local turbulence--were not accounted for. Such failures occur in both steam and feedwater lines.

The conventional approach to modeling and predicting FAC is to use data base correlations. These are not mechanistic but rely on previous observations. FAC tends to be linear with time.

In general, the main dependencies of FAC on alloy composition, temperature, $\mathrm{pH}$, potential, and flow have been studied and reasonable information is available.

However, FAC for very long times has not been studied nor have the interactions with aged materials. 
FAC has an important associated effect of producing hydrogen in proportion to the loss of material. Neither the rate of absorption nor the effects on properties of the substrate are well understood.

\subsubsection{WP: Adequacy of current models of flow accelerated corrosion, especially when combined with possible galvanic effects or flow disturbances that might be associated with weldments}

\section{$\underline{1 . \text { Background }}$}

Models available for FAC are based mainly on correlations. Physical insights into FAC rely on the stability of passive films: $\mathrm{pH}$ approaching minimum solubility, $\mathrm{Fe}_{2} \mathrm{O}_{3}$ is better than $\mathrm{Fe}_{3} \mathrm{O}_{4}$, adding chromium is beneficial. Also, minimizing turbulence is beneficial. Enhanced FAC at welds has been observed in piping and equipment (e.g. feedwater heaters) at over 30 plants globally covering BWR, PWR and VVER designs. The precise reason for this enhancement is currently unknown.

\section{Objective of WP}

Develop a more fundamentally based model that permits an analytical approach to optimizing resistance to FAC.

\section{Work outline}

Develop a fundamentally based model for FAC that includes input from theory of fluid flow near surfaces and the evolution of dissolving species and the fluid surface film. The second input is associated with the solubility of the films as functions of $\mathrm{pH}$, potential, and film composition. A third input is associated with the defect structure of the film that can provide a basis for the oxidation rate of the film. In these inputs, include potential effects of galvanic currents and flow disturbances that might be associated with weldments.

Conduct experimental validation of the improved analytical modeling. Sufficient data from plants are available for calibrating the analytical model.

\subsubsection{WP: Absorption of hydrogen produced in FAC}

\section{$\underline{1 . \text { Background }}$}

Hydrogen is produced during FAC as a result of the continued oxidation of iron or alloy substrate. Some of this hydrogen enters the metal. The rate of hydrogen production is reduced as the potential is increased - which also reduces the rate of FAC owing to the increased stability of films.

Three important aspects of hydrogen production are not known: (a) whether the rate of production is stoichimetric; (b) what fraction of the hydrogen produced enters the metal substrate; (c) where the hydrogen is produced on an atomic scale.

In addition, effects of hydrogen produced in FAC are not known: (a) Does the hydrogen interact with SCC or with creep? (b) Does the hydrogen affect the fracture resistance? 


\section{Objective of WP}

a. Quantify the production of hydrogen entry into the metal.

b. Elucidate and quantify the effect of FAC-produced hydrogen on properties of the substrate.

\section{$\underline{\text { 3. Work outline }}$}

Develop a FAC model experiment that is capable of monitoring the absorption of hydrogen in real time. Incorporating a dynamic monitor of hydrogen flux should provide such data. This system would also monitor the production of $\mathrm{Fe}^{2+}$ and $\mathrm{Fe}^{3+}$ dynamically under conditions of controlled potential. Hydrogen entering the solution would also be monitored. The state of the surface and properties of the film would be monitored with electrochemical impedance monitoring.

\subsubsection{WP: SCC of replacement materials}

\section{$\underline{\text { 1. Background }}$}

Some cold worked carbon steel has irregularly exhibited SCC on a water outlet of a PWR but irregularly. It appears that that the irregularity is associated with the FAC removing the initiation sites for SCC since the FAC velocity exceeds the velocity of the initiation stage; only the most rapidly moving initiation sites are spared. If the carbon steel is replaced with an alloy with a much lower FAC rate, then the SCC initiation rate could exceed the countervailing FAC rate, and SCC of the cold worked material could be accelerated.

\section{Objective of WP}

Determine whether a cold worked alloy with a lower FAC rate will sustain a higher SCC rate.

\section{$\underline{\text { 3. Work outline }}$}

Measure the SCC rate of initiation and propagation for proposed cold worked alloys to replace cold worked carbon steel under PWR outlet conditions. Compare these rates with the reduced rate of recession due to FAC. Such alloys should also be considered relative to the lowered but finite hydrogen absorption.

\subsubsection{Fracture Resistance}

\subsubsection{Introduction}

Many of the topics in the work plans discussed thus far deal with SCC type degradations. Eventually, according to Figure 1 the SCC becomes sufficiently extensive that fracture occurs. There is an assumption that fast fracture is independent of the environment in which it occurs, contrary to the SCC. This assumption is now being challenged.

Also, it has been assumed that welds in nickel base alloys had high fracture resistance over a broad range of temperatures. This assumption is also being questioned. 


\subsubsection{WP: Fracture resistance in environments}

\section{$\underline{\text { 1. Background }}$}

Some recent experiments have led to challenging the assumption that fracture resistance of welds, especially, is independent of the chemical environment although dependent on the thermal environment. Also, such concerns apply to welds with unstable structures where properties change with aging.

\section{Objective of WP}

Determine the extent to which chemical environments affect the fracture resistance in PWR and BWR (NWC, HWC) environments.

\section{$\underline{\text { 3. Work outline }}$}

Conduct fracture resistance testing of stainless steel and Ni-base weld materials carried out under RCS operating conditions for PWRs and BWRs.

Assess any significant effects.

\subsubsection{WP: Fracture resistance of Fe- and Ni-base alloys at low temperatures}

\section{$\underline{1 . \text { Background }}$}

It appears that $\mathrm{Fe}$ - and $\mathrm{Ni}$-base alloys may be prone to lowered fracture resistance after they have been exposed to hydrogenated high temperature water, and are tested at temperatures below $150 \mathrm{C}(302 \mathrm{~F})$ at specific applied strain rates. These conditions may exist during transient reactor operations such as when shutting down the plant. Early work has shown that Alloy 690 weld material was especially prone to such lowered resistance to fracture. This lowered resistance to fracture seems to be related to environments favoring entry of hydrogen into the materials, e.g. PWR deaerated environments and BWR HWC.

While no failures have been attributed to this effect, it has been reproduced in the laboratory. Also, such results were observed twenty years ago with SCC propagation at RT in Alloy 600 specimens removed from autoclave testing.

\section{Objective of WP}

Assess this loss of fracture resistance at low temperatures in Fe- and Ni-base allows as a function of temperature, material composition, material aging.

Develop a mechanistic understanding for this effect.

Determine what operating evolutions could lead to premature failures by this effect and develop experiments to assess such possibilities. 


\section{$\underline{\text { 3. Work outline }}$}

a. Measure fracture resistance of Fe- and Ni-base alloys and welding materials before and after aging.

b. Consider a range of microstructures and orientations.

c. Measure absorption of hydrogen in specimens.

d. Develop a mechanistic understanding.

e. Develop a model for the occurrence of such effects in practice. 


\subsection{Mitigation, repair and replacement}

\subsection{Introduction}

As understanding of degradation is developed from projects in Section 5.0 and similar programs, programs to consider mitigation can be developed further and implemented. In this section some programs of mitigation, repair and replacement are discussed where their need is already evident.

\subsection{WP: Surface modification techniques to reduce residual stress and strain and improve SCC and fatigue resistance}

\section{$\underline{1 . \text { Background }}$}

The SCC susceptibility, growth rate and high-cycle fatigue are severely affected by residual stress in the materials and the SCC growth rate and low-cycle fatigue are severely affected by residual strain in the materials. As a result, methods to reduce the residual stress and strain of the materials for pressure boundary components are extremely important to mitigate materials degradation. Many techniques have been used effectively for LWR components including local thermal treatments (e.g., a band heater or laser) to reduce stress/strain and mechanical treatments (e.g., peening by shot, water-jet or laser methods) to alter the residual stress. Up to this time, these techniques were basically developed by individual private companies with details for application of techniques different and typically proprietary to each company. Therefore, to properly evaluate and optimize these mitigation techniques to benefit commercial LWRs world wide, independent research is needed.

An alternative modification approach to provide protection for SCC and fatigue is to completely remove the surface layers where cracking initiates. A simple method is the removal of the damaged (corroded or cracked) or cold-worked layer or locally heat-affected zone by grinding, machining or another abrasive technique. The application of a thin cladding of a corrosion-resistant alloy to the surface by laser techniques may also be highly beneficial in certain circumstances (e.g., alloy 690 at J-welds in PWR lower-head penetrations). Once again, there is a significant need to properly evaluate the effectiveness of these surface modification approaches.

The effective reduction of the residual stress and strain and improvement in SCC and fatigue resistance of materials using the various techniques are not always reliable and reproducible. The reliability, reproducibility, and effectiveness of the techniques must be verified by laboratory and mock-up testing.

\section{Objective of WP}

To evaluate and validate that surface modification techniques for improving SCC and fatigue resistance of components are reliable and reproducible.

\section{$\underline{\text { 3. Work outline }}$}

Quantitative measurements (e.g., x-ray and/or SEM backscatter imaging) of residual stresses and strains would be performed as a function of location in the components of interest. Once the capacity to reduce stresses and strains is demonstrated, tests would be conducted to evaluate the effectiveness of the 
mitigation treatment to significantly improve the materials resistance to SCC and fatigue degradation. This evaluation can be conducted using laboratory and mock-up tests. In order to check the possibility of detrimental side effects, materials modified by the thermal or mechanical techniques should be tested from the view point of the mechanical properties, microstructure, dimension, corrosion properties, and surface roughness.

The research discussed above for the thermal/mechanical stress/strain reduction techniques should also be conducted for the surface removal approaches. Once the surface damaged or altered layer is removed, the reliability of this mitigation treatment in improving SCC and fatigue performance should be evaluated by laboratory and mock-up tests. Application reliability for the corrosion-resistant cladding is critical and detailed characterizations of the cladding should be done followed by appropriate laboratory and mock-up tests.

A critical aspect for these techniques to modify stresses and strains will be their long-term stability and effectiveness in mitigating degradation. Accelerated aging would be employed to assess long-term changes in the modified material. Temperature-accelerated corrosion, SCC and fatigue testing should be conducted under controlled conditions to evaluate the effectiveness of modifying residual stress and strain to the end of plant life.

\subsection{WP: Surface coatings for mitigating SCC and corrosion}

\section{$\underline{1 . \text { Background }}$}

An inhibitive treatment or coating of metal-alloy surfaces has been proposed as an effective mitigation of corrosion and stress corrosion cracking (SCC) for BWR components. The approach is to employ the inhibitive nature of ceramic compounds in deterring the redox reactions required for metal corrosion. In theory, this type of coating could deter the major redox reactions (namely the oxidation of $\mathrm{H}_{2}$, the reduction of $\mathrm{O}_{2}$, the reduction of $\mathrm{H}_{2} \mathrm{O}_{2}$, and the oxidation of metals) in the high-temperature water environment. The exchange current densities (ECDs) of these reactions on the base metal surface would accordingly decrease. In a typical, oxidizing BWR environment that usually contains hundreds of ppb $\mathrm{O}_{2}$ and tens of $\mathrm{ppb} \mathrm{H}_{2} \mathrm{O}_{2}$, corrosion of stainless steel (SS) components will be significantly reduced if the ECDs of the $\mathrm{O}_{2}$ and $\mathrm{H}_{2} \mathrm{O}_{2}$ reduction and $\mathrm{SS}$ oxidation reactions are effectively decreased. In addition, the effectiveness of HWC could be enhanced in terms of a reduced electrochemical corrosion potential (ECP) accompanied by a lower $\mathrm{H}_{2}$ consumption or even without any added hydrogen.

\section{Objective of WP}

The objective of this coating work is the development and quantitative evaluation of inhibitive coatings for corrosion and SCC mitigation.

\section{$\underline{\text { 3. Work outline }}$}

Candidates to be used as the coating material can be different but should bear a common nature of deterring oxidant reduction and metal oxidation. Prominent examples that merit further study are zirconium oxide $\left(\mathrm{ZrO}_{2}\right)$ and titanium oxide $\left(\mathrm{TiO}_{2}\right)$. Preliminary results have demonstrated their positive benefit in terms of comparatively lower corrosion rate and lower corrosion potential. 
There are issues with regard to practicality of application methods, and coating integrity and durability. In addition, the $\mathrm{TiO}_{2}$ coating technique was proposed mainly with the simultaneous presence of ultraviolet photon radiations with a certain range of wavelength. Its effectiveness in the absence of the ultraviolet radiation for components away from core regions should be addressed.

For each coating and alternate techniques of application, the influence of long-term, high-temperature exposure on the coatings should be assessed along with the influence of component loading/deformation. Quantitative examinations of SCC response should also be included to fully evaluate the mitigation capabilities of the coatings. Finally, the effects on the performance of fuel and on the integrity of fuel rod surfaces should also be investigated.

\subsection{WP: Modification of water chemistry of BWRs}

\section{$\underline{1 . \text { Background }}$}

The generally oxidizing environment in the primary coolant circuit (PCC) of a boiling water reactor (BWR), exacerbated by the radiolysis process of water in the core region, poses a serious threat of stress corrosion cracking (SCC) to structural components. An effective method to mitigate SCC problems is to modify the BWR water chemistry, namely from an oxidizing one to a reducing one. In the past decades, hydrogen water chemistry (HWC) alone and with noble metal chemical addition (NMCA) have been widely adopted and have been generally successful. However, concerns remain for this approach for SCC mitigation with issues of the optimal hydrogen levels, the possibility of incomplete protection and undesirable increase of radiation fields.

\section{Objective of WP}

The research objective within this topic is focused on an improved understanding of normal and offnormal water chemistry effects on SCC resistance of BWR components. In particular, quantitative evaluations of water chemistry on SCC are needed. This should include the influence of hydrogen concentrations and electrochemical potentials on SCC of Ni-base alloys and stainless steels (in and outof-core). Solution chemistry additions for mitigation are of direct interest ranging from $\mathrm{Zn}$ to more complex alternative chemistries.

\section{Work outline}

Further research on HWC/NMCA is recommended to ensure effective mitigation is obtained. For example, continuous injection of noble metals into a BWR or other approaches to restore the catalytic activity of already present noble metals should be considered carefully since impurities in the BWR coolant may contaminate the deposited noble metals and thus reduce, gradually, their catalytic activities.

There is also a concern that platinum or other noble metals may catalyze the oxygen reduction reaction in the absence of sufficient hydrogen and may promote accelerated SCC in a BWR. A possible solution to this problem is to find a different catalyst that would catalyze only the oxidation reaction of hydrogen and be inert to oxygen reduction. Alternate water chemistry is an approach that needs additional study to deal 
with the problems of SCC in BWRs. The most promising candidates in replacing hydrogen at the moment seem to be alcohols (e.g., methanol or ethanol) and hydrazine. Both alcohol and hydrazine can act as reducing agents in the PCC of a BWR; and preliminary experimental results have demonstrated that these chemicals could effectively scavenge dissolved oxygen, and they do not form significant amounts of radioactive, volatile species after reacting with water.

Although the main goal of zinc addition (preferably prior to the adoption of HWC/NMCA) is to reduce the shutdown dose rate in a BWR, it is possible that the structural components may actually benefit from the surface composition modification after zinc addition in terms of deterred SCC, probably resulting from less conducting property of the treated component surfaces. In each of these cases, quantitative examinations of SCC response are needed along with proper characterizations of water chemistry effect on corrosion product films.

\subsection{WP: Modification of water chemistry of PWRs}

\section{$\underline{1 . \text { Background }}$}

An optimum hydrogen concentration needs further consideration. Recent work has demonstrated a significant variation in SCC crack growth rates for Ni-base alloys with electrochemical potential (with respect to the $\mathrm{Ni} / \mathrm{NiO}$ line) as affected by the amount of injected hydrogen. It is important that this variability be quantitatively understood. The PWR water environment also has other complexities particularly on the secondary side where significant off-normal chemistries can develop in crevices. Water chemistry modifications (e.g., B/Li ratios) and additions (e.g., Zn) have been used without a clear definition on their influence on SCC susceptibility.

\section{Objective of WP}

The research objective within this topic is focused on an improved understanding of normal and offnormal water chemistry effects on SCC resistance of PWR components. In particular, quantitative evaluations of water chemistry on SCC are needed in several areas. This should include the influence of hydrogen concentrations and electrochemical potentials on SCC of Ni-base alloys and stainless steels (in and out-of-core). Solution chemistry additions for mitigation are of direct interest ranging from $\mathrm{Zn}$ to more complex alternative chemistries.

\section{Work outline}

There have been concerns that the currently adopted hydrogen injection rate in PWR primary water may not be appropriate to minimize IGSCC in Ni-base alloy components. Further study is needed including quantitative crack-growth-rate testing to better quantify the relationships among hydrogen concentration, electrochemical potential (versus the $\mathrm{Ni} / \mathrm{NiO}$ line) and cracking. It is critically important to establish this response for the lower-Cr alloys (e.g., alloy 600 and weld metals) and higher-Cr replacement alloys (alloy 690 and weld metals).

Although the main goal of $\mathrm{Zn}$ additions is to reduce the shutdown dose rate in a PWR, it is possible that the structural components may actually benefit from the surface composition modification. Quantitative 
examinations of SCC response are needed along with adequate characterizations of water chemistry as it affects the integrity of passive films.

Chemistry modifications can be much more aggressive on the PWR secondary-side environment. Recent observations of high $\mathrm{Pb}$ concentrations in surface films, IG attack and IGSCC cracks suggest that it may be beneficial to add species that can remove $\mathrm{Pb}$ from solution. It becomes important to understand the solution chemistry in the secondary-side water and in crevices. Thermodynamics and kinetics of reactions between primary impurities of concern (e.g., $\mathrm{Pb}$ and $\mathrm{S}$ ) with possible mitigation species (e.g. hydrazine) need to be determined and critical tests performed.

\subsection{Welding optimization for microstructural control and stress/strain Modification to improve hot cracking and SCC resistance}

\subsubsection{Introduction}

Weldments continue to be a primary location of stress-corrosion cracking (SCC) in LWR systems. While problems related to heat-affected-zone (HAZ) sensitization and intergranular (IG) SCC of austenitic stainless steels in BWRs have been significantly reduced, SCC has now been observed in HAZs of nonsensitized and often L-grade materials. A key aspect of this SCC susceptibility results from weldinginduced local strains and the final residual stresses. In addition, cracking has been observed in dissimilar metal welds where Ni-base alloy weld metals are used. Interdendritic (ID) or IGSCC has been observed in both BWRs and PWRs with recent examples for PWR pressure vessel penetrations (upper and lower head) producing the most concern. By comparison to the Ni-base alloy welds, stainless steel welds have shown much greater resistance to SCC although a few cases of cracking have been identified in BWR components. This brief overview demonstrates the critical need for an improved understanding of welding materials and the welding process itself.

The research objective of this topic area is broad-based and encompasses existing LWR weldments and materials, replacement materials, repair considerations and new welding approaches for next generation LWRs. A combination of experiments and modeling is proposed to develop fundamental understanding of weld metal and the HAZ metallurgy. These characteristics would be linked to SCC and hot cracking. The emphasis is expected to be on Ni-base alloy dissimilar-metal welds, but is not limited to these materials. A key aspect will be establishing microstructural/micro-chemical and stress/strain evolution in the weld metal and HAZ as a function of welding procedures and component aspects. The ability to model these relationships effectively may allow welding approaches to be tailored on a pass-by-pass basis to optimize final weldment resistance to service failure. Several WPs for research tasks are given below. These are provided to illustrate a few specific areas where fundamental understanding is needed and are not intended to restrict proposed ideas and research within this general topic. 


\subsubsection{WP: Improved understanding of the microstructural/microchemical evolution and hot cracking in nickel-base alloy weld metals}

\section{$\underline{1 . \text { Background }}$}

The understanding of the metallurgy in Ni-base alloy welds is not sufficient to effectively assess performance. It is highly desirable to expand the knowledge base through detailed characterizations of LWR-qualified weldments

\section{Objective of WP}

Improve the understanding of Ni-base alloy weldments.

\section{Work outline}

Examinations should be performed at moderate-to-high resolutions of weldments removed from LWR service, mock-ups welds and various test welds fabricated with alloy 182/82 and alloy 152/52.

Measurements should be performed spanning macroscopic to microscopic techniques and in some case will require characterizations at nanometer resolutions. The intent will be to greatly expand the understanding of weld metal structures in actual and simulated LWR service components with a focus on solidification segregation and second-phase precipitation particularly at inter-dendritic grain boundaries.

The microstructural and microchemical features will be related to the susceptibility of hot cracking for both the low-Cr alloy 182/82 welds and the high-Cr, alloy 152/52 welds.

\subsubsection{WP: Influence of weld metal microstructure/microchemistry and pre-existing hot cracks on SCC of Ni-base alloys}

\section{$\underline{\text { 1. Background }}$}

An important difference of opinion exists between the technical community who believe cracking in Nibase alloy weld metal (alloy 182 or 82) can occur solely due to SCC and the utility community who believe that susceptibility primarily results from pre-existing hot cracks due to poor manufacturing. Key tests are needed to assess critically the influence of not only pre-existing hot cracks, but solidification segregation or precipitation on SCC.

\section{Objective of WP}

Determine the origin of SCC in welds of Ni-base alloys.

\section{$\underline{\text { 3. Work outline }}$}

An improved understanding of dendritic and grain boundary compositions in weld metals should be established and used to create systematically realistic conditions of material for quantitative SCC crackgrowth tests. Gleeble experiments should be conducted to document controlled heating and cooling on 
interfacial structure and composition. Finally, the influence of pre-existing hot cracks on SCC initiation and propagation should be explored. Initial experiments should be conducted on samples removed from laboratory welds where hot cracking has been investigated.

\subsubsection{WP: Assessment and modeling of strain and stress states in weld metal and heat-affected- zone regions for optimized welding}

\section{Background}

SCC susceptibility in both weld metal and HAZ regions is typically produced by welding-induced local strains and the associated residual stresses. Prior work related to BWR pipe cracking has examined welding procedures and component issues such as pipe diameter and constraint on the plastic strains developed in the HAZ on a pass-by-pass basis.

\section{Objective of WP}

Validate predictions of welding-induced stresses and strains.

\section{$\underline{\text { 3. Work outline }}$}

Modern finite element modeling (FEM) approaches can effectively evaluate temperature, stress and strains that evolve dynamically during welding. Additional experimental work is needed to assess FEM predictions on a pass-by-pass basis to quantify the predictive capability. Once established, FEM should be used to systematically evaluate effects of welding procedures on the stress/strain evolution and even microstructural changes (through the temperature/strain history) for specific weld-metal and HAZ regions.

Controlled experiments will be conducted to test model parameters and validate predictions. The intent will be to select weld parameters for optimizing microstructures of weldments and final stress/strain conditions. 


\subsection{Nondestructive examination techniques for inservice inspection and monitoring}

\subsection{Introduction}

Current periodic inservice inspections attempt to identify degradation before such degradation results in component failure. Advanced inspection and monitoring techniques could provide the capability for reliable and timely identification of degradation for planning and implementing repair or replacement of components before failure occurs. Advanced inspection monitoring techniques that re capable of detecting the precursors to degradation can play an important role in a PMDM process as susceptible components could be identified early enough to develop and implement mitigation actions as well as repair or replacement as desired.

\subsection{WP: Detection and characterization of material degradation precursors}

\section{$\underline{1 . \text { Background }}$}

Presently, NDE is used to identify defects (cracks, fabrication flaws, wall thinning) that have already developed and may challenge component integrity. The capability to detect and characterize the precursors to degradation initiation enables proactive materials degradation management by mitigation as well as by timely repair or replacement.

The precursor stage of degradation may exhibit physical characteristics substantially different than the macro-defect that ultimately manifests. The ability to predict degradation by detecting and characterizing precursor state(s) may require an inspection capability that is:

a. evolutionary (i.e., higher spatial resolution ultrasound)

b. revolutionary (i.e., entirely new application of physics/engineering to this NDE problem).

The technical issues for development of new NDE approaches to precursor detection and characterization range from advanced engineering concepts to more fundamental understanding of how physical states and material features (or properties) are exhibited and hence, measurable.

\section{Objective of WP}

Design, develop, and evaluate advanced laboratory NDE techniques to quantify precursor state, validate theories on precursors and demonstrate potential for field deployment.

Validate the techniques by inspecting/monitoring mockups under realistic testing conditions and in situ reactor components.

\section{$\underline{\text { 3. Work outline }}$}

NDE technology for identifying and quantifying precursors to degradation is a new field. Research is needed to develop a sound technical foundation for advances in measurement science related to precursors. Development of new/advanced NDE theory and systems needs to occur in parallel with precursor materials research. 
Research activities include:

1. Establish or identify potential measurable precursors to degradation

a. Localized surface chemistry changes

b. Surface phenomena (bubbles, micro cracks, voids, etc.)

c. Material properties changes.

2. Develop theoretical models that provide the physical basis for direct and indirect relationships between material degradation precursors and NDE measurement(s).

3. Develop new/advanced NDE inspection measurements and sensors with sufficient spatial and contrast resolution, signal-to-noise ratio, etc. for precursor assessment.

4. Demonstrate developed NDE systems on mockups and reactor components.

\subsection{WP: Detection and evaluation of micro/macro cracks}

\section{$\underline{1 . \text { Background }}$}

In nuclear power plants microcracks are initiated and their growth is driven by the surface degradation caused by environmental factors such as coolant chemistry, pressure, vibrations, high temperature, etc. The growth of micro cracks into larger cracks contributes to the failure of major components in nuclear power plants. Thus detection and evaluation of micro cracks can be a key step in the proactive management of materials degradation.

However, using conventional nondestructive testing methods such as bulk wave ultrasonic testing and eddy current testing it may not be possible to detect and evaluate micro cracks quantitatively since these conventional methods have been developed primarily for detection and evaluation of defects having relatively large size.

Therefore, new nondestructive testing techniques are necessary for improving the detection and evaluation of micro cracks.

Conventional NDE techniques have not shown the capability to detect and characterize micro cracks, however laboratory research techniques indicate the potential for detecting and evaluating micro cracks.

Some of the research under development includes the following:

a. The detection of material degradation caused by corrosion-fatigue has been demonstrated using a computer controlled backscattered surface wave system.

b. Very high-frequency surface wave acoustics (in GHz range) have demonstrated the detection of micro-scale stress corrosion cracks based on velocity variation.

c. Time reversal techniques for improving probability of detection (POD) of small flaws such as hard alpha inclusions, stress corrosion cracks, circular cracks, etc have been adopted. 


\section{Objective of WP}

a. Development and evaluation of NDE techniques for reliable detection and accurate characterization of micro cracks in LWR components.

b. Determine characteristics of micro cracks parameters (size, number, distribution, etc.) and their influence on materials degradation status.

\section{$\underline{3 . \text { Work outline }}$}

The research to be conducted includes the following:

- Investigation of performance and limitations of conventional NDE methods for detection and evaluation of micro cracks.

- Develop theoretical models for predicting responses from micro cracks that describe the underlying physics related to generation and acquisition process.

- Development of new signal processing and interpretation methods for quantitative micro crack evaluation.

- Develop new/advanced NDE techniques for detection and evaluation of micro cracks located on the surface and/or embedded in the subsurface.

- Establish relationships between micro crack parameters and materials degradation status.

\subsection{WP: Continuous monitoring for detecting LWR materials degradation}

\section{$\underline{1 . \text { Background }}$}

Degradation has been occurring in light water reactors (LWRs) since reactors started operation. NDE is one layer of the defense-in-depth for safe operation by detecting degradation before it challenges the structural integrity of nuclear reactor components.

There are significant limitations to the required NDE that is performed on a periodic basis as part of the inservice inspection (ISI) program. Improvements can be made to ISI programs to overcome some of the limitations through improvements in how frequently inspections are performed (reduction from a 10 year interval to every refueling outage), the effectiveness of the NDE method (employing SAFT or phased arrays versus conventional amplitude based UT), etc. Other limitations are not solvable with simplistic improvements in the ISI program. For example, there are a number of locations where access to the areas requiring inspection are limited because the surface of the component is in an as welded condition or surface geometries (tapers) limit inspection.

There are also limitations because of other components or structures preventing delivery of the NDE energies to the zones requiring inspection. In addition there are classes of problems such as the coarse grained materials which are found in cast stainless steels, dissimilar metal welds, corrosion resistant cladding and the far side inspection of austenitic stainless steels for which reliable and effective inspections have not been developed. 
Limitations of periodic ISIs, which are conducted infrequently and on a relatively small sampling basis of the accessible components, can be overcome by the online continuous monitoring of the reactor and its components using techniques such as acoustic emission.

\section{Objective of WP}

a. Develop and demonstrate continuous on-line methods to monitor all forms of LWR materials degradation as it initiates and grows.

b. Include in the evaluation other methods besides AE that can be used to provide more information about degradation precursors on a continuous on-line basis.

c. Validate continuous on-line technology on operating plants to demonstrate the viability for performing this type of monitoring without false alarms and to provide an accurate reflection of degradation status.

\section{$\underline{\text { 3. Work outline }}$}

Although AE has been demonstrated and extensively tested for fatigue in pressure vessel steels and IGSCC in stainless steel, this study will demonstrate the technology for a wide range of LWR materials and expected degradation mechanisms to establish the case that all degradation occurring or expected to occur can be detected and evaluated.

In addition, the $\mathrm{AE}$ demonstrations that have been conducted in the past on operating plants occurred over 10 years ago and advances in computers, electronics and sensors will be integrated into a new state-ofthe-art system for validation on nuclear power plants.

Review degradation precursors and processes and assess other monitoring technologies such as guided waves to support, compliment, replace and/or enhance AE continuous monitoring.

Conduct demonstrations of technology to address engineering issues of cabling and full plant monitoring needs.

Assess all forms of nuclear power plant emissive energies to determine viability for passive monitoring of materials degradation.

\subsection{WP: Screening of array probe data for steam generator tube inspections}

\section{$\underline{1 . \text { Background }}$}

As the demands for reducing the time for steam generator inspections increases, advanced eddy current array probes, such as the X-probe and others, are becoming more popular. They provide detection capabilities similar to those of industry standard rotating probes, yet they can scan tubes at speeds typical of bobbin probes. However, the large quantities of data generated by these probes make data analysis time consuming. The maximum benefit from steam generator inspections with the array probes can only be realized if techniques are available to quickly analyze the large amounts of data. 


\section{Objective of WP}

Develop screening software to identify regions requiring analyst attention with the objective of shortening analysis time and providing safeguard against human error.

\section{$\underline{\text { 3. Work outline }}$}

Develop software that automatically screens eddy current data and identifies flaw signals that need analyst attention, but ignores non-flaw signals. Evaluate the effectiveness of this software to provide similar or better results for probability of flaw detection as manual (human) analysis, while reducing the time and manpower needed for data analysis.

\subsection{WP: Effect of crack conductivity on detection and sizing of SG tube cracks}

\section{$\underline{1 . \text { Background }}$}

Low detectability of cracks has often been attributed to either the presence of ligaments across the crack opening or to the presence of a family of short cracks with ligaments in between. Understanding the correlation between flaw parameters such as crack depth, crack tightness, percent degraded area and the presence of crack ligaments to the NDE responses is paramount in predicting the reliability of SG inspections.

\section{Objective of WP}

To establish correlations between crack morphology parameters and crack conductivity and to determine their effect on probability of detection and crack sizing.

\section{$\underline{3 . \text { Work outline }}$}

Using pulled tube specimens and a family of samples containing laboratory produced SCCs and EDM notches, measure electrical conductivity across the defects (cracks) in an attempt to correlate crack opening and other crack morphology parameters with eddy current probe responses.

Use the results to develop better interpretation methods of NDE signals and to improve the understanding of some of the factors affecting detectability and characterization of cracks in steam generator tubing. 


\section{Distribution}

No. of

Copies

\# Name

Organization

Address

City, State and Zip Code

\# Name

Organization

Address

Address line 2

COUNTRY

\# Organization

Address

City, State and Zip Code

Name

Name

Name

Name

Name (\#)
No. of

Copies

\# Name

Organization

Address

City, State and Zip Code

\# Internal Distribution

Pacific Northwest National Laboratory

P.O. Box 999

Richland, WA 99352

Name

Mailstop

Name

Mailstop

Name

Mailstop

Name

Mailstop

Name

(PDF) 


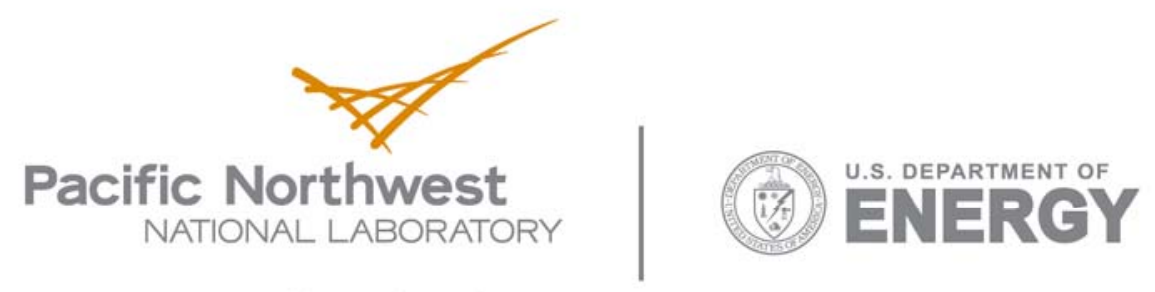

902 Battelle Boulevard

P.O. Box 999

Richland, WA 99352

1-888-375-PNNL (7665)

www.pnl.gov 